\title{
Klaus-Dieter Rohleder
}

\section{Die Osthandelspolitik \\ der EWG-Mitgliedsstaaten, \\ Großbritanniens und der USA gegenüber den \\ Staatshandelsländern Südosteuropas}

Verlag Otto Sagner München · Berlin · Washington D.C.

Digitalisiert im Rahmen der Kooperation mit dem DFG-Projekt „Digi20“

der Bayerischen Staatsbibliothek, München. OCR-Bearbeitung und Erstellung des eBooks durch den Verlag Otto Sagner:

http://verlag.kubon-sagner.de

() bei Verlag Otto Sagner. Eine Verwertung oder Weitergabe der Texte und Abbildungen, insbesondere durch Vervielfältigung, ist ohne vorherige schriftliche Genehmigung des Verlages unzulässig. 


$$
\begin{aligned}
& Z 61.42(13 \\
& \text { SÜDOSTEUROPA-STUDIEN }
\end{aligned}
$$

\section{S ÜD OSTEUROPA - STUDIEN}

im Namen der Südosteurupa-Gesellschaft herausgegeben von WALTER ALTHAMMER

Claus-Dieter Rohleder

Die Osthandelspolitik der EWG-Mitgliedstaoten, GroBbritanniens und der USA gegenüber den Staatshandelsländern Suidosteuropas 


\section{SÜDOSTEUROPA-GESELLSCHAFT}

8 München 22, Widenmayerstr. 49 - Tel. 294402

\section{PRÄSIDIUM}

Präsident: $\quad$ Dr. Walter Althammer, MdB, Augsburg

Vizepräsidenten: Prof. Dr. Hermann Gross, München

Alfred Hönig. Salzburg

Dr. Günther Müller, MdB, München

Schatzmeister: Bankdirektor Dr. Hamilkar Hofmann, Müchen

Beisitzer: Dr. Mathias Bernath, München

Redakteur Hans Hartl, Starnberg

Prof. Dr. Hans-Joachim Kissling, München

Landeshauptmann Dr. Ing. Hans Lechner, Salzburg

Bankdirektor Dr. Ernst Lederer, Frankfurt

Prof. Dr. Alois Schmaus, München

Dr. Emanuel Turczynski, München

WISSENSCHAFTLICHER BEIRAT

Vorsitzender: Prof. Dr. Alois Schmaus, München

Stellv. Vorsitzender: Prof. Dr. Hermann Gross, München

Sekretär:

Dr. Emanuel Turczynski, Müchen 


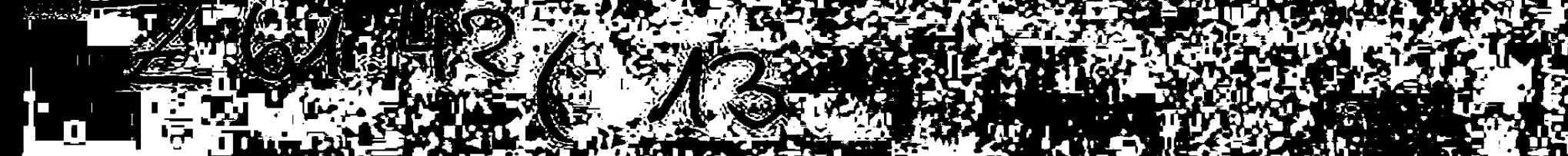

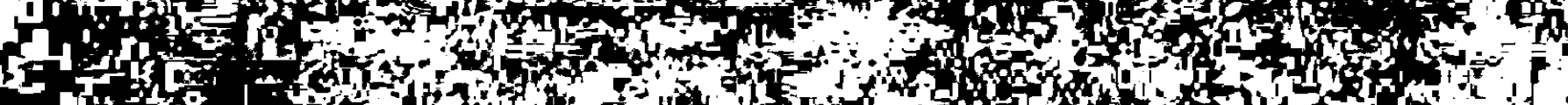

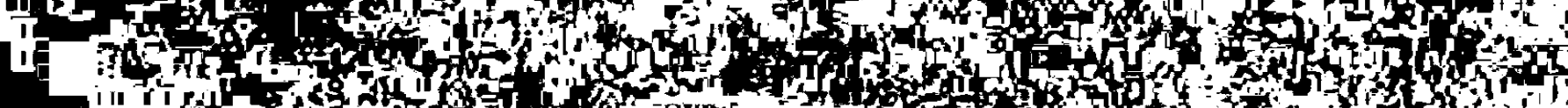
1.

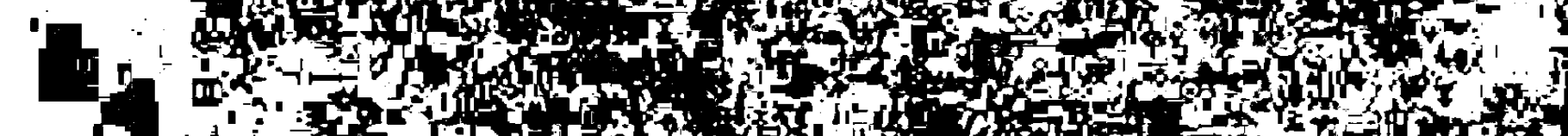
1 w

- T .

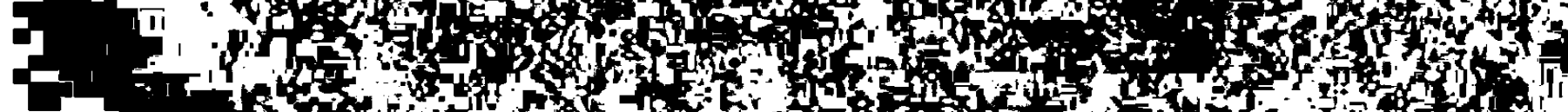
(4)

- I l bا

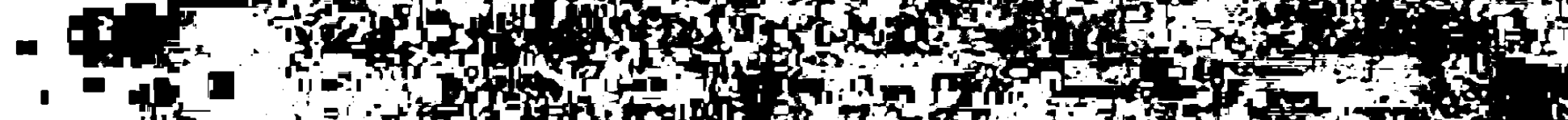

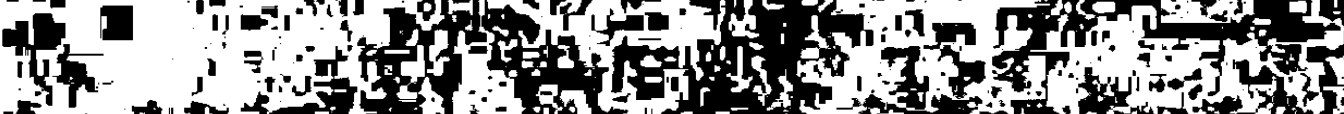

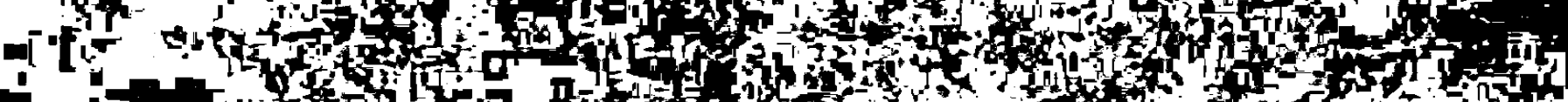

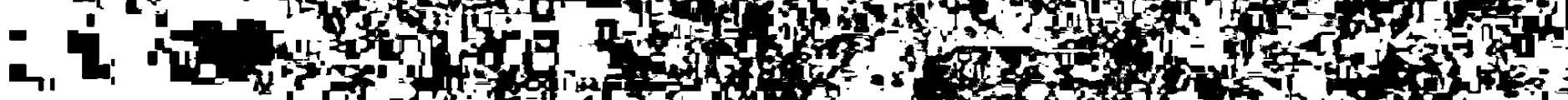

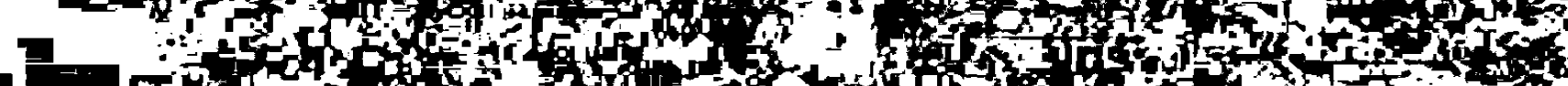

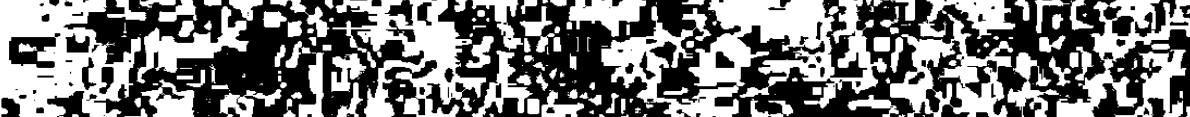
1.73

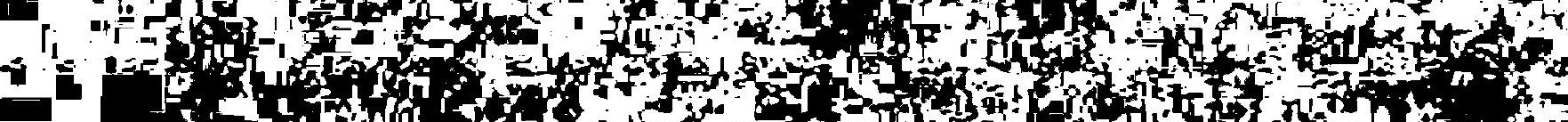
L I- 10 , - T Pad

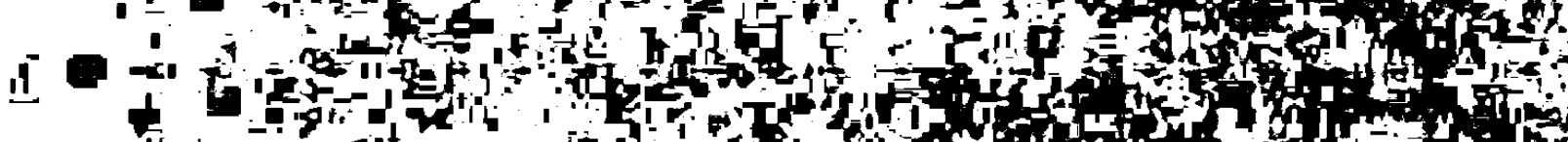

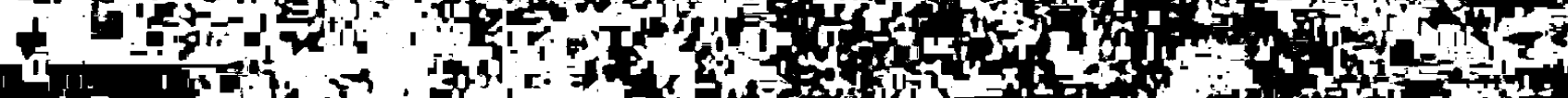
-

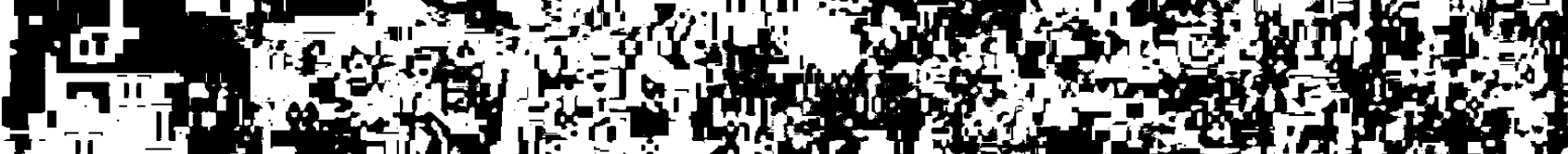

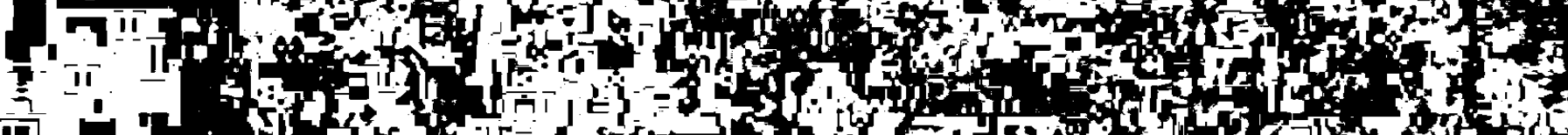
F I -

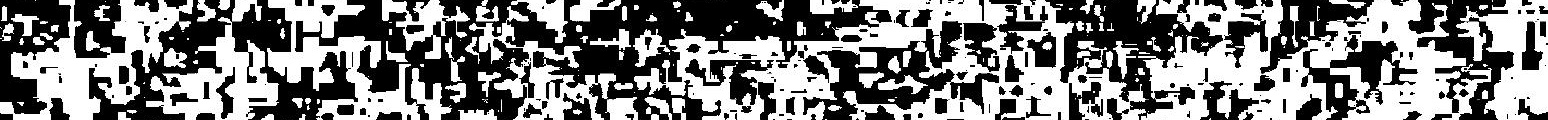
-

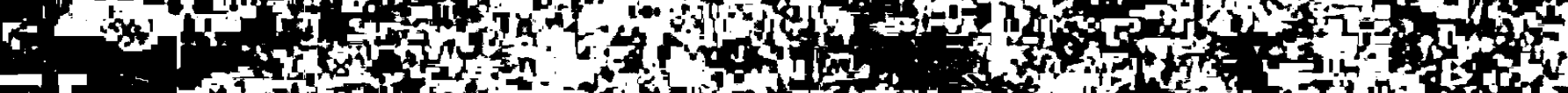

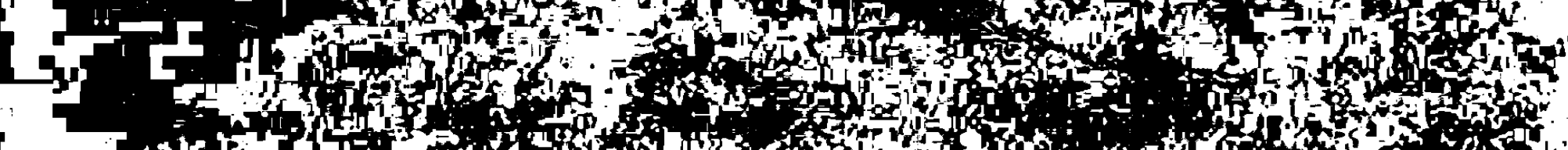

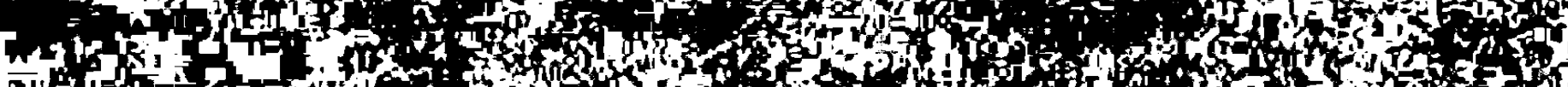
p.

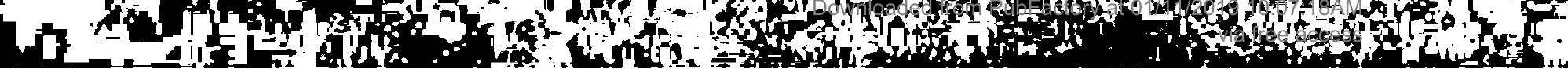





\section{S Ü D O S TE U RO PA - S T U DIEN}

im Namen der Südosteuropa-Gesellschaft herausgegeben von WALTER ALTHAMMER

Claus-Dieter Rohleder

Die Osthandelspolitik der EWG-Mitgliedstaaten, GroBbritanniens und der USA gegenüber den Staatshandelsländern Südosteuropas 
Diese Arbeit wurde mit einem Preis der Südost europa-Gesellschaft ausgezeichnet.

Mtunchan

Redaktion: Dr. Hanna Gülich-Bielenberg, Kiel 


\section{Vorwort}

Die vorliegende Dissertation entstand unter der Leitung meines hochverehrten Lehrers Herrn Professor Dr. Hermann Gross, dem ich für die tberlassung des Themas und sein Interesse an meiner Arbeit danke. Ebenso fühle ich mich Herrn Professor Dr. Hans Möller für seine Hilfe sehr verbunden.

Es ist mir weiterhin eine angenehme Pflicht, dem Deutschen Akademischen Austauschdienst für die Gewährung eines Dissertationsstipendiums aufrichtig zu danken. Durch einen dadurch ermöglichten dreimonatigen Forschungsaufenthalt in den USA konnten eingehende Quellenstudien und zahlreiche Besprechungen mit Experten der Verwaltung und der Wirtschaftspraxis sowie Fachgelehrten wichtiger Ostforschungszentren durchgeführt werden. Dies hat zum Gelingen der Arbeit nicht unwesentlich beigetragen und ich bin für die mir auch in den USA zuteil gewordene Hilfsbereitschaft und Anregungen großen Dank schuldig.

Freundliche Unterstützung wurde mir a uch vom Kieler Institut für Weltwirtschaft gewährt, wodurch mir die Auswertung der internationalen Literatur erheblich erleichtert wurde.
4. Januar 1969
Claus D. Rohleder 
Now

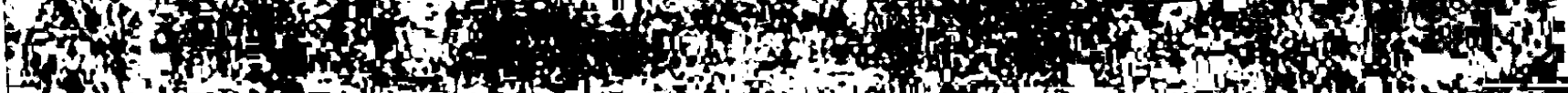
940 s.

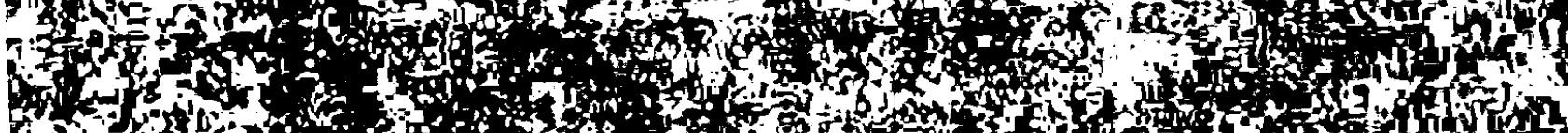

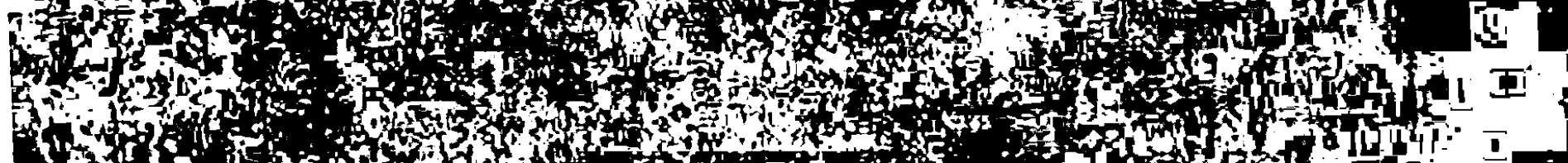

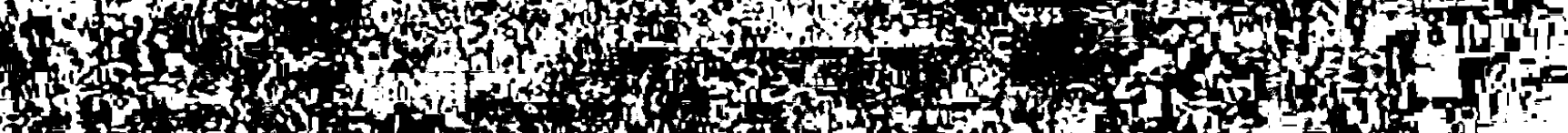
Why

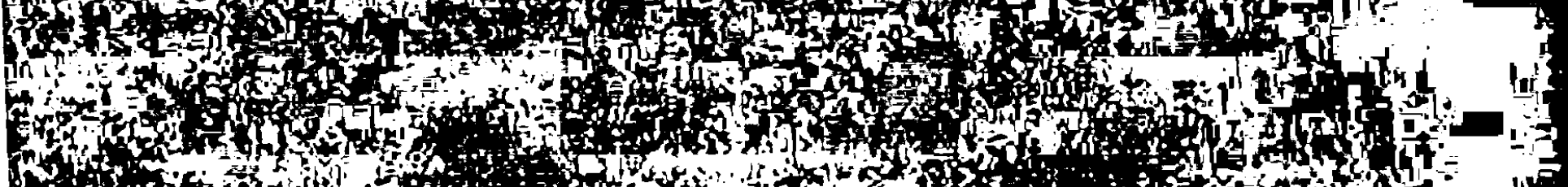

Hafor

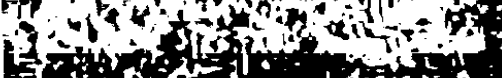

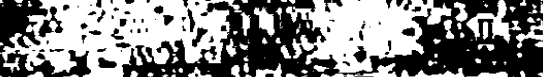

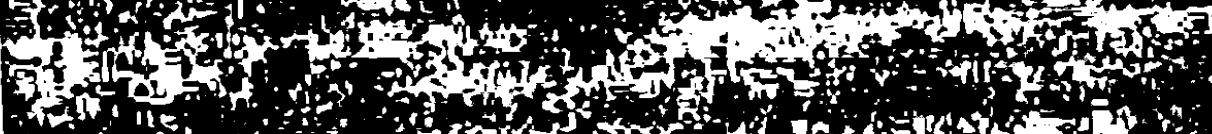

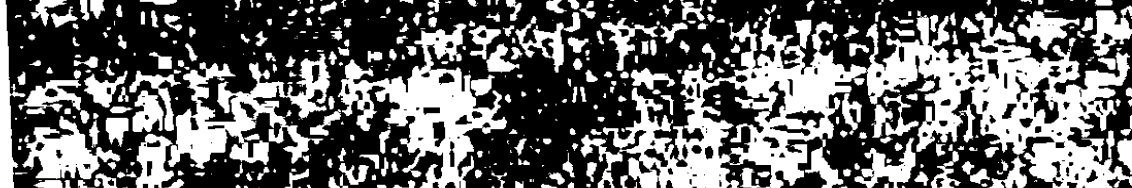

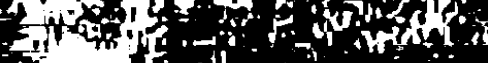

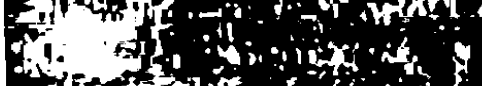

of

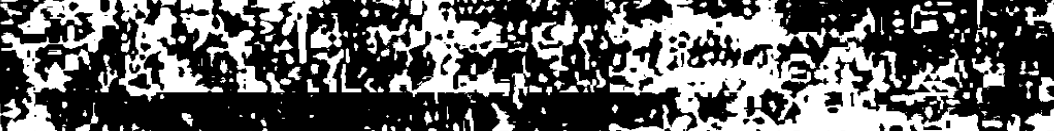

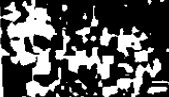

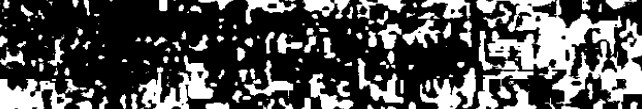

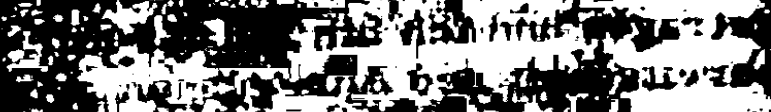

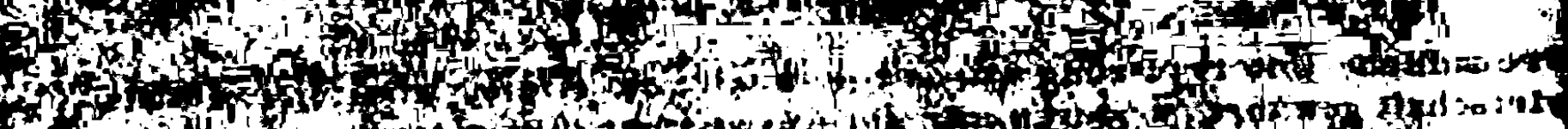
6.

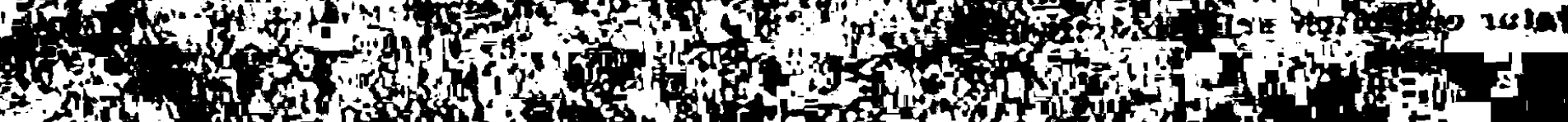
* ath

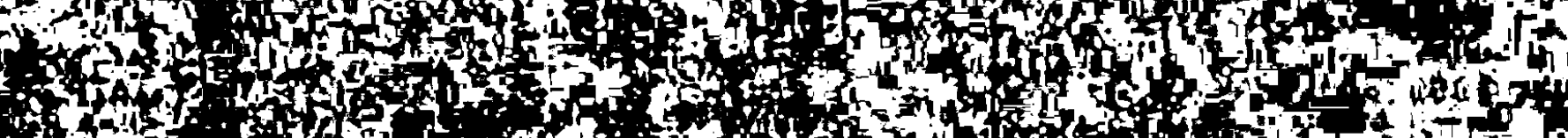

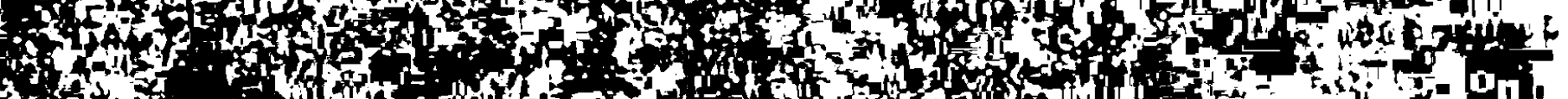
(h) (4)

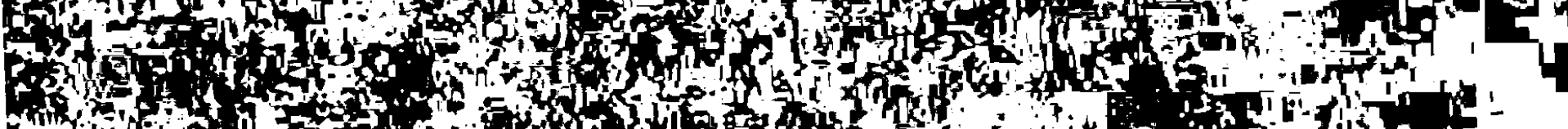

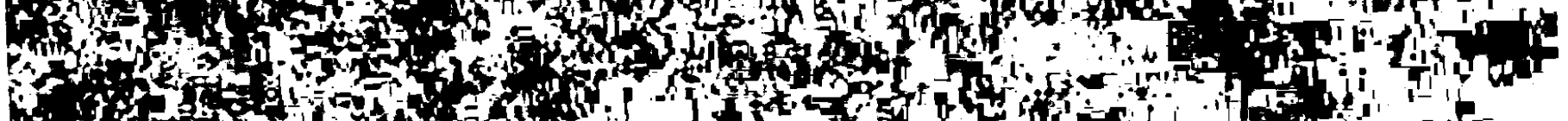

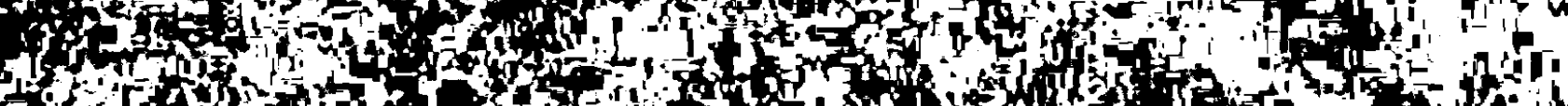

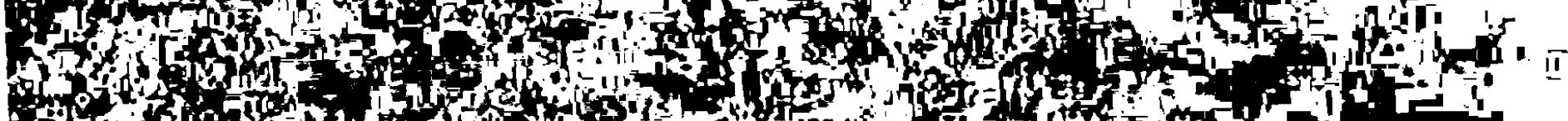

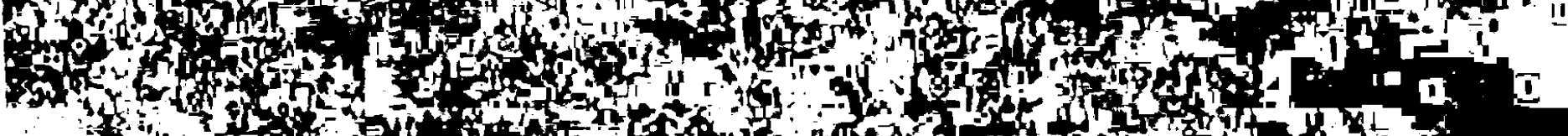

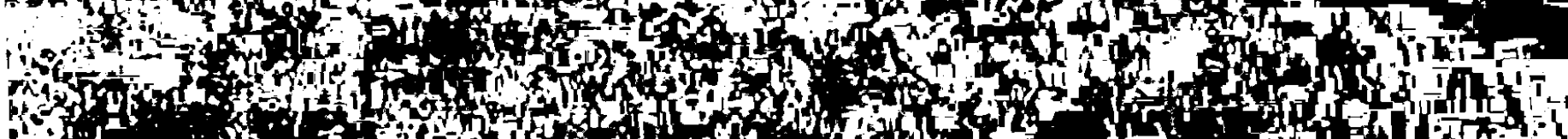
1.

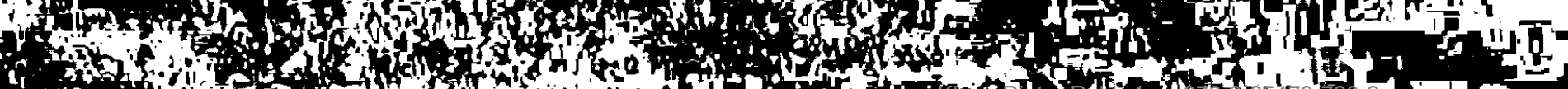

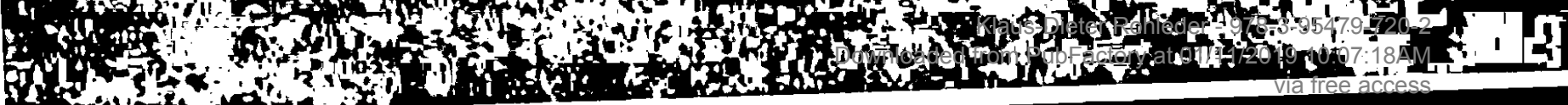




\section{Inhaltsverzeichnis}

Seite

I. Allgemeine Bemerkungen $\quad 9$

1. Die Aufgabenstellung $\quad 9$

2. Die regionale Beschränkung $\quad 10$

II. Entwicklung des Ost-Westhandels seit dem Ende des Zweiten Weltkriegs

1. Die Veränderung der Wirtschaftsstrukturen der südosteuropäischen Staatshandelsländer seit der Sozialisierung

2. Die Entwicklungsperioden des Ost-Westhandels nach dem Zweiten Weltkrieg

3. Umfang und Struktur des gegenwärtigen Handels der EWG-Mitgliedstaaten, Großbritanniens und der USA mit den Staatshandelsländern Südosteuropas

III. Grundprobleme der Osthandelspolitik

1. Der Begriff der Osthandelspolitik

2. Die politische Bedeutung

3. Das Zusammentreffen von marktwirtschaftlichen und zentralverwaltungswirtschaftlichen Wirtschaftssystemen

a) Der Gegensatz der Wirtschaftssysteme

b) Die Systembezogenheit der außenwirtschaftlichen und außenwirtschaftspolitischen Zielsetzungen

4. Grundzüge der Entwicklung der Osthandelspolitik seit dem Ende des Zweiten Weltkriegs

5. Die Bedeutung der Handelsvertragstechnik für die Regelung der Ost-Westhandelsbeziehungen

6. Die Osthandelspolitik als Konglomerat von systemneutralen und systembezogenen Maßnahmen

7. Die Auswahl der zu untersuchenden handelspolitischen Aktivitäten 
IV. Darstellung der Osthandelspolitik der EWG-Mitgliedstaaten, Großbritanniens und der USA gegenüber den Staatshandelsländern Südosteuropas

1. Ausfuhrwirksame Maßnahmen der EWG-Mitgliedstaaten, Großbritanniens und der USA

a) Ausfuhrbeschränkungen

al) Das Internationale Ausfuhrkontrollsystem

a2) Die Ausfuhrbeschränkungen der EWGMitgliedstaaten

a3) Die Ausfuhrbeschränkungen Großbritanniens

a4) Die Ausfuhrbeschränkungen der USA

a41) Die Beschränkungen der Güterausfuhr

a42) Die exterritoriale Anwendung der amerikanischen Ausfuhrkontrollen

a5) Zusammenfassung

b) Die Ausfuhrkreditpolitik

b1) Die Berner Union

b2) Die Ausfuhrkreditpolitik der EWGMitgliedstaaten

b3) Die Ausfuhrkreditpolitik Großbritanniens

b4) Die Ausfuhrkreditpolitik der USA

76

b41) Die Bestimmungen der "Johnson Act"

b42) Die Bestimmungen der "Foreign Aid and Related Appropriations Act"

b5) Zusammenfassung

2. Einfuhrwirksame Maßnahmen der EWG-Mitgliedstaaten, Großbritanniens und der USA

a) Mengenbeschränkungen versus Preisbelastungen

b) Die Einfuhrpolitik der EWG-Mitgliedstaaten

b1) Die vergemeinschafteten einfuhrpolitischen Maßnahmen der EWG-Mitgliedstaaten

b11) Preisbelastungen und Mengenbeschränkungen von marktordnungsgebundenen Agrareinfuhren auf Grund der gemeinsamen EWG-Agrarpolitik

b12) Preisbelastungen von nichtmarktordnungsgebundenen Agrargütern sowie Waren industriellgewerblicher Art

b1 3) Mengenbeschränkungen für Roheisen- und Stahleinfuhren 
b2) Verordnungsvorschläge der EWG-Kommission zur Aufstellung gemeinsamer Liberalisierungslisten der Einfuhr und zur Abwehr anomaler Handelspraktiken

b3) Die residuale Einfuhrpolitik der EWG-Mitgliedstaaten

c) Die Einfuhrpolitik Großbritanniens

d) Die Einfuhrpolitik der USA

e) Zusammenfassung

V. Schlußbemerkung 


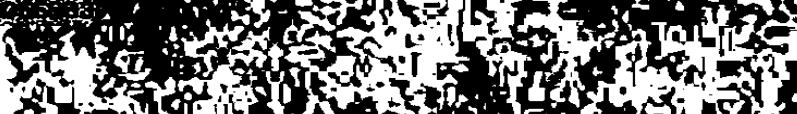

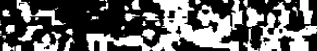

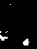

Hor .

간.

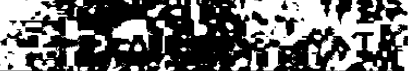

the

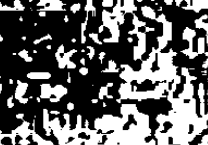

ato

(3)

int

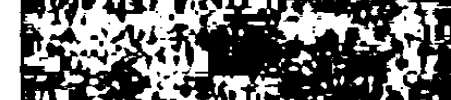

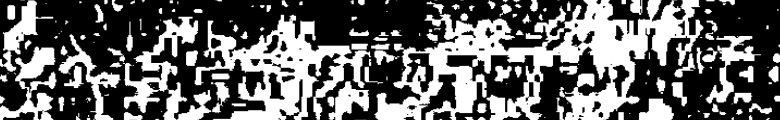

2.7.

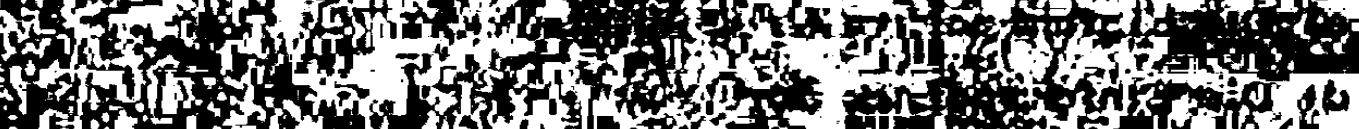

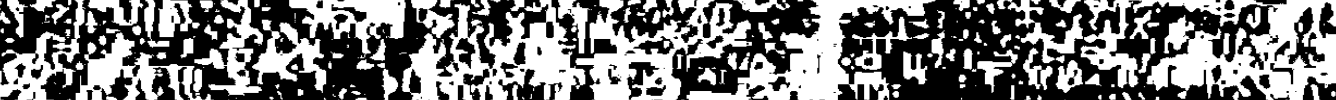

40

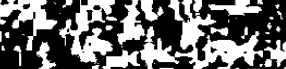

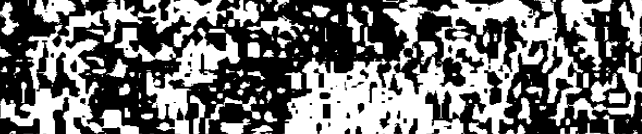

for 14ter

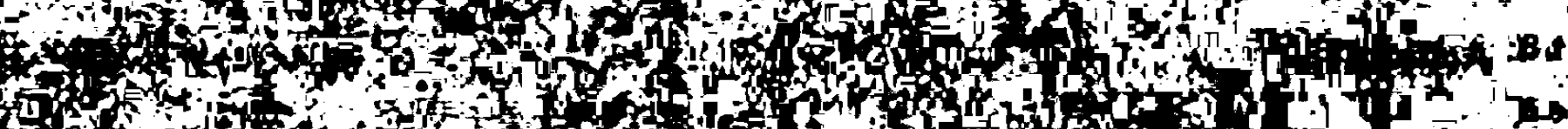

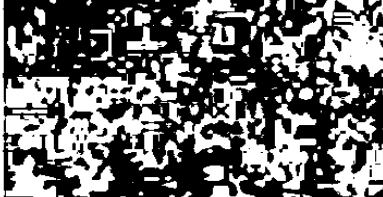

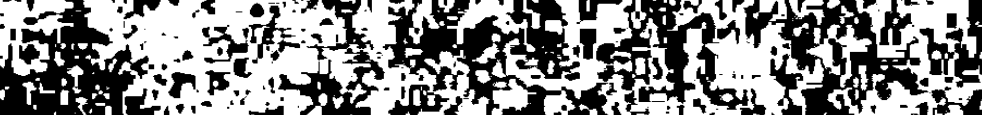

(n)

* a to

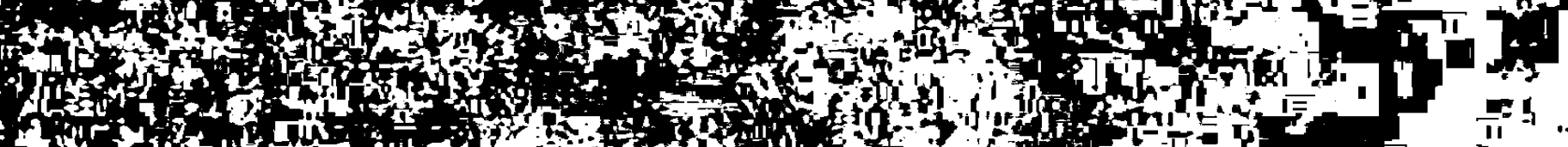

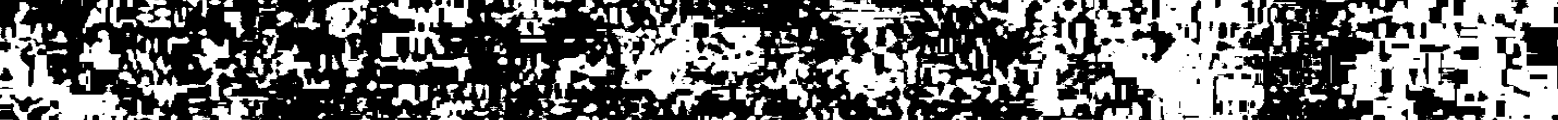

Lets

\section{Fy}

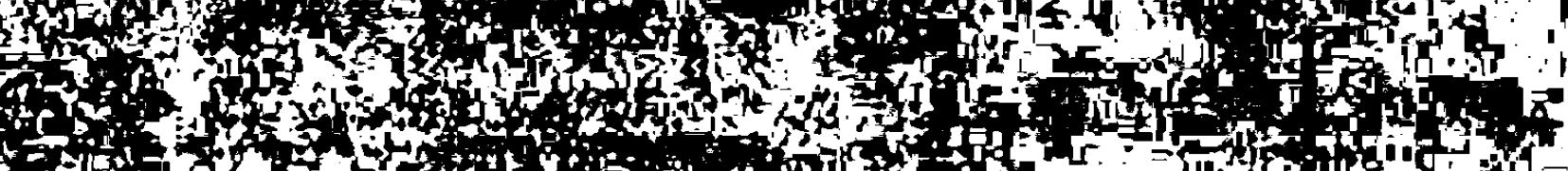
(5-30) (3)

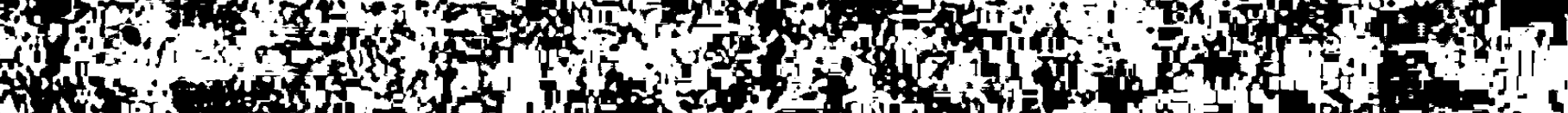

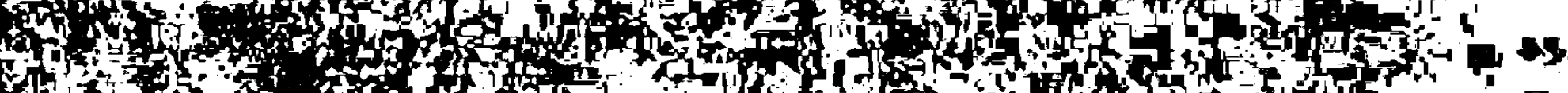

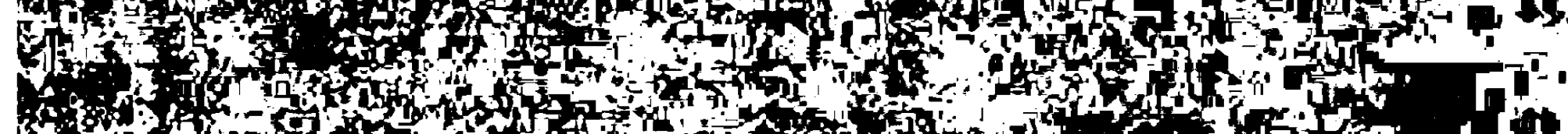

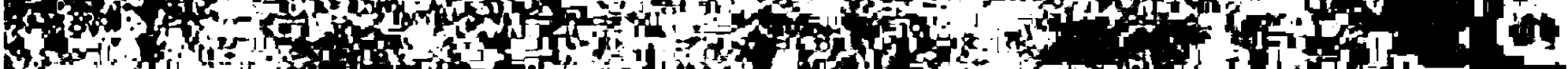
25

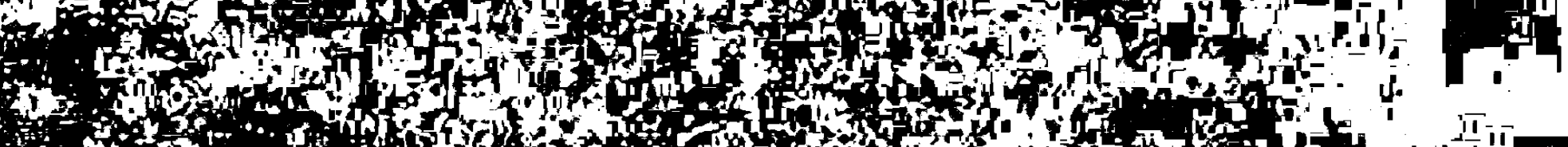

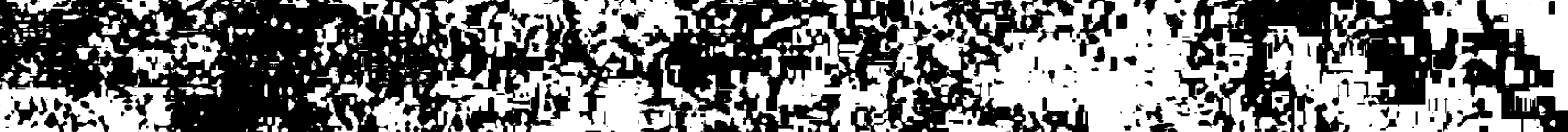
2y x

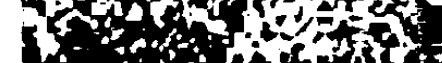

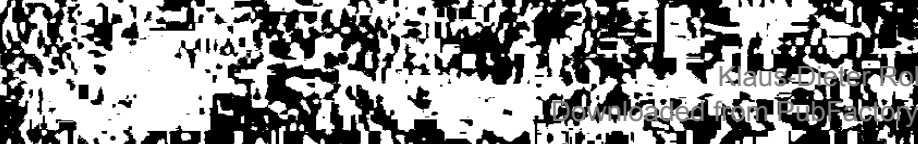




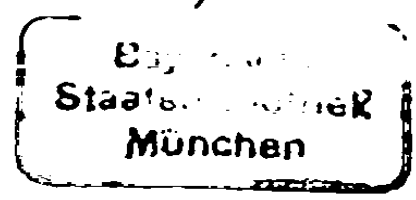

\section{Allgemeine Bemerkungen}

\section{DIE A U F G B E NTELL U N ${ }^{1}$}

Die gegenüber der Vorkriegszeit vergleichsweise wenig intensiven OstWesthandelsbeziehungen der Nachkriegszeit nehmen seit einigen Jahren ständig an Bedeutung $z u$. Das Augenmerk der westlichen Länder richtet sich dabei nicht unwesentlich auf die südosteuropäischen Staatshandelsländer, die wegen der raschen und umfangreichen Industrialisierung als ausbaufăhige Märkte für einen verstärkten Handelsaustausch zunehmend geeignet erscheinen.

Die Bemühungen um einen Abbau der politischen Spannungen zwischen West und Ost wirkten sich günstig auf das handelspolitische Klima aus und förderten diese Entwicklung erheblich. Vor allem die Mitgliedstaaten der Europäischen Wirtschaftsgemeinschaft ${ }^{2}$ und Großbritannien waren bestrebt, die wirtschaftliche Zusammenarbeit mit den ost- und südosteuropäischen Staatshandelsländern durch handelspolitische Liberalisie rungsmaßnahmen zu verstärken. ${ }^{3}$ Selbst die Vereinigten Staaten von Amerika (USA) haben - entgegen ihrer früheren ablehnenden Haltung - ihre Einstellung zum Osthandel grundsätzlich geändert, wenn auch die militärischen Auseinandersetzungen in Südostasien eine Anpassung an westeuropăische Osthandelspraktiken bisher weitgehend verhinderten.

Bevor im folgenden auf die Osthandelspolitik der EWG-Mitgliedstaaten, Großbritanniens und der USA gegenüber den Staatshandelsländern Südosteuropas im einzelnen eingegangen wird, ist es nützlich, einen Blick auf den gegenwärtigen Handelsaustausch $z u$ werfen. Gerade weil in den Handelsbeziehungen $z$ wischen West und Ost viele politische Momente enthalten sind, besteht die Gefahr, die nüchterne wirtschaftliche Grundlage zu übersehen, auf der dieser Handel beruht und die einen großen Teil seiner Besonderheiten ausmacht. ${ }^{4}$

1 Die der Untersuchung zugrunde liegende Materialsammlung wurde im wesentlichen im Juli 1968 abgeschlossen.

${ }^{2}$ Im weiteren auch als EWG-Mitgliedstaaten bezeichnet.

${ }^{3} \mathrm{Vgl}$. Hermann GROSS, Die Liberalisierungsprobleme im Ost-West-Handel, "Wissenschaftlicher Dienst Südosteuropa", Jg. XVII, H. 10, München 1968, S. 145 ff.

- Vgl. auch Europăisches Parlament, Sitzungsdokumente 1965 - 1966, Bericht im Namen des Außenhandelsausschusses über Fragen der gemeinsamen Handelspolitik der Gemeinschaft gegenüber Staatshandelsländern, Berichterstatter: Walter Löhr, Dok. 10 (Deutsche Ausgabe), 22. März 1965, S. 1 . 
Im Anschluß an diesen Abschnitt folgen eine Festlegung des Begriffes der Osthandelspolitik, eine Charakterisierung politisch und okonomisch bedingter Grundprobleme der Osthandelspolitik sowie ein kurzer historischer Abriß der Entwicklung der Osthandelspolitik seit dem Zweiten Weltkrieg. Danach wird die Auswahl der im Mittelpunkt der Untersuchung stehenden handelspolitischen Aktivitäten der westlichen Länder gegenüber den südosteuropäischen Staatshandelsländern getroffen.

Die vorliegende Untersuchung stellt sich die Aufgabe, typische handelspolitische Maßnahmen ausgewählter westlicher Länder gegenüber den Staatshandelsländern Südosteuropas zu kennzeichnen und gegenüberzustellen. Damit soll ein Beitrag zur analytischen Betrachtung der Ost-Westhandelsbeziehungen im allgemeinen geleistet werden. Daß dies auf Grund der Unübersichtlichkeit und weitgehenden Unzugänglichkeit vor allem des einschlägigen offiziellen Quellenmaterials der verschiedenen westlichen Länder nur ein Versuch bleiben muß, sei an dieser Stelle ganz besonders hervorgehoben.

Die Arbeit beabsichtigt keine Darstellung der Gesamtheit der osthandelspolitischen Maßnahmen westlicher Länder gegenüber dem Ostblock. Da die bislang $z u$ diesem Themenkreis veröffentlichten Untersuchungen sich meines Wissens zumeist nur mit der Charakterisierung einer osthandelspolitischen Aktivităt mehrerer westlicher Lănder (vorwiegend Ausfuhrkontrollpolitik) oder mehrerer osthandelspolitischen Aktivităten eines Landes befassen, ' könnte die vorliegende Arbeit dennoch geeignet sein, eine - wenn auch nicht vollständige - Übersicht über mehrere kennzeichnende osthandelspolitische Aktivitäten mehre $r$ e $r$ westlicher Länder zu geben.

\section{DIE REGIONALE BESCHR ÄNKUNG}

Die Beschränkung der Untersuchung auf die EWG-Mitgliedstaaten, Großbritannien und die USA einerseits und a uf die südosteuropäischen Staatshandelslănder andererseits hat verschiedene Gründe.

Was die westlichen Marktwirtschaften anbelangt, so sind diese sowohl wirtschaftlicher als auch politischer Natur. Die genannten westeuropăischen Länder repräsentieren die bedeutendsten Westhandelspartner der ost- und sủdosteuropäischen Staatshandelsländer. Dies ist vor allem zurückzuführen auf die traditionellen Handelsbeziehungen $z$ um südosteuro-

' Vgl. Gunnar ADLER-KARLSSON, Western Economic Warfare 1947 - 1967, Stockholm 1968, S. 4. 
päischen Wirtschaftsraum vor dem Zweiten Weltkrieg, 1 auf die relative geographische Nähe und die, wenn auch beschränkten, aber sicherlich bestehenden Absatzmöglichkeiten bestimmter südosteuropäischer Exportprodukte in westeuropăischen Ländern.

Was die USA betrifft, so sind für ihre Beziehungen zu Ost- und Südosteuropa weniger wirtschaftliche als vielmehr politische Elemente entscheidend. Besondere Bedeutung kommt den USA insofern zu, als sie zumeist bemüht waren, den Handel mit dem Osten aus politischen Gründen niedrig $\mathrm{zu}$ halten und ihn als außenpolitisches Instrument im Rahmen der internationalen westlichen Kooperation einzusetzen. ${ }^{2}$ Die Eingliederung der USA in die Untersuchung ist auch dadurch gerechtfertigt, daß sich die USA nach Aufgabe ihrer weitgehenden osthandelspolitischen Zurückhaltung zu einem nennenswerten Konkurrenten Westeuropas in der Belieferung der ost- und südosteuropäischen Staatshandelsländer mit hochwertigen Investitions- und Konsumgütern erweisen könnten. ${ }^{3}$ Diese Möglichkeit wird

1 Vgl. hierzu Hermann GROSS, Südosteuropa, Bau und Entwicklung der Wirtschaft, Beihefte zur Leipziger Vierteljahresschrift für Südosteuropa, H. 1, Leipzig 1937;

ders., Die Außenhandelsverflechtung der Südoststaaten, in: SüdosteuropaJahrbuch, Bd. 4, hrsg. von Rudolf Vogel, München 1960, S. $3 \mathrm{ff}$.

2 Vgl. Hans MÖLLER, Internationale Wirtschaftsorganisationen, Wiesbaden 1960, S. 119; John C. CAMPBELL, Europe, East and West, in: The United States and Eastern Europe, ed. by Robert F. Byrnes, Englewood Cliffs/New Jersey 1967 , S. 136 .

${ }^{3}$ Während die amerikanische Wirtschaft eine Intensivierung des Ost-Westhandels sehr begrüßen würde und auch von der augenblicklichen Regierung in ihren Bemühungen um entsprechende handelspolitische Erleichterungen unterstützt wird, verhalten sich der Kongreß und die offentliche Meinung auch weiterhin recht konservativ.

Zum Problem der Einstellung der USA zum Ost-Westhandel - vor allem der Haltung der Regierung, des Kongresses, der Wirtschaft, der offentlichen Meinung und der akademischen Kreise - sei verwiesen auf:

Gunnar ADLER-KARLSSON, Western Economic Warfare 1947 - 1967, a.a.O., S. $34 \mathrm{ff}$. und S. 110;

Nathaniel Mc KITTERICK, East West Trade, The Background of U.S.-Policy, New York 1966;

Private Boycotts vs the National Interest, Department of State Publication, No. 8117, Washington D.C. 1966;

Statement on U.S. - Policy Toward East-West Trade by Committee on Commercial Policy, United States Council of the International Chamber of Commerce Inc., Committee Report, April 21, 1967;

East-West Trade. Hearings before the Committee on Foreign Relations, U.S. Senate, Part I and II (March-April 1964/February 1965), Washington D.C.; East-West Trade. A Compilation of Views of Businessmen, Bankers and Academic Experts, Committee on Foreign Relations, U.S. Senate, Washington D. C., November 1964. 
von maßgeblicher amerikanischer Seite hervorgehoben. Begründet wird sie zumeist damit, daß die von den sozialistischen Ländern Ost- und Südosteuropas gewünschten Industrieerzeugnisse aus den USA einen höheren technischen Standard haben als vergleichbare westeuropäische Güter und die damit den Industrialisierungskonzepten der sozialistischen Länder besser entsprechen. '

Die Beschränkung auf die südosteuropäischen Staatshandelsländer ist überwiegend auf ökonomische Gründe zurückzuführen. Die Länder Albanien, Bulgarien, Rumänien und Ungarn ${ }^{2}$ gehören dem östlichen Block mit zentralistisch-planwirtschaftlicher Staatswirtschaftsordnung (Staatshandelsländer) an und stellen ein von byzantinisch-osmanischen Kulturelementen beeinflußtes Übergangsgebiet von der agrarischen zur industriellen Wirtschaftsstufe dar. Diese Länder sind zwar in sich kein geschlossener Wirtschaftsraum im engeren Sinne, doch erscheint es berechtigt, auf Grund der wirtschaftlichen, sozialen, historischen und kulturellen Gemeinsamkeiten von einem Wirtschaftsraum im weiteren Sinne innerhalb des kommunistischen Blocks zu sprechen. ${ }^{3}$

Sieht man von Albanien ab, dessen besondere politische und wirtschaftliche Verhältnisse und Außenbeziehungen es sinnvoll erscheinen lassen, dieses Land von der beabsichtigten Untersuchung auszuklammern, ${ }^{4}$ so

1 Vgl. Robert B. WRIGHT, East-West Trade: The Iron Curtain Countries Eighteen Years Later, "Department of State Bulletin", Washington D.C., Dec. 1964, S. 819;

Mose L. HARVEY, East-West Trade and United States Policy, New York 1966, S. 49 ff.

2 Jugoslawien wird nicht $z u$ den Staatshandelsländern gezăhlt.

${ }^{3}$ Vgl. Hermann GROSS, Südosteuropa, Bau und Entwicklung der Wirtschaft, a.a.O.; ders., Die Außenhandelsverflechtung der Südoststaaten, a.a.O.; ders., Wirtschaftssysteme und Wirtschaftspolitik der südosteuropäischen Staaten, in: Südosteuropa-Jahrbuch, Bd. 7, hrsg. von Walter Althammer, München 1965, S. 1 ff.

4 Vgl. William E. GRIFFITH, Albania and the Sino-Soviet Rift, Cambridge/ Mass. 1962;

Hermann GROSS, Albanien zwischen den Mächten, Ein Beitrag zur ErschlieBung unterentwickelter Gebiete, Sonderdruck des "Wirtschaftsdienstes", H.6, Hamburg 1949, S. 3 ff.;

Stavro SKENDI, Albania, Mid-European Studies Center of the Free Europe Committee, New York 1956;

Robert SCHWANKE, Entwicklungstendenzen in der albanischen Wirtschaft, "Osteuropa-Wirtschaft", Jg. 10, H. 2, Stuttgart 1965, S. 112 ff.;

Kurt WESSELY, Chinas Brückenkopf in Europa, "Der Volkswirt", Frankfurt a. M. 1965, Nr. 143;

Theodor ZOTSCHEW, Die wirtschaftlichen Probleme Albaniens, "OsteuropaWirtschaft", Jg. 7, H. 1, Stuttgart 1962, S. $39 \mathrm{ff}$. 
versuchen die südosteuropäischen Staatshandelsländer eine ähnliche außenwirtschaftspolitische Konzeption zu verwirklichen. Entsprechend den wirtschaftlichen, politischen und historischen Entwicklungen und Gegebenheiten Bulgariens, Rumäniens und Ungarns ist diese zwar im Detail von Land zu Land verschieden. Insgesamt aber bestehen noch so viele Gemeinsamkeiten, durch die sie sich von den entsprechenden Konzeptionen der höher entwickelten Industrieländer Osteuropas und auch der Sowjetunion unterscheiden, so daß man diese Länder auch im Rahmen einer außenwirtschaftlichen West-Ostanalyse zusammenfassen kann. 


\section{Entwicklung des Ost.Westhandels seit dem Ende des Zweiten Weltkriegs}

\section{DIE VERÄNDERUNG DER WIRTSCHAFTSSTRUKTUREN DER SÜDOSTEUROP ̈ISCHEN STAATSHANDELSL ̈̈N - DER SEIT DER SOZIALISIERUNG}

Nach Beendigung des Zweiten Weltkriegs zwang die Sowjetunion den ostund südrsteuropäischen Ländern - mit Ausnahme Griechenlands und der Türkei - die sozialistische Wirtschafts- und Sozialordnung sowjetischen Musters auf. In den südosteuropäischen Staaten wurde dies ganz besonders forciert, und nach der unmittelbaren Einflußnahme der Sowjetunion a uf die Regierungsbildungen ab 1948 war eine souveräne Wirtschaftspolitik dieser Länder kaum noch möglich. ${ }^{1}$ Als besonders Polen und die Tschechoslowakei Bereitschaft zeigten, das Hilfsangebot der Vereinigten Staaten von Amerika im Rahmen des Marshallplanes anzunehmen, gründete die Sowjetunion im Jahre 1949 den "Rat für gegenseitige Wirtschaftshilfe" (RGW) ${ }^{2}$ als Instrument der östlichen Integration.

Nach dem sowjetischen Modell und den Grundprinzipien der marxistischleninistischen Wirtschaftspolitik mußte in diesen Staaten ein Übergang von mehr oder weniger stationären Agrarwirtschaften zu dynamisch expandierenden Industriestaaten unter zentralistisch-planwirtschaftlichem Vorzeichen vollzogen werden. Dies war jedoch - entsp rechend der von der Sow jetunion seit Lenin entwickelten Theorie - nur dann möglich, wenn die Wachstumsrate der Produktionsmittelindustrie über der der Konsumgüterindustrie und der Landwirtschaft lag. ${ }^{3}$

' Vgl. Hermann GROSS, Der wirtschaftspolitische Umbruch in Südosteuropa, "Wissenschaftlicher Dienst Südosteuropa", Jg. 9, H. 10/11, München 1960, S. 113.

2 Der "Rat für gegenseitige Wirtschaftshilfe" (RGW) wird auch als COMECON (Council for Mutial Economic Assistance) bezeichnet.

Vgl. Michael KASER, Comecon-Integration, Problems of the Planned Economies, London - New York - Toronto, 2. Aufl. 1967;

Hermann GROSS, Economic Integration of Eastern Europe, in: Aspects of Modern Communism, ed. by Richard F. Staar, Columbia S. C. 1968, S. $143 \mathrm{ff}$.

${ }^{3} \mathrm{Vgl}$. Hermann GROSS, Neuere Tendenzen in der Agrar- und Industrialisierungspolitik Ostmittel- und Südosteuropas, in: Südosteuropa-Jahrbuch, Bd. 3, hrsg. von Wilhelm Gülich, München 1959, S. 78. 
Der Prozeß der damit verbundenen wirtschaftlichen Umstrukturierung wurde eingeleitet unter volliger Mißachtung der unterschiedlichen wirtschaftlichen Ausgangssituationen in den südosteuropäischen Volkswirtschaften. Zwar erhöhte sich die industrielle Produktion um ein Vielfaches, aber die Voraussetzungen eines gesunden und organischen Ausbaus der wirtschaftlichen Struktur der Länder wurde weitgehend vernachlässigt. Dies mußte zu folgenschweren, produktionsstörenden Disproportionalitäten führen und zog infolge der notwendigen Selbstfinanzierung der forcierten Industrialisierung durch Konsumbeschränkung und $Z$ wangssparen empfindliche Einbußen in der Höhe des Lebensstandards nach sich. 1 Außerdem verloren die südosteuropäischen Länder Bulgarien, Rumänien und Ungarn, die vor 1945 traditionelle Agrarexportländer waren, ihre Einnahmequelle aus den Ausfuhren landwirtschaftlicher Produkte, ohne sie durch entsprechende eigene industrielle Exporte kompensieren zu können. Sie waren sogar vielfach gezwungen, beträchtliche Mengen von Nahrungsmitteln aus dem Westen zu importieren.

\section{DIE ENTWICKLUNGSPERIODEN DES OST- WEST- HANDELS NACH DEM ZWEITEN WELTKRIEG}

Die Entwicklung des Ost-Westhandels in den letzten zwanzig Jahren läßt sich in mehrere charakteristische Abschnitte gliedern:

Obgleich die wirtschaftliche Entwicklung in den ost - und südosteuropäischen Ländern ausgesprochen von den ideologisch-politischen Zielen der marxistisch-leninistischen Doktrin nach sowjetischer Auslegung unter entscheidender materieller und organisatorischer Mitwirkung der Sowjetunion bestimmt wurde, versuchte man anfänglich dennoch, den ehemals engen Kontakt mit den westlichen Industrieländern wieder aufzunehmen. Die Folge war, daß bis zum Jahre 1948/49 das Volumen des Ostblockaußenhandels (einschließlich der Sowjetunion) mit dem Westen größer war als das gesamte Intrablock-Außenhandelsvolumen; dies gilt ganz besonders für den Südosten. 2

1 Vgl. die Ausführungen von KUROWSKI, zitiert bei Theodor ZOTSCHEW, Die Entwicklungsprobleme der polnischen Wirtschaft, in: Material uber die wirtschaftliche Lage und Entwicklung der Volksrepublik Polen, Institut für Weltwirtschaft, Forschungsabteilung, Kiel 1957, S. 5 (Originalquelle: "Zycie Gospodarcze", Warschau vom 25.2.1956).

${ }^{2} \mathrm{Vgl}$. Bruno KIESEWETTER, Entwicklungstendenzen im A ußenhandel der europäischen Ostblockstaaten, "Osteuropa-Wirtschaft", Jg. 3, H. 2, Stuttgart 1958, S. 114. 
Im Jahre 1948 betrug der prozentuale Anteil des Westhandels am gesamten nationalen Außenhandel der Tschechoslowakei 70 v.H., Polens 66 v. H., Rumäniens 29 v.H. und Ungarns 66 v.H. 1

Vor dem Krieg, d.h. im Jahre 1937, wickelten die drei Länder Bulgarien, Rumänien und Ungarn etwa drei Viertel ihres Außenhandels mit den mittelund westeuropăischen Industrieländern ab. ${ }^{2}$

Mit der Gründung des RGW durch die Sow jetunion (1949) wollten die Russen eine weitere Annäherung an den Westen verhindern. Die eigentliche regionale Umorientierung des Außenhandels der ost- und südosteuropăischen Staaten während des ersten Jahrzehnts nach dem Zweiten Weltkrieg war jedoch "'.. in erster Linie bedingt durch die Reparationslieferungen an die Sowjetunion, z.T. im Rahmen der von ihr kontrollierten ' Gemischten Gesellschaften' sowie durch die Position der Sowjetunion als Mittler im Handel mit den bedeutendsten osteuropăischen Gütern. "3 Die Handelsbeziehungen zwischen Ost und West kamen fast vollständig zum Erliegen. Von 1950 bis 1953 betrug die Zuwachsrate des Außenhandels des RGW mit dem Westen nur mehr 13,2 v. H., während sich die des Intrablockhandels im gleichen Zeitraum auf $81,6 \mathrm{v}$. H. belief. ${ }^{4}$

Nach dem Tode Stalins im Jahre 1953 verbesserten sich die Handelsbeziehungen der westlichen Staaten mit dem Ostblock merklich. Eine der vorangegangenen Periode völlig entgegengesetzte Entwicklung begann, die durch die Aufstände in Polen und Ungarn noch verstärkt wurde. Im Zeitraum von 1953 bis 1956 wuchs der Intrablockhandel nur um 14,6 v. H., der Handel mit dem Westen dagegen um 76, 5 v. H. ${ }^{5}$

Die Entwicklung des Ost-Westhandels nach 1956, vor allem jedoch nach 1958, ist gekennzeichnet durch das schnelle Ansteigen des östlichen Einfuh rbedarfs an hochwertigen Industrieausrüstungen. Zurückzuführen ist dies auf die ehrgeizigen und langfristigen Investitionsprogramme des Ostens. Da dieser Investitionsbedarf im RGW nur ungenügend zu befriedigen war, bemühten sich die sozialistischen Lănder besonders um ent-

' Die vergleichsweise niedrige Zahl für Rumänien läßt sich daraus erklären, daß dieses Land damals unter stärksten sow jetischen Einfluß geriet. - Dies dürfte wohl auch für Bulgarien gelten, obgleich hierfür keine Zahlen zu erhalten waren. Vgl. H. OLSIENKIEWICZ, Problems of East-West Trade: Trade and Liberalisation, "Bulletin of the Institute for the Study of the USSR", Vol. 11, No. 6, München 1964, S. 8.

$2 \mathrm{Vgl}$. Hermann GROSS, Die Außenhandelsverflechtung der Südoststaaten, a. a. O., S. 20 Tab. 1 .

${ }^{3}$ Ders., Ergebnisse und Probleme des COMECON, "Wissenschaftlicher Dienst Südosteuropa", Jg. XVI, H. 4/5, München 1967, S. 50.

4 Vgl. H. OLSIENKIEWICZ, a.a.O., S. 9.

$5 \mathrm{Vgl}$. ebd. 
sprechende Importe aus den westlichen Industrieländern. Damit verbunden war eine Tendenz zur Konzentrierung der Handelsbeziehungen auf die Bundesrepublik Deutschland, Frankreich, Italien und Großbritannien. Seit "Camp David" versuchten jedoch auch die Amerikaner verstärkt in den Ost-Westhandel einzusteigen.

Der kommunistische Block unter der Führung der Sowjetunion hat sich damit gegen Ende der fünfziger Jahre endgültig zur Intensivierung der Handelsbeziehungen mit den westlichen Industriestaaten entschlossen. Die in diesem Zusammenhang oft diskutierte Frage, wie weit der Ost-Westhandel ausgedehnt werden kann, ist wohl dahingehend zu beantworten, daß, wenn die speziellen Handelshemmnisse einmal beseitigt sind, unter rein wirtschaftlichen Aspekten noch genügend Erweiterungsmöglichkeiten bestehen; diese dürften jedoch von der Sowjetunion aus politischen Erwăgungen auch weiterhin begrenzt werden.

Daß sich trotz verstärktem Ost-Westhandelsverkehr am Primärziel des Kommunismus langfristig nichts ändern wird, kommt in einem Vortrag Chruschtschows in Warschau im Oktober 1956 zum Ausdruck: "Natürlich müssen wir uns darüber im klaren sein, daß wir nicht ewig koexistieren können. Einer von uns $m u ß$ ins Grab. Wir wollen nicht ins Grab. Sie (die Westmächte; Anm.d. Verf.) wollen auch nicht ins Grab. Was bleibt also zu tun? Wir müssen sie ins Grab stoßen."' Die Geschehnisse in Osteuropa im Sommer 1968 haben gezeigt, daß diese Gedanken nicht tot sind.

\section{UMFA NG UND STRUKTUR DES GEGENW ARTIGEN HANDELS DER EWG-MITGLIEDSTAATEN, GROSS- BRITANNIENS UND DER USA MIT DEN STAATS- HANDELSLÄNDERN SÜDOSTEUROPAS}

Der Anteil der EWG- Mitgliedstaaten, Großbritanniens und der USA belief sich im Jahre 1966 auf 15,4 v. H. des bulgarischen, 25, 9 v. H. des rumănischen und 16,6 v. H. des ungarischen Gesamtaußenhandels. Gegenủber dem Jahre 1960 hat damit dieser Westhandelsanteil am Gesamtaußenhandel Bulgariens um 64 v.H. und Rumäniens um 56 v.H., im Falle Ungarns dagegen nur um $10 \mathrm{v} . \mathrm{H}$. zugenommen. Diese Entwicklung war begleitet von einem zum Teil recht erheblichen Rückgang des Anteils des RGW am Gesamthandel Bulgariens und Rumäniens, nicht aber Ungarns. Die entsprechenden RGW-Anteilswerte gingen für Bulgarien um 16,6 v. H. auf $67,2 \mathrm{v} . \mathrm{H}$. und für Rumänien um $18,4 \mathrm{v} . \mathrm{H}$. auf $54,6 \mathrm{v} . \mathrm{H}$. zurück. Lediglich der entsprechende ungarische Anteil ist mit 62, 5 v. H. im Jahre 1966 annähernd gleich geblieben gegenüber dem Jahre 1960 .

1 Zitiert nach Theodor ZOTSCHEW, Der Ost-West-Handel der Donaustaaten im Zeichen der Koexistenz, "Der Donauraum", Jg. 8, H. 1/2, Wien 1963 , S. 61 . 
Während damit im Jahre 1966 zwischen einem Sechstel und einem Viertel des Außenhandels der südosteuropäischen Staatshandelsländer mit den genannten westlichen Ländern abgewickelt wurde, belief sich der Anteil dieses Handelsaustausches am EWG-Gesamtaußenhandel im gleichen Jahr nur auf 1, 2 v.H., im Fall Großbritanniens sogar nur auf 0, 8 v. H. und erreichte im Fall der USA verschwindende 0,1 v. $H$.

In absoluten Zahlen ausgedrückt wurden 1966 zwischen den EWG-Staaten und den südosteuropäischen Staatshandelsländern Warenwerte in Höhe von 1. 280, 7 Mill. US- \$ ausgetauscht. Der entsprechende Wert belief sich für Großbritannien auf 232,0 Mill. US- \$, für die USA auf 55, 4 Mill. US- \$. Vom Handel der EWG mit den Staatshandelsländern Südosteuropas entfielen annähernd $50 \mathrm{v} . \mathrm{H}$. allein auf die Bundesrepublik Deutschland. Kennzeichnend für die Handelsbeziehungen $z$ wischen den genannten westlichen Ländern und den südosteuropäischen Staatshandelsländern ist ein beträchtliches und stetiges Handelsbilanzdefizit, das im Fall -Bulgariens und Rumäniens sogar erhebliche Zunahmen aufweist. Der entsprechende Einfuhrüberschuß Bulgariens hat sich im Jahre 1966 gegenüber $1960 \mathrm{mehr}$ als vervierfacht und eine Hobe von $122,3 \mathrm{Mill}$. US- \$ erreicht. Das rumänische Defizit erhöhte sich im gleichen Zeitraum auf mehr als das Zehnfache und belief sich 1966 auf 89,9 Mill. US- \$. Ungarn macht wiederum eine Ausnahme. Sieht man vom Jahre 1964 ab, wo das Handelsbilanzdefizit einen Höchststand erreichte, so ging der Einfuhrüberschuß gegenüber 1960 sogar um rund $30 \mathrm{v} . \mathrm{H}$. auf $34,2 \mathrm{Mill}$. US- $\$$ zurück. ${ }^{1}$

Die warenstrukturelle Zusammensetzung des Handels der verschiedenen westlichen Länder mit den südosteuropäischen Staatshandel sländern ist nicht so homogen wie häufig angenommen wird. Ohne an dieser Stelle auf die möglichen Ursachen einzugehen, sollen die Handelsbeziehungen der EWG-Mitgliedstaaten, Großbritanniens und der USA zu den Staatshandelslädern hinsichtlich ihrer Warenstruktur kurz untersucht werden:

Der Handelsaustausch der im Mittelpunkt stehenden westeuropăischen Länder, vor allem aber der Mitgliedstaaten der EWG, mit Bulgarien, Rumänien und Ungarn zeigt den Charakter eines Handels zwischen Industriestaaten auf der einen und Agrar- und Rohstoffexportstaaten auf der anderen Seite. Die Struktur des Warenaustausches zwischen den USA und diesen sozialistischen Lăndern dagegen ließe eher auf den Handel zweier ăhnlich strukturierter Wirtschaftsräume schließen, von denen keiner besondere Ausfuhr- oder Einfuh rpräferenzen aufweist.

Aggregiert man jeweils den gesamten Warenaustausch der verschiedenen westlichen Partner mit ihren südosteuropäischen Handel spartnern zu nur zwei Warengruppen (vgl. Tabelle 1), wobei man unter den Sammelbezeich-

\footnotetext{
Im einzelnen sei verwiesen auf die Tabellen 1 - 4 im Anhang, denen auch die
} obigen Zahlen entnommen wurden. 
Tabelle 1: Die Struktur des Außenhandels der EWG-Mitgliedstaaten, Großbritanniens und der USA mit den südosteuropaischen Staatshandelslandern in $\mathbf{v} . H$. des Gesamtwarenaustausches

Bulgarien Rumanien Ungarn

$\begin{array}{llllllll}\text { SITC-Gruppen } & \text { E } & \text { A } & \text { E } & \text { A } & \text { E } & \text { A }\end{array}$

EWG im Jahre 1965

$\begin{array}{rrrrrrr}0-4 & 80,1 & 11,7 & 89,2 & 11,7 & 73,9 & 19,8 \\ 5-8 & 19,3 & 88,1 & 8,6 & 87,4 & 24,8 & 79,6\end{array}$

Gro@britannien im Jahre 1966

$\begin{array}{rrrrrrr}0-4 & 44,2 & 4,7 & 57,2 & 12,5 & 46,0 & 9.1 \\ 5-8 & 55,8 & 94,9 & 42,8 & 87,0 & 53,3 & 88,6\end{array}$

USA im Jahre 1966

$\begin{array}{lllllll}0-4 & 70,9 & 47,2 & 22,2 & 34,9 & 20,7 & 77,0 \\ 5-8 & 25,0 & 52,8 & 75,5 & 64,8 & 79,2 & 22,0\end{array}$

$E=$ Einfuhr

$A=$ Ausfuhr

Quellen: Vgl. Tabellen 5 - 7 im Anhang.

nungen "Agrarerzeugnisse und Rohstoffe" die SITC'-Gruppen 0 bis 4, unter "Industrielle und gewerbliche Erzeugnisse" die SITC-Gruppen 5 bis 8 erfaßt, 2 so ergibt sich folgendes Bild:

Im Jahre $1965^{3}$ setzte sich die EWG-Einfuhr aus Bulgarien zu 80, 1 v. H., aus Rumänien zu 89, 2 v. H. aus Agrarerzeugnissen und Rohstoffen zusammen. Nur 19, 3 v. H. der Gesamteinfuhren aus Bulgarien und 8, 6 v. $H$. aus Rumänien bestanden aus industriellen und gewerblichen Erzeugnissen. Eine umgekehrte Zusammensetzung zeigte die Ausfuhr der EWG in diese Länder. Dabei entfielen 88,1 v. H. im Falle Bulgariens und 87, 4 v. H. im Falle Rumäniens a uf die industriell-gewerbliche Gütergruppe. Ähnlich, doch nicht so ausgeprägt, war der Handel mit Ungarn strukturiert. 24, 8 v. H. der EWG-Einfuhr aus und 79,6 v. H. der EWG-Ausfuhr nach Ungarn umfaßten Güter industriell-gewerblicher Natur.

Ein etwas ausgeglicheneres Verhältnis zwischen den beiden Hauptwarengruppen zeigt der Handel Großbritanniens mit den südosteuropäischen Staatshandelsländern. Im Jahre 1966 setzte sich die britische Einfuhr aus Bulgarien $z u$ 44,2 v. H., aus Rumänien zu 57,2 v. H. und aus Ungarn zu $46 \mathrm{v} . \mathrm{H}$. aus Agrarerzeugnissen und Rohstoffen zusammen. Ein ähnliches Bild wie im Fall der EWG ergibt sich jedoch für die Ausfuhr. Zwischen

1 SITC - Standard International Trade Classification.

2 Die SITC-Gruppe 9 "Sonstige" wurde hier unberücksichtigt gelassen.

$3 \mathrm{Vgl}$. Anmerkung zu Tabelle 6 im Anhang.

Die Zahlen für 1966 dürften aber keine wesentliche Änderung in den warenmäßigen Proportionen gebracht haben. 
87 v.H. und 94, 9 v.H. der Exporte Großbritanniens in die südosteuropäischen Staatshandelsländer bestanden aus industriellen und gewerblichen Waren.

Wich der britische Handel mit Südosteuropa nur in der Zusammensetzung der Einfuhr von der Warenstruktur des EWG-Handels ab, so fallen die USA auch auf der Exportseite aus der Reihe. Nur 20, 7 v. H. der Einfuhren aus Ungarn und $22,2 \mathrm{v} . \mathrm{H}$. der aus Rumánien - jedoch 70, $9 \mathrm{v} . \mathrm{H}$. der Importe aus Bulgarien - waren im Jahre 1966 Agrarerzeugnisse oder Rohstoffe. Utber zwei Drittel der Einfuhren der USA aus Rumänien und Ungarn umfaßten industriell-gewerbliche Waren. Was die US-Ausfuhr anbelangt, so erreichte der Anteil der Agrarprodukte und Rohstoffe an der Gesamtausfuhr in die jeweiligen sozialistischen Länder im selben Jahr eine Höhe zwischen $34,9 \mathrm{v} . \mathrm{H}$. und $77 \mathrm{v} . \mathrm{H}$. - Dies ist ein gegenüber Westeuropa vergleichsweise sehr hoher Anteil. ${ }^{1}$

Dieser grobe Überblick über Entwicklung und Stand der Ost-Westhandelsbeziehungen im allgemeinen und die der EWG-Mitgliedstaaten, Großbritanniens und der USA zu den Staatshandelsländern Südosteuropas im besonderen moge als Hintergrund zum Verständnis der nachfolgenden Ausführungen genügen.

1 Zur Zusammensetzung der Warengruppen vgl. Tabellen 5 - 7 im Anhang. 


\title{
III. Grundprobleme der Osthandelspolitik
}

\author{
1. DER BEGRIFF DER OSTHANDELSPOLITIK
}

Entsprechend der zugrundegelegten Aufgabenstellung befaßt sich die Untersuchung mit der Außenhandelspolitik ausgewählter westlicher Länder gegenüber den Staatshandelsländern Südosteuropas. Hierbei wird bewußt zwischen Außenwirtschaftspolitik im allgemeinen und Außenhandelspolitik als speziellem Teilbereich der Außenwirtschaftspolitik - im gegebenen Fall als spezifischer Teilbereich einer Ostaußenwirtschaftspolitik - unterschieden.

Entgegen dem Sprachgebrauch der Wirtschaftspraxis und vielfach auch der wirtschaftswissenschaftlichen Literatur erfolgt daher eine Beschränkung auf solche außenwirtschaftspolitische Maßnahmen, die die Regelung der Warenverkehrsbeziehungen zu den Staatshandelsländern Südosteuropas zum Ziele haben.

Legt man dem Begriff der Osthandelspolitik die allgemeine Definition der Außenwirtschaftspolitik zugrunde, ' so ist unter der Osthandelspolitik die staatliche Beeinflussung und Gestaltung von wirtschaftlichen Variablen und Daten zu verstehen, die unmittelbar in die Warenverkehrsbeziehungen der Wirtschaftssubjekte westlicher Marktwirtschaften zu den Partnern in verschiedenen Volkswirtschaften mit sozialistischen Wirtschafts- und Gesellschaftsordnungen eingehen. Eine derartige Abgrenzung von anderen Bereichen der Außenwirtschaft und der Außenwirtschaftspolitik erscheint notwendig, da sowohl in der Praxis des Ost-Westhandels als auch in der Literatur über den Ost-Westhandel eine solch begriffich eindeutige Begrenzung nach außenwirtschaftlichen Bereichen selten ist. ${ }^{2}$

Die Untersuchung bezieht sich im wesentlichen auf die staatliche Osthandelspolitik, wobei auch die EWG, deren gemeinschaftliche Osthandelspolitik zunehmend den Bereich nationaler Osthandelspolitik der Mitgliedstaaten einschränken dürfte, mit berücksichtigt wird. Interessant ist, daß die EWG (Art. 110 des Vertrages zur Gründung der EWG) nur von der Vereinheitlichung der Handelspolitik im allgemeinen und der gegenüber Staats-

' Vgl. Hans MÖLLER, Außenwirtschaftspolitik, Wiesbaden 1961, S. 137.

2 Die Begriffe Osthandel und Osthandelspolitik werden nicht selten als Sammelbezeichnungen für die verschiedensten außenwirtschaftlichen und außenwirtschaftspolitischen Bereiche wie Waren-, Dienstleistungsverkehr, unentgeltliche Leistungen und Kapitalverkehr verwendet. 
handelsländern im besonderen spricht, d.h. also, daß sich die schon effektiven und zukünftigen gemeinschaftlichen außenwirtschaftspolitischen Regelungen auf die Handelspolitik als Teilbereich der Außenwirtschaftspolitik beschränken. Die anderen Bereiche - vorbehaltlich einer Erweiterung der vertraglichen Bestimmungen bzw. einer entsprechenden Auslegung des Art. 110 - werden demnach auch weiterhin den nationalen staatlichen Kompetenzen der Mitglieder unterliegen. Zu bedenken ist jedoch, daß eine Koordinierung der Wirtschaftspolitik (Art. $104 \mathrm{f}$.) außenwirtschaftliche Konsequenzen haben könnte, die über die der Außenhandelspolitik hinausgehen.

Wenngleich bisher nur von der staatlichen Außenhandelspolitik die Rede war, so bedeutet dies nicht, daß nicht auch große Verbånde oder sonstige Interessengruppen versuchen, die Außenhandelsbeziehungen eines Landes, insbesondere zum Ostblock, planmäßig zu beeinflussen. "Solche Einflüsse bilden jedoch entweder eine Ausnahme oder wirken sich letztlich in der staatlichen Außenwirtschaftspolitik aus."' Eine Beeinflussung der offiziellen amerikanischen Osthandelspolitik durch solche nichtstaatliche Stellen ist nicht unerheblich und die Handlungsfähigkeit der staatlichen Stellen wird davon in erstaunlich hohem Maße bestimmt. ${ }^{2}$

\section{DIE POLITISCHE BEDEUTUNG}

"Staatliche Außenwirtschaftspolitik ist ... jede nach außen gerichtete staatliche Politik, die sich wirtschaftlicher Mittel bedient. Daraus folgt, daß die Außenwirtschaftspolitik als ein Teilgebiet der Außenpolitik angesehen wird." 3 - Dies gilt analog für die Außenhandelspolitik, da diese als Teilbereich der Außenwirtschaftspolitik definiert ist.

Die im vorausgegangenen Abschnitt getroffene Begriffsabgrenzung der Osthandelspolitik berücksichtigt weder die weltwirtschaftspolitischen noch die außenpolitischen Aspekte der staatlichen Handelspolitik und damit auch nicht die mögliche Beeinflussung der wirtschaftlichen und politischen Ordnung der Welt durch eine eigene nationale Weltwirtschaftspolitik. ${ }^{4} \mathrm{Da}$ sich für größere, politisch und wirtschaftlich einflußreiche Länder aber immer ein unmittelbarer Zusammenhang und eine Wechselwirkung zwischen Außenwirtschaftspolitik, Weltwirtschaftspolitik und Außenpolitik ergeben, ${ }^{5}$ muß die Handelspolitik als wesentliches Element der Welthan-

1 Hans MÖLLER, Außenwirtschaftspolitik, a.a.O., S. 37.

2 Vgl. Private Boycotts vs the National Interest, a.a. O.; Nathaniel Mc KITTERICK, East-West Trade. The Background of U.S. Policy, a.a.O.

3 Peter BERNHOLZ, Außenpolitik und internationale Wirtschaftsbeziehungen, Frankfurt a. M. 1966, S. 53 .

- Vgl. Hans MÖLLER, Außenwirtschaftspolitik, a.a.O., S. 35 f.

5 Ebd. 
dels- und Außenpolitik eines Landes gesehen werden. Die staatliche Außenwirtschaftspolitik (Außenhandelspolitik) stellt jedoch nur einen Teil des staatlichen außenpolitischen Operationsspielraumes zur Veränderung der staatlichen Präferenzskala oder des Operationsspielraumes anderer Länder' dar, denn "... die politischen Ziele gehen ... über die unmittelbaren Zwecke der Wirtschaft hinaus; diese erscheinen nur als Mittel für die andersartigen $Z$ wecke des Staates. Kein $Z$ weifel, diese Ideen sind lebendig und beeinflussen die internationale Wirtschaftspolitik von Grund aus. Umgekehrt freilich ist die Außenpolitik Voraussetzung und Bedingung für die ruhige und stetige Entfaltung des Wirtschaftslebens selbst." 2

Außenpolitisch gesehen stehen grundsätzlich zwei Effekte des Außenhandels im Vordergrund, nämlich der "Versorgungseffekt" (supply-effect) und der "Beeinflussungseffekt" (influence-effect). ${ }^{3}$ Zum einen wird der Handel also zur Quelle der wirtschaftlichen und militärischen Stärkung einer Volkswirtschaft (supply-effect), zum anderen aber auch zu einem wirtschaftlichen Instrument mit dem Ziel, den Handelspartner im Sinne der eigenen außenpolitischen Präferenzskala zu beeinflussen (influenceeffect). ${ }^{4}$ Obgleich die Bedeutung der Außenhandelspolitik als Mittel der Außenpolitik zu allen Zeiten und bei allen Ländern offenbar ist, erscheint sie besonders groß in bestimmten außenpolitischen Situationen und bei wirtschaftsmächtigen Staaten. ${ }^{5}$ Daß im Fall des Handels der westlichen Industrienationen mit den Staatshandelsländern Südosteuropas eine solche "besondere" außenpolitische Situation besteht und ein Machtungleichgewicht gegeben ist, liegt auf der Hand. ${ }^{\circ}$ Der Versorgungseffekt und der Beeinflussungseffekt sind daher die entscheidenden außenpolitischen Angelpunkte des westlichen Handels mit den Staatshandelsländern. ${ }^{7}$ Im Handel mit den kommunistischen Ländern kommen jedoch heute in weit höherem Maße ökonomische Interessen zur Geltung als in der unmittelbaren Nach-

' Vgl. Peter BERNHOLZ, a.a. O., S. 53.

2 Franz EULENBURG, Grundriß der Sozialökonomie, VIII. Abt. Außenhandel und Außenhandelspolitik, Tübingen 1929, S. 77.

${ }^{3} \mathrm{Vgl}$. Albert O. HIRSCHMAN, National Power and the Structure of Foreign Trade, Berkeley and Los Angeles 1945, S. $14 \mathrm{f}$.

4 Vgl. ebd.

5 Vgl. Alfred KRUSE, Außenwirtschaft, Die internationalen Wirtschaftsbeziehungen, Berlin 1965, S. 6.

- Vgl. Matthias SCHMITT, Osthandel auf neuen Wegen, Aktuelle Fragen der Weltwirtschaft, hrsg. von Andreas Predöhl, Hamburg 1968, S. 12.

7 Die Wirkung des Beeinflussungseffektes ist umso größer, je kleiner ein Land ist und je mehr es vom Außenhandel abhängig ist. Konkret bedeutet dies, daß der Westen im Handel mit den südosteuropăischen Staatshandelsländern einen weit größeren Beeinflussungsspielraum hat als z. B. im Handel mit der Sowjetunion. Vgl. auch Albert O. HIRSCHMAN, a.a.O., S. $18 \mathrm{ff}$. 
kriegsperiode. Dies ist weniger eine Folge veränderter Interessen oder der Entpolitisierung der außenwirtschaftlichen Beziehungen, sondern ergibt sich vielmehr aus der politischen Neueinschătzung dieser Beziehun. gen. Im Hinblick auf die möglichen Nebenfolgen hat sich der politische Zweck dieser Außenwirtschaftsbeziehungen geändert. Dennoch sind sie weiterhin eingebettet in die Gesamtproblematik der Ost-Westbeziehungen, jedoch unter einem anderen, man könnte sagen positiven Vorzeichen. ${ }^{1}$ Sie bleiben auch zukünftig von den in Ost und West verfolgten gesamtpolitischen Zielen abhängig. Zu bedenken ist aber, daß sich heute offensichtlich auch die Außenpolitik der Staatshandelsländer Südosteuropas mehr an wirtschaftlichen und damit auch außenwirtschaftlichen Notwendigkeiten $z u$ orientieren beginnt. 2

Im Gegensatz zu Westeuropa ist die Entstehung einer spezifischen Osthandelspolitik der USA weniger auf die ideologischen und ökonomischen Unterschiede zum Sowjetblock als vielmehr auf die politische Entwicklung im Anschluß an den Zweiten Weltkrieg zurückzuführen. ${ }^{3}$ Während die Vereinigten Staaten von 1917 bis 1949 im Handel mit der Sowjetunion keine Sonderregelungen anwandten, entschlossen sie sich unter dem Eindruck der wirtschaftlichen und militärischen Macht der Sowjetunion sowie der drohenden Gefahr einer über Ost- und Südosteuropa hinausgehenden kommunistischen Expansion, den Handel mit der Sowjetunion zu "verpolitisieren"' " Damit verband sich die Absicht, ihn als schlagkräftiges außenpolitisches Instrument $z u$ gebrauchen. ${ }^{5}$ Der Beginn des "kalten Krieges"' und die damit verbundenen politischen Entwicklungen brachten diese Handelsbeziehungen endgültig in die politische Agenda. ${ }^{6}$ Die Handelspolitik

'Vgl. Hermann GROSS, Die Liberalisierungsprobleme im Ost-West-Handel, a.a. O.

2 Im einzelnen sei auf folgende Literatur verwiesen:

Hans KROLL, Entpolitisierung des Osthandels schaff neue Moglichkeiten, Beilage zum "Industriekurier", Düsseldorf v. 13.4.1967; Wolfgang SCHRÖDER, Osthandel politisch sehen, "junge Wirtschaft", Jg. 14, H.9, Bad Godesberg 1966, S. 325 f.; Fritz SCHENK, Die Enkel der Revolution, ebd., S. 337 f.; Heiner ERNST, Der Osthandel - eine politische Waffe?, Stuttgart 1964; Michael VON BERG, Die strategische Bedeutung des Ost-West-Handels, Leiden 1966.

3 Vgl. Russel BAKER, Legal Aspects of East-West Trade, A Rational View. Address given before the "East-West Trade" Briefing Session of the American Management Association, New York, May 20, 1964, unveröffentlichtes Manuskript.

- Vgl. die Rede von Dean Rusk im Jahre 1964 vor dem Senate Foreign Relations Committee, zitiert nach Nathaniel Mc KITTERICK, a.a.O., S. 7.

5 Vgl. Mose L. HARVEY, a.a.O., S. 7.

- Zu denken ist an den Rückzug der Sowjetunion von der Marshallplan-Konferenz im Jahre 1947, die Gründung des Kominform im gleichen Jahr, die kommunistische Machtergreifung in der Tschechoslowakei und anderen VolksdeFortsetzung siehe nächste Seite 
gegenüber dem Ostblock wurde zu einem "Instrument der nationalen Sicherheit" mit dem Ziel, die Expansion des Kommunismus zu verhindern und die Gefahr eines Krieges zu vermindern. Gleichzeitig wurde sie zu einem "Instrument der Entspannung", mit dem Ziel, die Auflösungserscheinungen innerhalb des Ostblocks zu fördern.'

Ein Wandel in der amerikanischen Osthandelspolitik trat erst ein, als man die Handelsbeziehungen zum Ostblock als Kommunikationskanal erkannte und begann, ihnen ein positives außenpolitisches Gewicht beizulegen. ${ }^{2}$ Dem entsprach das neue Konzept des "bridge-building" der amerikanischen Regierung. ${ }^{3}$ Ausgehend vom Grundsatz des "treating different countries differently" 4 sollte die Handelspolitik dem Zweck dienen ".. to achieve reconciliation with the East a shift from the narrow concept of coexistence to the broader vision of peaceful engagement."

Fortsetzung der Fußnote 6 von Vorseite:

mokratien, an den Korea-Krieg, aber auch an die Berliner Krisen; vgl. hierzu S. 39.

"Our trade policy toward Communist countries is an integral part of our overall policy toward international communism, and we must view it in this broad framework", in: East-West Trade. Hearings before the Committee on Foreign Relations, U.S. Senate, Part I, a.a.O., S. 4 (Auszug aus einer Rede von Dean Rusk im Jahre 1964 vor dem Senatskomitee für auswärtige Beziehungen).

1 Vgl. East-West Trade. Hearings Part I, a.a.O.; "The Battle Act Report of 1964", Seventeenth Report to Congress, Department of State, Washington D. C. 1965 , S. 5 ff.; John C. CAMPBELL, American Policy Towards Eastern Europe: Three Choices Ahead, Minneapolis and London 1965, S. $83 \mathrm{ff}$.; J. FELDMAN, Trade between Eastern Countries and the U.S., in: East-West Trade, American Management Association, New York 1964, S. 22; Dean RUSK, Why we Treat Different Communist Countries Differently. Department of State Publication No. 7999, Washington D.C. 1964, S. 7.

2 Vgl. George F. KENNAN, On Dealing with the Communist World, New York and Evanston 1964; Foy D. KOHLER, East-West Relations: Shapping a Stable World, "Department of State Bulletin", No. 1436, Washington D. C., Jan. 2, 1967, S. 11; Nathaniel Mc KITTERICK, a.a.O., S. 26.

3 Vgl. "State Department Bulletin", Washington D.C., o. No., Dec. 21, 1964, S. 876 .

"Die Politik des "bridge building" differenziert zwischen der Sowjetunion und den ost- bzw. südosteuropäischen Ländern. Vgl. Andrew GYORGY, The Role of Nationalism in Eastern Europe: From Monolith to Policentrism, in: Eastern Europe in Transition, ed. by Kurt London, Baltimore 1966, S. 3 ff.; Kurt LONDON, Communism in Eastern Europe; Polycentrism, Splittism and After, ebd., S. 19 ff.

${ }^{5}$ Auszug aus einer Rede von Präsident Johnson am 7.10.1966 in New York, zitiert nach Alexander B. TROWBRIDGE, Peaceful Engagement with the East. Address prepared for delivery at the International Trade Session, National Foreign Trade Convention, New York, Nov. 2, 1966, U.S. Comm-Doc. 38314. 
Wăhrend lange Zeit der Satz von Adam SMITH "... defense is of much more importance than opulence ..."' die westliche Handelspolitik gegenüber den kommunistischen Ländern zu regieren schien, vollzieht sich heute im Hinblick auf die Differenzierung der politischen Subsystembeziehungen zwischen den sozialistischen Ländern Südosteuropas und der Sow jetunion offenbar eine Umorientierung im Sinne Stuart MILLs: "It is commerce which is rapidly rendering war obsolete, by strengthening and multiplying the personal interests which are in natural opposition to it. And it may be said without exageration that the great extent and rapid increase of international trade, in being the principal guarantee of the peace of the world, is the great permanent security for the uninterrupted progress of the ideas, the institutions, and the character of the human race." 2

3. DAS ZUSAMMENTREFFEN VON MARKTWIRTSCHAFTLICHEN UND ZENTRALVERWALTUNGSWIRTSCHAFTLICHEN WIRTSCHAFTSSYSTEM E N

a) Der Gegensatz der Wirtschaftssysteme

Das eigentlich Charakteristische der Außenhandelsbeziehungen zwischen den sozialistischen und den kapitalistischen Ländern ist das Aufeinandertreffen der spezifischen Gesetzmäßigkeiten der verkehrswirtschaftlichen (marktwirtschaftlichen) und der zentralverwaltungswirtschaftlichen Wirtschafts - und Gesellschaftsformen. ${ }^{3}$

Die unmittelbare Übernahme des traditionellen sow jetischen Wirtschaftssystems in Bulgarien, Rumänien und Ungarn brachte die bewußte Etablierung des wirtschaftspolitischen Wertsystems und Ordnungsprinzips der Zentralverwaltungswirtschaft mit institutionell und funktionell neugesetzten Priorităten. Damit verbunden war eine Unterordnung sämtlicher Wirtschaftseinheiten unter die staatlich-imperative Zentralplanung, eine Neuordnung der Eigentumsverfassung und des Preis- und Verteilungssystems $\mathrm{zu}$ einem systemadäquaten Instrument der zentralen Wirtschaftsführung.

Im Gegensatz zum marktwirtschaftlichen Außenwirtschaftssystem allgemein westlicher Prägung erfolgt in den Staatshandelsländern eine staatsmonopolistische Organisation des gesamten außenwirtschaftlichen Verkehrs.

1 Adam SMITH, Wealth of Nations, New York 1935, S. 431.

2 John Stuart MILL, Principles of Political Economy, London - New York Toronto 1929 , S. 582 .

${ }^{3}$ An dieser Stelle wird auf die Grundzüge des marktwirtschaftlichen A ußenhandelssystems nicht năher eingegangen; vielmehr sollen in aller Kürze die wesentlichen Elemente des zentralverwaltungswirtschaftlichen Außenhandelssystems dargestellt werden. 
Hauptzweck dieses verfassungsrechtlich verankerten Monopols ist es

1. den Handelsverkehr mit dem Ausland den jeweiligen Bedürfnissen der internen, nationalen Wirtschaftsplanung unterzuordnen,

2. die strenge Trennung der Binnenwirtschaft von der Außenwirtschaft zu verwirklichen und

3. den für die Planung der Volkswirtschaft verantwortlichen Behörden einen maximalen Handlungsspielraum $\mathrm{zu}$ geben für die Kontrolle und Lenkung der Einflüsse, die aus den zwischenstaatlichen Wirtschaftsbeziehungen herrühren.'

Augenblicklich erfährt dieses Außenhandelsmonopol in den Zentralverwaltungswirtschaften Südosteuropas, entsp rechend den schon realisierten und noch geplanten Wirtschaftsreformen, eine institutionelle Veränderung. Sie besteht darin, daß bestimmte Aufgabenbereiche des totalen Monopols an organisatorisch neu konzipierte Funktionsträger übertragen werden. Das bedeutet jedoch keine funktionelle Änderung, höchstens eine Auflockerung des Außenhandelsmonopols im Sinne einer administrativen Dezentralisation. ${ }^{2}$ Die ausführenden Organisationseinheiten des Außenhandelsmonopols sind die nach Wirtschaftsbranchen gegliederten Außenhandelsgesellschaften. ${ }^{3}$

Arbeitsgrundlage des Außenhandelsmonopols ist der nach Warengruppen, Ländern und Währungsgebieten aufgegliederte Außenhandelsplan. Dieser basiert auf den Erfordernissen der gesamten Volkswirtschaftsplanung sowie den internationalen Verpflichtungen auf Grund der block-internen Arbeitsteilung. Aus den jährlich festzustellenden Materialbilanzen ${ }^{4}$ wird der Importbedarf ermittelt. Gleichzeitig bilden die Überschüsse, die sich aus diesen Bilanzen ergeben, die Grundlage des Exportplans, für den im allgemeinen der Gesichtspunkt der Mittelbeschaffung für den Import sowie

1 Vgl. Erich KLINKMÜLLER, Organisation und Planung der Außenwirtschaft, in: Osteuropa-Handbuch, Bd. Sowjetunion, Teil: Das Wirtschaftssystem, hrsg. von Werner Markert, Köln und Graz 1965, S. 508.

2 Vgl. Imre VAJDA, The Role of Foreign Trade in a Socialist Economy, Budapest 1965 , S. 153 .

$3 \mathrm{Vgl}$. Viktor KNAPP, The Function, Organization and Activities of Foreign Trade Corporations in the European Socialist Countries, in: The Sources of the Law of International Trade, ed. by Clive M. Schmithoff, New York 1964, S. 52-69; Karl C. THALHEIM, Grundzüge des sow jetischen Wirtschaftssystems, Köln 1962 .

$4 \mathrm{Vgl}$. Michael MONTIAS, Planning with Material Balances in Soviet-Type Economies, "The American Economic Review", Vol. XLIX, 5, o. O., 1959. 
der Rückzahlung von Krediten maßgebend ist. ' Den außenhandelsrelevanten Entscheidungen liegen prinzipiell Mengenüberlegungen zugrunde. Im Zuge der Wirtschaftsreformen scheinen sich aber hier langsam Kriterien durchzusetzen, welche Nutzen- und Rentabilitätsvergleiche zumindest im Ansatz ermöglichen sollen. ${ }^{2}$

Die Preisplanung im Außenhandel erfolgt weitgehend unabhängig von der internationalen Preisstruktur. In der Zentralverwaltungswirtschaft werden die Binnenpreise noch immer von staatlichen Stellen sowohl unabhängig von Angebot und Nachfrage der betreffenden Güter als auch mehr oder weniger unabhängig von den jeweiligen tatsächlichen Kostenrelationen meistens für einen Zeitraum von mehreren Jahren festgelegt. Da eingeführte Güter, unabhängig von Qualitätsunterschieden sowie sonstigen Wettbewerbsfaktoren $z u$ gleichen Preisen wie vergleichbare oder substitutive einheimische Waren auf dem Binnenmarkt angeboten werden und außerdem der staatliche Planträger bestimmt, welche Waren überhaupt eingeführt werden, hat der westliche Exporteur keine preispolitische Einwirkungsmöglichkeit auf den betreffenden Markt. Seit einiger Zeit ist man in den Staatshandelsländern jedoch bemüht, die Binnenpreise an Weltmarktpreise heranzuführen, da diese gewisse Anhaltspunkte für außenhandelsbestimmte Wirtschaftlichkeitsberechnungen geben. ${ }^{3}$ Die Staatshandelsländer bieten ihre Exportwaren im Westen zu den Preisen an, die auf Grund der jeweiligen Weltmarktlage erzielbar sind. Die nicht planbaren Exportpreise stehen aber in keinerlei Beziehung zum Verkaufspreis derselben Waren im Inland. Da eine Nachprüfung der Kostenbezogenheit eines Gutes nicht möglich ist und ein Vergleich des Angebotspreises in einem dritten, nichtmarktwirtschaftlichen Land mit dem Angebotspreis in einem marktwirtschaftlichen Land ebenfalls unmöglich ist, läßt sich den Staatshandelsländern ein Dumping kaum nachweisen.

Neben der Ordnung der Marktformen der Außenwirtschaft und der Aufstellung und Koordination des Außenhandelsplans durch staatlich-zentrale Ver-

1 Vgl. Frederic L. PRYOR, The Communist Foreign Trade System, London 1963, S. 55; ders.. The Organization of Trade in the European Communist Nations and the Implications for East-West Trade, in: East-West Trade. A Symposium ed. by Philip E. Uren, Toronto 1966, S. 50; Trade Problems between Countries Having Different Economic and Social Systems, in: Proceedings of the United Nations Conference on Trade and Development, Geneva, 23 March - 16 June 1964, Vol. VI, Trade Expansion and Regional Grouping, Part I, S. $113 \mathrm{f}$.

2 Vgl. Alec NOVE, Die sowjetische Wirtschaft, Wiesbaden 1964, S. 217 . Daß dies nur Ansätze sind, ergibt sich aus der praktischen Undurchführbarkeit von tatsăchlichen Wirtschaftlichkeitsberechnungen auf Grund der angewandten Kosten- und Preisprinzipien.

3 Vgl. Trade Problems between Countries Having Different Economic and Social Systems, a.a.O., S. 125 . 
waltungsstellen liegt in der Rangordnung sowie in den Trägern der außenwirtschaftlichen und außenwirtschaftspolitischen Zielsetzungen ein weiterer wesentlicher Unterschied zum marktwirtschaftlichen Außenhandelssystem. ' Hierauf soll im nächsten Abschnitt eingegangen werden. ${ }^{2}$

b) Die Systembezogenheit der außenwirtschaftlichen und außnwirtschaftspolitischen Zielsetzungen

Katalogisiert man die außenwirtschaftlichen und außenwirtschaftspolitischen Zielsetzungen in den sich berührenden Wirtschafts- und Gesellschaftsordnungen, so muß von den je nach Wirtschaftssystem verschiedenen Zielträgern ausgegangen werden. Diese werden im Fall der Marktwirtschaft westlichen Typs repräsentiert von den Unternehmern in Gestalt von Exporteuren und Importeuren auf der einen, dem Staat und politischen Interessengruppen auf der anderen Seite, im Fall der Zentralverwaltungswirtschaft jedoch nur von staatlichen Institutionen. ${ }^{3}$

In der Marktwirtschaft kommen grundsätzlich nur die einzelnen wirtschaftsindividuen als Träger der Außenwirtschaft in Frage. Sieht man

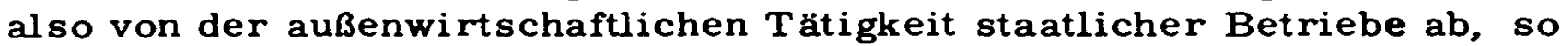
kann man davon ausgehen, daß die im Rahmen der Außenwirtschaftsbeziehungen $z u$ den sozialistischen Ländern relevanten mikroökonomischen Zielvorstellungen der marktwirtschaftlichen Wirtschaftssubjekte annăhernd identisch sind mit denen, die im freien Außenwirtschaftsverkehr der westlichen Staaten untereinander angesteuert werden.

Privatwirtschaftliche Ziele der Außenwirtschaft sind:

1. Gewinnerzielung,

2. Umsatzausweitung,

3. Streben nach Macht und Prestige,

4. Beschäftigung von Überkapazităten. ${ }^{4}$

Der Staat verfolgt in der Marktwirtschaft im allgemeinen keine den privatwirtschaftlichen Zielen vergleichbaren außenwirtschaftlichen Ziel setzungen. Sofern der Staat jedoch entsprechend einer bestimmten, der Außenwirt-

I Vgl. Handworterbuch der Sozialwissenschaften, Art. Außenhandelspolitik.

2 Zum Problem der Wirtschaftsreformen sei im einzelnen verwiesen auf: Wirtschaftsreformen in Osteuropa, hrsg. von Karl C. Thalheim und Hans-Hermann Höhmann, Köln 1968.

${ }^{3}$ Vgl. hierzu auch Alfred KRUSE, a.a. O., S. 586 f.

4 gl. Erich KLINKMÜLLER, Zur Strategie des Ost-West-Handels, "Osteuropa-Wirtschaft", Jg. 9, H. 3, Stuttgart 1964, S. 1 ff.; Edmund HEINEN, Die Zielfunktion der Unternehmung. Sonderdruck aus: Zur Theorie der Unternehmung, Festschrift zum 65. Geburtstag von Erich Gutenberg, hrsg. von Helmut Koch, Wiesbaden 1962, S. 9 ff. 
schaft übergeordneten, binnenwirtschaftlichen oder außenpolitischen Zielsetzung gezwungen ist, in die außenwirtschaftliche Sphäre der Wirtschaftssubjekte einzugreifen, wird er nicht außenwirtschaftlich, sondern außenwirtschaftspolitisch tătig.

Dem Staat obliegt in der Marktwirtschaft eine Koordinierungs- und Steuerfunktion der außenwirtschaftlichen Beziehungen. Er bedient sich dazu systemgerechter Instrumente der Wirtschaftspolitik im allgemeinen, der Außenwirtschaftspolitik im besonderen und ermöglicht die Realisierung systemkonformer Ziele der Volkswirtschaft, und zwar sowohl auf binnenals auch auf außenwirtschaftlicher Ebene. 1

Wenn man davon ausgeht, "daß es nur allgemeine oberste wirtschaftspolitische Zielsetzungen gibt, und daß sich außenwirtschaftspolitische Ziele aus diesen ableiten lassen, kann man trotzdem in einem ganz bestimmten Sinn auch von außenwirtschaftspolitischen Zielen sprechen: auf Grund der Hauptwirkungen des Einsatzes außenwirtschaftlicher Inst rumente können nämlich einige oberste wirtschaftspolitische Zielsetzungen enumeriert werden, die sich besonders leicht und eindeutig mit Hilfe einer geeigneten A ußenwirtschaftspolitik verfolgen lassen." 2

Solche außenwirtschaftspolitischen Zielsetzungen, wie sie sich aus der in der angewandten Wirtschaftspolitik sich niederschlagenden Kombination des marktwirtschaftlichen Grundprinzips mit dem Prinzip der autonomen oder auch kooperativen Lenkung der Außenwirtschaft ergeben, sind:

1. Außenwirtschaftspolitische Ziele im engeren Sinn

a) Beeinflussung der binnenwirtschaftlichen Einkommensverteilung,

b) Konjunkturbeeinflussung.

c) Sicherung des volkswirtschaftlichen Wachstums.

2. Zielsetzungen der langfristigen Außenwirtschaftspolitik (Außenwirtschaftsordnung) und kurzfristige Lenkungspolitik

a) Ordnung der außenwirtschaftlichen Beziehungen zu systemfremden Volkswirtschaften,

b) Entwicklungsförderung und Auslandshilfepolitik,

c) Reform der Weltgeldordnung,

d) Eingliederung von Wirtschaftsunionen und Freihandelszonen in die Weltwirtschaft,

e) Regelung des Außenhandels mit Agrarprodukten und landwirtschaftlichen Rohstoffen. ${ }^{3}$

"Den Bestimmungen des "General Agreement on Tariffs and Trade" (GATT) und des "International Monetary Fund" (IMF) zufolge sind direkte staatliche Eingriffe in den Handel von entwickelten Marktwirtschaften nur in Ausnahmefallen gestattet. Vgl. Trade Problems between Countries Having Different Economic and Social Systems, a.a.O., S. $116 \mathrm{ff}$.

2 Hans MÖLLER, Außenwirtschaftspolitik, a.a.O., S. 138.

${ }^{3} \mathrm{Vgl}$. ders., ebd., S. $138 \mathrm{ff}$. 
Der Aktivitat des Staates kommt im Rahmen der außenwirtschaftlichen Beziehungen $z u$ kommunistischen Ländern verstärkte Bedeutung $z u$, da hiermit eine Gefährdung wirtschaftspolitischer Ziele sowie systembezogener Grundprinzipien der Marktwirtschaft verbunden sein kann. Nur eine aktive Tätigkeit des Staates, d.h. eine Betätigung, die über den Umfang der innerhalb der westlichen Weltwirtschaftsordnung gehandhabten Außenwirtschaftspolitik hinausgeht, begegnet dieser Gefahr. Neben den oben erwăhnten außenwirtschaftspolitischen Zielsetzungen sind noch jene Ziele zu nennen, welche als Subziele einer aktiven oder auch passiven Außenpolitik anzusehen sind und im Beeinflussungs- sowie Versorgungseffekt zum Ausdruck kommen. Gerade diese außenpolitisch determinierten Ziele der Außenwirtschaftspolitik sowie die in vergleichsweise größerem Umfang notwendig werdende staatliche Aktivität können weitere charakteristische Elemente der westlichen Außenwirtschaftsbeziehungen zu den sozialistischen Ländern sein.

Was die Zielstruktur der Zentralverwaltungswirtschaft sowjetischen Typs anbelangt, so läßt sich hier, entsprechend den ordnungspolitischen Grundzügen dieses Wirtschaftstyps, keine eindeutige Abgrenzung nach außenwirtschaftlichen und außenwirtschaftspolitischen Zielen treffen.

Das hat vorwiegend seine Ursache darin, daß der Staat sowohl als Träger außenwirtschaftlicher als auch außenwirtschaftspolitischer Ziele gleichzeitig fungiert und sich selbst diejenigen Handlungsmaximen zuweist, innerhalb derer er außenwirtschaftlich tätig wird. Der Staat ist damit Subjekt und Objekt der Außenwirtschaftspolitik zugleich.

Die Deckung der Zielträgerbereiche sowie der Mittel-Zweck-Relationen ergibt sich aus der Dominanz der Politik als Leitmaxime der Außenwirtschaft. ${ }^{1}$ Sie geht so weit, daß die Frage berechtigt erscheint, ob nicht die gesamte Außenwirtschaft nur als außenpolitisches Instrument gewertet werden muß. ${ }^{2}$ Den außenwirtschaftspolitischen Zielsetzungen der südosteuropäischen Staatshandelsländer lag, zumindest bis zum Eintritt in die Periode der Wirtschaftsreformen, in erster Linie die ideologisch-politische Zielsetzung der marxistischen Doktrin sow jetischer Auslegung zugrunde. Zentraler Mittelpunkt dieser Zielsetzung war das Streben nach Autarkie. Dies ist den Zentralverwaltungswirtschaften einerseits aus Systemgründen immanent, da interne Vorgänge leichter gesteuert werden können als Wirtschaftsbeziehungen zum Ausland, andererseits jedoch auch aus Gründen der politischen Motivationsstruktur dieser Wirtschafts- und

' Vgl. Erich KLINKMULLLER, Organisation und Planung der Außenwirtschaft, a.a.O., S. 502; Michael VON BERG, Die strategische Bedeutung des OstWest-Handels, a. a. O., S. 32 ff.

2 Vgl. Gerard CURZON, Multilaterial Commercial Diplomacy, New York and Washington D.C. 1965 , S. 298. 
Gesellschaftsordnung. I Als weitere außenwirtschaftspolitische Zielsetzungen sind zu nennen:

1. Ergănzung der binnenländischen Produktionsstruktur,

2. Ergánzung und Ausgleich der gesamtwirtschaftlichen Produktionsplanung.

3. Abstoßung von Überschüssen,

4. Beschäftigung von Ửberkapazitäten,

5. Beschleunigung des wirtschaftlichen Wachstums,

6. Ausschaltung der konjunkturellen Schwankungen des Auslandes,

7. Eingliederung in übernationale sozialistische Wirtschaftsbereiche. ${ }^{2}$

Diese außenwirtschaftspolitischen Zielsetzungen, die als Subziele des politischen Oberzieles der Verwirklichung des Vollkommunismus zu verstehen sind, lagen allen ost- und südosteuropăischen Staatshandelsländern pauschal und ohne Berücksichtigung der nationalen volkswirtschaftlichen Gegebenheiten zugrunde. ${ }^{3}$

Mit dem Eintritt dieser Länder in die Intensivierungsphase ihrer wirtschaftlichen Entwicklung - Ungarn befindet sich schon in dieser Entwicklungsphase, Rumănien steht heute unmittelbar davor, Bulgarien dagegen wirtschaftet vergleichsweise noch am weitesten extensiv - ergibt sich für sie die zwingende Notwendigkeit, ihre Wirtschaftspolitik zu überprüfen. Um die bisherige Wirtschaftsentwicklung nicht zu gefährden, sind - wie das Beispiel Ungarn und Rumănien zeigt - verschiedene Schwerpunktverlagerungen in den außenwirtschaftspolitischen Zielsetzungen notwendig. Zwar wird die marxistische Politik weiterverfolgt und der Weltsozialismus durch Industrialisierung und industrielle internationale Kooperation weiter gestärkt, doch wird gleichzeitig eine Vertiefung der internationalen Wirtschaftsbeziehungen $z u$ allen Ländern und damit verbunden ein $P l a t z$ im Rahmen der internationalen Arbeitsteilung angestrebt.

1 Vgl. Karl C. THALHEIM, a.a.O., S. $115 \mathrm{f}$.

Auf Grund einer bis zum Jahre 1965 reichenden Analyse der Außenhandelspläne der kommunistischen Staaten kommt PRYOR zum Ergebnis, daß das praktische Handeln in den ostlichen Staaten immer noch entscheidend vom Autarkiedenken geprăgt ist.

Vgl. Frederic L. PRYOR, The Communist Foreign Trade System, London 1963 , S. 48 und S. 110.

Dazu ist festzustellen, daß man innerhalb des RGW heute wohl mehr von einer "Gruppenautarkie" als von einer "Individualautarkie" der einzelnen Staatshandelsländer sprechen sollte.

2 Vgl. Karl C. THALHEIM, a.a.O., S. 115 f.; Erich KLINKMULLER, Zur Strategie des Ost-West-Handels, a.a.O., S. 9 f.; ders., Organisation und Planung der Außenwirtschaft, a.a.O., S. 501.

${ }^{3} \mathrm{Vgl}$. Hermann GROSS, Neuere Tendenzen in der Agrar- und Industrialisierungspolitik Ostmittel- und Südosteuropas, a.a.O., S. 72 ff. 
Eine Gegenüberstellung der außenwirtschaftlichen und außenwirtschaftspolitischen Ziele der Markt- und Zentralverwaltungswirtschaften zeigt, daß sich trotz bedeutungsvoller Zielgegensätze - sowohl wirtschaftlicher als vor allem auch politischer Art - insgesamt eine weit gehende Komplementarität von Einzelzielen oder Zielgruppen ergibt. Die Aufnahme und Unterhaltung von gegenseitigen Handelsbeziehungen erscheint demzufolge sinnvoll. Ungeklärt bleibt, inwieweit die Zielkomplementarität aus der jeweiligen Gesamtzielst ruktur der Außenwirtschaft und Außenwirtschaftspolitik resultiert oder nur aus einer zufälligen Ergänzungsmöglichkeit wirtschaftlicher und außenpolitischer Partialziele. Im Zusammenhang des Gesamtzielsystems und unter Berücksichtigung des Zeitfaktors könnte sich die augenblickliche Zielkomplementarität langfristig als Zielgegensat $z$ erweisen. ${ }^{1}$

4. GRUNDZÜGE DER ENTWICKLUNG DER OSTHANDELSPOLITIK SEIT DEM ENDE DES ZWEITEN

WELTKRIEGS

Die Vorstellungen der USA über die Gestaltung der Weltwirtschaft nach Beendigung des $Z$ weiten Weltkriegs waren getragen vom Leitbild einer einheitlichen Weltwirtschaft klassisch-liberaler Prägung. Ungehinderte Handels- und Kapitalverkehrsbeziehungen bei weltweiter internationaler Arbeitsteilung auf der Grundlage echter Kostenvorteile sollten das universelle System der "one world economy" verwirklichen. ${ }^{2}$

Diese Konzeption einer einheitlichen Weltwirtschaft ist jedoch an den Veranderungen der machtpolitischen Verhältnisse in Ost- und Südosteuropa sowie an den zunehmenden Gegensätzen der östlichen und westlichen Wirtschaftsordnungen gescheitert. Bereits im Jahre 1945 zeichnete sich für die Sowjetunion eine erhebliche Ausdehnung ihrer politischen und okonomischen Einflußsphäre in den ost- und südosteuropäischen Ländern ab, und nach der Konsolidierung der politischen Verhältnisse im sowjetischen Einflußbereich erfolgte eine ökonomische Abschirmung dieser Länder vom Westen mit dem Ziel, den Ostblock zu einem zweiten - "sozialistischen" Weltmarkt zusammenzuschließen. ${ }^{3}$ Verschiedene westliche Länder beseitigten in den Jahren 1946 und 1947 den seit dem Ende des Zweiten Welt-

1 Vgl. Erich KLINKMÜLLER, Zur Strategie des Ost-West-Handels, a. a. O. ; Bruno KIESEWETTER, Die Wandlungen der Handelspolitik in Südosteuropa, in: Südosteuropa-Jahrbuch, Bd. 2, hrsg. von Wilhelm Gülich, München 1958, S. $63 \mathrm{ff}$.

2 Vgl. Joachim WILLMANN, Grundsatzfragen des Ost-West-Handels, "EuropaA rchiv", Folge 1, Bonn 1965, S. 15.

${ }^{3}$ Die Gründung des "Rates für gegenseitige Wirtschaftshilfe" erfolgte als Gegenzug zum "Marshall-Plan" (1947 verkündet) der USA. 
kriegs zumeist bestehenden vertragslosen Zustand im Handel mit den ostund südosteuropăischen Ländern und schufen hiermit die Voraussetzung, daß der Handel über bloße Gegenseitigkeitsgeschäte (Kompensationsgeschäfte) hinaus ausgedehnt und damit dem Wiederaufbau der betroffenen Länder unter westlicher Mitwirkung der Weg bereitet werden konnte. Zu diesem Zweck stellten westliche Länder selbst Handelskredite zur Verfügung. I Die vertragliche Grundlage des Handels der späteren Bundesrepublik Deutschland mit Ungarn und Bulgarien wurde im Jahre 1947 von den westlichen Besatzungsmächten geschaffen. Das erste Handels- und Zahlungsabkommen mit Rumänien konnte jedoch erst 1954 geschlossen werden, nachdem auf Vermittlung der "European Commission for Europe" (ECE) im Jahre 1953 die Kontakte zwischen deutschen und rumänischen Vertretern hergestellt worden waren. Die Vertragsverhandlungen fanden zwischen dem 1952 konstituierten "Ostausschuß der deutschen Industrie" und der rumänischen Außenhandelsgesellschaft "Agroexport" statt. 2

Während sich so eine normale Entwicklung der Handelsbeziehungen zwischen West und Ost abzuzeichnen schien, ${ }^{3}$ entschloß sich der Westen unter Führung der USA angesichts der sowjetischen Aggressivität und der vollständigen Verstaatlichung des Außenhandels der ost- und südosteuropäischen Länder ab 1948/1949 zu einer Überprüfung seiner handelspolitischen Konzeption gegenüber den kommunistischen Ländern. 4

Als Folge der kommunistischen Machtübernahme in der Tschechoslowakei, der Berlin-Blockade und des Korea-Krieges begannen die westlichen Länder, die Zweckmäßigkeit ihrer Handelsbeziehungen mit den Staatshandelsländern zu überdenken und schützende handelspolitische Maßnahmen zu ergreifen. Dies führte zur Entstehung eines multinationalen Handelsembargos gegenüber den kommunistischen Ländern, das im Jahre 1952/1953 seinen Höhepunkt erreichte.

Jugoslawien, das 1948 aus dem Kominform ausgeschlossen wurde, war hiervon nicht betroffen.

Gleichzeitig unterwarf man die Einfuhren aus den betreffenden Ländern strengen quantitativen Einfuhrbeschränkungen, jedoch wurde die Meistbegünstigung seitens Westeuropas nicht aufgehoben, lediglich die USA stoppten die Meistbegünstigungsbehandlung im Jahre 1951.

' Vgl. Bruno KIESEWETTER, Der Ostblock-Außenhandel des östlichen Wirtschaftsblocks einschließlich China, Berlin 1960, S. 30; Economic Survey of Europe in 1948, United Nations, Geneva 1949, S. 155.

2 Vgl. ders. ebd., S. 201.

$3 \mathrm{Vgl}$. Economic Survey of Europe in 1948, a. a. O.

- Vgl. Klaus-Heinrich STANDKE, Der Handel mit dem Osten, Baden-Baden 1968. 
Die Rückkehr zum multilateralen Handel, die vom Europäischen Wirtschaftsrat ("Organization for European Economic Co-ope ration", OEEC) seit 1949 in Etappen vorangetrieben und 1955 beendet wurde, blieb auf die Länder der 'Europäischen Zahlungsunion'" (EZU) beschränkt. ' Zwar waren Bulgarien, Polen, Rumänien, die Tschechoslowakei und Ungarn zur Welthandelskonferenz in Havanna (1947) eingeladen worden, doch traten sie dem GATT - ursp rünglich als Provisorium bis zum Inkrafttreten der "Havanna-Charta" gedacht - mit Ausnahme der Tschechoslowakei nicht bei. Die Zielsetzung des GATT, eine betrăchtliche Ausweitung des Welthandels durch möglichst weitgehende Abschaffung von Handelshemmnissen, wurde deshalb nicht bestimmendes Element der Außenhandelspolitik dieser Länder. Rumänien und Ungarn nehmen seit 1957 bzw. 1966 als Beobachter an den Tagungen des GATT-Rates und des GATT-Ausschusses für Handel und Entwicklung teil; 1967 wurde auch Bulgarien als Beobachter zugelassen. Da diese Staatshandelsländer zur Welthandelskonferenz von Havanna eingeladen worden waren, haben sie das Recht, um Entsendung von Beobachtern zu den GATT-Tagungen nachzusuchen, obgleich sie der Konferenz selbst ferngeblieben waren. Von den anderen Ostblockländern ist nur die Tschechoslowakei formelles Mitglied des GATT, weil sie bei dessen Gründung noch eine demokratische Staatsverfassung hatte. Polen war von 1960 bis 1966 als assoziiertes Mitglied dem GATT lose verbunden und nahm an der Arbeit der Vertragsparteien teil. 1967 billigte der GATT-Rat die Aufnahme Polens als Vollmitglied. 2

Nach dem Tode Stalins setzte sich trotz der politischen Spannungen und Krisen bei den westlichen - vor allem westeuropäischen Regierungen die Überlegung durch, daß intensivere Wirtschaftsbeziehungen zwischen Ost und West langfristig ein wichtiges Mittel zur Erhaltung und Sicherung des Weltfriedens seien. ${ }^{3}$ In der $F$ olgezeit führte diese veránderte westliche Haltung, gleichzeitig aber auch das wachsende Interesse der kommunistischen Länder an Handelsbeziehungen mit den westlichen Industrieländern, zu einer stetigen Expansion des Ost-Westhandels. Wie sehr jedoch die Normalisierung hinter den Erwartungen der westlichen Handelspartner zurückblieb, wird aus dem "Zwischenbericht über die ERP" der OEEC vom Dezember 1948 ersichtlich, ${ }^{4}$ in dem die westeuropåischen Länder eine Vorschau auf ihre Außenhandelserwartungen mit den ost- und südosteuropäischen Ländern gaben. Diese Zahlen sahen für das Jahr 1952/1953 einen Handelsumsatz vor, "der, auf das heutige Preisniveau bezogen in

i Vgl. Bruno KIESEWETTER, a.a.O., S. 198; Anton ZOTTMANN, Theorie und Politik der Außenwirtschaft, Stuttgart und Düsseldorf 1967, S. $162 \mathrm{f}$.

2 Vgl. Hermann GROSS, Kennedy-Runde und Ost-West-Handel, "Der DonauRaum", Jg. 12, H. 3, Wien 1967, S. 121 f. Vgl. auch S. $110 \mathrm{f}$.

${ }^{3} \mathrm{Vgl}$. Joachim WILLMANN, Grundsatzfragen des Ost-West-Handels, a.a. O., S. 19.

" "European Recovery-Program" (ERP) - dieses Programm bildete mit die Grundlage für die Marshall-Plan-Hilfe. 
den meisten Fälen erst 1960, jedoch, bezogen auf ein unverăndertes Preisniveau, bis heute nicht erreicht wurde."' Dennoch trat der OstWesthandel, nicht zuletzt auf Grund der Auflockerung der westlichen handelspolitischen Maßnahmen, in der Mitte der fünfziger Jahre aus der Stagnation heraus. Zurückzuführen ist dies vornehmlich auf den Abbau der Ausfuhrrestriktionen, der wesentlich durch den sich mit zunehmendem Wiederaufbau Westeuropas verstärkenden Exportdruck in den westeuropäischen Ländern bedingt war. Keine entscheidenden Fortschritte ergaben sich im Bereich der Ausfuhrkreditpolitik, doch machten einige westliche Lănder Zugestăndnisse in der Transferierbarkeit der von den Ostblockländern durch Exporte in den Westen erlosten Devisen. ${ }^{2}$

Der Abschluß des Vertrages von Rom zur Gründung der Europäischen Wirtschaftsgemeinschaft (EWG) im Jahre 1957 mit Wirkung zum 1.1.1958 hatte zunächst keine unmittelbaren osthandelspolitischen Wirkungen; die ersten gemeinsamen außenhandelspolitischen Maßnahmen wurden Anfang der sechziger Jahre beschlossen. Dennoch standen die kommunistischen Länder diesen westeuropăischen Integrationsbemühungen anfänglich sehr ablehnend gegenüber. Diese Einstellung begann sich erst ab ca. $1963 \mathrm{zu}$ ändern, als sie gezwungen waren, die EWG als wirtschaftliche und politische Realităt zu akzeptieren und deren handelspolitische Beschlüsse hinzunehmen. ${ }^{3}$

Kennzeichnend für diese progressive Phase der Ost-Westhandelsbeziehungen sind auch die Abschlüsse langfristiger Handels- und Zahlungsabkommen zwischen west- und osteuropäischen Ländern, die Errichtung von Handelsmissionen und die zunehmende Bedeutung von Messen als Marktveranstaltung. 4

Der wachsende Einfuhrbedarf der ost- und südosteuropäischen kommunistischen Länder an Investitionsgütern, nach den Aufständen in Polen und Ungarn in erhöhtem Maße jedoch auch an Konsumgütern, kamen den Ausfuhrinteressen Westeuropas entgegen. Die dadurch induzierte Exportakti-

1 Gunnar ADLER-KARLSSON, Der Circulus vitiosus der Autarkie im Ost-WestHandel, in: Koexistenz zwischen Ost und West-Konflikt, Kooperation, Konvergenz, hrsg. von Hans Mayrzedt und Helmut Romé, Wien - Frankfurt Zürich 1967, S. 249.

$2 \mathrm{Vgl}$. Economic Bulletin for Europe, United Nations, Geneva 1958, S. 57.

${ }^{3}$ Zur Einstellung der Ostblocklander gegenüber der EWG sei verwiesen auf:

"Osteuropăische Rundschau", Jg. 13, H. 12, München 1967, S. 3 ff.; Rolf SANNWALD, Die Sow jetunion und die westeuropäische Integrationspolitik, in: Ostblock, EWG und Entwicklungsländer, hrsg. von Erik Boettcher, Stuttgart 1963, S. 87; "Dokumentation der Zeit", Informations-Archiv, hrsg. vom Deutschen Institut für Zeitgeschichte, Jg. 14, H. 270, Berlin (Ost), S. $42 \mathrm{ff}$.

4 Vgl. Economic Bulletin for Europe, a. a. O., S. 57. 
vität wurde jedoch noch immer gebremst durch die beschränkten Finanzierungsmöglichkeiten der Staatshandelsländer - sei es durch Exporte in den Westen und entsprechende Verrechnung des Gegenwertes in zweiseitigen Abkommen (unter Ausnützung des swings), sei es durch Ausfuhren in den Westen und damit verbundenen Erwerb transferierbarer Devisen.' Dies führte zu Beginn der sechziger Jahre zur Bereitschaft Westeuropas, in erhöhtem Maße langfristige Abkommen mit den Staatshandelsländern abzuschließen und deren Ausfuhrmöglichkeiten durch eine Auflockerung der Einfuhrbestimmungen zu verbessern, gleichzeitig aber auch die östliche Importfähigkeit durch großzügigere Ausfuhrkreditfazilitäten zu fördern. Beschleunigt wurde dieses handelspolitische Entgegenkommen durch die außenhandelsbezogenen Reformbestrebungen in den Staatshandelsländern und die damit verbundene Hoffnung auf eine Verminderung wirtschaftssystematischer Gegensätze.

Als zuverlässiges Anzeichen für den Fortschritt der Erweiterung des OstWesthandels erwies sich während fast zwei Jahrzehnten die handelspolitische Arbeit im Rahmen der Europäischen Wirtschaftskommission der Vereinten Nationen (ECE). Von allen Institutionen der Vereinten Nationen (UNO) hat die ECE den hăufigsten und unmittelbarsten Kontakt mit den Problemen der wirtschaftspolitischen Zusammenarbeit von Ost und West. Von besonderer Bedeutung waren die Beratungen von 1953 und 1954. Ihr Erfolg lag vor allem darin, daß sie die Möglichkeit zu zweiseitigen Gesprächen zwischen Partnern boten, die entweder keine diplomatischen Beziehungen unterhielten oder selbst zögerten, Verhandlungen zu beginnen. ${ }^{2}$ 'Der erwartete große Fortschritt bei der Entwicklung gemeinsamer Methoden der Mitgliedsländer der Kommission ${ }^{3}$ zur Verbesserung des Ost-WestHandels und der Zahlungsübereinkommen scheint jedoch nur höchst langsam heranzureifen. Zwischen den gemachten Vorschlägen und den tatsächlichen Ergebnissen kann nur ein indirekter Zusammenhang nachgewiesen werden. Die einzigen Verbesserungen in den letzten Jahren gingen in die Richtung eines wachsenden Vertrauens in langfristige Abmachungen und eines zunehmenden Rückgriffs auf konvertible Währungen bei der Regelung bilateraler Bilanzen. " Weitere Verhandlungsrunden über die Handelspolitik fanden im Rahmen der ECE durch die Sachverständigen-ad-hocGruppe in den Jahren 1963 und 1964 statt. Hierbei standen im wesentlichen Bemühungen im Vordergrund, die Zahlungs- und Verrechnungsbedingungen im Hinblick auf eine Multilateralisierung des Handels flexibler zu gestalten. Der Arbeit der ad-hoc-Gruppe war bislang jedoch kein nachhalti-

1 Vgl. Economic Bulletin for Europe, Geneva 1957, S. 49.

2 Vgl. Rudolf NÖTEL, Die Rolle der Vereinten Nationen im Ost-West-Handel, in: Koexistenz zwischen Ost und West, a.a.O., S. 265 f.

${ }^{3}$ Folgende sozialistische Länder sind Mitglieder der ECE: Albanien, Bulgarien, Bjellorußland (Weißrußland), Jugoslawien, Polen, Rumänien, Sow jetunion, Tschechoslowakei, Ungarn und Ukraine.

'Rudolf NÖTEL, a.a.O., S. 267. 
ger Erfolg beschieden.' Die Handels- und Entwicklungskonferenz der Vereinten Nationen im Jahre 1964 gab der internationalen Zusammenarbeit neue Impulse und trug dazu bei, die unterschiedlichen Standpunkte zu klären und die Kernprobleme des Ost-Westhandels näher zu umreißen. ${ }^{2}$

Eine neue Initiative, auf internationaler Ebene zu einer beiderseitig vorteilhaften Ordnung der Handelsbeziehung zu gelangen, stellt der Versuch der "Organization for Economic Co-operation and Development" (OECD) ${ }^{3}$ dar, in einem direkten Abkommen mit dem Osten ${ }^{4}$ ausstehende und dringliche handelspolitische Probleme zu lösen. ${ }^{5}$ Hier ist auch auf die Bemühungen des GATT, der Internationalen Handelskammer und der "European League for Economic Cooperation" (ELEC) um eine Verbesserung des handelspolitischen Klimas hinzuweisen. ${ }^{6}$

Obgleich die Bemühungen um Entspannung zwischen den beiden Weltblöcken den Versuch nach Rückkehr zu normalen Verhältnissen im Ost-Westhandel verstärkten, ist bisher der entscheidende Durchbruch zur Normalisierung nicht gelungen. Fortschritte in dieser Richtung wurden jedoch erzielt, wenn auch zumeist nur im Rahmen bilateraler Handelsabkommen der beteiligten Handelspartner.

' Vgl. Rudolf NÖTEL, a.a.O., S. 268; vgl. auch Economic Bulletin for Europe, Geneva 1956, S. 61 .

${ }^{2} \mathrm{Vgl}$. Economic Bulletin for Europe, Geneva 1964, S. $32 \mathrm{ff}$.

${ }^{3}$ Nach Lösung der wichtigsten Wiederaufbauprobleme in Europa wurde die OEEC in die OECD umgewandelt.

- Bisher ist ungewiß, wer auf östlicher Seite der Handelspartner der OECD sein soll.

$5 \mathrm{Vgl}$. "Ost-West-Kurier", Hannover v. 4.11.1967; "Wirtschafts- und Sozialpolitik", Informationsdienst für die Deutsche Wirtschaft, Ausgabe 42/67, Bonn 21.10.1967.

- Vgl. European League for Economic Cooperation; Economic, Industrial, Scientific and Technical Cooperation between the Countries of Eastern and Western Europe, Round Table Organized in Brussels, Feb. 24th and 25 th 1967, Publication No. 41;

International Chamber of Commerce, Paris, Commission on the Expansion of International Trade (Meeting on 30th and 31st January 1967), Trade between Collectivist Economies and the Rest of the World, Statement, adopted by the 81 st Session of the Executive Comittee (15.2.1967), Doc. No. 102/99 Rev. 16.12.1967. 
5. DIE BEDEUTUNG DER HANDELSVERTRAGSTECHNIK FÜR DIE REGELUNG DER OST-WESTHANDELS-

BEZIEHUNGEN

Im allgemeinen wird der Handel zwischen westlichen und östlichen Ländern im Rahmen meist mehrjăhriger Handels- und Zahlungsabkommen abgewickelt. Während der Handelsvertrag oder das Handelsabkommen Vereinbarungen über die Zollpolitik, Mengenbeschränkungen und die verschiedenen qualitativen handelspolitischen Aktivitäten enthäl, regelt das Zahlungsabkommen den Ausgleich bilateraler Handelsbilanzsalden, also den Verrechnungsverkehr. ' Bilaterale Handelsabkommen und - verträge finden jedoch nicht nur im Ost-Westhandel, sondern überall dort Anwendung, wo Devisenbewirtschaftung, verbunden mit Einfuhrbeschränkungen, den internationalen Güteraustausch hem mt. ${ }^{2}$

Da der Handelsverkehr zwischen Ost und West, im Gegensatz zum westlichen Weltwirtschaftssystem (GATT), nicht im Rahmen multinational gültiger handelspolitischer Vereinbarungen abläuft und die Währungen der ost- und südosteuropäischen Staatshandelsländer nicht konvertibel sind, wird der Handel der meisten westlichen Länder mit den jeweiligen Staatshandelsländern in bilateralen Handelsabkommen sozusagen "sondergeregelt". Die Handelsvertragstechnik ist daher von ganz besonderer Wichtigkeit. ${ }^{3}$

Die zweiseitigen Handelsverträge und - abkommen im Ost-Westhandel stekken nur den Rahmen des vorgesehenen Handelsaustausches ab und begrenzen das Handelsvolumen nach oben; ausdrückliche Abnahme- und Lieferverpflichtungen enthalten sie nicht. Ebensowenig sind die zum Austausch gelangenden und in den Warenlisten aufgeführten Güter mengenmäßig verbindlich und Preise werden grundsätzlich nicht festgelegt.

Die Gründe für die Anwendung eines bilateralen Handelsaustausches und Verrechnungsverkehrs ergeben sich vor allem aus den Wesenszügen des zentralverwaltungswirtschaftlichen Außenhandelssystems. Für die Staatshandelsländer ist es dringend notwendig, ihren Außenhandel durch langfristige Vereinbarungen auf zweiseitiger Basis zu planen, $d . h$. annähernd

1 Vgl. Hans MÖLLER, Außenwirtschaftspolitik, a.a.O., S. 98 ff.; Robert L. ALLEN, Soviet Economic Warfare, Washington D. C. 1960, S. $93 \mathrm{f}$.

${ }^{2}$ Vgl. Hans MÖLLER, Handelspolitik zwischen Bilateralismus und Multilateralismus, "Weltwirtschaftliches Archiv", Bd. 68, H. 2, Hamburg 1952, S. $203 \mathrm{ff}$.

${ }^{3}$ Aus diesem Grunde wäre es wünschenswert, die Handelsvertragstechnik der westlichen Länder als osthandelspolitisches Instrument einer näheren Untersuchung im Rahmen des Kapitels IV zu unterziehen. Dies ist jedoch aus rein informatorischen Gründen nicht möglich. 
verbindliche, in die laufende Gesamtwirtschaftsplanung einbeziehbare Daten zu erhalten. Hinzukommt, daß der Mangel an internationalen Zahlungsmitteln und die fehlende Konvertibilität der eigenen Währungen keinen multilateralen $W$ arenaustausch zulassen. Jedoch wird diese Organisation des $z$ wischenstaatlichen Handelsverkehrs mit den Ostblockländern auch von westlichen Ländern ganz gern gesehen. Durch die Einräumung bzw. Errichtung von Einfuhrkontingenten sind die westlichen Marktwirtschaften in der Lage, ihre Märkte nur denjenigen Ostblockgütern zu öffnen, von denen keine marktstörenden Einflüsse auf Grund von Niedrigpreiseinfuhren zu erwarten sind. Gleichzeitig aber erhält der westliche Handelspartner ein "bargaininginstrument" gegenüber den Staatshandelsländern, das ihm gegebenenfalls ermöglicht, Einfuhrkontingente nur dann einzuräumen, wenn der sozialistische Handelspartner zu bestimmten Gegenleistungen ${ }^{l}$ bereit ist. Dadurch erhäl der westliche Handelspartner einen Aktionsparameter, der geeignet erscheint, die stärkere Verhandlungsposition des östlichen Außenhandelsmonopols zu schwächen.

Sowohl die EWG-Mitgliedstaaten als auch Großbritannien, nicht aber die USA regeln ihren Handel mit den Staatshandelsländern Bulgarien, Rumänien und Ungarn im Rahmen solcher Abkommen. Im Zuge der Verbesserung des politischen Klimas zwischen Ost und West nach Stalins Tod wurden die ersten Handelsabkommen und - verträge zwischen westlichen und kommunistischen Ländern abgeschlossen. In diese Zeit der nachlassenden internationalen Spannungen fiel auch die Wiederaufnahme direkter Handelsbeziehungen zwischen der Bundesrepublik Deutschland und der Sow jetunion sowie Rumänien.

Im Fall der Bundesrepublik kommt den Handelsabkommen und - verträgen besondere Bedeutung zu. Da mit Ausnahme der Sowjetunion und Rumänien bislang keine diplomatischen Beziehungen bestehen, erfüllen diese Handelsabmachungen zumindest teilweise eine politische Kommunikationsfunktion. Aus diesem Grunde ist die Bundesrepublik Deutschland auch weiterhin an der Aufrechterhaltung des bilateralen Charakters der Außenhandelsbeziehungen $z u$ den meisten Ostblockländern interessiert. Im Hinblick auf die zukünftige gemeinsame Handelspolitik der EWG gewinnt diese Einstellung naturlich besonders an Gewicht. Nach Meinung der Deutschen CEPESGruppe ${ }^{2}$ sind jedoch die bisherigen, durch ihre politische Sonderstellung bedingten Vorbehalte der Bundesrepublik gegenüber einer vergemeinschafteten Handelspolitik der EWG aus heutiger Sicht nicht mehr gerechtfertigt. ${ }^{3}$

1 Zu denken ist beispielsweise an östliche Abnahmezusagen in bestimmter Hobe oder die Zusage, dem westlichen Exporteur den Einsatz absatzpolitischer Inst rumente zu ermöglichen.

${ }^{2}$ CEPES = Europăische Vereinigung für wirtschaftliche und soziale Entwicklung.

3 Vgl. "Europăische Gemeinschaft", H. 9, Bonn Sept. 1967, S. 9 und S. 22; Carl A. EHRHARDT, EWG und die Koordinierung des Osthandels, "Außenpolitik', Jg. 16, H. 6, Stuttgart 1965, S. 390 f. 
Die ersten Ansätze zur schrittweisen und koordinierten Einführung einer gemeinsamen Handelspolitik der EWG betrafen institutionelle Maßnahmen zur Vorbereitung gemeinsamer Handel sverträge und gehen auf den 20.6. 1960 zurück. A uf Beschluß des Ministerrats wurde damals die sogenannte "EWG-Klausel" "geschaffen, die in alle zukünftigen Handelsvertrăge mit Drittländern eingefügt werden sollte. Dadurch wollte man erreichen, daß bei der angestrebten Einführung der gemeinsamen Handelspolitik am 1.1. 1970 und dem damit verbundenen UUbergang der Zuständigkeiten vom nationalen Bereich in den der Gemeinschaft, die EWG-Organe alle erforderlichen Verhandlungen aufnehmen können, die sich möglicherweise aus der notwendigen Anpassung der bestehenden Handelsabkommen an ein gemeinschaftliches Abkommen ergeben. 2 Außerdem, und dies ist vor allem für die Dauer der Übergangszeit, also bis zum 31.12.1969, relevant, bestimmte der Ministerrat, daß die beiden Partner eines bilateralen Handelsvertrages allenfalls gegenseitige Konsultationen aufzunehmen hätten, sofern eine Anpassung des bilateralen Handelsvertrages an neue, wăhrend der Laufzeit erlassene EWG-Bestimmungen notwendig werden würde. ${ }^{3}$

Bei Abkommen mit westlichen Handelspartnern hat der Einbau dieser Klausel bisher kaum Schwierigkeiten gemacht. Da jedoch hierfür die Anerkennung der EWG als Zollunion durch das vertragschließende Drittland Voraussetzung ist - diese Anerkennung durch die Staatshandelsländer de jure aber noch nicht erfolgte - stieß sie gerade bei Handelsverträgen mit diesen auf erfolgreichen Widerstand. Gerade den Staatshandelsländern gegenüber aber käme dieser Klausel größte Bedeutung zu. ${ }^{4}$ Sozusagen als Ersatz konnten jeweils Revisionsklauseln in die Handelsverträge mit Staatshandelsländern aufgenommen werden. Dadurch wurde es möglich, sowohl das Gesamtabkommen als auch einzelne Bestimmungen mit Jahresfrist zu kündigen und neue Verhandlungen $z u$ fordern. ${ }^{5}$ Ergänzend dazu be-

1 Wortlaut der EWG-Klausel: "Wenn die aus dem Vertrag zur Gründung der Europäischen Wirtschaftsgemeinschaft sich ergebenden Verpflichtungen bezüglich der schrittweisen Einführung einer gemeinsamen Handelspolitik es erfordern, werden so kurzfristig wie möglich Verhandlungen eingeleitet, mit dem Ziel, alle zweckdienlichen Änderungen in diese Abkommen aufzunehmen." Vierter Gesamtbericht über die Tätigkeit der Europäischen Wirtschaftsgemeinschaft (16. Mai 1960 - 30. April 1961), Brüssel, Mai 1961, Ziff. 192.

$2 \mathrm{Vgl}$. den Bericht des Außenhandelsausschusses des Europåischen Parlaments über Fragen der gemeinsamen Handelspolitik der Gemeinschaft gegenüber Staatshandelsländern, a.a.O., S. 4.

${ }^{3} \mathrm{Vgl}$. Otto Wolf VON AMERONGEN, Die EWG und ihre Möglichkeiten der Zusammenarbeit mit den Ostblockstaaten, in: Handels- und Währungspolitik im Gemeinsamen Markt, Schriftenreihe des Forschungsinstituts der FriedrichEbert-Stiftung, Hannover 1965, S. 84.

- Vgl. Carl A. EHRHARDT, a.a.O., S. 395.

$5 \mathrm{Vgl}$. "Industriekurier", Düsseldorf vom 30.3.1965. 
schloß der Ministerrat am 9.10.1961, daß die Geltungsdauer von nationalen Handelsvertrăgen auf die Ưbergangszeit zu beschränken sei und alle Handelsabkommen, die weder die EWG-Klausel noch eine jährliche Kündigungsfrist enthalten, eine Geltungsdauer von einem Jahr nicht überschreiten dürfen. ${ }^{1}$ Die gleiche Entschließung des Ministerrats ermächtig.e die EWG-Kommission, gemeinsam mit den Mitgliedsländern bis spätestens zum 1.1.1966 alle in Kraft befindlichen Handels- und Schiffahrtsverträge zu überprüfen, um sicherzustellen, daß sie die vertraglich vorgesehene Einführung einer gemeinsamen Handelspolitik nicht behindern. Außerdem verpflichteten sich die Mitgliedstaaten, die Termine für das Auslaufen der zweiseitigen Handelsabkommen mit dritten Ländern zu synchronisieren. Zum selben Zeitpunkt beschloß der Ministerrat ein Konsultationsverfahren, das "bei der Aushandlung" von Abkommen über Handelsbeziehungen sowie bei der Änderung des Liberalisierungsstandes anzuwenden ist. 2

Die Bestimmungen des Ministerrats von 1960/1961 wurden von den Mitgliedstaaten der EWG bisher jedoch recht großzügig gehandhabt. Zurückzuführen ist dies vorwiegend auf die Änderung der politischen Verhältnisse und das zunehmende Interesse am Osthandel, nicht zuletzt aber ach auf die zahlreichen Derogationen der Mitglieder. ${ }^{3}$

Im Gegensatz zu den EWG-Mitgliedstaaten und Großbritannien haben die USA bislang keine bilateralen Handels- und Verrechnungsabkommen mit Staatshandelsländern abgeschlossen. Da der Handelsverkehr mit den Ostblockländern nur auf Devisenbasis abgewickelt wird, entfällt die Warenkontingentierung als Mittel zum Ausgleich von bilateralen Handelsbilanzsalden. Ein besonderer Verrechnungsmodus ist deshalb nicht erforderlich. Wie die spăteren Ausführungen zeigen werden, sind aus gesetzlichen Gründen bilaterale Zollabsprachen mit Staatshandelsländern bis heute im allgemeinen nicht möglich und ein Handelsvertrag oder - abkommen wird auch aus diesem Grunde überflüssig. Da die amerikanische Zollpolitik gegenüber den meisten Staatshandelsländern des Ostblocks durchaus geeignet ist, die Einfuhr von marktstörenden Gütern zu verhindern, eine Aushandlung von Einfuhrkontingenten deshalb unterbleiben kann, kăme praktisch nur der Regelung verschiedener qualitativer handelspolitischer Maßnahmen Bedeutung zu.

1 Vgl. Amtsblatt der Europăischen Gemeinschaften, Nr. 71 v. 9.10.1961; Bericht im Namen des Außenhandelsausschusses des Europăischen Parlaments über Fragen der gemeinsamen Handelspolitik, a.a.O., S. 4 f.; "Neue Zürcher Zeitung'' v. 10.5.1964.

${ }^{2}$ Vgl. Carl A. EHRHARDT, a.a.O., S. 395; Amtsblatt der Europăischen Gemeinschaften, Nr. 71 v. 9.10.1961.

$\int^{3} \mathrm{Vgl}$. Rolf SANNWALD, Die Europåische Wirtschaftsgemeinschaft und der Osthandel, "Europa-Archiv". Folge 4, Bonn 1965, S. 124. 
Wie wichtig dennoch der Abschluß solcher Handelsabkommen besonders im Hinblick auf eine Modifizierung der bisherigen, nahezu statischen amerikanischen Osthandelspolitik ist, kommt im Untersuchungsergebnis des "Special Committee on United States Trade Relations with Eastern European Countries and the Soviet Union" zum Ausdruck." Die Empfehlungen dieses Komitees, das von Präsident Johnson im Jahre 1965 mit der Untersuchung der amerikanischen Osthandel spolitik beauftragt worden war, wurden zur Grundlage für die Vorlage der "East-West Trade Relations Act" vom Jahre 1966. 2 Dieser Gesetzesentwurf ist zwar bis heute vom Kongreß nicht angenommen worden - eine Annahme ist wegen des Vietnamkrieges auch für die unmittelbare Zukunft nicht zu erwarten - doch gibt sie Aufschluß darüber, wie sich die USA eine Neuordnung ihrer Osthandel spolitik vorstellen. Am entscheidendsten dürfte hierbei sein, daß die starre gesetzliche Regelung der Osthandelspolitik aufgegeben und zu einem System der fallweisen und den spezifischen Besonderheiten der jeweiligen Handelsbeziehungen gerecht werdenden Osthandelspolitik übergegangen werden soll. Größte Aufmerksamkeit mißt man dabei zukünftigen bilateralen Handelsverträgen und-abkommen bei. Sie sollen, dem Wortlaut der Vorlage zufolge, einen hilfreichen Rahmen für die praktische Abwicklung des Handelsverkehrs mit den Staatshandelsländern bilden ("... provide a framework helpful to private United States firms conducting business relations with Communist state trading agencies"). Ein solches Handelsabkommen, abzuschließen auf maximal drei Jahre, gäbe der amerikanischen Regierung die Möglichkeit, von ihrer "schematischen" Osthandelspolitik abzugehen und ihre handelspolitischen Instrumente selektiv einzusetzen. ${ }^{3}$

\section{DIE OSTHANDELSPOLITIK ALS KONGLOMERAT VON SYSTEMNEUTRALEN UND SYSTEMBEZOGENEN MAS S NA H ME N}

In Anbetracht der die Osthandelspolitik überlagernden Probleme wirtschaftlicher und politischer Art erscheint es zweckmåßig, die Gesamtheit der handelspolitischen Maßnahmen nach ihrer wirtschaftlichen und politischen Erforderlichkeit zu gruppieren. Bisher sind Versuche zu einer derartigen

I Vgl. Report to the President of the Special Committee on U.S. Trade Relations with Eastern European Countries and the Soviet Union, Department of State Publication No. 8061, Commercial Policy Series 201, March 1966.

2 Der Text dieser Gesetzesvorlage wurde im "Department of State Bulletin", No. 1404, Mai 30, 1966, sowie in "The Battle Act Report of 1966" veroffentlicht.

${ }^{3}$ Harold J. BERMAN, John R. GARSON, Possible Effects of the Proposed EastWest Trade Relations Act upon U.S. Import, Export and Credit Controls, "Vanderbild Law Review", Vol. 20, No. 2, Nashville/Te., March 1967, S. $279 \mathrm{ff}$. 
Systematisierung der osthandelspolitischen Maßnahmen jedoch nie über den Ansatz hinausgekommen, und ein Versuch dieser Art soll an dieser Stelle gar nicht erst unternommen werden.' Dennoch ist es notwendig, sich deutlich vor Augen zu halten, daß sowohl die ökonomisch als auch die politisch bedingten Maßnahmen der Osthandelspolitik nicht nur systembezogene, sondern sehr wohl auch systemneutrale Erforderlichkeit aufweisen.

Diejenigen osthandelspolitischen Maßnahmen, die aus ökonomischen Gründen ergriffen werden, setzen sich nämlich zusammen

1. aus Maßnahmen, welche grundsätzlicher, also systemneutraler Art sind und damit auch im Handelsverkehr zwischen Marktwirtschaften anfallen und

2. aus solchen, welche aus den ökonomisch bedingten Besonderheiten wirtschaftssystemarer und zielfunktioneller Art des Handels zwischen Marktwirtschaften und Staatshandelsländern resultieren und damit systembezogen sind.

Eine analoge Zweiteilung läßt sich für die aus politischen Gründen erforderlich werdenden Maßnahmen durchführen. Daher kann man wiederum unterscheiden zwischen Maßnahmen, die

1. systemneutral sind, da sie auf Grund der allgemeinen Beziehung zwischen Außenpolitik und Handelspolitik anfallen und solchen, die

2. systembezogen sind, da sie als Folge der politischen Beziehungen zwischen Wirtschafts- und Gesellschaftsordnungen westlichen und östlichen Typs angesehen werden müssen.

Im Hinblick auf die Ausführungen in den nachfolgenden Kapiteln muß man sich also darüber im klaren sein, daß nicht alle handelspolitischen Maßnahmen gegenüber den Staatshandelsländern systembezogen, man könnte sagen "osthandelstypisch", sind. Sie stellen lediglich einen Teil der insgesamt aktivierten oder aktivierbaren handelspolitischen Maßnahmen dar und überlagern diejenigen systemneutraler Art. Dieses Netz von systemneutralen und systembezogenen Maßnahmen kann aber im Rahmen dieser Untersuchung nicht entflochten werden. Die Auswahl der "osthandelstypischen", also systembezogene Maßnahmen, wird sich daher grundsätzlich danach orientieren, was in der wirtschaftswissenschaftlichen Literatur über den Ost-Westhandel und die Osthandelspolitik übereinstimmend als charakteristische osthandelspolitische Aktivität angesehen wird.

1 Vgl. zu diesem Problem vor allem Nicolas SPULBER, East-West Trade and the Paradoxes of the Strategie Embargo, Paper presented before the Conference on International Trade and International Planning. University of South California, Dec. 1966, unveroffentlichtes Manuskript. 
7. DIE AUSWAHL DER ZU UNTERSUCHENDEN HANDELSPOLITISCHEN AKTIVIT ÄTEN

Bevor die Auswahl der zu untersuchenden handelspolitischen Aktivitäten getroffen wird, soll eine kurze Ubersicht über die theoretisch möglichen außenhandelspolitischen Instrumente gegeben werden: ${ }^{1}$

1. Währungspolitische Inst rumente

a) Wechselkurspolitik

b) Spaltung des Devisenmarktes

2. Preisbelastungen und Preisentlastungen

(Zölle, Steuern, Prämien, Subventionen etc.)

3. Mengenpolitik

(Kontingente, Aus- und Einfuhrverbote etc.)

4. Äußere Finanz- und Auftragspolitik staatlicher Stellen

(Auslandsaufträge, Ausfuhrförderung durch staatliche Ausfuhrkreditgarantien und - bürgschaften)

5. Institutionelle (qualitative) Maßnahmen

(Verwaltung an der Grenze, Zahlungsverkehrsvorschriften, Marktorganisation etc. )

6. Monopolistische Organisation des Außenhandels

7. Die Beeinflussung des Verhaltens anderer Staaten (Handelsvertragstechnik)

Stellt man nunmehr die Frage, nach welchen Prinzipien die Auswahl erfolgt, so sind - entsprechend der allgemeinen Fragestellung der Arbeit folgende Auswahlprinzipien zu nennen:

1. Primärprinzip

Die handelspolitischen Aktivitäten müssen nach übereinstimmender Meinung in der Literatur "osthandelstypisch" sein. Dies bedeutet nicht, daß ausschließlich solche handelspolitischen Aktivitäten ausgewählt werden, welche nur im Ost-Westhandel zur Anwendung kommen, sondern es werden auch jene Aktivitäten erfaßt, die zwar nicht nur, so doch überwiegend im Ost-Westhandel eingesetzt werden und als besonders charakteristisch angesehen werden.

' Dieser Übersicht liegt die Systematik der außenwirtschaftspolitischen Instrumente von MÖLLER zugrunde. Vgl. ders., Außenwirtschaftspolitik, a.a.O., S. $39 \mathrm{ff}$. 


\section{Sekundärprinzipien}

a) Die jeweiligen Aktivitäten müssen für alle westlichen Länder (soweit sie hier untersucht werden) in einem ausgeglichenen Umfang e $r$ f a B bar und gegenüberstellbar sein.

b) Auf Grund der außenpolitischen Bedeutung der Osthandelspolitik im allgemeinen und verschiedener handelspolitischer Aktivitäten im besonderen (z.B. Handelsvertragstechnik) lassen sich mitunter nur unzureichende Informationen gewinnen. Vertraulich zur Verfügung gestellte Informationen bleiben unberücksichtigt. Dies bedeutet, daß die Aktivitäten auch dem Grundsatz der Publizierbarkeit genügen müssen.

Obgleich diese Kombination der Auswahlprinzipien nur eine unter mehreren möglichen ist, erscheint sie im Hinblick auf Aussagefähigkeit, Systematik und Vollständigkeit der auszuwählenden Aktivitäten sinnvoll. Daß aber kein absoluter Anspruch auf Systematik und Vollständigkeit erhoben werden kann, dürfte wohl nicht so sehr auf die Kombination der Auswahlgrundsătze als vielmehr auf das generelle Informationsproblem zurückzuführen sein.

In Anlehnung an die insgesamt möglichen handelspolitischen Instrumente und unter Berücksichtigung der Auswahlprinzipien werden folgende handelspolitische Aktivitäten in den Mittelpunkt der weiteren Untersuchung gestellt:

1. Preisbelastungen und Preisentlastungen

Auswahl: Einfuhrzollpolitik

2. Mengenpolitik

Auswahl: Mengenbeschränkungen (Ein- und Ausfuhrseite)

3. Äußere Finanz- und Auftragspolitik

Auswahl: Ausfuhrkreditpolitik

4. Beeinflussung des Verhaltens anderer Staaten

Auswahl: Beeinflussung der Osthandelspolitik westeuropăischer Lănder durch die USA

Alle anderen handelspolitischen Instrumente bleiben aus den genannten Gründen unberücksichtigt.

Damit ist nun klargestellt, welche Aktivitäten dargestellt werden. Abweichend von der durch MÖLLER vorgegebenen Systematik werden diese jedoch in Anlehnung an das in der Literatur über den Ost-Westhandel und die Osthandelspolitik übliche Gliederungsschema umgruppiert und den Hauptgruppen "Ausfuhrpolitik" und "Einfuhrpolitik" untergeordnet. 


\section{Darstellung der Osthandelspolitik der EWG-Mitgliedstaaten, GroBbritanniens und der USA gegenüber den Staatshandelsländern Südosteuropas}

1. A USFUHRWIRKSAME MASSNAHMEN DER EWG-MITGLIEDSTAATEN, GROSSBRITANNIENS UND DER US A

a) Ausfuhrbeschränkungen

a1) Das Internationale Ausfuhrkontrollsystem

Im November 1949 wurde unter dem Druck der politischen Ereignisse und auf Initiative der USA ein multilaterales Ausfuhrkontrollsystem gegenüber dem "Sino-Sowjetischen Block" ins Leben gerufen, dem sich bis zum Jahre 1953 alle NATO '-Länder - mit Ausnahme Islands - und a uch Japan anschlossen. ${ }^{2}$

Die sogenannte "Consultative Group", das gemeinsame Kontrollorgan dieser Länder, setzte sich aus zwei Arbeitsgruppen zusammen, nämlich dem "Coordinating-Committee" (COCOM) und dem "China-Committee" (CHINCOM). Das COCOM wurde zuständig für den Handel mit Ost- und Südosteuropa einschließlich der Sow jetunion, aber ohne Jugoslawien; das CHINCOM dagegen für den Handel mit Rotchina und Nordkorea. ${ }^{3}$

" "North Atlantic Treaty Organization" = NATO.

2 Auf die multilaterale westliche Embargopolitik, insbesondere deren historische Entwicklung sowie die damit verbundenen Konflikte zwischen den beteiligten Ländern wird im einzelnen nicht eingegangen. Hierzu sei verwiesen auf folgende Literatur: Gunnar ADLER-KARLSSON, The Western Economic Warfare 1947 - 1967, a.a.O.; Nicolas SPULBER, East-West Trade and the Paradoxes of the Strategic Embargo, a.a.O.; Harold J. BERMAN, John R. GARSON, United States Export Controls-Past, Present, and Future, "Columbia Law Review", Vol.67, No. 5, New York, May 1967; Luther HODGES, United States Policy on East-West Trade, in: East-West Trade, American Management Association, New York 1964; R. OAKESHOTT, The Strategic Embargo; An Obstacle to East-West Trade, "World Today", Vol. 19, London Jan.-Dec. 1963.

Vor dem Inkrafttreten des multilateralen Embargos wandten die USA seit dem März 1948 ein unilaterales Embargo gegenüber dem Ostblock an.

${ }^{3}$ Das COCOM wurde 1950, das CHINCOM 1951 gegründet. Beide Arbeitsgruppen stellen einen freiwilligen Zusammenschluß ohne vertragliche Grundlage dar, demzufolge die mündliche Vereinbarung gilt, die als strategisch gekennzeichneten Waren nicht an den Ostblock zu liefern. Vgl. Russel BAKER, Legal Aspects of East-West Trade. A Rational View before the "East-West Trade" Briefing Session of the American Management Association, New York, May 20, 1964, unveroffentlichtes Manuskript. 
Folgende geheime Ausfuhrlisten wurden aufgestellt:

1. Liste I: Waren, deren Ausfuhr verboten war (totally embargoed),

2. Liste II: Waren, deren Ausfuhr Mengenbeschränkungen unterlag,

3. Liste III: Waren, deren Ausfuhr sorgfältig überwacht wurde,

4. Liste IV: Waren, deren Ausfuhr nach Rotchina und Nordkorea verboten war (China-Liste). '

Im Jahre 1957 wurde die spezielle China-Liste aufgelöst, wodurch das "China-Differential" wegfiel und die Arbeitsgruppe des CHINCOM mit der des COCOM vereinigt wurde. ${ }^{2}$ Damit wurde die ehemalige China-Liste (Liste IV) entbehrlich. Liste III wurde neu gefaßt und bezog sich nunmehr auf Waren, die Ausfuhrkontrollen unterworfen werden konnten, sobald ihre Ausfuhr in den Ostblock überhandzunehmen drohte oder sonstige Gründe eine strengere Überwachung erforderlich machten. ${ }^{3}$

Ein weiteres Jahr später wurden die Listen II und III aufgelöst und ein neues System sekundärer Ausfuhrkontrollen in Form der sogenannten Überwachungsliste (watch-list - Liste IV) eingeführt. Heute bestehen nurmehr die Liste I, die eigentliche Embargo-Liste und die Liste IV, die Úberwachungsliste. 4

Wichtig ist, daß selbst die Waren der Liste I keinem absoluten Ausfuhrverbot mehr unterliegen. Jedoch wird jeder Export einer aufgeführten Ware in ein kommunistisches Land - Jugoslawien ausgenommen - von der Zustimmung der internationalen Ausfuh rüberwachungsbehorde (COCOM) abhängig gemacht. ${ }^{5}$

Während die internationalen Ausfuhrkontrollen in der Zeit des Korea-Krieges und besonders im Jahre 1953 ihren Höhepunkt erreichten, war die Ausfuhrrestriktionspolitik der in der "Consultative Group" zusammengeschlossenen Länder schon ab 1954 zunehmend von einer Differenzierung der Auffassungen über die Zweckmäßigkeit dieser Politik gekennzeichnet.

1 Vgl. BERMAN, GARSON, United States Export Controls-..., a.a. O., S. 835.

2 Nordvietnam war auch bisher schon von COCOM erfaßt worden. Gegenüber Kuba wird von den USA ein einseitiges Embargo angewendet.

$3 \mathrm{Vgl}$. "The Battle Act Report of 1957", a.a.O., S. 28.

"Vgl. "The Battle Act Report of 1959", a.a.O.

3 Zwischen Juli 1964 und Juni 1966 hat die COCOM-Gruppe verschiedentlich den Export von Embargogütern in kommunistische Länder aus Belgien, Frankreich, der Bundes republik Deutschland, Italien, Japan, den Niederlanden und Großbritannien genehmigt.

Vgl. "The Battle Act Report of 1966". 
Dies hatte zur Folge, daß noch im gleichen Jahr die erste Revision der COCOM-Listen durchgeführt wurde.'

Im Jahr der Aufhebung des "China-Differentials" (1957) vereinbarten die COCOM-Länder eine jährliche Revision der verbliebenen Listen, und schon ein Jahr darauf erfolgte eine erneute beträchtliche Kürzung. ${ }^{2}$ Die letzte Revision wurde im Jahre 1966 und Anfang des Jahres 1967 vollzogen. Die Liste I umfaßt heute ca. 100 Warenpositionen, die Liste IV nur noch rund 20 Positionen. ${ }^{3}$

Die Kürzungen und Aktualisierungen der internationalen Kontrollisten wurden und werden im allgemeinen immer gegen den Willen der USA durchgesetzt. Nach Meinung der USA erfüllen diese Ausfuhrkontrollen gegenüber kommunistischen Ländern sowieso nur Minimal anforderungen, die nicht durch weitere Kürzungen geschwächt werden dürften.

Um von den mit den USA befreundeten Ländern - insbesondere aber jenen, die nicht der "Consultative Group" angehorren - eine größere Kooperation auf dem Gebiet der Ausfuhrkontrolle zu erzwingen, erlie $\beta$ der US-Kongre $\beta$ im Jahre 1951 die "Mutual Defense Assistance Control Act". Der Verabschiedung dieses Gesetzes, das allgemein als "Battle Act" bekannt ist, waren verschiedene Bemühungen des Kongresses vorausgegangen, Sanktionen gegenüber westlichen Ländern bei Verstőßen gegen die amerikanischen Ausfuhrkontrollrichtlinien gesetzlich $\mathrm{zu}$ fixieren. Zu denken ist vor allem an das "Cannon-Amendment" vom Jahre 1950 und das "Kem-Amendment" vom Jahre 1951."

Hauptzweck der "Battle Act" sollte es vornehmlich sein,

1. eine gesetzliche Handhabe zur Einstellung der amerikanischen Auslandshilfe gegenüber Ländern zu bieten, welche strategische Güter in kommunistische Länder liefern,

2. die Mitwirkung der USA in der "Consultative Group" $z u$ institutionalisieren.

Die "Battle Act" erstreckt sich auf zwei Warenlisten. Die erste, Title I, Category A, enthält Waffen, Kriegsgerăt und Spaltmaterial. Die zweite, Title I, Category B, weist auf andere strategische Materialien und Güter hin.

'Vgl. "The Battle Act Report of 1953".

Nicolas SPULBER, East-West Trade and the Paradoxes of the Strategic Embargo, a.a. O.

2 Vgl. "The Battle Act Report of 1958".

${ }^{3} \mathrm{Vgl}$. Nicolas SPULBER, East-West Trade and the Paradoxes of the Strategic Embargo, a.a.O.

4 Vgl. Nathaniel Mc KITTERICK, a.a.O., S. 12 ff. 
Die Bestimmungen dieses Gesetzes sehen vor, daß die USA einem Land weder militărische noch wirtschaftliche noch finanzielle Hilfe gewähren bzw. Solche Hilfe abbrechen, sofern dieses Land wissentlich den Export irgendwelcher Güter der genannten Listen in Länder oder Ländergruppen erlaubt, welche die Sicherheit der USA gefährden. Expressis verbis werden die Sowjetunion und die Länder ihres Herrschaftsbereichs als solche die US-Sicherheitsinteressen gefährdenden Länder angesehen.

Im Hinblick auf Title I, Category B, besteht eine Ausnahme insofern, als der Präsident der Vereinigten Staaten von Amerika, entgegen den grundsätzlichen Bestimmungen des Gesetzes, das Recht hat, solche Hilfe im Einzelfall dennoch zu gewăhren, wenn ein Abbruch bzw. eine Nichtgewăhrung von Hilfe eindeutig den US-Sicherheitsinteressen widersprăche.

Title II der 'Battle Act" enthält praktisch die gleichen allgemeinen Warengruppen wie Title I, Category B, jedoch werden die spezifischen Waren im Einzelfall als von geringerer strategischer Bedeutung angesehen.' Es handelt sich dabei um Güter, welche zwar nach Auffassung des Außenministeriums einer Kontrolle unterworfen sein sollten, deren Export durch die anderen westlichen Länder in den Ostblock jedoch nicht die Sanktionen wie im Falle des Exports von Title I-Gütern nach sich ziehen.

Die zwei Listen von Title I entsprechen annähernd der COCOM-Liste I. Zwar ist Title I, Category A, nicht klassifiziert, doch deckt sie sich eindeutig mit der "Munitions and Atomic Energy-List" der COCOM-Liste I. Title I, Category B, stimmt in etwa mit den anderen Teilen der COCOMListe I überein. Die letzte Revision der "Battle Act" Title I-Listen folgte der Revision der COCOM-Listen Ende 1966 und Anfang 1967. Sie wurde im März 1967 wirksam. ${ }^{2}$ Die "Battle Act" Liste Title II entspricht der COCOM-Liste IV. ${ }^{3}$ Sie umfaßt Waren, welche die USA gew ohnlich nicht in kommunistische Länder ausführen, deren Embargo jedoch von den anderen COCOM-Ländern nicht akzeptiert wurde.

Die Länder der "Consultative Group" wandten vor dem Inkrafttreten der "Battle Act" ein System der multilateralen Reexportkontrolle strategischer Güter an. Im allgemeinen unterliegen die Güter der COCOM-ListeI dem "Import-Certificate" (IC) und dem "Delivery-Verification" (DV) - Verfahren, nicht dagegen die Güter der Liste IV (watch-list). Da jedoch die in der amerikanischen "Commodity Control List" (Ausfuhrliste)" enthal-

$1 \mathrm{Vgl}$. "The Battle Act Report of 1967"; BERMAN, GARSON, United States Export Controls-..., a.a. O., S. 837.

2 Vgl. "The Battle Act Report of 1956" - dieser Report enthält die bisher umfassendste Darstellung der internationalen Ausfuhrkontrollen; "The Battle Act Report of 1966"; "The Battle Act Report of 1967".

3 Vgl. BERMAN, GARSON, United States Export Controls-..., a.a. O., S. 839.

Vgl. S. 60 . 
tenen strategischen Güter weit zahlreicher sind als die der COCOM-Liste (praktisch enthält die "Commodity Control List" auch Güter der COCOMListe IV), findet das DV-Verfahren durch die USA in weit großerem Umfang Anwendung als durch die anderen COCOM-Länder. Letztere unterwerfen zumeist nur die Güter der COCOM-Liste einer strengen Ausfuhrkontrolle bzw. verbieten deren Ausfuhr in kommunistische Länder.

\section{a2) Die Ausfuhrbeschränkungen der EWG-Mitgliedstaaten}

Die Ausfuhrpolitik der EWG-Mitgliedstaaten ist bisher unberührt geblieben von gemeinschaftlichen handelspolitischen Maßnahmen der EWG. Auf diesem Sektor ergeben sich demzufolge keine Beschrănkungen der autonomen handelspolitischen Kompetenz der Mitgliedsländer.

\section{Die Bundesrepublik Deutschland}

Gemäß $\$$ Abs. 1 des "Außenwirtschaftsgesetzes" (AWG)' bestehen in der Bundesrepublik Deutschland im Grundsatz keine Ausfuhrbeschränkungen. Unbeschadet der grundsätzlichen Bestimmungen in $\$ 1$ sowie einer Ausnahmemöglichkeit auf Grund eines Bundestagsbeschlusses bei Vorliegen besonderer Umstände sind jedoch folgende Ausfuhrbeschrănkungen möglich:

1. zur Erfüllung von zwischenstaatlichen Vereinbarungen ( $\$ 5 A W G$ ),

2. zur Abwehr schädigender Einwirkungen aus fremden Wirtschaftsgebieten ( $\$ 6$ AWG), 2

3. zum Schutz der Sicherheit und der auswärtigen Interessen ( $\$$ AWG),

4. zum Schutz des lebenswichtigen Bedarfs im Wirtschaftsgebiet der Bundesrepublik ( $\$ 8$ AWG). ${ }^{3}$

Nach Maßgabe des $\$ 7$ AWG können zum Schutz der Sicherheit und der auswärtigen Interessen "... insbesondere beschränkt werden

1. im Rahmen der auf die Durchführung einer gemeinsamen Ausfuhrkontrolle gerichteten internationalen Zusammenarbeit die Ausfuhr oder Durchfuhr von

a) Waffen, Munition und Kriegsgerät,

b) Gegenstände, die bei der Entwicklung, Erzeugung oder dem Einsatz von Waffen, Munition und Kriegsgerät nützlich sind oder

c) Konstruktionszeichnungen und sonstige Fertigungsunterlagen für die in Buchstabe a) und b) bezeichneten Gegenstände,

1 Das AWG löste am 1.8.1961 das von der Militärregierung im Jahre 1949 erlassene "Gesetz zur Devisenbewirtschaftung und Kontrolle des Güterverkehrs" ab. Die Kompetenzen im Außen- und Interzonenwirtschaftsverkehr waren jedoch schon 1955 in den Zuständigkeitsbereich der Bundes regierung übergegangen.

Vgl. dazu S. 94.

${ }^{2}$ Diese Bestimmung gewinnt besondere Bedeutung im Rahmen der Einfuhrpolitik; vgl. S. $94 \mathrm{ff}$.

${ }^{3} \S 5-8$ sind in Verbindung mit $\$ 27$ AWG zu sehen. 
2. die Ausfuhr von Gegenständen, die zur Durchführung militärischer Aktionen bestimmt sind ..."'

Nummer (1) Abs. 2 des $\$ 7$ AWG bezieht sich somit vor allem auf die sicherheitspolitisch bedingten internationalen Ausfuhrkontrollen der "Consultative Group" (sie entsprechen der Embargo-Liste I des COCOM). Die davon betroffenen, zumeist strategischen Güter sind nach Maßgabe von $\$ 5$ der "Außenwirtschaftsverordnung" (AWV) in Verbindung mit $\$ 7$ Abs. 1 AWG in Teil I der offiziellen deutschen Ausfuhrliste verzeichnet. ${ }^{2}$ Diese Liste gliedert sich in folgende Kategorien:

A: Internationale Liste für Waffen, Munition und Rüstungsmaterial

B: Internationale Kernenergieliste,

C: Internationale Kontrolliste für verschiedene Waren, ${ }^{3}$

D: Kontrolliste sonstiger Waren. 4

Teil II der Ausfuhrliste enthält im wesentlichen Waren, deren Ausfuhr in die EWG gewissen Qualitätskontrollen entsprechend den EWG-Qualitätsnormen unterworfen sind. ${ }^{5}$

Gemäß $\$ 5 \mathrm{AWV}$ in Verbindung mit $\$ 7 \mathrm{AWG}$ bedarf die Ausfuhr der in Teil I der Ausfuhrliste genannten Güter grundsätzlich der Genehmigung. Das gleiche gilt für die Unterlagen und technischen Daten zur Fertigung der Waren, die in Teil I, Abschnitt A, B und $C$ genannt sind. Die in Teil I, Abschnitt $C$ und $D$ aufgeführten Waren können ohne Genehmigung exportiert werden, wenn das Einfuhrland ein Land der Länderliste $A$ oder $B^{6}$ ist und wenn außerdem entsprechend dem der Ausfuhr zugrundeliegenden Vertrag keine Waren im Werte von mehr als 1.000, - DM geliefert werden sollen. ${ }^{7}$

I 7 Abs. 2 AWG.

2 Vgl. Anlage AL der AWV.

${ }^{3}$ Metallbearbeitungsmaschinen, chemische Anlagen, Mineral olanlagen, elektrische Anlagen und Krafterzeugungsanlagen, allgemeine industrielle Ausrüstungen, Transportmittel, elektronische Geräte, Metalle, Mineralien, Chemikalien, Metalloide, Mineralölerzeugnisse, Kautschuk und-erzeugnisse (dies natürlich nur insoweit, als sie von strategischer Bedeutung sind und gegen die Sicherheit und auswärtigen Interessen verstoßen).

4 Luft- und Motorfahrzeuge, soweit sie nicht schon unter A erfaßt sind.

$5 \mathrm{Vgl}$. $\$ 5 \mathrm{AWG}$ in Verbindung mit $\$ 6 \mathrm{a} \mathrm{AWV}$.

- Die Länderlisten $A$ und $B$ finden sich in der Anlage II zum Außenwirtschaftsgesetz; Länderliste $C$ in der Anlage $L$ zur Außenwirtschaftsverordnung. Länderliste $A$ enthălt die OECD-Stammländer sowie die mit der EWG verbundenen Gebiete; Länderliste B umfaßt die GATT-Länder, also auch Jugoslawien. Die Länderliste $C$ dagegen enthält die Ostblockländer.

7 Der Teil I der deutschen Ausfuhrliste ist vergleichbar mit Title I, Categories $A$ and $B$ der "Battle Act" der USA; vgl. Russel BAKER, Robert BOHLIG, The Control of Exports - A Comparison of the Laws of the United States, Canada, Japan and the Federal Republic of Germany, "International Lawyer", Vol. I, No. 2, Washington D.C., Jan. 1967, S. $163 \mathrm{ff}$. 
Im Hinblick auf die Staatshandelsländer Südosteuropas läßt sich feststellen, daß für sämtliche in den Abschnitten A, B, C und D der Ausfuhrliste I verzeichneten Waren Genehmigungen erforderlich sind. In den Fälen, wo es sich um Güter (bzw. technische Daten) der Abschnitte A und B handelt, werden Ausfuhrgenehmigungen gewöhnlich nicht erteilt. Die unter $C$ und D zusammengefaßten Waren dagegen können im allgemeinen bei Vorliegen einer Ausfuhrlizenz in diese Länder exportiert werden. Die Erteilung der Lizenz ist abhängig von den in $\$ 5-7$ AWG genannten Kriterien.

Wie die meisten westlichen Länder untersagt also auch die Bundesrepublik den Export von Gütern der internationalen strategisclen Liste. AuBerdem sind 225 Waren ausfuhrgenehmigungspflichtig, die der internationalen Liste nicht angehören und zumeist agrarischer Natur sind.'

Weiteren Ausfuhrrestriktionen unterliegen verschiedene Metalle infolge des großen binnenländischen Bedarfs.

Von den genannten Beschränkungen abgesehen dürfen grundsätzlich alle Waren frei in die Ostblockländer ausgeführt werden. 2 Unbeschadet sonstiger Bestimmungen ist entsprechend $\$ 7$ AWV die Ausfuhr aller Waren in Ostblockländer jedoch immer dann genehmigungspflichtig, wenn die Lieferung gegen ein Zahlungsziel erfolgt, das 180 Tage überschreitet. ${ }^{3}$ Der Antrag auf Erteilung einer Ausfuhrgenehmigung muß vom deutschen Exporteur gestellt werden $(\$ 17 \mathrm{AWV})$. Werden Waren, die auf der internationalen Liste verzeichnet sind, in Länder ausgeführt, die die COCOM-Kontrollen respektieren, so ist mit dem Antrag zur Lizenzausstellung eine Unbedenklichkeitsbestätigung (IC) des betreffenden Landes beizufïgen. Geht die Ware dagegen in ein Land, das die COCOM-Kontrolle nicht anerkennt, so ist ein ähnliches, den Endverbrauch der Ware kennzeichnendes Dokument erforderlich. Entsprechend dem "Runderlaß Außenwirtschaft" Nr. 39/61 sind die deutschen Behorden außerdem berechtigt, den beabsichtigten Endverbrauch von COCOM-kontrollierten Waren zu überprüfen. Solche Nachweise können in Form von Wareneingangsbescheinigungen (DV) eines das COCOM anerkennenden Landes oder ähnlicher Nachweise eines Nicht-COCOM-Landes erbracht werden.4

Die für Warenausfuhr wie auch für Wareneinfuhr notwendigen Genehmigungen werden von den den Bundesministerien für Wirtschaft bzw. Landwirtschaft nachstehenden Bundesämtern für gewerbliche Wirtschaft bzw.

'Vgl. Beilage zum "Bundesanzeiger", Koln, Nr. 114 vom 24.6.1965.

2 Für den Interzonenhandel gelten gesonderte Bestimmungen.

$3 \mathrm{Vgl}$. "Bundesanzeiger", Köln, Nr. 86 vom 6.5.1966.

4 Die Einzelheiten über das IC- und DC-Verfahren der Bundesrepublik sind im genannten Runderlaß beschrieben.

Vgl. auch "The Battle Act Report of 1967", Appendix C, S. 46. 
Ernăhrung und Landwirtschaft in Frankfurt am Main ausgestellt.'

\section{Frankreich}

Das französische Ausfuhrkontrollsystem unterwirft den Export sämtlicher strategischer Waren in Ostblockländer der Genehmigungspflicht. Daneben besteht noch eine quotenabhängige Ausfuhrlizensierung für bestimmte Knappheitsgüter, die aber auch gegen alle Länder außerhalb der FrancZone und der EWG wirkt.

Die Ausfuhrkontrolle strategischer Güter wird grundsätzlich ăhnlich gehandhabt wie von den anderen Ländern der "Consultative Group". Die französische "Liste strategischer Waren zur Überwachung des Endverbrauchs und der Endbestimmung", die große Ähnlichkeit mit der britischen Embargoliste aufweist, ${ }^{2}$ wird entsprechend den COCOM-Beschlüssen revidiert und periodisch im "Moniteur Officiel du Commerce International" (MOCI) veroffentlicht. Ohne COCOM-Zustimmung werden prinzipiell keine Ausfuhrgenehmigungen in Länder des Ostblocks für Warenkategorien dieser Liste erteilt. ${ }^{3}$

Exportlizenzantrăge französischer Exporteure sind bei dem "Service des Autorisations Commerciales" einzureichen. Frankreich wendet ebenfalls das IC- und DV-Verfahren an. 4 Neben den IC- und DV-Kontrollmöglichkeiten besteht eine weitere insofern, als der französische Exporteur vor der Abwicklung von Lieferungen in Ostblockländer (aber auch nach Ägypten und in die Türkei) eine vom Finanzministerium bestätigte Verpflichtung abgeben muß, sämtliche im Zug des entsprechenden Ausfuhrgeschäftes verdienten konvertiblen Währungsbeträge in nationale Franc-Währung umzutauschen. Durch die Erteilung oder Nichterteilung des ministeriellen Sichtvermerks (visa) läßt sich eine recht effektive zusätzliche Kontrolle erreichen. 5

'Das Verfahren der Ausfuhrkontrolle wurde laut "Bundesanzeiger" $\mathrm{Nr} .86 \mathrm{v}$. 6.5.1966 (8. Verordnung zur Änderung der AWV) für Exporteure zahlreicher und gleichbleibender Sendungen erleichtert. Unter gewissen Voraussetzungen und auf Antrag gestattet die Oberfinanzdirektion demnach eine Vereinfachung insofern, als für die notwendige Vorausanmeldung beim Versandzollamt lediglich eine Ausfuhrkontrollmeldung an Stelle des Ausfuhrscheins eingereicht werden kann. Diese Meldung muß lediglich Angaben enthalten, die die Identifizierung der Ausfuhrsendung durch die Ausgangsstelle ermöglichen.

2 Vgl. S. 56.

$3 \mathrm{Vgl}$. Selling the Soviet Market, Business International, Geneva 1965, S. $42 \mathrm{f}$.

"Vgl. "The Battle Act Report of 1967", S. $44 \mathrm{f}$.

${ }^{5} \mathrm{Vgl}$. Selling the Soviet Market, a.a. O., S. 42. 
Sämtliche Waren auf der italienischen Ausfuhrliste ("Tabella Export")" bedürfen, unabhängig vom jeweiligen Bestimmungsland, einer Ausfuhrgenehmigung. Diese wird vom Finanzministerium auf Grund einer Ermächtigung des Außenhandelsministeriums erteilt. Die "Tabella Export" enthält alle international anerkannten Embargogüter und wird periodisch vom "Istituto Nazionale per il Commercio Estero" (ICE) veröffentlicht. ${ }^{2}$

Die restlichen Güter können genehmigungsfrei exportiert werden; lediglich Ausfuhren in die DDR sind auch im Fall nichtstrategischer Güter von einer Sondergenehmigung abhängig. ${ }^{3}$

Über die Erteilung von Exportlizenzen entscheidet ein interministerielles Kommittee. Das IC-DV-Verfahren wird ebenfalls angewendet. 4

Belgien - Niederlande - Luxemburg (Benelux)

Am 23.5.1935 wurde zwischen Belgien und dem Großherzogtum Luxemburg die Belgisch-Luxemburgische Verwaltungskommission ("Commission Administrative Mixte Belgo-Luxembourgoise") gebildet. Sie hat zur Aufgabe, die Maßnahmen beider Länder zur Regelung der Ein- und Ausfuhrkontrolle zu koordinieren.

Grundsätzlich unterliegen sämtliche Waren der Ausfuhrkontrolle, jedoch können die betreffenden Ministerien für bestimmte Waren und Länder die Kontrollmaßnahmen aufheben. Neben der Ausfuhrkontrolle durch Lizenzen werden gelegentlich auch Sonderkontrollen durchgeführt, um die Utbereinstimmung der Ware und des Bestimmungslandes mit der betreffenden Lizenz zu überprüfen. Im übrigen akzeptierte die gemeinsame Verwaltungskommission die COCOM-Richtlinien. ${ }^{5}$

Die Niederlande machen die Ausfuhr aller strategischen Waren von Einzellizenzen abhăngig. Da prinzipiell alle Exporte aus diesem Land eine Genehmigung erfordern, die meisten Exportgüter jedoch einem generellen A usfuhrgenehmigungsverfahren unterliegen, kommt der Einzellizenz eine besondere Kontrollbedeutung $z \mathrm{u}$. Sie wird ausgestellt vom "Centrale Dienst voor In-en Uitvoer". Strategische Waren im Werte unter 250, - US- $\$$ sind von der Einzelgenehmigungspflicht ausgenommen, sofern sie für ein COCOM-Land oder ein die COCOM-Regelungen anerkennendes Land bestimmt sind. Auch von den Niederlanden wird das IC-DV-Verfahren angewandt.

1 Sie ist seit dem 1.10 .1962 gultig.

$2 \mathrm{Vgl}$. "The Battle Act Report of 1967", S. 48.

${ }^{3} \mathrm{Vgl}$. Selling the Soviet Market, a.a.O., S. 45.

Vgl. Klaus-Heinrich STANDKE, Der Handel mit dem Osten, a.a. O., S. 202.

s Vgl. "The Battle Act Report of 1967", S. 42. 
Die wichtigsten britischen Ausfuhrkontrollen beziehen sich auf Güter der sogenannten Embargo-Liste, die praktisch dieselben Güter enthält wie die COCOM-Liste der international kontrollierten Güter strategischer Art. Sie erstrecken sich nicht nur auf kommunistische Länder, sondern auch auf eine Reihe von westlichen Staaten, ausgenommen Mitgliedsländer des britischen Commonwealth, Irland, Südafrika und die Vereinigten Staaten von Amerika.'

Ausfuhrgenehmigungen solcher Güter in die Länder der "Eastern Area" 2 sowie Rhodesien werden gewöhnlich nicht erteilt. Die vollständige Embargo-Liste ist in der ergänzten "Strategic Goods (Control)Order" vom Jahre 1961 und der ebenfalls erweiterten "Export of Goods (Control)Order" von $1963 \mathrm{zu}$ finden. Eine gestraffte Ausfuhrkontrolliste ("Consolidated Embargo List") wird in bestimmten Zeitabständen in dem "Board of Trade Journal" veröffentlicht und berücksichtigt dabei jeweils entsprechende Änderungen. Dem "Board of Trade" (Handelsministerium) obliegt auch die Verwaltung der Ausfuhrkontrollen.

Folgende Güterkategorien sind in der "Consolidated Embargo List" aufgeführt:

Kategorie
"1
"1
"
"
"1
"
"
"

A: Munition

B: Kernenergetische Stoffe

C: Metallbearbeitende Maschinen

D: Chemische und petrochemische Anlagen

E: Elektrische Anlagen und Krafterzeugungsanlagen

F: Allgemeine industrielle Anlagen

G: Transportausrüstungen

H: Elektronische Geräte

I: Wissenschaftliche Instrumente und phototechnische Anlagen

J: Strategische Metalle und Mineralien

K: Chemische Metalloide und Erdolprodukte

L: Synthetischer Gummi und Filme. ${ }^{3}$

Die periodischen Änderungen der Embargo-Liste erfolgen nur in Übereinstimmung mit den COCOM-Regelungen."

'Vgl. "The Battle Act Report of 1967", S. 53.

2 Eastern Area: Albanien, Bulgarien, DDR, Mongolische Volksrepublik, Nordkorea, Nordvietnam, Polen, Rotchina, Rumänien, Sowjetunion, Tschechoslowakei und Ungarn.

${ }^{3} \mathrm{Vgl}$. Selling the Soviet Market, a.a.O., S. 40;

R. OAKESHOTT, a.a.O., S. 243.

4 Dies ist auch bei allen anderen Mitgliedern der "Consultative Group" der Fall. 
Die letzten Änderungen haben weitgehend einen Abbau des Embargos gebracht. Vor allem wurden verschiedene Metalle und industrielle Anlagen vom Embargo ausgeklammert. Neu aufgenommen wurden beispielsweise Neutronenröhren, Kontrollinstrumente für Atomenergieprozesse und verschiedene Metalle. Wie die meisten westlichen Länder wendet auch Großbritannien das IC-DV-Verfahren an. ${ }^{t}$

Eine besondere Rolle spielte Großbritannien im Zusammenhang mit dem entscheidenden Abbau des Embargos im Jahre 1954. Damals setzte der britische Premier Churchill den ganzen Einfluß des Vereinigten Königreiches ein, um die nahezu totalen Ausfuhrrestriktionen gegenüber den Ostblockländern zu vermindern. Auf der Bermuda-Konferenz im Jahre 1954 machte Churchill deutlich, daß "die amerikanischen Standpunkte für den Handel mit den sozialistischen Ländern kein Modell für die Staaten Europas sein könnten". '2 Noch im gleichen Jahr durchbrach Großbritannien die internationalen Restriktionsbestimmungen, indem es den Begriff "strategisch" gegenüber den USA unterschiedlich $\mathrm{zu}$ definieren begann.

Damit wurde eine weitgehende Revision der international kontrollierten Listen eingeleitet. 3

\section{a4) Die Ausfuhrbeschränkungen der USA}

\section{a41) Die Beschränkungen der Güterausfuhr}

Grundsätzlich unterliegen sämtliche nicht landwirtschaftlichen Exporte der USA, seien es Güter oder technische Daten, irgendwelchen Ausfuhrbestimmungen. ${ }^{4}$ Nichtstrategische Ausfuhren in nichtkommunistische Länder erfordern lediglich eine Ausfuhrerklärung (sogenannte "general licen$s^{\prime \prime}=$ "Exporter's Declaration"). Im Falle des Exportes in kommunistische Länder sind jedoch eine Reihe von formellen und materiellen Hindernissen direkter und indirekter Art $z u$ überwinden.

Die wichtigste gesetzliche Grundlage der Exportrestriktionen im allgemeinen und gegenüber den kommunistischen Lăndern im besonderen bildet

I Vgl. Selling the Soviet Market, a.a. O., S. 41.

$2 \mathrm{Vgl}$. E. HOFFMANN, Der Osthandel der Anderen, "Informationen über den innerdeutschen Handel und West-Ost-Handel", H. 1, Berlin Jan. 1960, S. 26. 3 Ygl. S. 49.

Ausgenommen ist Kanada. Vgl. BERMAN, GARSON, United States Export Controls, a.a.O., S. 792 . 
die sogenannte "Export Control Act" vom Jahre 1949. 1 Seit seinem Inkrafttreten ist dieses Gesetz siebenmal verlängert und im Jahre 1962 entscheidend erweitert worden. ${ }^{2}$ Die Durchführung und Ubberwachung der Bestimmungen dieses Gesetzes obliegt der Exportkontrollabteilung ("Office of Export Control of the Bureau of International Commerce" = OEC) des Handelsministeriums. Damit ist das OEC zustăndig für die Erteilung der Ausfuhrgenehmigungen nahezu aller genehmigungspflichtigen Waren, sofern sie über die allgemeine Ausfuhrgenehmigung ("general license") hinausgehen. Ausgenommen hiervon sind lediglich nukleare Materialien der "Atomic Energy List", für deren Lizenzierung die Atomenergiebehörde ("Atom Energy Commission" - AEC) zuständig ist. Handelsschiffe wiederum werden von der Schiffahrtsabteilung des Handelsministeriums lizenziert; Waffen, Munition und Kriegsgüter - zusammengefaßt unter der sogenannten "Munitions-List" - vom Außenministerium; Gold, Narkotika und elektrischer Strom von der "Federal Power Commission". Militärische Güter schließlich, die unter die Bestimmungen der "Mutual Security Act" von 1954 fallen, werden vom Verteidigungsministerium genehmigt. ${ }^{3}$

Die "Export Control Act" verbietet alle Exporte strategischer Art" (alle Güter, die in der sogenannten "Positive List"s verzeichnet sind) in die Sow jetunion und die Ost- und südosteuropäischen Staatshandelsländer. Alle anderen, demzufolge nichtstrategische Waren, können nur bei Vorliegen

1 Dieses Gesetz sollte den Präsidenten der Vereinigten Staaten mit Vollmachten ausstatten, die ihn in die Lage versetzen, eine den jeweiligen politischen Entwicklungen entsprechende Exportpolitik zu verfolgen.

Vgl. A Background Study on East-West Trade, Committee on Foreign Relations, U.S. Senate, Washington D.C., April 1965, S. 38; BERMAN und GARSON zufolge hatte es darüber hinaus den Zweck zu erfüllen, die internationalen Warenströme zugunsten der Marshall-Plan-Länder zu lenken. Vgl. dies., ebd., S. 795.

2 Die letzte Verlängerung erfolgte 1965, die nächste ist 1969 făllig. Die Ergänzungen im Jahre 1965 sind, abgesehen von der Verschärfung einiger Strafbestimmungen im Fall des Verstoßes gegen die "Export Control Act", für den Ost-Westhandel unbedeutend gewesen.

${ }^{3}$ Vgl. A Background Study on East-West Trade, a.a.O.; Selling the Soviet Market, a.a.O., S. 35.

Die folgenden Ausführungen beschränken sich nur auf die vom OEC angewandten Ausfuhrkontrollen.

4 Als strategisch werden solche Güter angesehen, ". . which would make a significant contribution to the warmaking power of the Soviet Bloc". "The Battle Act Report of 1954", S. 1.

5 Die strategischen Güter waren bis 1965 in einer "Positive List of Controlled Commodities" verzeichnet.

Vgl. S. 59 f. 
einer Einzellizenz ("validated license") in den Ostblock exportiert werden.' Ausgenommen sind jene Waren, die der Ausnahmeliste GLSA ("General License Soviet Area") angehören. Waren dieser Liste benotigen nur eine Ausfuhrerklärung des Exporteurs, die den Stempel "GLSA" trägt. Für knappe Güter kann jederzeit eine Ausfuhrsperre erlassen werden. Waren, die weder der positiven Liste noch der GLSA-Liste angehören, also Waren, die nicht unmittelbar als strategisch angesehen werden, denen aber dennoch eine größere Bedeutung beigemessen wird als den Gütern der GLSA-Liste, erfordern Einzellizenzen. Die Genehmigung des Exportantrages eines Gutes dieser Warengruppe ist infolgedessen davon abhängig, wie das OEC diese Ware hinsichtlich ihrer militärischen bzw. ab dem Jahre 1962 auch wirtschaftlichen Bedeutung bewertet.

Die "Export Control Act" verhinderte vor dem Jahre 1962 nur Ostexporte von militärischer Bedeutung. Eine Ergänzung dieses Gesetzes im Jahre 1962 brachte eine Erweiterung und damit eine Verschärfung insofern, als nunmehr auch Güter vom Export ausgeschlossen wurden, die nach Meinung des $O E C$ einen wesentlichen Beitrag zur wirtschaftlichen Stärkung der kommunistischen Länder leisten können. ${ }^{2}$

In der Praxis vertritt das OEC den Grundsatz, daß es im Hinblick auf die Stärkung des Ostblocks nicht so sehr entscheidend ist, woher das Gut kommt, sondern vielmehr, ob ein kommunistisches Land dieses überhaupt erwerben kann. Gewöhnlich wird eine Ausfuhrgenehmigung selbst dann erteilt, wenn die Ware einen "beträchtlichen" Beitrag zur ökonomischen Stărkurıg des Ostblocks leistet, diese Ware oder ein Substitut hingegen auch aus anderen, nichtkommunistischen Quellen $z u$ ähnlichen Bedingungen wie aus den USA zu beziehen ist. Die Genehmigung wird jedoch gewöhnlich abgelehnt, wenn das betreffende kommunistische Land diese Ware in den USA $z u$ den weitaus günstigsten Bedingungen hinsichtlich Preis, Qualităt und ahnlichem kaufen könnte.

Obgleich der amerikanische Exporteur seinen Antrag auf eine Ausfuhrgenehmigung einreichen kann, bevor eine feste Bestellung seitens des kommunistischen Interessenten vorliegt, verlangt das OEC einen Nachweis darüber, ob das betreffende kommunistische Land ernste Kaufabsichten

' Die Einzellizenz ist ein Dokument, "... issued to/on an exporter by the Department of Commerce authorizing the exportation of a particular commodity (or technical data) to a particular consignee in a particula country for a particular use." BERMAN and GARSON, United States Export Controls, a.a. O., S. 819 .

${ }^{2}$ Vgl. dies., ebd., S. $800 \mathrm{f}$. 
hat und ein Abschluß bei Erteilung der Lizenz wahrscheinlich ist. 'Gewöhnlich hat eine Ausfuhrgenehmigung eine Gültigkeitsdauer von sechs Monaten (ein Jahr für Projektlizenzen). Eine Verlängerung ist maximal für sechs Monate möglich. 2

Im Jahre 1965 wurden die verschiedenen Ausfuhrgenehmigungslisten aus technischen Gründen vereinheitlicht und in der sogenannten "Commodity Control List" zusammengefaßt. Diese neue gemeinsame Liste, vom Handelsministerium veröffentlicht, enthält sämtliche Warenpositionen der auf dem SITC-Klassifikationssystem aufgebauten amerikanischen Exportwarenklassifikation ("Statistical Classification of Domestic and Foreign Commodities exported from the United States"). Sie gibt für jede Ware mittels entsprechender Kennzeichnung durch ein Ländergruppensymbol an, in welche Länder diese spezielle Ware nur bei Vorliegen einer Einzellizenz ausgeführt werden darf. ${ }^{3}$ Folgende Länder- oder Ländergruppensymbole finden Anwendung: ${ }^{4}$

1. Lăndergruppe $\mathrm{T}$ : Lănder der westlichen Hemisphäre, ausschließlich Kanada und Kuba

2

"1

3.

4.

5.

11

7.
V: alle nichtkommunistischen Länder der Welt außerhalb der westlichen Hemisphäre, einschließlich Jugoslawien

W: Polen und Rumänien

$X$ : Hongkong und Macao

Y: Länder des Sow jetblocks, ausgenommen Länder der Ländergruppe W (also Albanien, Bulgarien, DDR, Sowjetunion, Tschechoslowakei und Ungarn sowie die Mongolische Volksrepublik)

Z: Rotchina, Nordkorea, Nordvietnam, Kuba

S: Rhodesien (diese Ländergruppe besteht seit dem $14.11 .1966)$

$1 \mathrm{Vgl}$. Selling the Soviet Market, a.a.O., S. 36; BERMAN und GARSON, United States Export Controls, a.a.O., S. 815. - Das OEC wird in seiner Arbeit von drei interministeriellen Organen beraten; diese sind das "Operation Committee", die "Policy Planning Division" und das "Advisory Committee on Export Policy". Personell setzen sich diese Komitees zusammen aus Vertretern des Außen-, Handels-, Verteidigungs- und Schatzministeriums.

Vgl. BERMAN und GARSON, ebd., S. 806.

${ }^{2} \mathrm{Vgl}$. Selling the Soviet Market, a.a.O., S. 36. Die USA kennen sehr strenge Strafbestimmungen im Fall eines Verstoßes gegen die Ausfuhrkontrollbestimmungen. Im einzelnen sei hierzu verwiesen auf BERMAN und GARSON, ebd., S. $798 \mathrm{f}$.

${ }^{3} \mathrm{Vgl}$. BERMAN und GARSON, United States Export Controls, a.a.O., S. 820 f.

4 Der Hauptunterschied zu der von 1957 bis 1965 angewandten Ländergruppierung besteht darin, daß Polen und Rumänien als gesonderte Lándergruppe behandelt werden.

Vgl. BERMAN und GARSON, ebd., S. $820 \mathrm{f}$. 
Da sich die vorliegende Untersuchung auf die Staatshandelsländer Südosteuropas beschränkt, sind für die weiteren Betrachtungen die Ländergruppen $W$ und $Y$ relevant.

Innerhalb der Gruppe $Y$ wird vom $O E C$ eine inoffizielle Untergruppierung in der Weise vorgenommen, daß z. B. die Ausfuhrgenehmigungspraxis gegenüber Ungarn liberaler gehandhabt wird als z.B. gegenüber Albanien, bzw. gegenüber Bulgarien liberaler als gegenüber der DDR. ' Rumänien genießt seit dem Jahre 1964, als die Auseinandersetzungen mit der Sowjetunion und dem RGW offen zutage zu treten begannen, einen ähnlichen Status wie Polen seit 1957. Im Vergleich zur Ländergruppe Y (Bulgarien und Ungarn) ergeben sich hieraus insofern Vorteile, als die Praxis der Ausfuhrkontrollen liberaler gehandhabt wird. ${ }^{2}$ Das bedeutet, daß eine Ware, deren Export z. B. nach Ungarn nicht genehmigt werden würde, möglicherweise nach Rumänien ausgeführt werden kann. Dies ist jedoch abhängig von der fallweisen Entscheidung des OEC und ist nicht formal geregelt. Diese liberalere Politik gegenüber Rumänien ist möglich, weil es sich bereit erklärt hat, von den USA für bestimmte Exportgüter auferlegte Wiederausfuhrverbote zu beachten.

Im Oktober 1966 wurde eine Erleichterung der Ausfuhr in kommunistische Länder durchgeführt. Rund 400 nicht strategische Güter, für deren Ausfuhr bisher Einzellizenzen erforderlich waren, können nunmehr mit einer allgemeinen Ausfuhrgenehmigung exportiert werden. $1800 \mathrm{~W}$ arenpositionen bleiben aber dem strengen Ausfuhrverfahren unterworfen.

Eine weitere Ausfuhrerleichterung wurde im Mai 1968 wirksam. Hie rbei handelte es sich vornehmlich um eine ergänzende Aufhebung von Einzellizenzen sowie eine Beschleunigung des Lizenzierungsverfahrens für Musterlieferungen im Werte bis 200 . US- $\$ .^{3}$

Da die meisten der von diesen beiden Ausfuhrerleichterungen betroffenen Güter bisher auch schon ausgeführt werden konnten - ihr Export war eben von der Erteilung einer Einzellizenz abhängig, die für diese Waren üblicherweise gewährt wurde - bedeuten diese Maßnahmen gegenüber der Ländergruppe $Y$ (ausgenommen die DDR) praktisch nur eine Verwaltungsvereinfachung. Von einer tatsächlichen Erweiterung der Ausfuhrmöglichkeiten kann man nur in beschränktem Maß sprechen. Auf Grund dieser Änderung des Lizenzierungsverfahrens ist zum Teil die Sonderstellung Rumăniens (und auch Polens) wieder weggefallen."

I Vgl. BERMANN und GARSON, United States Export Controls, a.a. O., S. 823.

2 Vgl. "Export Control", 68th Quarterly Report 20, Washington D.C. 1964;

"Department of State Bulletin", No. 924, Washington D. C. 1964.

3 Vgl. "The New York Times" v. 12.5.1968; "Neue Zürcher Zeitung" v. 27.10. 1966.

"Vgl. "The New York Times" v. 8.10.1966; "Wall Street Journal", New York v. 14.10.1966. 
Versucht man, die gegenüber den Staatshandelsländern Südosteuropas geltenden Restriktionen im Zusammenhang mit den Ausfuhrkontrollen gegenüber anderen Ländern bzw. Ländergruppen zu sehen, so läßt sich feststellen, daß für Ausfuhren nach Bulgarien, Rumänien und Ungarn die Bestimmungen gegenüber Ländergruppe $T$ und $V$ als Minimalbeschränkungen anzusehen sind. Entsprechend repräsentieren die gegenüber den Ländern der Gruppe $Z$ bestehenden Restriktionen, denen zufolge Ausfuhren in diese Länder in allen Fällen von Einzelgenehmigungen (die praktisch nicht erteilt werden ') abhängen, die Maximalbestimmungen für die südosteuropäischen Staatshandelsländer. Die Ausfuhrbestimmungen gegenüber den Gruppen W und $Y$ liegen somit $z w i s c h e n$ den Minimal- und Maximalbestimmungen. Verschiedene Waren, die gewöhnlich Einzellizenzen für Exporte nach Ländern der Gruppe $Y$ bedürfen, können mit allgemeinen Ausfuhrgenehmigungen nach Ländern der Gruppe W (also Rumänien) ${ }^{2}$ ausgeführt werden und schließlich werden bestimmte Länder der Gruppe $Y$ bevorzugt vor anderen Ländern dieser Gruppe. Im Hinblick auf die noch nicht verabschiedete "East-West Trade Relations Act", die einen Rahmen schaffen könnte für die wechselseitige Förderung eines sowohl für die USA als auch die kommunistischen Länder vorteilhaften Handels, ist $z u$ vermuten, daß die USA eines Tages von diesem System der streng negativen Ausfuhrkontrollen abgehen könnten. Obgleich das vorgelegte Gesetz die bestehende Struktur der amerikanischen Exportkontrollen nicht antastet, bieten doch die angestrebten bilateralen Handelsabkommen Gelegenheit, diese Restriktionen durch die Einführung eines Systems der positiven Kontrollen so $z u$ modifizieren, daß sie in der Lage sein könnten, den Handel zu fördern anstatt $\mathrm{zu}$ behindern. ${ }^{3}$

Im Rahmen dieser Arbeit wird nicht näher auf die Vielzahl der Bestimmungen ${ }^{4}$ und Besonderheiten eingegangen, die die amerikanischen Agrar-

I Vgl. Harold J. BERMAN, John R. GARSON, Possible Effects of the Proposed East-West Trade Relations Act, a.a.O., S. 289.

$2 \mathrm{Zu}$ diesem Ergebnis kommen BERMAN und GARSON. Dies kann von mir jedoch nicht bestätigt werden, da offensichtlich die seitens der USA im Anschluß an die amerikanisch-rumănischen Handelsgesprăche vom Jahre 1964 angekündigten Exporterleichterungen gegenüber Rumänien bisher nur insoweit zum Tragen kamen, als die Genehmigung von speziellen Lizenzen seither liberaler gehandhabt wird als gegenüber der Ländergruppe $Y$. Meines Wissens hat dies bislang noch nicht dazu geführt, daß gegenüber Rumănien eine teilweise Aufhebung der Einzellizenzen zugunsten des allgemeinen Genehmigungsverfahrens erfolgt wăre.

Vgl. auch"Die Zeit", Hamburg v. 22.5.1964.

$3 \mathrm{Vgl}$. BERMAN und GARSON, Possible Effects of the Proposed East-West Trade Relations Act, a. a.O., S. 287.

$4 \mathrm{Zu}$ denken ist vor allem an die "Agricultural Trade Development and Assistance Act", die "Food for Peace Act", die "Agricultural Appropriations Act", die "Agricultural Act" und das "Findley-Amendment". 
ausfuhren regeln.' Die sich für Agrarausfuhren nach Bulgarien, Rumänien und Ungarn ergebenden Konsequenzen lassen sich dahingehend zusammenfassen, daß Exporte landwirtschaftlicher Überschußgüter gegen nationale Währung oder Kredit nicht zulässig sind. Sofern diese Ausfuhren jedoch gegen Barzahlung in US-Dollar erfolgen, sind sie grundsătzlich - sieht man von Knappheitsbeschränkungen ab - möglich. ${ }^{2}$ Im Zusammenhang mit den amerikanischen Ausfuhrbeschränkungen gegenüber den Staatshandelsländern Südosteuropas wären auch Transportbeschränkungen zu erwähnen. Da jedoch im allgemeinen autorisierte Exporte (dies gilt auch für Importe) ohne Einschränkung sowohl in amerikanischen als auch ausländischen Schiffen transportiert werden dürfen, soll auf die gesetzlichen Sonderbestimmungen nicht eingegangen werden. Ausnahmebestimmungen betreffen vor allem die Ausfuhr landwirtschaftlicher Überschußgüter (unter dem "Public Law 480"), Lieferungen strategischer Güter sowie Waren der "Atomic Energy List". 3

a42) Die exterritoriale Anwendung der amerikanischen Ausfuhrkontrollen

Amerikanische Firmen, die ihren Sitz im Ausland haben, ausländische Tochterfirmen amerikanischer Stammhăuser sowie amerikanische Beteiligungsfirmen (auf die der amerikanische Partner "entscheidenden" Einfluß hat) unterliegen amerikanischen Ausfuhrbeschränkungen im Hinblick a uf den Reexport amerikanischer Waren und die Ausfuhr von strategischen Waren, soweit sie mit Hilfe amerikanischen "know hows" erstellt wurden.

Werden von den genannten Firmen nicht strategische Waren in europăische Ostblockländer ausgeführt, so kommen keine Beschränkungen zur Anwendung, vorausgesetzt, es wird dafür Sorge getragen, daß die betreffenden Waren nicht in die "Total" - Embargoländer (Rotchina, Nordkorea, Nordvietnam und Kuba) reexportiert werden.

Im Hinblick auf die Staatshandelsländer Südosteuropas ergeben sich die wichtigsten gesetzlichen Bestimmungen aus den "Transaction Control Re-

'Verwiesen sei auf "The Battle Act Report of 1967'; Russel BAKER, Legal Aspects of East-West Trade, a.a.O.; "Neue Zürcher Zeitung" v. 10.3.1967; "Washington Post" v. 9.12.1966; "Frankfurter Allgemeine Zeitung" v. 24. 12.1965 und v. 3.1.1967; "The New York Times" v. 31.12.1966 und v. 25.2. 1967.

2 Diese Beschräkung der Agrarausfuhren haben vor allem den Zweck, die Rückkehr dieser Güter auf den Weltmarkt und damit dessen Störung zu verhindern.

$3 \mathrm{Vgl}$. Selling the Soviet Market, a.a.O., S. $39 \mathrm{f}$;

"The Battle Act Report of 1967', S. $56 \mathrm{f}$. 
gulations" des Jahres 1953.' Demnach unterliegt der Handel der betroffenen Firmen mit Waren, die in der internationalen Exportkontrolliste verzeichnet sind, der Lizenzierungspflicht durch das amerikanische Schatzministerium.

Da die Warenliste der "Transaction Control Regulations" weitgehend der COCOM-Liste I entspricht, treffen diese amerikanischen Firmen in den NATO-Lăndern (Ausnahme Island) und in Japan im allgemeinen keine gröBeren Ausfuhrrestriktionen als die Firmen der betreffenden Lănder. In der Genehmigung des Exports einer ausfuhrpflichtigen Ware durch die lokalen Behörden (entsprechend nationalen und internationalen Ausfuhrbeschränkungsgrundsätzen) ist lediglich ein Antrag auf Erteilung einer amerikanischen Lizenz bei der "Foreign Assets Control"-Abteilung des amerikanischen Schatzministeriums zu stellen. Wenn die lokalen Behörden ihre Genehmigung erteilen, wird sie gewöhnlich auch vom Schatzministerium gegeben.

Die Gegenüberstellung der Ostausfuhrpolitik der USA und westeuropäischer Länder ist unmittelbar mit der Frage verbunden, inwieweit die USA auf die Ausfuhrpolitik der westeuropäischen Länder einwirken. Die enge Verbundenheit der Osthandelspolitik mit der Außenpolitik kommt natürlich im Bereich der Ausfuhrpolitik besonders zur Geltung, und eine Beeinflussung der westeuropăischen Exportpolitik gegenüber den kommunistischen Ländern ist vorwiegend politisch motiviert. Folgende Möglichkeiten der Einflußnahme kommen in erster Linie in Betracht:

\section{Konsequente Anwendung der "Battle Act",}

2. Restriktionen gegenüber westeuropäischen Firmen mit entscheidungsbestimmender amerikanischer Beteiligung.

3. Beschränkungen des Reexportes westeuropäischer Firmen, soweit zur Herstellung der jeweiligen Exportgüter amerikanische Vorprodukte oder "know how" Verwendung fand, und diese der amerikanischen Ausfuhrkontrolle gegenüber kommunistischen Ländern unterliegen,

4. politischer Druck seitens der USA.

1 Daneben sind noch eine Reihe weiterer gesetzlicher Bestimmungen wirksam, welche seit dem Korea-Krieg angewendet werden und auf der "Trading with the Enemy Act" von 1917 basieren. - Zu denken ist vor allem an die "Foreign Assets Control Regulations" und die "Cuban Assets Control Regulations", welche vor allem Wăhrungsbeschränkungen gegenüber den "Total"-EmbargoLändern regeln. Direkte Konsequenzen für die südosteuropäischen Staatshandelsländer ergeben sich hieraus jedoch nicht.

Vgl. Russel BAKER, Legal Aspects of East-West Trade, a.a.O.; ders. und Robert BOHLIG, The Control of Exports, a.a.O., S. 187; BERMAN und GARSON, United States Export Controls, a.a.O., S. 867; Selling the Soviet Market, a.a.O., S. $37 \mathrm{f}$. 
Auf die Möglichkeiten (1) und (2) wurde schon eingegangen. Bei (3) ist festzustellen, daß strategische Güter nur dann nach Westeuropa verkauft werden, wenn der westeuropaische Importeur sich vertraglich verpflichtet, diese Güter nur unter Beachtung der amerikanischen Ausfuhrrestriktionen in kommunistische Länder weiterzuverkaufen. ' Ähnliches gilt für Exportgüter, zu deren Herstellung in Westeuropa amerikanische Lizenzen oder Patente benötigt werden. Obgleich unveröffentlichte technische Daten einige mit strategischer Bedeutung ausgenommen - auf Grund allgemeiner Ausfuhrgenehmigungen in nichtkommunistische Länder verkauft werden dürfen, bedeutet dies nicht, daß die ausländischen (d.h. hier westeuropăischen) Importeure oder Lizenznehmer die damit erstellten Erzeugnisse auch wieder frei ausführen können. ${ }^{2}$ Praktische Bedeutung erhalten diese Beschränkungen nur, wenn es sich um Güter handelt, die nicht auf der internationalen Kontrolliste stehen und damit keinen westeuropäischen Ausfuhrbeschränkungen gegenüber kommunistischen Länderin unterliegen, wohl aber amerikanische Ausfuhrgenehmigungen erfordern würden. ADLER-KARLSSON vertritt die Meinung, daß westeuropäische Geschäftskreise diese amerikanischen Sekundärrestriktionen nicht selten als ein Mittel ansehen, die westeuropăische Aktivität und Konkurrenz auf den osteuropăischen Märkten zu beschränken. Dies gilt ganz besonders für die Beeinflussung der westeuropäischen Ausfuhrpolitik mit a ußenpolitischen Mitteln oder durch Versuche, entsprechende ad hoc-Änderungen der internationalen Exportkontrolliste durchzusetzen. ${ }^{3}$ Auf die Möglichkeit der politischen Beeinflussung wird im Rahmen dieser Arbeit nicht eingegangen. 4

\section{a5) Zusammenfassung}

Die Ausfuhrbeschränkungen der hier im Mittelpunkt stehenden westlichen Länder zeigen, daß mit unterschiedlichen Techniken offensichtlich gleiche Effekte zu erzielen sind. Vereinfacht lassen sich im Hinblick auf die zu exportierenden Güter folgende zwei Kontrollvarianten unterscheiden:

1. Alle Güter unterliegen einer Ausfuhrgenehmigung, 5 jedoch wird eine solche, im Gegensatz zu strategischen Gütern, mehr oder weniger formlos und generell erteilt, oder

2. es werden nur strategische Güter ausfuhrbeschränkt. ${ }^{6}$

1 Dies gilt auch für Bestandteile eines Erzeugnisses, vgl. Gunnar ADLERKARLSSON, Western Economic Warfare 1947-1967, a.a.O., S. 135. 2 Vgl. Selling the Soviet Market, a.a.O., S. 37.

${ }^{3} \mathrm{Vgl}$. Gunnar ADLER-KARLSSON, Western Economic Warfare 1947 - 1967, a.a.O., S: $135 \mathrm{f}$.

4 Vgl. dies., ebd.

s Die generelle Genehmigungspflicht erfüllt zumeist den Zweck, die statistische Ausfuhrmeldung zu sichern.

6 In diesem Fall ist vom Exporteur selbst eine statistische Ausfuhrmeldung einzureichen. - In dieser sehr vereinfachten Katalogisierung bleiben knappheitsbedingte Ausfuhrbeschränkungen etc. unberücksichtigt. 
Was die regionale Ausfuhrkontrolle anbelangt, so finden ebenfalls zwei Varianten Anwendung:

1. Entweder sind Exporte in alle Länder genehmigungsbedürftig, in NichtOstblockländer jedoch im allgemeinen erlaubt, oder

2. es unterliegen nur strategische Ausfuhren in Ostblockländer Ausfuhrbeschränkungen.

Besonderes Augenmerk richten die westlichen Ausfuhrkontrollbehorden auf den Osthandel über Drittländer. Demgemäß kommt dem internationalen IC-DV-System recht große Bedeutung zu. Bei Ausfuhren strategischer Güter in Nicht-Ostblockländer, die dieses System nicht anerkennen, machen die meisten westlichen Länder die Genehmigung von entsprechenden Nachweisen über den Endverbleib der Waren abhängig. Ein ganz besonderes Problem stellt dieser Handel über dritte Länder für die USA dar, da die zahlreichen ausländischen Niederlassungen und Beteiligungen den sogenannten "black-door trade" begünstigen.

In der Praxis der Ausfuhrbeschränkungen der westeuropăischen Länder werden nur die Güter der internationalen Kontrolliste von einer generellen Ausfuhrgenehmigungspflicht erfaßt. Alle anderen Waren industriellgewerblicher Art, aber auch Rohstoffe und Agrargüter, können von einigen wenigen Ausnahmen abgesehen frei in die südosteuropäischen Staatshandelsländer exportiert werden. Eine ausfuhrpolitische Diskriminierung dieser Länder durch ihre westeuropäischen Handelspartner ergibt sich aber insofern, als Ausfuhrgenehmigungen für strategische Güter der internationalen Liste nach Bulgarien, Rumänien und Ungarn nicht erteilt werden.

Diese Benachteiligung hat in Wirklichkeit jedoch nur geringen Einfluß auf die Einfuhrstruktur der südosteuropäischen Staatshandel sländer. Soweit diese Länder an einer wirtschaftlichen und nicht militärischen Stärkung und Modernisierung interessiert sind, erwachsen aus den westeuropăischen Ausfuhrkontrollen - von bürokratischen Hindernissen abgesehen kaum nennenswerte Hemmnisse. Eine ausfuhrpolitische Behinderung bzw. Diskriminierung des Ostexports von Waren der internationalen Liste ohne strategisch-militärische Bedeutung wirkt sich nur insoweit aus, als vom westlichen Exporteur eine Ausfuhrgenehmigung eingeholt werden muß. Diese wird, insbesondere für die südosteuropăischen Staatshandelsländer, zumeist erteilt.

Eine gemeinschaftliche Ausfuhrpolitik der EWG gegenüber Drittlándern im allgemeinen und Staatshandelsländern im besonderen ist noch nicht einmal im Ansatz vorhanden. Entsprechend ergeben sich daher bislang keine Konsequenzen für die nationale Ausfuhrpolitik der EWG-Mitgliedsländer gegenüber den Staatshandelsländern Südosteuropas. 
Was die USA anbelangt, so sind alle Waren, die geeignet sind, einen wesentlichen Beitrag sowohl zur militärischen als auch zur wirtschaftlichen Stärkung des Ostblocks zu leisten, von der Ausfuhr in die kommunistischen Länder ausgenommen. Die Mehrzahl der nichtstrategischen Waren erfordert beim Export nach Bulgarien, Rumänien und Ungarn die Ausstellung von Einzellizenzen. Davon ausgenommen sind die Waren der GLSA-Liste sowie die in den Jahren 1966 und 1968 freigegebenen Güterarten. Einzellizenzen an Staatshandelsländer werden immer dann nicht erteilt, wenn die betreffenden Güter einen wesentlichen Beitrag zur wirtschaftlichen Stärkung des Ostblocks leisten könnten. Hervorzuheben ist jedoch, daß dies entsprechend der jeweiligen außenpolitischen Situation unterschiedlich ausgelegt und damit eine Differenzierung der Ausfuhrkontrolle erreicht werden kann. Agrarlieferungen können, soweit sie gegen Barzahlung in US- $\$$ erfolgen, an alle kommunistischen Länder Südosteuropas unbeschränkt vorgenommen werden.

Die Staatshandelsländer Südosteuropas sehen sich damit heute noch recht umfangreichen ausfuhrpolitischen Beschränkungen durch die Vereinigten Staaten von Amerika gegenüber. Diese gehen weit über Umfang und $A b-$ sicht der westeuropäischen Beschränkungen hinaus und können bei entsprechend enger Auslegung praktisch sämtliche industriellen Ausfuhren in die genannten Länder unterbinden.

Während die westeuropäischen Länder seit Mitte der fünfziger Jahre ständig bemüht sind, den internationalen - und damit, sieht man von unbedeutenden Ausnahmen ab, ihren eigenen - Ausfuhrkontrollrahmen zu verkleinern und die Exportrestriktionen gegenüber den kommunistischen Ländern abzubauen, haben die USA ihr eigenes Ausfuhrkontrollsystem, für das die internationalen Kontrollen lediglich die Minimalerfordernisse erfüllen, kaum korrigiert. Entscheidend ist auch, daß die Vereinigten Staaten diese Kontrollen auf den Gesichtspunkt der "wirtschaftlichen" Bedeutung der Ausfuhren ausdehnen und sie nicht auf den der "militärischen" beschränken. Da die südosteuropäischen Staatshandelsländer aber besonders an neuester Technologie interessiert sind, wird die Mehrzahl derjenigen Waren von den Beschränkungen erfaßt, die am dringendsten benötigt werden und im Ostblock nicht $z u$ erhalten sind.

Ein weiterer Gesichtspunkt, der bisher nicht beachtet wurde und sowohl für Westeuropa, ganz besonders jedoch für die USA von Wichtigkeit ist, ergibt sich aus der Instabilität der Ausfuhrbestimmungen. Westliche Exporteure werden nicht nur von den administrativen und bürokratischen Schwierigkeiten, die mit der Ausfuhr in kommunistische Länder verbunden sind, abgehalten, sondern sie zögern auch, in den sozialistischen

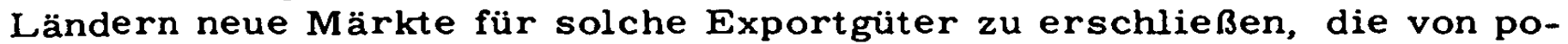
tentiellen Ausfuhrkontrollverschärfungen betroffen sein könnten. I Wenn

$1 \mathrm{Vgl}$. Trade Problems between Countries Having Different, a.a. O., S. 133 f. 
die westliche Exportpolitik von den kommunistischen Ländern hăufig als entscheidendes Hindernis für eine vorteilhafte gegenseitige Handelsexpansion angesehen wird, so ist dies heute vor allem auf die USA zu beziehen.'

b) Die Ausfuhrkreditpolitik

\section{b1) Die Berner Union}

Um eine Úbersteigerung der Ausfuhrkreditgewährung ${ }^{2}$ aus Konkurrenzgründen zu vermeiden, trafen die Exportkreditversicherer zahlreicher Industriestaaten - darunter die USA und die westeuropäischen Industrieländer - eine gemeinsame Gegenmaßnahme auf internationaler Ebene. Im Jahre 1934, drei Jahre nach der Weltwirtschaftskrise, wurde die "Union d'Assureurs des Crédits Internationaux" in Bern gegründet. ${ }^{3}$

Diese sogenannte "Berner Union" ist ein Verein nach Schweizer Recht und stellt einen Zusammenschluß von 25 staatlichen und privaten Kreditversicherungsinstitutionen aus 20 Ländern dar. Ein kleines Sekretariat wird ständig in Paris unterhalten.

Hauptaufgabe der "Berner Union" ist es, für eine vernünftige Verwendung von Kreditversicherungen im internationalen Geschäft $z u$ sorgen, insbesondere aber, Versicherungsbedingungen und Zahlungsziele aufeinander abzustimmen. 4 Sie kann jedoch nur Empfehlungen, nicht aber verpflichtende Richtlinien erteilen, wie die Kreditfristen und - bedingungen in vernünftigen Grenzen gehalten werden können. ${ }^{5} \mathrm{Da}$ gewöhnlich die Maximallaufzeit des Versicherungsschutzes die Dauer der Zahlungsfrist bestimmt, die der Exporteur seinem Abnehmer einrăumen kann, wurde die Laufzeit der staatlich abgesicherten Kredite, für (1) schwere Investitionsgüter auf funf Jahre, für (2) Verbrauchsgüter auf sechs Monate und für (3) langlebige Verbrauchsgüter und leichte Investitionsgüter auf eine nur wenig längere Zeitspanne beschränkt. Über die Selbstbeteiligungsquoten wurden keine allgemeinen Grundsătze erlassen. ${ }^{\circ}$

' Vgl. N.L. LYUBIMOV, Soviet Foreign Trade Problems, "International Affairs", No. 8, Moscow 1965, S. 12 ff.; Trade Problems between Countries Having Different, a.a.O., S. 134.

2 Zur allgemeinen Problematik der Ausfuhrfinanzierung sei verwiesen auf: Claudio SEGRE, Die mittelfristige Exportfinanzierung, hrsg. von der Kreditanstalt für Wiederaufbau, Frankfurt/M. 1959. SEGRE gibt auch eine hervorragende Übersicht über die mittelfristigen Exportkredit-Versicherungssysteme Großbritanniens, Frankreichs und Deutschlands.

${ }^{3}$ Vgl. F. UNGER, A ußenhandelsfinanzierung, Frankfurt/M. 1963, S. 98.

- Vgl. Staatliche Exportkreditfinanzierung in Großbritannien, USA und der Bundesrepublik, "Wirtschaftsdienst", H. 5, Hamburg Mai 1960, S. 256.

$5 \mathrm{Vgl}$. "Die Welt", Hamburg v. 29.8.1964.

6 Vgl. Staatliche Exportkreditfinanzierung. a.a. O., S. 256. 
Die Empfehlungen der "Berner Union" enthalten keine Diskriminierung des Ostblocks, vielmehr sollen sie einen fairen Wettbewerb zwischen den Exporteuren der Industrieländer sicherstellen. Im Zusammenhang mit langfristigen, über die kommerziellen Erfordernisse hinausgehenden Exportkrediten an Entwicklungsländer wurden die Empfehlungen wiederholt verletzt. Man rechtfertigte dies zumeist mit der wirtschaftlichen Sonderstellung der Entwicklungsländer und der diesen Ländern zu gewăhrenden Hilfe. Einige Staaten folgerten hieraus, daß die Empfehlungen zur Limitierung der Exportkreditversicherungsfristen nach der "Berner Union" tuberholt seien und der verlängerte Versicherungsschutz allgemein angewendet werden könne, auch gegenüber den Ostblockländern.

Speziell im Zusammenhang mit der Kreditgewährung an Ostblockländer ging es in der westlichen Diskussion primär darum, ob Kredite aus politischen Gründen überhaupt gewährt werden sollten. Die Limitierung von Zahlungsfristen war eine Sekundärfrage und stand anfänglich überhaupt nicht zur Diskussion. Eines der politischen Hauptargumente war, daß "... die westliche Wirtschaftspolitik, zu deren Instrumentarium die Handelskredite zăhlen, nichts tun soll, was den wirtschaftlichen Aufschwung des Ostblocks besonders fördern würde." 1

Eine Bedeutung kommt der Frage der westlichen Kreditgewährung an die Ostblockländer eigentlich erst seit wenigen Jahren zu und ist vorwiegend auf die enorme Zunahme der Lieferungen langlebiger Erzeugnisse der Investitionsgüterindustrie einschließlich kompletter Industrieanlagen zurückzuführen.

Mit ihrem Verhandlungsgeschick und der starken Verhandlungsposition haben es die staatlichen Außenhandelsgesellschaften der Staatshandelsländer (Außenhandelsmonopol) ausgezeichnet verstanden, die Ausfuhrkreditgewährung als ausfuhrwirksames Wettbewerbsmittel auszunützen und von den westlichen Unternehmen weitgehende Kreditkonzessionen zu erreichen. Gerade hierin liegt eines der wirtschaftlichen Hauptargumente gegen Exportkredite an Ostblockländer. Dagegen ist gegen die Gewăhrung von branchen- und handelsüblichen Krediten auch innerhalb des Ostblockgeschäts nichts einzuwenden.

Eine Reihe von Versuchen, die meist auf amerikanische und deutsche Initiativen zurückgingen, innerhalb der NATO oder der EWG zu einheitlichen Normen in der Exportkreditgewährung gegenüber den Staatshandelsländern zu kommen, sind bisher fehlgeschlagen. Diese Initiativen betrafen jedoch nur solche Kredite, die über die Richtlinien der "Berner Union" hinausgingen.

I Klaus-Heinrich STANDKE, a.a.O., S. 76. 
Heute geht es bei der Diskussion um Ostkredite nicht mehr um die Frage, ob solche überhaupt gewährt werden sollen, sondern vielmehr darum, ob eine auf Grund der Verhandlungsposition des kommunistischen Außenhandelsmonopols durchgesetzte unwirtschaftliche Kreditfrist eines westlichen Exporteurs im Wettbewerb mit einem anderen Exporteur zu vertreten ist. Mit anderen Worten: Es geht um Maßnahmen, den westlichen Kreditwettlauf, den "Export um jeden Preis", einzudämmen.

\section{b2) Die Ausfuhrkreditpolitik der EWG-Mitgliedstaaten}

Wie im Fall der Ausfuhrpolitik ergibt sich bislang keine Einschränkung der nationalen Ausfuhrkreditpolitik der EWG-Mitgliedstaaten durch eine gemeinsame EWG-Handelspolitik. Zwar wurde eine Vergemeinschaftung der Ausfuhrkreditpolitik von verschiedenen Mitgliedsländern hăufig gefordert, doch konnten bis heute keine wesentlichen Fortschritte in dieser Richtung erzielt werden.

Der Ministerrat beschaftigte sich im Herbst $1964 \mathrm{mit}$ dem Problem und war bemüht, eine Abstimmung und Angleichung der Laufzeiten staatlich verbürgter Lieferantenkredite durchzusetzen. Er mußte sich jedoch mit einem Hinweis auf das im Mai 1962 vereinbarte Konsultationsverfahren begnügen.' Einem Beschluß des Ministerrats zufolge sind nämlich die EWG-Partner seit 1962 zur gegenseitigen Konsultation verpflichtet, sofern sie einen Exportkredit verbürgen wollen, der in Abweichung von den Regeln der "Berner Union" eine über fünf Jahre hinausgehende Laufzeit hat. ${ }^{2}$ Das Konsultationsverfahren wurde ab dem 1.9.1967 dahingehend abgeändert, daß die bisherige Beschrănkung der Konsultationserforderlichkeit auf Staatshandelsländer wegfällt, nachdem sich Italien und Frankreich wiederholt gegen eine derartige Diskriminierung der Staatshandelsländer gewandt hatten. ${ }^{3}$

Eine Übereinkunft hinsichtlich einer Begrenzung der von den einzelnen EWG-Mitgliedstaaten den Staatshandelsländern zur Verfügung gestellten Kreditvolumina ist bisher nicht erwogen worden, "obwohl das Ausmaß der vom Ostblock eingegangenen Verschuldung und die ungeachtet des geringen Delkredere-Risikos daraus resultierende Gefahr handelspolitischer Erpressungen die gemeinsame Handelspolitik der EWG nachhaltig beeinflussen kann." 4

' Vgl. Rolf SANNWALD, Die Europăische Wirtschaftsgemeinschaft und der Osthandel, a.a.O., S. 126; Joachim WILLMANN, Grundsatzfragen des Ost-WestHandels, a.a.O., S. 21; Carl A. EHRHARDT, a.a.O., S. $398 \mathrm{f}$.

${ }^{2} \mathrm{Vgl}$. Bericht im Namen des Außenhandelsausschusses des Europáischen Parlaments über Fragen der gemeinsamen Handelspolitik, a.a. O., S. 15.

${ }^{3} \mathrm{Vgl}$. "Süddeutsche Zeitung", München v. 25.7.1967.

- Bericht im Namen des A ußenhandelsausschusses des Europaischen Parlaments über Fragen der gemeinsamen Handelspolitik, a.a.O., S. 16. 
Seit der Vorlage des im Namen des Außenhandelsausschusses des Europäischen Parlaments erstellten Berichts über Fragen der gemeinsamen Handelspolitik der Gemeinschaft gegenüber Staatshandelsländern konnte sich der Ministerrat auf Vorschlag des "Arbeitskreises für die Koordinierung der Kreditversicherung, der Bürgschaften und Finanzkredite" I lediglich über gemeinsame Maßnahmen zur Verbesserung der Zusammenarbeit $\mathrm{zw}$ ischen Unternehmen der Mitgliedstaaten auf den Auslandsmärkten einigen.

Ungeachtet der bescheidenen Fortschritte in der Vergemeinschaftung der Ausfuhrkreditpolitik erklärte der Ministerrat in seiner Entschließung vom 11.5.1966 über die gleichgewichtige Entwicklung der Gemeinschaft, "... daß er im Bereich der Handelspolitik vorrangig die Praxis der Mitgliedsländer auf dem Gebiet der Ausfuhrkredite gegenüber den Staatshandelsländern und Ostdeutschland prüfen wolle." 2 Bisher allerdings hat der Rat diese Absichtserklärung kaum in die Praxis umgesetzt und die EWG-Partner können gegenüber Ost- und Südosteuropa noch immer eine weitgehend autonome Ausfuhrkreditpolitik realisieren.

\section{Die Bundesrepublik Deutschland}

Trotz der weitgehenden Liberalisierung des deutschen Außenhandels nach der Ablossung der Bestimmungen der Militärregierung durch das Außenwirtschaftsgesetz ${ }^{3}$ hielt die Bundesregierung an den von der Militärregierung gesetzten Prinzipien fest, Exportkredite an kommunistische Länder nicht zu gestatten. 'Die deutschen Exporteure konnten somit nur gegen Dokumentenkassi oder im Westen zahlbare unwiderrufliche Akkreditive an den Ostblock verkaufen. ${ }^{5} \mathrm{Da}$ jedoch Kapitaltransaktionen zwischen der Bundesrepublik und anderen Ländern - einschließlich kommunistischer - keinerlei Beschrănkungen unterlagen, wurden Finanzkredite von diesem Verbot nicht erfaßt. Somit war es also jedem deutschen Geldinstitut und jedem Deviseninländer möglich, den ostlichen Handelspartnern Finanzkredite zur Verfügung zu stellen. ${ }^{\circ}$

1 Vgl. Neunter Gesamtbericht über die Tätigkeit der Europäischen Wirtschaftsgemeinschaft (1..April 1965 - 31. März 1966), Brüssel, Juni 1966, Ziff. 300.

2 Arbeitsdokument des Ausschusses für Außenwirtschaftsbeziehungen des Europăischen Parlaments über die Probleme der Handelsbeziehungen zwischen der Gemeinschaft und den Staatshandelsländern Osteuropas, Berichterstatter: Karl Hahn, PE 18438,30 , 10.1967, S. 25.

3 Vgl. S. 94.

4 Vgl. Ernst LEDERER, Kreditprobleme im Verkehr mit dem Südosten, in: Südosteuropa-Jahrbuch, Bd. 4, hrsg. von Rudolf Vogel, München 1960, S. 71 f. $5 \mathrm{Vgl}$. ebd.

- Vgl. H. von WALLENBERG-PACHALY, Policy and Practice of the Federal Republic of Germany, in: East-West Trade, An Analysis of Trade between Western Nations and the Soviet Bloc, American Management Association, New York 1964, S. 34. 
Das Außenwirtschaftsgesetz verbot lediglich Lieferantenkredite, nicht aber Finanzkredite. Deutsche Banken konnten dennoch nicht helfend einspringen, da sie entweder aus gesetzlichen Gründen dazu nicht in der Lage waren (Hypothekenbanken, Sparkassen und Girozentralen) oder nicht über genügend langfristige Mittel verfügten. Außerdem bestand keine Möglichkeit, diese Kredite durch staatliche Bürgschaften der Hermes-Kredit-Versicherungs-AG abzusichern. Die "Hermes" übernahm zwar die Versicherung des Produktionsprozesses, ' deckte damit aber nur solche Ostblockausfuhrgeschäfte, bei denen Lieferung gegen Kasse erfolgte. ${ }^{2}$ Infolge der Entwicklung in den anderen westeuropäischen Staaten und nicht zuletzt auf Grund des vorübergehenden Rückgangs des Osthandelsvolumens im Jahr $1962 / 63$ sah sich die Bundesrepublik jedoch seit 1964 gezwungen, ihre Ostkreditpolitik $\mathrm{zu}$ revidieren. Sie entschloß sich, Kreditfristen im Rahmen der Fünfjahresgrenze der "Berner Union" für Ostblockländer mit Ausnahme der Sowjetunion und der Tschechoslowakei zuzulassen und auch staatlich $z u$ verbürgen. ${ }^{3}$ Bald darauf ging man noch einen Schritt weiter und genehmigte Kreditlaufzeiten bis zu fünf Jahren auch für diese zwei Ostblockländer. Gleichzeitig aber betonte die Bundesregierung, Bundesbürgschaften für Ausfuhrkredite auch weiterhin nur gegenüber Polen und den südosteuropäischen Staatshandelsländern zu leisten. ${ }^{4}$ Für Geschäfte mit der Sowjetunion und der Tschechoslowakei bestand somit bei der AusfuhrKredit-AG weiter keine Refinanzierungsmöglichkeit, da diese die Abdekkung der politischen und kommerziellen Risiken durch die "Hermes" voraussetzt. Lediglich kurzfristige Exportfinanzierungen bis $z$ u zwei Jahren uber die Hausbank des Exporteurs wurden von der Ausfuhr-Kredit-AG ohne "Hermes"-Bürgschaft refinanziert. 5

Im März 1965 hat sich die Bundesregierung endlich zu einer einheitlichen und neuen Konzeption ihrer Ostkreditpolitik durchgerungen. Damit fiel auch die Schlechterstellung der Sow jetunion und der Tschechoslowakei weg, und die Absicherung von Ausfuhrkrediten wurde generell für fünf Jahre möglich. Außerdem können seither in Ausnahmefällen (sogenannten "matching-Fällen") - nach Prüfung der politischen und wirtschaftlichen Notwendigkeit - Bürgschaften bis $z u$ acht Jahren gewăhrt werden. Da die Kreditlaufzeiten erst von der Inbetriebnahme der erstellten Anlagen und nicht vom Vertragsabschluß an gerechnet werden, ergeben sich in Einzelfällen sogar Ziele bis zu elf Jahren. Die Bundesregierung betrachtet diese

1 Versicherer ist hier der Staat, vertreten durch die "Hermes" als Mandatar des Bundes.

$2 \mathrm{Vgl}$. Leonhard STITZ-ULRICI, Probleme im Investitionsguterexport nach dem Südosten, in: Südosteuropa-Jahrbuch, hrsg. von Rudolf Vogel, Bd. 4, München 1960, S. $75 \mathrm{ff}$.; "Handelsblatt", Düsseldorf v. 31.8.1964.

3 Vgl. "Frankfurter Allgemeine Zeitung" v. 26.1.1965.

"Vgl. "Die Zeit", Hamburg v. 4.9.1964.

5 Vgl. Selling the Soviet Market, a.a. O., S. 44. 
Entscheidung, besonders im Hinblick auf eine zukünftige gemeinsame EWGKreditpolitik, ausdrücklich als Utbergangslösung. '

Eine weitere Erleichterung trat im April 1966 in Kraft. Entgegen der bis dahin geltenden Bestimmung, daß - unbeschadet der Ausfuhrbeschränkungen - Exportgeschäfte mit Ländern der Länderliste $C$ nur genehmigungsfrei sind, wenn sie gegen Barzahlung erfolgen, bedürfen seither all jene Exportgeschäfte keiner Genehmigung mehr, die Kreditfristen von nicht mehr als sechs Monaten vorsehen. Dies wird sich vor allem in einer Erleichterung der kleinen und mittleren Exporte auswirken und damit der Ausweitung des Warenverkehrs mit den Staatshandelsländern Rechnung tragen. ' Obgleich zwar auch bisher schon vereinzelt Zahlungsziele bis zu 180 Tagen auf besonderen Antrag hin genehmigt wurden (sogenannte "gestreckte Barzahlung"), sind seit April 1966 derartige Sonderanträge nicht mehr notwendig. 3

Interessant ist, daß sich die deutsche Exportindustrie in den vergangenen Jahren zunehmend ein weiteres Finanzierungsmittel zunutze machte, mit dessen Hilfe sie sich nicht nur die notwendige Liquidität verschaffe, sondern auch das Risiko vollständig abgeben konnte, ohne sich einer Kreditversicherung bedienen zu müssen. Es handelt sich dabei um die Möglichkeit, Lieferforderungen gegenüber Ostblockländern am internationalen Finanzmarkt à forfait zu verkaufen. Die den Exporteuren bei Lieferung übergebenen langfristigen Wechsel konnten dadurch bei einer internationalen Finanzierungsstelle ohne Rückgriffsrecht diskontiert werden. ${ }^{4}$

Frankreich

Das Problem der Kreditlaufzeiten im Handelsverkehr des Westens mit dem Ostblock wurde in Frankreich bis zum Jahre 1963 sehr zurückhaltend diskutiert. Trotz der systematischen Annäherung an die Ostblockländer hat sich die französische Regierung lange Zeit einer Ausweitung der Kreditfristen widersetzt. Man war dort, ähnlich wie in der Bundesrepublik Deutschland und den USA - im Gegensatz zu Großbritannien - der Meinung, daß eine Ausdehnung der Laufzeiten auf mehr als fünf Jahre über den Rahmen eines Warenkredits hinausginge und bereits Wirtschaftshilfe darstelle.

Durch die Kreditbereitschaft der Briten ${ }^{5}$ entstanden jedoch verschärfte Wettbewerbsbedingungen und die Aussichten, daß Frankreich seinen Anteil

\footnotetext{
'Vgl. "Frankfurter Allgemeine Zeitung"' v. 19.3.1965.

2 Vgl. "Bundesanzeiger", Köln, Nr. 86 v. 6.5.1966.

${ }^{3} \mathrm{Vgl}$. Klaus-Heinrich STANDKE, a.a.O., S. 174;

'Süddeutsche Zeitung", München v. 1.4.1966.

4Vgl. Ernst LEDERER, Ostkredite - neue Lösungen für alte Probleme?, Beiheft zu "Der Volkswirt", Nr. 21, Frankfurt/M. v. 25.5.1967, S. 29.

5 Vgl. S. 75.
} 
am Ost-Westhandel aufrechterhalten würde, verschlechterten sich. Zwar versicherte der französische Finanzminister noch Anfang 1964, daß sich Frankreich auch weiterhin an die Empfehlungen der "Berner Union' halten werde, doch schon im selben Jahr ließ Staatspräsident de Gaulle verlauten, daß Frankreich seine zukünftige Haltung in dieser Frage von London abhăngig machen würde. Damit hat Frankreich seine Zurückhaltung in dieser Frage aufgegeben, was besonders den Interessen verschiedener Kreise der französischen Industrie entsprach.'

Im Jahre 1964 wurde in Paris bekannt, daß mit der Sowjetunion Verhandlungen über die Ausdehnung der durch die "Compagnie Française d'Assurance pour le Commerce Extérieur" (COFACE) garantierten Lieferkreditfristen auf 10 bis $12 \mathrm{~J}$ ahre geführt wurde. Die Finanzierung sollte in diesem Fall von einer Bankengruppe übernommen werden. 2

Kreditbewilligungen, die die Richtlinien der "Berner Union" überschritten, wurden jedoch erst nach 1965 in großßerem Umfang gewährt. ${ }^{3}$

\section{Italien}

Schon im Jahre 1961 hat Italien der Sow jetunion einen langfristigen Kreditplafonds in Höhe von $100 \mathrm{Mill}$. US- \$ bereitgestellt. " Ähnliche Kreditzusagen mit Laufzeiten bis zu 12 Jahren erfolgten daraufhin auch bald an Bulgarien, Polen, Rumánien, die Tschechoslowakei und Ungarn. Im Jahre 1964 jedoch gaben die italienischen Behörden bekannt, da $\beta$ sie weiterhin grundsätzlich an der Fünfjahresgrenze der "Berner Union" festhalten würden. Der Prüfungsausschuß für die staatlichen Kreditgarantien wurde jedoch ermächtigt, für Sonderfälle längere Kreditfristen zuzulassen, zumal angesichts der internationalen Konkurrenzsituation diese Art der Exportförderung wichtig sei. Wie die italienische Praxis zeigt, wurden die der Sow jetunion und den ost - und südosteuropăischen Staatshandelsländern zugesagten Kreditlaufzeiten bisher nur in relativ geringem Ausmaße in Anspruch genommen. 5

'Vgl. "Die Zeit", Hamburg v. 4.9.1964.

2 Dieser Kredit kam noch im gleichen Jahr zust-ande, wies jedoch nur eine Laufzeit von sieben Jahren auf.

Vgl. "Handelsblatt", Düsseldorf v. 31.8. 1964;

E. HOFMANN, Der Osthandel der Anderen, a. a.O., S. 31 .

${ }^{3}$ Vgl. Klaus-Heinrich STANDKE, a.a.O., S. 212.

- Vgl. Der Außenhandel Osteuropas, Mitteilungen der Bundesstelle für Außenhandelsinformation, Jg. 11, Nr. 148, Koln 1961.

$5 \mathrm{Vgl}$. "Nachrichten für den Außenhandel", Köln v. 9.1.1964. 
Belgien - Niederlande - Luxemburg (Benelux)

Im Gegensatz zu den Niederlanden ist der Anteil der langfristigen Exportgeschäfte am Osthandelsvolumen Belgiens recht erheblich. Im Falle Belgiens handelt es sich hierbei vorwiegend um kreditierte Anlagelieferungen nach den südosteuropäischen Staatshandelsländern. Wie die Niederlande sieht auch Belgien die Fünfjahresgrenze der "Berner Union" nicht mehr als verbindlich an. I

Der Kreditgewăhrung Luxemburgs kommt quantitativ keine Bedeutung $z u$.

\section{b3) Die Ausfuhrkreditpolitik Großbritanniens}

Großbritannien, das vergeblich versuchte der "Berner Union" den Status eines verbindlichen Regierungsabkommens zu geben, sah sich seit Anfang der Sechziger Jahre nicht mehr an die Berner Empfehlungen gebunden. Schon 1961 war es dazu übergegangen, mit Hilfe seines staatlichen Ausfuhrkreditversicherungsinstitutes, dem "Export Credit Guarantee Department" (ECGD) - ein dem "Board of Trade" unterstelltes Regierungsinstitut -, Exportfinanzierungen abzusichern, die weit über die Berner Richtlinien hinausgingen. Seither sind solche finanziellen Garantien mit Laufzeiten bis zu 17 Jahren und einer Verzinsung zum Kapitalmarktzins schon zur festen Praxis geworden. ${ }^{2}$ Als erstes NATO-Land vergab Großbritannien langfristige, staatlich versicherte Kredite an die Sowjetunion. ${ }^{3}$

Großbritannien kennt seit dem Jahre 1961 keine spezifische Ost-Kreditpolitik mehr. Die Grundsätze, die in der Kreditvergabe gegenüber Ostblockländern Anwendung finden, gelten gleichfalls gegenüber nichtkommunistischen Ländern. ${ }^{4}$

Im Außenhandelsverkehr mit den kommunistischen Ländern führte Großbritannien nicht nur neue Kreditfisten, sondern auch die Form des auftragsgebundenen Globalkredits ${ }^{5}$ und des Finanzkredits ein. Da der Finanzkredit, nach britischer Meinung, die Bestimmungen der "Berner Union" nicht verletzt, ist $z$ u erwarten, daß diese Kreditform weiter an Boden gewinnen wird.

1 Vgl. Klaus-Heinrich STANDKE, a.a.O., S. 239 und S. 245.

$2 \mathrm{Vgl}$. Staatliche Exportkreditfinanzierung und -versicherung in Großbritannien, USA und der Bundesrepublik, a.a.O., S. 256; "Handelsblatt", Düsseldorf v. 30.9.1964.

${ }^{3} \mathrm{Vgl}$. "Handelsblatt", Düsseldorf v. 31.8.1964.

4 Selling the Soviet Market, a.a.O., S. 42.

$5 \mathrm{Vgl}$. J. SCOTT, The London Viewpoint, in: East-West Trade, American Management Association, a.a.O., S. 30 . 
b41) Die Bestimmungen der "Johnson Act"

Ebenso wie in der Frage der Ausfuhrbeschränkungen haben die USA auch auf dem Gebiet der Kreditgewährung eine feste Haltung eingenommen. "Aus der Überlegung heraus, daß die Einräumung von langfristigen Kre. diten im Zeitpunkt ihrer Gewährung das Kräfteverhältnis zwischen Ost und West einseitig zugunsten des Ostens verschiebt, wird die Kreditgewährung an den Ostblock in den USA als strategisch bedeutsames Instrument angesehen."'

Abgesehen von den politischen Motiven der Vereinigten Staaten besteht in Gestalt der "Johnson Act" vom Jahre 1934 ein rechtliches Hindernis für die Einräumung von Krediten ("loans") ${ }^{2}$ durch amerikanische Privatpersonen, - gesellschaften oder andere private Organisationen an kommunistische Länder. Dieses Gesetz, das im Jahre 1945 ergănzt wurde, stellt eine der strengsten amerikanischen Handelsrestriktionen gegenüber den Ostblocklándern dar. Es bestimmt, daß jede Kreditgewährung von privater amerikanischer Seite gegenüber Ländern, die mit ihren finanziellen Verpflichtungen aus den "Leih- und Pachtvertrăgen" gegenüber den USA im Verzug sind, als Verbrechen ("crime") angesehen wird. 3

Das Gesetz bezieht sich nicht auf die Tätigkeit offentlicher Institutionen der Exportfinanzierung, wie z.B. der "Commodity Credit Corporation". Gesondert geregelt ist die von den Bestimmungen der "Johnson Act" ebenfalls ausgenommene Tätigkeit der "Export-Import Bank of the United States" ("Export-Import Bank Act" aus dem Jahre 1945). Weiterhin findet

'Klaus-Heinrich ST ANDKE, a. a.O., S. 230.

2 Unter "loan" ist ein lăngerfristiger Kredit, unter "credit" lediglich ein Zahlungsziel zu verstehen.

${ }^{3}$ Neben der Sowjetunion, die ihre Schulden gegenüber den USA aus dem Leihund Pachtvertrag ("lend-lease") in Hobe von 10,5 Mrd. US- \$ noch nicht beglichen hat, sind auch die anderen ost- und südosteuropáischen sozialistischen Länder mit Ausnahme Bulgariens gegenüber den USA verschuldet. Die Restschuld Jugoslawiens belief sich im Jahre 1963 auf $0,6 \mathrm{Mill}$. US- \$. Vgl. East-West Trade, Hearings Part I, a.a. O., S. 29.

Vgl. auch Selling the Soviet Market, a.a.O., S. 38;

Klaus-Heinrich STANDKE, a. a.O., S. $230 \mathrm{f}$.;

E. BENDHEIM, Amerika und die Frage des Osthandels, "Wirtschaftsdienst", Jg. 44, H. 12, Hamburg 1964, S. 538; A New Look at Trade Policy Toward the Communist Bloc, Subcommittee on Foreign Economic Policy, Joint Economic Committee, Nov. 10, Washington D.C. 1961, S. 71.

4Am 13.3. 1968 wurde der Name der "Export-Import Bank of Washington" geandert in "Export-Import Bank of the United States". Vgl. Public Law 90-267, 90 th Congress v. 13.3.1968. 
die "Johnson Act" keine Anwendung auf private Versicherungsgesellschaften, die im Rahmen der 'Foreign Credit Insurance Association" (FCIA) tătig werden und häufig mit der "Export-Import Bank" zusammenarbeiten (meistens kurz- und mittelfristige Exportgeschäfte).'

Das Gesetz wurde im Jahre 1945 durch die Bestimmung ergänzt, daß die entsprechenden Kreditbeschränkungen ebenfalls nicht auî Länder angewendet werden sollen, die trotz ihrer Verschuldung gegenüber den USA Mitglieder des Internationalen Währungsfonds (IMF) und der Internationalen Bank für Wiederaufbau und Entwicklung (IBRD=Weltbank) sind. Dies hatte zur Folge, daß die Bestimmungen der "Johnson Act" praktisch auf die kommunistischen Länder beschränkt wurden. Lediglich Jugoslawien und Bulgarien waren ausgenommen. Jugoslawien, weil es Mitglied beider internationaler Organisationen ist; Bulgarien, weil es keine Schulden aus dem "Leih- und Pachtvertrag" hat. '

Der in der "Johnson Act" verwendete Begriff "loan"' wurde nicht näher definiert. Diese Unsicherheit, wann eine Zahlungsfrist noch als Zahlungsziel ("credit") und wann als Kredit ("loan") anzusehen ist, führte schon kurz nach der Verabschiedung des Gesetzes im Jahre 1934 zu einer Auslegung durch den Generalstaatsanwalt. Ihr zufolge sollte das Gesetz nicht auf normale, handelsübliche Zahlungsziele (also "credits") zutreffen. ${ }^{3}$

In Anbetracht der Spannungen nach dem Zweiten Weltkrieg und der sehr konservativen Haltung der amerikanischen Bankwelt setzte sich nach und nach die Auffassung durch, daß kurzfristige Zahlungsfristen bis zu 180 Tagen als handelsübliche Zahlungsziele, nicht aber als Kredit anzusehen seien. Zahlungsfristen über sechs Monate werden im allgemeinen als Kredit betrachtet. 4 Diese Interpretation des Generalstaatsanwalts wurde im Jahre 1963 im Zusammenhang mit den Weizenverkäufen an die Sowjetunion einer neuerlichen Überprüfung unterzogen. ${ }^{5}$ Weder der Generalstaatsan-

$1 \mathrm{Vgl}$. BERMAN und GARSON, Possible Effects of the Proposed East-West Trade Relations Act, a.a.O., S. 297.

$2 \mathrm{Vgl}$. "The Battle Act Report of 1967", S. $6 \mathrm{f}$.

3 "... drafts, checks, and other ordinary aids to banking and commercial transactions which are obligations in a broad sense but not in the sense intended." BERMAN und GARSON, Possible Effects of the Proposed East-West Trade Relations Act, a.a.O., S. 294.

4 Diese Sechsmonatsgrenze geht zurück auf eine inoffizielle Empfehlung des Generalstaatsanwalts.

${ }^{5}$ An dieser Stelle ist $z$ e erwähnen, daß im Zusammenhang mit den sowjetischen Weizenkäufen weder die Sowjetunion um eine Kreditierung nachgesucht hat noch die betreffenden amerikanischen Exportunternehmen Kredite gewährt haben. Als die Sowjetunion jedoch ihre erste formelle Anfrage wegen der Käufe an die USA richtete, bestand darüber noch keine Klarheit und man nahm an, daß ein Kreditansuchen erfolgen könnte. 
walt noch das Außenministerium haben die inoffizielle Sechsmonatsfrist verlängert. Vielmehr ersetzten beide Stellen lediglich den inoffiziellen, zeitlich aber eindeutigen Anhaltspunkt durch einen ebenfalls inoffiziellen, jedoch recht dehnbaren. Es ist daher unwahrscheinlich, daß zukünftig eine Unternehmung oder eine Bank diese Grenze von sechs Monaten überschreiten wird, solange keine eindeutige und klare offizielle Stellungnahme vorliegt. Die Formulierung, daß die notwendige Einräumung von Zahlungsfristen für Exportverkäufe nicht als Kredit im Sinne der "Johnson Act" $\mathrm{zu}$ verstehen ist, ist keinesfalls geeignet, die Rechtssicherheit zu erhöhen. 1

b42) Die Bestimmungen der "Foreign Aid and Related Appropriations Act"

Theoretisch können heute amerikanische Exporteure ihren östlichen Handelspartnern kurz- und mittelfristige Kredite gewähren, sofern dies für den jeweiligen Geschäftszweig handelsüblich ist. ${ }^{2}$ Entsprechend der gegenwärtigen Gesetzgebung können aber auf keinen Fall ähnlich langfristige Kreditbedingungen wie im Fall der westeuropäischen Konkurrenz eingeräumt werden. Amerikanische Exporteure, die solche handelsüblichen kurz- und mittelfristigen Kredite anbieten, tun dies allerdings auf ih $r$ eigenes Risiko, denn eine staatliche Kreditabsicherung oder -garantie ist grundsätzlich verboten. Die im Jahre 1964 verabschiedete "Foreign Aid and Related Appropriations Act" untersagt der "Export-Import Bank" nicht nur die Finanzierung von Exporten in kommunistische Länder, sondern auch die Absicherung und Garantie derartiger Kredite. ${ }^{3}$ In Übereinstimmung mit der US-Außenpolitik findet diese Bestimmung jedoch keine Anwendung auf Jugoslawien.

Das Gesetz verfügt weiter, daß die "Export-Import Bank" unter bestimmten Ausnahmebedingungen sehr wohl Exporte in kommunistische Länder finanzieren, absichern und garantieren kann. Dann nämlich, wenn der Präsident der Vereinigten Staaten dies genehmigt, weil er der Meinung ist, daß es im nationalen Interesse der USA liegt. Diese Ausnahme hat er jedoch im Einzelfall gegenüber dem Repräsentantenhaus und dem Kongreß zu vertreten. 1

Solche auf Grund der Entscheidung des Präsidenten möglichen Kreditabsicherungen sind mit Laufzeiten von sechs Monaten bis maximal sechs Jahren gegenüber den südosteuropäischen Staatshandelsländern aber auch gegenüber Polen und der Tschechoslowakei möglich.

1 Vgl. Russel BAKER, Legal Aspects of East-West Trade, a.a.O.

2 Vgl. Selling the Soviet Market, a.a.O., S. 29; BERMAN und GARSON, Possible Effects of the Proposed East-West Trade Relations Act, a. a. O., S. 295.

$3 \mathrm{Vgl}$. Selling the Soviet Market, a.a.O., S. 38.

$1 \mathrm{Vgl}$. East-West Trade Hearings, Part I, a.a.O., S. $27 \mathrm{ff}$. 
Am 13. März 1968 wurde die "Export-Import Bank Act" vom Jahre 1945 am weitere fünf Jahre verlängert und im Hinblick auf die Kreditpolitik zegenüber den kommunistischen Ländern unter dem Eindruck der kriegecischen Auseinandersetzungen in Südostasien neu gefaßt. Demzufolge darf die "Export-Import Bank" zukünftig Kredite weder gewähren noch absichern, wenn

A. 1. diese Exporte in ein kommunistisches Land gehen,

2. diese Exporte in ein nichtkommunistisches Land gehen und von dort in ein kommunistisches Land reexportiert werden,

es sei denn, der Präsident ist der Meinung, daß solche Transaktionen im nationalen Interesse liegen und er seinen Beschluß innerhalb von $30 \mathrm{Tagen}$ dem Senat und dem Repräsentantenhaus mitteilt.

Weiterhin ist der Bank diese Betätigung untersagt, wenn die Exporte (Waren, technische Daten) in Länder gehen,

B. 1. die sich mit den USA in einer kriegerischen Auseinandersetzung befinden (mit oder ohne Kriegserklärung),

2. deren Regierungen Waren, Nachschubgüter, Militärgüter etc. sowie Militärberater in ein Land senden, das mit den USA in kriegerische Handlungen verwickelt ist. '

Diese Verschärfung der amerikanischen Kreditpolitik im Handel mit dem Osten verhindert praktisch jegliche Kreditgewährung an kommunistische Länder. Obgleich die Bestimmungen (A. 1.) und (A. 2.) wiederum eine Ausnahmeregelung durch den Präsidenten vorsehen, ist eine solche augenblicklich sehr unwahrscheinlich - Jugoslawien vielleicht ausgenommen und im Fall der südosteuropăischen Staatshandelsländer wohl auch nicht durchzusetzen. Die Bestimmungen (B. 1.) und (B. 2.) sind unmittelbar auf den Vietnamkrieg zugeschnitten, und da alle Ostblockregierungen Nordvietnam in irgendeiner Weise unterstützen, ist eine Exportkreditierung ihnen gegenüber verboten. Eine Ausnahme gibt es in diesem Fall nicht. Da das Gesetz hier ausdrücklich von Regierungen spricht, kann das bedeuten, daß Jugoslawien, wo formell gesehen nicht unbedingt die Regierung im Sinne von (B. 2.) tătig zu werden braucht, von den Konsequenzen des Gesetzes ausgenommen wird. ${ }^{2}$

Wie in der Praxis die zukünftige Exportkreditpolitik aussehen wird, läßt sich heute noch nicht überblicken. Im Hinblick auf die "East-West Trade Relations Act', die die bisher bestehende Struktur der Exportkreditrestriktionen ebensowenig antastet wie die der Ausfuhrkontrolle, ist jedoch

Vgl. Public Law 90-267, 90th Congress v. 13.3.1968.

Vgl. "Washington Post" v. 22.2.1968; "The New York Times" v. 8. 11. 1967. 
anzunehmen, daß künftig strittige Fragen finanzieller und vermögensrechtlicher Art im Rahmen der vorgesehenen bilateralen Abkommen geregelt und die Negativbestimmungen der "Johnson Act" umgangen werden könnten. 1

\section{b5) Zusammenfassung}

Auf Grund der zugänglichen Materialien läßt sich feststellen, daß seit den Jahren 1964/1965 eine formelle kreditpolitische Benachteiligung der südosteuropäischen Staatshandelsländer gegenüber Jugoslawien und nichtkommunistischen Ländern seitens der EWG-Mitgliedstaaten nicht mehr besteht. Dies gilt für Großbritannien schon seit dem Jahre 1961 .

Die Zahlungsbedingungen im Handel zwischen West- und Osteuropa sind weitestgehend normalisiert, und die von westlicher Seite eingeräumten Kredite entsprechen den international üblichen Terminen. ${ }^{2}$ Auch materiell, d.h. im Hinblick auf die jeweils zur Verfügung gestellten Kreditplafonds und Bürgschaften, besteht keine Diskriminierung mehr. Vielmehr ist $z u$ beobachten, daß die westeuropäischen, insbesondere deutschen Kreditversicherer gerade im Verkehr mit den südosteuropäischen Staatshandelsländern aus zumeist politischen Überlegungen sehr entgegenkommend sind. ${ }^{3}$

Eine gemeinsame EWG-Ausfuhrkreditpolitik besteht bislang nicht. Was die USA betrifft, so sind seit Mărz 1968 alle Exportfinanzierungs- und - versicherungsmöglichkeiten durch die staatliche "Export-Import Bank" gegenüber allen kommunistischen Ländern untersagt. Ausgenommen sind hiervon handels- und branchenübliche kurz- und mittelfristige Kreditfazilitäten privater amerikanischer Exporteure an die Länder Rumänien und Ungarn. Jedoch werden für diese Kredite, die den Charakter von Zahlungszielen haben müssen, weder staatliche Garantien oder Bürgschaften noch Finanzierungsmittel als solche bereitgestellt. Auf Bulgarien finden die Bestimmungen der "Johnson Act" keine Anwendung, die Beschränkungen nach der überarbeiteten "Export-Import Bank Act" aber gelten ebenfalls. Die Auswirkungen der amerikanischen Kreditpolitik auf den Handel mit den Staatshandelsländern Südosteuropas sind nun nicht so gravierend, wie es den Anschein hat. Dies vor allem deshalb, weil der Einsatz der Kreditpolitik als handelspolitisches Instrument von der jeweiligen Exportkontrollpolitik abhängig ist. Da diese keinen allzu großen Spielraum für ausgedehntere südosteuropäische Anlage- und Investitionsgüterkäufe läßt, wirkt sich die Kreditpolitik nicht entscheidend aus. Dennoch kann man sagen, daß der Spielraum, den die Ausfuhrkontrollpolitik läßt, durch die kaum bestehenden Kreditie rungsmöglichkeiten noch mehr eingeschränkt wird.

1 Vgl. BERMAN und GARSON, Possible Effects of the Proposed East-West Trade Relations Act, a. a. O., S. $296 \mathrm{ff}$.

2 Vgl. Ernst LEDERER, Ostkredite - neue Lösungen für alte Probleme, a.a.O., S. 29.

${ }^{3} \mathrm{Vgl}$. "Handelsblatt", Düsseldorf v. 23./24.8.1968. 
2. EINFUHRWIRKSAME MASSNAHMEN DER EWG-MITGLIEDSTAATEN, GROSSBRITANNIENS UND DER US A

a) Mengenbeschränkungen versus Preisbelastungen

Im Gegensatz zu den USA gewähren sämtliche hier betrachteten westeuropäischen Länder den Staatshandelsländern Südosteuropas die meistbegün- 2 stigte Zollbehandlung. Im Fall der EWG-Länder bedeutet dies, daß alle Einfuhren aus den betreffenden kommunistischen Ländern einheitlich den vergemeinschafteten EWG-Außenzolltarif und die vereinheitlichten $\mathrm{Ab}$ schöpfungssätze zu überwinden haben. Eine zollpolitische Diskriminierung der südosteuropäischen Staatshandelsländer zugunsten von nichtkommunistischen Drittländern oder eine unterschiedliche Behandlung durch EWGLänder findet nicht statt. Da Bulgarien, Rumänien und Ungarn dem GATT nicht angehören, besteht dazu seitens der westeuropäischen Länder a priori keine Verpflichtung. Die zwingende und unbedingte Einräumung der Meistbegünstigung ist gemäß den GATT-Statuten abhängig von der Mitgliedschaft des zu begünstigenden Landes beim GATT. ${ }^{1}$ Die Aufnahme in das GATT setzt jedoch wiederum voraus, daß das um Aufnahme nachsuchende Land handels- und wirtschaftspolitische Zielsetzungen verfolgt, die sich mit den GATT-Statuten vereinbaren lassen ("... to act in a manner consistent with the general principles of nondiscriminating treatment" $)$ und dementsprechend Art. XVII (Staatliche Handelsunternehmen) voll akzeptiert. ${ }^{3}$

Jugoslawien, das im Jahre 1959 die Assoziierung mit dem GATT beantragte, konnte erst 1965, nachdem es das Außenhandelsmonopol aufgegeben, Ein- und Ausfuhrbeschränkungen weitgehend verringert und einen neuen Zolltarif sowie einen einheitlichen Wechselkurs eingeführt hatte, als Vollmitglied aufgenommen werden. 4

Die Tschechoslowakei wurde vor der kommunistischen Machtergreifung Gründungs- und damit Vollmitglied des GATT. Hieraus resultiert eine ganz besondere Situation, da dieses Land ursprünglich zwar den GATTStatuten voll zustimmte, deren materiellen Inhalt aber nach 1948 aus wirtschaftlichen und politischen Gründen nicht mehr erfülte. Dennoch wenden alle Mitglieder gegenüber der Tschechoslowakei GATT-Grundsätze an.

IVgl. Ferdinand K. LIEBICH, Grundriß des Allgemeinen Zoll- und Handelsabkommens (GATT), Baden-Baden 1967, S. $17 \mathrm{f}$.

${ }^{2}$ Gerard CURZON, a.a.O., S. 290.

${ }^{3}$ Vgl. Ferdinand K. LIEBICH, a.a. O., S. 76 f.; L. P. IMHOFF, Kommentar zum Allgemeinen Zoll- und Handelsabkommen (GATT), München - Berlin 1952, S. 147 ff.; Gerard CURZON, a.a.O., S. 307.

4 Vgl. Gerard CURZON, a.a.O., S. $301 \mathrm{ff}$. 
Eine Ausnahme machen lediglich die USA seit dem Jahre 1951, als die "Trade Agreements Extension Act" die Einrăumung der Meistbegünstigung gegenüber der Tschechoslowakei verbot. ' Diese nationale gesetzliche Bestimmung steht jedoch offensichtlich im Widerspruch zu den GATT-Grundsätzen, denen zufolge die Tschechoslowakei formell Anspruch auf GATTkonforme Behandlung durch die USA hat.

Als bisher einziges Staatshandelsland wurde im Jahre 1967 Polen in das GATT als Vollmitglied aufgenommen. Die Gegenleistung Polens besteht in Aufstockungen der Minimaleinfuhrkontingente für GATT-Mitgliedsländer. ${ }^{2}$

In diesem Zusammenhang stellt sich allgemein die Frage, ob die Meistbegünstigung im Ost-Westhandel als handelspolitisches Prinzip anzuerkennen ist. Insbesondere ist es zweifelhaft, ob hierfür ausreichende Voraussetzung gegeben ist. Im Mittelpunkt steht dabei die Frage, ob Zollvorteile, die gegenüber bestimmten Handelspartnern auf der Basis strikter Reziprozität ausgehandelt werden, automatisch an Länder weitergegeben werden können, die an derartigen Verhandlungen weder teilnehmen noch entsprechende, wenn auch systembezogene Gegenleistungen für Zollermäßigungen anbieten. Noch größere und aktuellere Bedeutung erhält dieses Problem im Hinblick auf die weltweiten Zollsenkungen im Rahmen der Beschlüsse der Kennedy-Runde. Eine Nichtweitergabe der allgemeinen Zollermäßigung an die betreffenden Staatshandelsländer könnte deren ohnehin schon schwache Exportstellung noch mehr gefährden. ${ }^{3}$

In Westeuropa ist man sich trotz all der genannten Probleme darüber klar geworden, daß insgesamt die Vorteile, ${ }^{4}$ die sich aus einer zollpolitischen Meistbegünstigungsbehandlung der südosteuropäischen Staatshandelsländer ergeben, bei weitem die damit verbundenen Nachteile überwiegen. Vor allem vertritt man die Meinung, daß die Gegenleistungen der Staatshandelsländer nicht ausschließlich tariflicher Art sein müssen; insbesondere, da man den erhohten Gefahren von Niedrigpreiseinfuhren mit Hilfe von zweiseitigen Regierungsvereinbarungen oder auch einseitigen westlichen Schutzmaßnahmen entgegentreten kann.

' Im weiteren sei hierzu verwiesen auf S. 104 f. sowie Gerard CURZON, a.a.O., S. $298 \mathrm{ff}$.

2 Vgl. Gerard CURZON, a.a.O., S. 303 f.; Hermann GROSS, Kennedy-Runde und Ost-West-Handel, a.a.O., S. 121 ff.

3 Vgl. Hermann GROSS, Kennedy-Runde und Ost-West-Handel, a.a.O.

- Zu denken ist vor allem daran, daß die Exportmöglichkeit der Staatshandelsländer in den Westen weitgehend die Exportmöglichkeit des Westens in diese Länder bestimmt. Mit anderen Worten: Da der Westen nach Ost- und Südosteuropa exportieren will, muß er umgekehrt den Staatshandelsländern normale Konkurrenzbedingungen einräumen. Unter diesem Aspekt sind auch die westlichen Maßnahmen zur Einfuhrliberalisierung insgesamt zu betrachten. 
Polen und die Tschechoslowakei beispielsweise haben als Gegenleistung für die Teilnahme an den Zollkonzessionen der Kennedy-Runde Einfuhrsteigerungen in Höhe von $30 \mathrm{bzw}$. $40 \mathrm{v} . \mathrm{H}$. für die nächsten fünf Jahre aus den an den Verhandlungen der Kennedy-Runde beteiligten Staaten vorgeschlagen. "Wenn dieses Angebot wohl auch kaum als eine adäquate Konzession angesehen werden kann, da alle Ostblockländer auf eine solche Importsteigerung aus dem Westen eingestandenermaßen dringend angewiesen sind, so ließe sich darüber immerhin verhandeln." I

Im Mittelpunkt der Einfuhrpolitik der westeuropäischen Länder gegenüber den Staatshandelsländern Südosteuropas stehen nicht wie in den USA preispolitische, sondern vielmehr - und damit wiederum im Gegensatz zu den USA - mengenpolitische Maßnahmen.

Zentrale Bedeutung kommt hierbei dem Einfuhrkontingent als Element eines bilateralen zwischenstaatlichen Abkommens zur Regelung des Waren-, Dienstleistungs- und Zahlungsverkehrs für einen bestimmten Zeitraum zu. ${ }^{2}$ Es handelt sich dabei meistens um Mengenkontingente, die eine Importbeschränkung auf die Warenart und die Warenmenge ermöglichen, von der die jeweilige westliche Regierung überzeugt ist, daß sie in dem betreffenden westlichen Land ohne Marktstörungen absorbiert werden kann. Dies gilt ganz besonders für landwirtschaftliche Erzeugnisse, aber auch für Konsumgüter, bei denen die westliche Industrie besondere Gefahren durch östlichen Niedrigpreisexport sieht. ${ }^{3}$

Neben dieser Schutzfunktion kommt, wie schon an anderer Stelle bemerkt, den Einfuhrkontingenten die Aufgabe zu, die westliche Verhandlungsposition gegenüber dem Außenhandelsmonopol der Staatshandelsländer zu stärken und damit Diskriminierungen zugunsten anderer westlicher Länder zu vermeiden. "To make negotiations possible, one must be able to deny access to one' $s$ own market, in order to have something to bargain about. '14

Obgleich diese Aufgaben für eine weitere Aufrechterhaltung der Einfuhrbeschränkungen sprechen, hat sich in den letzten Jahren die Entwicklung verstärkt, die mengenmäßigen Einfuhrbeschränkungen gegenüber verschiedenen, insbesondere den südosteuropäischen Staatshandelsländern abzubauen. Im einzelnen geht es dabei um die einseitige und vertraglich nicht festgelegte Abschaffung mengenmäßiger Einfürbeschränkungen für bestimmte Waren durch die automatische und unmittelbare Erteilung von

Hermann GROSS, Kennedy-Runde und Ost-West-Handel, a. a. O., S. 129.

2 Vgl. Alfred KRUSE, a.a.O., S. $330 \mathrm{f}$.

3 Vgl. Klaus-Heinrich STANDKE, a.a.O., S. 97.

$4 \mathrm{Vgl}$. Alec NOVE, East-West Trade in an Arms Control Context, in: Disarmament and World Economic Interdependence, publ. by Emile Benoit, Oslo 1967 , S. 207. 
Einfuhrlizenzen. ' Solchermaßen einfuh rliberalisierte Waren können nunmehr unter Beachtung der Zollbestimmungen unbeschränkt eingeführt werden. ${ }^{2}$ Relativ große Bedeutung kommt dieser Liberalisierung insofern $z u$, als dadurch die Exportmöglichkeiten der Staatshandelsländer (natürlich soweit sie von der Liberalisierung erfaßt werden) in die westeuropäischen Länder vergrößert werden. Daneben sind Anpassungsmöglichkeiten an sich verändernde westliche Marktbedingungen nicht mehr erst nach Ablauf bzw. Neuabschluß des Handelsabkommens, sondern jederzeit möglich. Da die Außenhandelsgesellschaften zur schnellen Ausnützung von Marktveränderungen und Marktchancen im allgemeinen noch $\mathrm{zu}$ wenig flexibel sind, ist die praktische Ausschöpfung der Anpassungsmöglichkeiten noch unzureichend.

Da Westen wie Osten an einer Ausdehnung des Handelsvolumens interessiert sind, besteht der zu überwindende Engpaß in der Menge der auf den Westmärkten absetzbaren Ostwaren. "Fürsprecher einer Bewegung für eine zunehmende Liberalisierung im Osthandel werden daher die Wirtschaftskreise sein, die Absatzmöglichkeiten für ihre eigenen Erzeugnisse in Ostblockländern sehen. Da es sich hier auf Grund der derzeitigen Struktur des West-Ost-Handels überwiegend um Investitionsgüter handelt, die der Osten nachfragt, werden diese Industriezweige von der durch die Liberalisierung ermöglichten verstärkten Konkurrenz von Ostwaren kaum berührt. Anders hingegen die westlichen Hersteller von Konsumgütern: Ihre Erzeugnisse fragt der Osten kaum nach, stattdessen strebt er eine Ausdehnung seiner Lieferungen auf diesem Sektor an. Die Folge ist, daß zum Schutz der einheimischen Hersteller solcher (meist Fertig-)Erzeugnisse, deren gesteigerte Einfuhr zu nedrigen Preisen eine Bedrohung für die Existenz des ganzen inländischen Industriezweiges darstellen würde, die Kontingentierung beibehalten wird." 3

b) Die Einfuhrpolitik der EWG-Mitgliedstaaten

b1) Die vergemeinschafteten einfuhrpolitischen Maßnahmen der EWGMitgliedstaaten

b11) Preisbelastungen und Mengenbeschränkungen von marktordnungsgebundenen Agrareinfuhren auf Grund der gemeinsamen EWG-Agrarpolitik

Eine wichtige Regelung im Hinblick auf die Vergemeinschaftung der Handelspolitik wurde am 24. Januar 1963 für die landwirtschaftlichen Einfuhren aus Staatshandelsländern getroffen, die der gemeinsamen Agrarpolitik

' Vgl. Hans MOLLER, Handelspolitik zwischen Bilateralismus und Multilateralismus, "Weltwirtschaftliches Archiv", Bd. 68, H. 2, Hamburg 1952, S. 228.

2 Vgl. Klaus-Heinrich STANDKE, a.a.O., S. 97.

3 Vgl. ebd. S. 98. 
unterliegen. ' Die betreffende Verordnung (3/63) wurde seither mehrmals verlängert, um Einzelfragen ergänzt und in ihrer Anwendbarkeit auf neugeschaffene landwirtschaftliche Marktordnungen erweitert. Die für den Handel mit den südosteuropäischen Staatshandelsländern wichtigsten Marktordnungen betreffen Getreide, Schweinefleisch, Geflügelfleisch, Eier, Obst und Gemüse, Wein (am 30.7.1962 in Kraft getreten), sowie Milch und Milcherzeugnisse und Rindfleisch (am 1.11.1964 in Kraft getreten). ${ }^{2}$

Diese besonderen Einfuhrregelungen für Erzeugnisse, die unter die EWGAgrarmarktordnung fallen, beruhen vornehmlich auf der Erwägung, daß eine unkontrollierte Liberalisierung der Einfuhr landwirtschaftlicher Erzeugnisse aus Ostblockländern das Markt- und Preisgefüge der EWG-Länder stören könnte. Ohne auf die technischen Besonderheiten dieser Regelungen im einzelnen einzugehen, ist es doch notwendig, zumindest ihre charakteristischen Wesenszüge kurz aufzuzeigen. ${ }^{3}$

Im Zuge der Verwirklichung der gemeinsamen Agrarpolitik trat an die Stelle einzelstaatlicher handelspolitischer Schutzmaßnahmen wie Zölle, Kontingente, Mindestpreise und Einfuhrabgaben ${ }^{4}$ für Marktordnungsgüter ein freier Importverkehr ohne mengenmäßige Beschränkungen bei gleichzeitiger Einführung des einheitlichen Preisbelastungssystems der $\mathbf{A b -}$

' Vgl. Verordnung Nr. $3 / 63$ des Ministerrats der EWG v. 24.1.1963 über die Handelsbeziehungen zu den Staatshandelsländern bei den unter die Verordnungen Nr. 19/20/21 und 22 des Rates vom 4.4.1962 fallenden Erzeugnissen. Amtsblatt der Europăischen Gemeinschaften Nr. 14 v. 29.1.1963.

${ }^{2} \mathrm{Vgl}$. Bericht im Namen des Außenhandelsausschusses des Europäischen Parlaments über Fragen der gemeinsamen Handelspolitik, a.a. O., S. 5; Amtsblatt der Europăischen Gemeinschaften, Nr. 127 v. 7.8.1964 sowie Nr. 223 v. 29.12. 1965 und Nr. 240 v. 27.12.1966; Verordnung Nr. 125/66; Sechster Gesamtbericht über die Tätigkeit der Europăischen Wirtschaftsgemeinschaft (1. Mai 1962 - 31. Mărz 1963), Brüssel Juni 1963, Ziff. 125 ff.; Siebter Gesamtbericht über die Tätigkeit der Europăischen Wirtschaftsgemeinschaft (1. April 1963 - 31. März 1964), Brüssel Juni 1964 , Ziff. 167 ff.; desgl. Achter Gesamtbericht (1. April 1964 - 31. März 1965), Brüssel Juni 1965, Ziff. 173 ff.

${ }^{3}$ Im einzelnen sei verwiesen auf den Bericht im Namen des Landwirtschaftsausschusses des Europäischen Parlaments über die allgemeinen Grundsätze für die Marktordnungen in der Endphase des Gemeinsamen Marktes, Berichterstatter: R. Blondelle, Dok. 43, 1967-1968 v. 8.5.1967; Der Gemeinsame Markt, 1965, hrsg. vom Presse- und Informationsdienst der Europåischen Gemeinschaften, H. 11, Bonn o.J.; Fünfter Gesamtbericht über die Tätigkeit der Europäischen Wirtschaftsgemeinschaft (1. Mai 1961 - 30. April 1962), Brüssel Juni 1962, Ziff. 104 ff.; Sechster Gesamtbericht über die Tätigkeit der Europåischen Wirtschaftsgemeinschaft, a.a.O.

4 Vgl. Fünfter Gesamtbericht über die Tătigkeit der Europăischen Wirtschaftsgemeinschaft, a.a.O., Ziff. 107. 
schöpfung mit Schutzzollwirkung. ${ }^{1}$ Der Abschópfungsbet rag gegenüber dritten Ländern entspricht der Differenz zwischen dem unter Zugrundelegung der günstigsten Einkaufsmoglichkeiten auf dem Weltmarkt ermittelten cif-Preis (cif - cost, insurance, freight, frei Bestimmungshafen) und dem Schwellenpreis des einführenden EWG-Mitgliedstaates bzw. dem gemeinschaftlichen EWG-Schwellenpreis für das betreffende Erzeugnis. ${ }^{2}$ Da am 1. Juli 1967 der gemeinsame Agrarmarkt für Getreide, Schweinefleisch, Eier und Geflügelfleisch ${ }^{3}$ errichtet wurde, kommen für diese Erzeugnisse nur mehr gemeinsame Schwellenpreise zum Ansatz (da die innergemeinschaftliche Abschópfung weggefallen ist). Zweck dieses Abschöpfungssystems ist es, ". . den Erzeugern der Gemeinschaft eine kontinuierliche Erzeugung unter normalen Umständen $z u$ gewährleisten." 4

Die Verordnungen auf der Grundlage der Art. 38 - 47 des Vertrages zur Gründung der EWG über die betreffenden Produkte bestimmen, daß Importe aus dritten Ländern auf Grund eben dieser Abschöpfungsregeln frei von mengenmäßigen Beschränkungen und Maßnahmen ähnlicher Wirkungen stattfinden, es sei denn, daß der Ministerrat auf Vorschlag der Kommission anders entscheidet. Im Fall der Agrareinfuhren aus den Ostblockländern ist eine solche Entscheidung ergangen (Ratsbeschluß vom 14.1.1962).5 Zwar erfolgt auch die Einfuhr der betreffenden Marktordnungsgüter aus den Staatshandelsländern nach Maßgabe der für diese Erzeugnisse vorgeschriebenen allgemeinen Einfuhrregelung preisbelastender Art. Im Hinblick auf die Besonderheiten der Handelsbeziehungen mit diesen Ländern

${ }^{1} \mathrm{Vgl}$. Michael VON BERG, Auswirkungen der EWG auf den Handelsverkehr zwischen EWG-Ländern und kommunistischen Staaten, "Osteuropa-Wirtschaft", Jg. 8, H. 3/4, Stuttgart 1963, S. 164.

${ }^{2}$ Grundrichtpreis - Pauschale (Frachtkosten zwischen Grenze und Grundrichtpreisort + Handelsspanne + Umsatzausgleichsteuer) = vorlăufiger Schwellenpreis (Ausgleichskoeffizienten berücksichtigen Abweichungen von der EWGStandardqualităt).

Schwellenpreis (endgültiger)-Abschopfung - cif-Preis (Preis frei EWG-AuBengrenze auf Basis Rotterdam; er ist unabhängig vom tatsächlichen Einkaufspreis des Importeurs). Eine Zusatzabschøpfung findet Anwendung, wenn der Angebotspreis eines Drittlandes unter den cif-Preis sinkt. Vgl. Fünfter Gesamtbericht über die Tätigkeit der Europăischen Wirtschaftsgemeinschaft, a.a.O., Ziff. 113 .

${ }^{3}$ Das gleiche gilt für Reis. "Die entsprechende Marktordnung trat am 1.9. 1964 in Kraft; der gemeinsame Agrarmarkt wurde am 1.9.1967 verwirklicht. Da dieser Marktordnung im Handel mit den betrachteten südosteuropäischen Lándern keine große Bedeutung zukommt, wird hierauf nicht näher eingegangen.

- Fünfter Gesamtbericht über die Tätigkeit der Europåischen Wirtschaftsgemeinschaft, a.a.O., Ziff. 114.

5 Vgl. Fünfter Gesamtbericht über die Tatigkeit der Europăischen Wirtschaftsgemeinschaft, a.a.O., Ziff. $104 \mathrm{ff}$. 
kommt jedoch eine Sonderregelung mengenpolitischer Art hinzu: Im Fall von Agrareinfuhren aus Ostblockländern erfolgt keine Aufhebung, sondern lediglich eine Neuordnung der mengenpolitisch notwendigen Beschränkungen. An die Stelle früherer Kontingente traten sogenannte Schätzbeträge, die in die bilateralen Handelsabkommen mit den Staatshandelsländern aufgenommen wurden. Diese Schätzbeträge basieren auf den 1960 und 1961 tatsächlich durchgeführten Einfuhren oder auf den für 1962 gemeinsam vereinbarten Kontingenten. Ausnahmsweise können, nach Absprache mit den Partnerländern der Gemeinschaft, auch höhere Schätzbeträge vereinbart werden. Von besonderer Bedeutung ist die Bestimmung, daß jedes Einfuhrland von sich aus die Einfuhr einstellen kann, wenn der Schătzbetrag erreicht ist und Marktstörungen drohen. Wird er um mehr als 20 v. H. überschritten und der Markt in einem Mitgliedsland ernstlich gefährdet, so kann die Kommission von sich aus oder auf Antrag dieses Landes die Einfuhr aussetzen.' Dadurch haben die Mitgliedstaaten die Möglichkeit, gegenüber den Ostblockländern vorübergehend vom Grundsatz der Liberalisierung abzuweichen. Dies bedeutet, daß das vom Ministerrat am 24. 1. 1963 beschlossene Verfahren es ermöglicht, "sämtliche mengenmäßigen Beschränkungen bei der Einfuhr der betreffenden Güter aus den Ostblockländern zu beseitigen, doch werden zu gleicher Zeit Kontrollen und ein Verfahren eingeführt, mit dessen Hilfe diese Liberalisierung im Fall von Marktstörungen wieder rückgängig gemacht werden kann." 2

Wie bekannt, hat Ungarn nach Polen als zweiter Ostblockstaat mit der EWG eine Vereinbarung im Bereich des Agrarhandels getroffen, derzufolge Ungarn sich verpflichtet, die Einschleusungspreise der EWG bei verschiedenen Marktordnungsgütern nicht zu unterbieten. Auf Grund dieser Verpflichtung hat die Kommission der Gemeinschaft beschlossen, bei den betreffenden ungarischen Ausfuhren keine Zusatzabschöpfungen mehr $z u$ erheben. ${ }^{3}$

Die EWG-Mitgliedstaaten verhielten sich gegenüber der gemeinsamen auBenhandelswirksamen Agrarpolitik recht unterschiedlich, und die EntschlieBung vom 24.1.1963 stellt eigentlich nur eine Kompromißformel dar. Dies rührt daher, daß die kommerziellen Interessen der einheimischen Industrie hinsichtlich der Ausfuhren in die Ostblockländer, ganz besonders jedoch in die südosteuropäischen Staatshandelsländer, berücksichtigt werden

' Vgl. Rolf SANNWALD, Die Europäische Wirtschaftsgemeinschaft und der Osthandel, a.a.O., S. 126; John P. de GARA, Trade Relations between the Common Market and the Eastern Bloc, Brugges 1964, S. 24.

Die Aussetzung der Einfuhr wurde bisher noch in keinem einzigen Fall verwirklicht. Vgl. Bericht des Außenhandelsausschusses des Europäischen Parlaments über Fragen der gemeinsamen Handelspolitik, a.a. O., S. 5 .

${ }^{2}$ Sechster Gesamtbericht über die Tătigkeit der Europäischen Wirtschaftsgemeinschaft, a.a. O., Ziff. 268.

3 Vgl. "Handel sblatt", Düsseldorf v. 22.7.1968. 
müssen. Auf Grund des bilateralen Ausgleichs der Handelsbilanzen sind die industriellen Exporte der EWG-Länder unmittelbar und direkt abhängig von den Devisenerwerbs- und Verrechnungsmöglichkeiten der Staatshandelsländer und damit weitgehend von der Möglichkeit, Agrarprodukte in den Westen zu exportieren. Verschiedentlich wurde auch befürchtet, daß eine restriktive Behandlung der östlichen Ausfuhren als Modell für eine ähnliche Regelung in anderen Wirtschaftsbereichen, so z. B. auf dem Energie- oder Industriesektor dienen könnte. Hinzu kommt, daß eine protektionistische Agrarpolitik die Gefahr einer innergemeinschaftlichen Überproduktion in sich birgt. ${ }^{1}$

Eine Neuregelung der Verordnung 3/63 wurde für Anfang 1968 ins Auge gefaßt (Vorschlag der Kommission vom 3.7.1967 (Kom. (67) 314 endg.)). Im wesentlichen geht es dabei darum, die Sonderstellung der Staatshandelsländer zu beseitigen. ${ }^{2}$

\section{b12) Preisbelastungen von nichtmarktordnungsgebundenen Agrargütern} sowie Waren industriell-gewerblicher Art

Grundsätzlich gelten für den Wirtschaftsverkehr der EWG mit Staatshandelsländern bei nichtmarktordnungsgebundenen Agrargütern und Gütern gewerblich-industrieller Art zollrechtlich keine Besonderheiten. ${ }^{3}$ Dies gilt auch, nachdem am 1.7.1968 die Zollunion vollendet wurde und gegenüber Drittländern ein einheitlicher Außentarif zur Anwendung kommt.

Die gegenseitige Zollangleichung bedeutet nun nicht, daß eine gemeinschaftliche Politik in Zollfragen erst ab diesem Zeitpunkt möglich ist. Vielmehr waren sich - im Gegensatz $z u$ anderen Bereichen der Handelspolitik schon frühzeitig sämtliche Mitgliedsländer der EWG darüber einig, daß Zollfragen, insbesondere Zolltarifverhandlungen, in die Zuständigkeit der Gemeinschaft übergeführt werden müssen und auch wurden.

I Im Juni 1965 übermittelte die Kommission dem Ministerrat einen Vorschlag zur Verlängerung der Gültigkeitsdauer der Verordnung Nr. 3/63. Der Rat billigte diesen Vorschlag am 29.12.1965. Vgl. auch Michael VON BERG, Erich KLINKMULLER, Die Einfuhrpolitik der Bundesrepublik Deutschland gegenüber den Ostblockländern und ihre Exportmöglichkeiten in die Bundesrepublik, "Konjunkturpolitik', Jg. 12, Berlin 1966, S. 339 ff.

${ }^{2}$ Dies dürfte sicherlich auch darauf zurückzuführen sein, daß der Anteil der Agrareinfuhren der EWG aus den ost- und südosteuropäischen Staatshandelsländern, gemessen am EWG-Gesamtaußenhandelsvolumen, recht gering ist.

${ }^{3} \mathrm{Vgl}$. Joachim BAUMANN, Außenwirtschafts-, zoll- und steuerrechtliche Fragen bei Kooperation nach dem Recht der EWG-Staaten, in: Rechtsfragen der Kooperation $z w i s c h e n$ Unternehmen in Ost und West. Studien des Instituts für Ostrecht, München - Herrenalb 1967, S. 82. 
Unmittelbar verbunden mit der Vergemeinschaftung des EWG-Außenzolltarifs ist der Abbau der Ein- und Ausfuhrzölle sowie sonstiger Abgaben mit zollăhnlicher Wirkung und der mengenmäßigen Beschränkung zwischen den Mitgliedstaaten.' Da die EWG die Ausnahmebestimmungen des GATT für Zollunionen in Anspruch nehmen kann, ist sie formell nicht gezwungen, die Meistbegünstigung auf der Grundlage der internen Vorteile, die sich die Mitgliedslănder gegenseitig gewähren, an Dritte weiterzugeben. ${ }^{2}$ Die Ostblockländer, an ihrer Spitze die Sowjetunion, wandten sich gegen diese Bestimmung des GATT und versuchten, durch zweiseitige Verhandlungen mit den Mitgliedstaaten die Meistbegünstigungsklausel auch für die innerhalb der Gemeinschaft schrittweise ermäßigten Zölle zu erhalten. Die kommunistischen Länder fühlten sich von der EWG diskriminiert, weil sie, ebensowenig wie die anderen Drittländer, nicht in den Genuß des gemeinschaftsinternen Zollabbaus kamen. Formal versuchte man die Diskriminierung mit der Nichtanerkennung der in den GATT-Statuten festgelegten Zollunion $z u$ begründen. ${ }^{3}$ Moskau verlangte im Jahre 1962 von Frankreich die Zuerkennung dieser Klausel, ließ aber diese Forderung im weiteren Verlauf der Handelsvertragsverhandlungen wieder fallen. "Die Sow jetunion interpretierte die Ausnahmebestimmungen des GATT als Ausdruck des Rechtsgedankens, daß dritte Staaten Kompensationsansprüche geltend machen könnten, solange die Zollunion nicht vollständig gebildet sei, und wandte für einige französische Produkte die Maximalsătze ihres kurz zuvor eingeführten zweigleisigen Zolltarifs an."4

Da nach Auffassung des Außenhandelsausschusses des Europäischen Parlaments die Sowjetunion damit die Existenz der EWG als Zollunion anerkannte, versuchte die EWG in der Folge, auch die Anerkennung des gemeinsamen Außenzolltarifs zu erzielen. In diesem Zusammenhang bot der Ministerrat, auf Vorschlag der Kommission, der Sow jetunion Zollsenkungen des gemeinsamen Zolltarifs für vier Produkte an, für die dieses Land Hauptlieferant der EWG ist (u. a. Kaviar und Wodka). Obgleich dieses An-

'Vgl. Neunter Gesamtbericht über die Tätigkeit der Europäischen Wirtschaftsgemeinschaft, a.a.O., Ziff. $26 \mathrm{ff}$.

2 Vgl. Ferdinand K. LIEBICH, a.a.O., S. 88 ff.; Helmut STEINBERGER, GATT und regionale Wirtschaftszusammenschlüsse, hrsg. vom Max PlanckInstitut für ausländisches offentliches Recht und Völkerrecht, Köln und Berlin 1963 , S. 93 ff.

${ }^{3}$ Vgl. Joachim WILLMANN, a.a.O., S. 20. Von den drei Ausnahmen des GATT von der Meistbegünstigung, nämlich der Freihandelszone, der Zollunion und dem Nachbarschaftsverkehr, erkennen die Ostblockländer nur den Nachbarschaftsverkehr an. Vgl. Kurt WESSELY, Österreichische Erfahrungen mit den RGW-Ländern im bilateralen Warenverkehr, in: Ost-West-Handel in Theorie und Praxis, a.a.O., S. 43.

4 Rolf SANNWALD, Die Europăische Wirtschaftsgemeinschaft und der Osthandel, a.a.O., S. 123 . 
gebot schon im Jahre 1963 überreicht wurde, ist eine Antwort in Brüssel bisher ausgeblieben.'

b13) Mengenbeschränkungen für Roheisen- und Stahleinfuhren

Da die Fusion der Europäischen Gemeinschaften ${ }^{2}$ - am 8.4.1965 von den Regierungen der Mitgliedstaaten beschlossen - endgültig am 1.7.1967 vollzogen wurde und die gemeinsame Kommission ihre Tătigkeit am 6. 7. 1967 aufnahm, sind die bis dahin erfolgten handelspolitischen Beschlüsse der Europäischen Gemeinschaft für Kohle und Stahl (EGKS) nunmehr Bestandteil der Handelspolitik der EWG. ${ }^{3}$ Im einzelnen handelt es sich dabei um folgende Maßnahmen:

Der Ministerrat der EGKS beschloß am 6.6.1963 mit Wirkung vom 1.7. 1963 eine Beschränkung der Stahleinfuhren aus Staatshandelsländern; am 15. 7. 1963 erging die gleiche Entscheidung für die Einfuhr von Roheisen. ${ }^{4}$ Die EGKS-Mitgliedstaaten, welche die Neigung zeigten, ihren Gesamtaustausch mit den Ostblockländern im Rahmen der Möglichkeiten zu steigern, sahen sich zu diesen Maßnahmen gezwungen, um der auch auf Niedrigpreiseinfuhren aus Ländern oder Gebieten mit Staatshandel zurückzuführenden Verschlechterung der Stahl- und Roheisenmarktlage zu begegnen. Im wesentlichen bestanden diese Maßnahmen in der Begrenzung der Volumen dieser Einfuhren auf das Niveau der in den zweiseitigen Handelsabkommen vereinbarten Kontingente," "... welche ihrerseits unter verschie-

' Vgl. Bericht im Namen des Außenhandelsausschusses des Europäischen Parlaments über Fragen der gemeinsamen Handelspolitik, a.a. O., S. 4; Jean REY, Les échanges extérieurs de la Communauté Economic Européenne, aspects particuliers des relations avec les pays de l'Est, in: Les Communautés Européennes et les Relations Est-Ouest, Bruxelles 1967, S. 24. 2 EWG, EGKS und Europäische Atomgemeinschaft (Euratom).

${ }^{3}$ Gemäß Art. 1 des Fusionsvertrages tritt der Rat der Europaischen Gemeinschaften an die Stelle des Rates der EWG, des Rates der Europaischen Atomgemeinschaft und des Besonderen Ministerrates der EGKS. Gleichzeitig ist die Kommission der Europăischen Gemeinschaften an die Stelle der bisherigen Exekutivorgane getreten. Vgl. Erster Gesamtbericht über die Tätigkeit der Gemei.sschaften 1967 (EGKS - EWG - Euratom), Brüssel-Luxemburg, Februar 1968, S. 17.

Zwei der vier Organe der Europäischen Gemeinschaft wurden damit von der Fusion berührt, nämlich der gemeinsame Ministerrat und die gemeinsame Kommission. Das Europäische Parlament und der Europäische Gerichtshof hatten schon vorher ihre organisatorische Einheit gefunden. Vgl. "Der Volkswirt", Frankfurt/M. Nr. 27 v. 7.7.1967, S. 1351.

- Vgl. Bulletin der Europăischen Gemeinschaft für Kohle und Stahl, Chronologie der Europăischen Gemeinschaft für Kohle und Stahl (1950 - 1966), Jg. 12 , N r. 4, Luxemburg 1967. 
denen Voraussetzungen gelockert werden können." I Die Einfuhrbeschränkungen wurden durch Vorschriften ergänzt, welche - die nach dem Montanvertrag normalerweise zulässigen - Angleichungen der Produzenten der Gemeinschaft an niedrigere Angebote der Staatshandelsländer untersagen. Die Entscheidung der Hohen Behörde über das Ausgleichsverbot erging am 15.1.1964. Zum gleichen Zeitpunkt wurden von der Behörde die gemeinsamen Schutzzölle an den Außengrenzen der Gemeinschaft für Stahl und Stahlerzeugnisse auf das Niveau des harmonisierten italienischen Zolltarifs (durchschnittlich etwa 9 v. H.) in Übereinstimmung mit den Vorschriften des GATT erhöht. ${ }^{2}$ Der gemeinsame Außenzolltarif jedoch wirkt nicht nur gegenüber den Staatshandelsländern, sondern gegenüber allen Drittländern. ${ }^{3}$ Das gleiche gilt für den ab demselben Zeitpunkt erhobenen spezifischen Zoll in Höhe von 7.- US- \$ je metrische Tonne Gußroheisen. Dieser Zoll blieb bis einschließlich 1966 in dieser Höhe bestehen, wurde jedoch ab 1967 auf 5.-US- \$ gesenkt. ${ }^{4}$ Für beide Erzeugnisgruppen können unter bestimmten Voraussetzungen Zollkontingente gewährt werden. ${ }^{5}$

Die Gesamtheit dieser Maßnahmen ist in unmittelbarem Zusammenhang zu sehen mit der schwierigen Situation auf dem Stahl- und Roheisenmarkt der Gemeinschaft. Es bestand unter den Mitgliedern daher Einverständnis darüber, daß die Wirkungen dieser Maßnahmen aufmerksam überwacht, gelockert und sogar aufgehoben werden müssen, sobald die verbesserten Marktbedingungen diese gestatten. Die gemeinschaftlichen Solidaritätsmaßnahmen zur Begrenzung der Einfuhr von Stahlerzeugnissen aus Staatshandelsländern wurden seit dem Jahre 1963 alljăhrlich verlăngert. Da-

1 14. Gesamtbericht über die Tätigkeit der Europăischen Gemeinschaft für Kohle und Stahl (1. Februar 1965 - 31. Januar 1966), Luxemburg, Mărz 1966, Ziff. 47.

${ }^{2} \mathrm{Vgl}$. 13. Gesamtbericht über die Tätigkeit der Europäischen Gemeinschaft für Kohle und Stahl (1. Februar 1964 - 31. Januar 1965), Luxemburg, März 1965, Ziff. 47; desgl., 12. Gesamtbericht (1. Februar 1963 - 31. Januar 1964), Luxemburg, März 1964, Ziff. 51 .

${ }^{3}$ In Anwendung der Bestimmungen für die Ưbergangszeit haben die Mitgliedstaaten der EGKS am 10.2.1958 für ihre A ußengrenzen auf dem Niveau der niedrigsten Sătze der Gemeinschaft einen harmonisierten Zolltarif aufgestellt. Bei Frankreich und Italien kam zu diesen Sătzen noch ein "geographischer Schutz" hinzu, der im Falle Italiens je nach Erzeugnis bis zu vier Punkte betragen konnte. Der durchschnitliche Schutzzoll der Gemeinschaft belief sich damit auf etwa 6 v. H.

Vgl. Sechster Gesamtbericht über die Tätigkeit der Europăischen Gemeinschaft für Kohle und Stahl, Bd. 1, "Die Politik der Hohen Behörde", Luxemburg, 13. April 1958.

-Vgl. 14. Gesamtbericht über die Tätigkeit der Europäischen Gemeinschaft für Kohle und Stahl, a.a. O., Ziff. 45.

5 Vgl. 13. Gesamtbericht über die Tätigkeit der Europäischen Gemeinschaft für Kohle und Stahl, a.a.O., Ziff. 47. 
durch war es möglich, "... die im gemeinsamen Markt für Stahl aufgetretenen Schwierigkeiten, die sich $\mathrm{z} . \mathrm{T}$. durch Preisverfall bemerkbar machten, erheblich $\mathrm{zu}$ verringern." 1

Da die Anfang 1964 eingeführten Außenzölle für Stahleinfuhren als Ausgangspunkt für die als Ergebnis der Verhandlungen im Rahmen der Kennedy-Runde vorgesehenen Herabsetzungen angenommen worden sind, blieben diese Zölle bis zum 30.6.1968 in Kraft. Am 1.7.1968 sollte eine erste (doppelte) Herabsetzungsstufe in Kraft treten, vor der die Kommission der Europäischen Gemeinschaften jedoch noch die erforderlichen Ausnahmebestimmungen erlassen mußte. ${ }^{2}$

Während der Stahl- und Roheiseneinfuhr aus den südosteuropăischen Staatshandelsländern relativ geringe Bedeutung zukommt, ist der Import von Erdöl und Erdölerzeugnissen von entschieden größerer Wichtigkeit. Bislang besteht zwar für Einfuhren dieser Art noch keine Gemeinschaftsregelung, doch veröffentlichten die Europäischen Gemeinschaften im August $1962 \mathrm{im}$ "Memorandum über die Energiepolitik" Vorschläge für die Verwirklichung eines gemeinsamen Energiemarktes. Der Grund dafür, daß eine gemeinsame Regelung bis heute nicht in die Tat umgesetzt werden konnte, ist wohl vor allem im Interessenkonflikt der Mitgliedsländer der Gemeinschaft $z$ u suchen. ${ }^{3}$

Im Rahmen eines zukünftigen gemeinsamen Energiemarktes dürften Einfuhrkontingente auch für Erdöl und Erdölerzeugnisse aus den Staatshandelsländern zu erwarten sein.

b2) Verordnungsvorschläge der EWG-Kommission zur Aufstellung gemeinsamer Liberalisierungslisten der Einfuhr und zur Abwehr anomaler Handelspraktiken

Eines der wichtigsten Anliegen der Kommission zur Vorbereitung einer gemeinsamen Handel spolitik gegenüber den Staatshandelsländern ist es, die nationalen Einfuhrkontingente und Liberalisierungslisten der einzelnen Mitgliedstaaten ${ }^{4}$ gemäß den im Arbeitsprogramm des Ministerrates zur

1 Erster Gesamtbericht über die Tätigkeit der Gemeinschaften 1967 (EGKS EWG - Euratom), a.a.O., Ziff. 498.

$2 \mathrm{Vgl}$. ebd., Ziff. 497.

${ }^{3} \mathrm{Vgl}$. Michael VON BERG, Auswirkungen der EWG auf den Handelsverkehr, a.a.O., S. $169 \mathrm{ff}$; ders. und Erich KLINKMÜLLER, Die Einfuhrpolitik der Bundesrepublik Deutschland gegenüber den Ostblockländern und ih re Einfuhrmöglichkeiten in die Bundesrepublik, a.a. O., S. $344 \mathrm{f}$.

4 Vgl. S. 94 ff. 
gemeinsamen Handel spolitik vom 25.9.1962 festgelegten Grundsätzen zu ersetzen. ' Den Vorschlägen der Kommission vom 26.2.1964 zufolge geht es vorwiegend darum, die eingeführten Güter im wesentlichen in drei Gruppen zusammenzufassen, "... von denen die erste liberalisiert werden könnte, während die zweite nichtliberalisierte Güter umfaßt und die dritte einem Sonderverfahren unterworfene Güter enthalten soll. " 2

Fortschritte bei der Aufstellung solcher Warenlisten sind erst in allerjüngster Zeit zu beobachten. So wird der seit dem 14.4.1964 vorliegende Verordnungsvorschlag über die Aufstellung einer gemeinsamen Liberalisierungsliste für die Einfuhr aus dritten Ländern seit Oktober 1967 vom Ministerrat geprüft; desgleichen der Vorschlag vom 18.5.1965 über die schrittweise Vergemeinschaftung des Verfahrens für die Verwaltung von Einfuhrkontingenten. Insbesondere hat die Kommission dem Rat am 28.9. $1966 \mathrm{zu}$ diesen Vorschlägen eine Reihe von notwendigen Anderungen, vor allem hinsichtlich einer verstärkten Mitwirkung der Kommission bei der Aufteilung der Kontingente vorgelegt. ${ }^{3}$

Eng verbunden mit der gemeinschaftlichen Neuordnung der Einfuhrregelung ist die Harmonisierung der Vorschriften der EWG-Mitgliedsländer gegenüber anomalen Handelspraktiken. Zur Abwendung von marktstörenden Niedrigpreiseinfuhren vor allem aus Staatshandelsländern hat die Kommission dem Ministerrat am 6.5.1965 daher einen Verordnungsvorschlag über den "Schutz gegen Praktiken von Dumping, Prämien und Subventionen aus nicht zur EWG gehörenden Ländern' zugestellt. 4

\section{b3) Die residuale Einfuhrpolitik der EWG-Mitgliedstaaten}

Nachdem in den vorangegangenen Abschnitten die gemeinschaftlichen einfuhrpolitischen Maßnahmen der EWG unter besonderer Berücksichtigung der Sonderbestimmungen für Staatshandelsländer betrachtet wurden,

1 Vgl. Sechster Gesamtbericht über die Tătigkeit der Europäischen Wirtschaftsgemeinschaft, a.a.O., Ziff. $263 \mathrm{ff}$; Arbeitsdokument des Ausschusses für Außenwirtschaftsbeziehungen des Europăischen Parlaments über die Probleme der Handelsbeziehungen zwischen der Gemeinschaft, a. a.O., S. 8; "Amtsblatt der Europäischen Gemeinschaften", Nr. 90 v. 5.10.1962.

2 Bericht im Namen des Außenhandelsausschusses des Europäischen Parlaments über Fragen der gemeinsamen Handelspolitik, a.a.O., S. 13.

${ }^{3} \mathrm{Vgl}$. Arbeitsdokument des Ausschusses für Außenwirtschaftsbeziehungen, a.a.O.; Otto Wolf von AMERONGEN, Die EWG und ihre Möglichkeiten der Zusammenarbeit, a.a.O., S. 85 .

- Dieser Vorschlag wurde unter Berücksichtigung der Initiativen, die auf diesem Sektor im Rahmen der Kennedy-Runde ergriffen wurden, am 17.2. 1966 ergänzend geăndert.

Vgl. Arbeitsdokument des Ausschusses für Außenwirtschaftsbeziehungen, a.a.O., S. $13 \mathrm{f}$. und S. 23 . 
schließt sich im weiteren Verlauf der Untersuchung eine Darstellung der noch in der autonomen Kompetenz der Mitgliedsländer verbliebenen OstEinfuhrregelungen an.

\section{Die Bundesrepublik Deutschland}

Mit der Beendigung des Besatzungsregimes in der Bundesrepublik gingen die Kompetenzen im Außen- und Interzonenwirtschaftsverkehr am 5.5. 1955 in den Zuständigkeitsbereich der Bundesregierung über. Die Ablösung des "Gesetzes zur Devisenbewirtschaftung und Kontrolle des Güterverkehrs" (Gesetz Nr. 53, Neufassung, veröffentlicht im Bundesanzeiger Nr. 2 vom 27.9.1949) der Militärregierung durch das AWG am 1.8.1961, das von einer grundsätzlichen Freiheit in der rechtlichen Ordnung des Außenwirtschaftsverkehrs ausgeht, brachte eine weitgehende Liberalisierung des deutschen Außenhandels.' Während die Einfuhr aus nichtkommunistischen Ländern weitgehend liberalisiert und genehmigungsfrei wurde, unterwarf man jedoch die Importe aus kommunistischen Ländern entsprechend $\$ 6$ AWG zur "Abwehr schädigender Einwirkungen aus fremden Wirtschaftsgebieten" verschiedenen Beschränkungen. Dies hatte zur Folge, daß bis zum Jahre 1966, als eine Teilliberalisierung der Wareneinfuhr aus bestimmten Ostblockländern beschlossen wurde, Importe aus kommunistischen Ländern grundsätzlich nur auf der Grundlage von Einfuhrkontingenten erfolgen konnten. Im Rahmen dieser Kontingente wurden die Waren auf dem Wege von Ausschreibungen im Bundesanzeiger zur Einfuhr freigegeben. Die jeweilige Höhe der Einfuhrkontingente, die keine Einfuhrverpflichtung darstellen, wird in bilateralen Verhandlungen mit dem kommunistischen Handelspartner bestimmt und findet ihren Niederschlag in den Warenlisten $z u$ den bestehenden Handels- und Zahlungsabkommen. 2 Da die Osthandelspolitik der Bundesrepublik generell durch eine $z$ unehmende Bereitschaft zur Ausdehnung des Handels gekennzeichnet ist, erfolgte nach gründlicher Vorbereitung im Jahre 1966 eine Modifikation dieser Politik. Dies ist jedoch nicht nur auf ökonomische, sondern in hohem Maße auch auf politische Gründe zurückzuführen. Die modifizierte Handelspolitik zielt dabei auf eine Erweiterung des Handels mit den sozialistischen Ländern primär durch Ausdehnung der Exportmöglichkeiten dieser Länder in die Bundes republik ab. Die Bundesrepublik hat damit aber kein Neuland beschritten, vielmehr ist sie nur dem Beispiel und den Erkenntnissen anderer westlicher Länder, vor allem Großbritanniens, gefolgt. ${ }^{3}$

\footnotetext{
1 Die Vorschriften der Militärbehörden über den Interzonenhandel blieben jedoch auch nach 1961 in Kraft.

Vgl. Michael VON BERG und Erich KLINKMÜLLER, Die Einfuhrpolitik der Bundesrepublik ge genüber den Ostblockländern, a.a. O., S. $336 \mathrm{f}$.

2 Vgl. ebd., S. $337 \mathrm{f}$.

$3 \mathrm{Vgl}$. ebd., S. $338 \mathrm{f}$.
} 
Im Handelsverkehr der Bundesrepublik mit Bulgarien, Rumänien und Ungarn' wird seit dem 6.5.1966 zwischen einem kontingentierten und einem nichtkontingentierten Bereich unterschieden. Obgleich nurmehr der kontingentierte Bereich Gegenstand von Handelsverträgen bzw. - abkommen ist, bedürfen doch auch die nichtkontingentierten Einfuhren weiterhin Einfuhrgenehmigungen. Im Gegensatz $z u$ den in bilateral ausgehandelten Kontingenten zusammengefaßten Warengruppen, für die das Einzelgenehmigungsverfahren gemäß $\$ 10$ Abs. 1 AWG in Verbindung mit der jeweiligen Einfuhrliste erforderlich ist, wird im sogenannten liberalisierten, also nicht quotengebundenen, Bereich die Ausschreibung mit laufender Antragstellung praktiziert. Im Rahmen dieses Verfahrens, das das System der "offenen Ausschreibung" ablöste, werden Einfuhrgenehmigungen in mengenmäßig unbeschränkter Höhe erteilt. Voraussetzung ist jedoch, daß

1. aus Kreisen der Wirtschaft keine Bedenken beim Bundesamt für gewerbliche Wirtschaft oder beim Bundesamt für Ernährung und Landwirtschaft geltend gemacht werden und

2. keines dieser Ämter selbst eine Einfuhrbeschränkung aus übergeordneten Belangen für erforderlich hält. ${ }^{2}$

Der Bereich der weiterhin kontingentierten Waren erstreckt sich vor allem auf sogenannte "neuralgische" Waren, ${ }^{3}$ deren mengenmäßig unbeschränkte Einfuhr in die Bundesrepublik gegen ein berechtigtes Schutzbedürfnis der Wirtschaft oder einzelner Wirtschaftszweige verstoßen würde. Einfuhrkontingente werden aber dennoch erteilt, weil insbesondere aus Gründen der binnenwirtschaftlichen Preisstabilisierung seitens der Bundesrepublik Interesse für diese Waren gezeigt wird. 4

Das liberalisierte Einfuhrverfahren wird derzeit nur gegenüber jenen Ostblockländern angewendet, mit denen die Bundesrepublik in handelsvertraglichen Beziehungen steht. Seit seinem Inkraftreten im Jahre 1966 ist es gegenüber den Staatshandelsländern Südosteuropas gültig.

Das System der laufenden Antragstellung und unmittelbaren Einfuhrlizenzierung ist mit Sicherungen gegen etwaige Marktstörungen durch Niedrigpreiseinfuhren verbunden. Um solche Störungen zu vermeiden, unterwarf man das Verfahren zur Einfuhrbeobachtung und Preisprüfung einer Neuregelung. Im $\mathrm{Fall}$ von ungerechtfertigt erscheinenden Preisunterbietungen der Ostblockländer müssen die den Bundesministerien für Wirtschaft bzw.

1 Desgleichen mit Polen und der Tschechoslowakei.

$2 \mathrm{Vgl}$. 10 Abs. 3 AWG in Verbindung mit den $\$ 5-7$ AWG.

Vgl. Joachim BAUMANN, a.a.O., S. $79 \mathrm{f}$.

${ }^{3}$ Neuralgische Waren sind vorwiegend Konsumgüter wie Textilien, Lederwaren, Holzwaren (insbesondere Möbel), Keramik und Spielwaren.

4 Vgl. Michael VON BERG und Erich KLINKMULLER, a.a.O., S. 346. 
Landwirtschaft nachgeordneten Bundesämter ${ }^{l}$ von Amts wegen oder auf Antrag der Unternehmer oder deren Verbände die Einfuhren solcher Güter für die Dauer ihrer Überprüfung aussetzen. Voraussetzung ist jedoch, daß, ähnlich wie in den meisten anderen westeuropäischen Ländern, sogenannte Preisprüfungsklauseln in den Handelsverträgen verankert sind. Diese sollen ein Urteil darüber ermöglichen, ob die Kalkulation nach den in westlichen Ländern üblichen und notwendigen vergleichbaren Richtlinien erfolgt. Bei liberalisierten Waren, die vorab in den Liberalisierungslisten als neuralgisch gekennzeichnet sind und bei denen Einfuhren zu nichtmarktgerechten Preisen zur ernsten Gefährdung einzelner Wirtschaftszweige führen könnten, sind die zuständigen Genehmigungsbehörden sogar angehalten, bereits bei Erteilung der Lizenz eine entsprechende Preisprüfung vorzunehmen. ${ }^{2}$

Weitere Kontrollmöglichkeiten ergeben sich aus der laufenden Beobachtung der Einfuhrentwicklung durch die genannten Behörden sowie die Stellungnahmen der Wirtschaft im Fall eines drohenden Schadens für bestimmte Wirtschaftsbereiche. ${ }^{3}$

Wird festgestellt, daß durch Importe zu nichtmarktgerechten Preisen beträchtliche Schädigungen der inländischen Erzeuger eingetreten sind oder einzutreten drohen, dann kann der "interministerielle Einfuhrausschuß" folgende Maßnahmen nach Maßgabe der AWG ergreifen, um die betreffenden Einfuhren unter Kontrolle zu bringen: ${ }^{4}$

"1. Auflage, die abgeschlossenen Einfuhrverträge vorzulegen,

2. Vorlage von Festofferten oder Vorbehaltungskontrakten bei Antragstellung,

3. Einhaltung bestimmter Mindest- oder Höchstpreise bei bestimmten Massengütern",

4. Streichung der betreffenden Ware aus der jeweiligen Ausschreibung mit laufender Antragstellung.

Die liberalisierten Ausschreibungen können, soweit dies zum Schutz der in $\$ 10 \mathrm{Abs}$. $3 \mathrm{AWG}$ genannten Belange unter Berücksichtigung der handelsund sonstigen wirtschaftspolitischen Erfordernisse geboten ist, ${ }^{5}$ wider-

' Bundesamt für gewerbliche Wirtschaft und Bundesamt für Ernährung und Landwirtschaft.

2 Vgl. "Nachrichten für den Außenhandel", Köln v. 6. 5. 1967; Hans Andreas SIEMANN, Liberalisierung der Osteinfuhr, Beiheft zu "Der Volkswirt", Nr. 21 v. 26.5.1967, S. 5; Klaus-Heinrich ST ANDKE, a.a.O., S. 173.

Nähere Einzelheiten über das Preisvergleichsverfahren finden sich im "Runderlaß Außenwirtschaft", Nr. 17/66.

$3 \mathrm{Vgl}$. "Runderlaß Außenwirtschaft", Nr. $17 / 66$.

Klaus-Heinrich STANDKE, a.a.O., S. 173.

5 Vgl. "Runderlaß Außenwirtschaft", Nr. 17/66. 
rufen werden. Die Einfuhr wird dann gestoppt und gegebenenfalls wieder in die Kontingentierung übergeführt. Insofern handelt es sich hier um eine Liberalisierung mit Vorbehalt (Quasiliberalisierung). Das deutsche System der laufenden Antragstellung stellt also keine de jure-Liberalisierung im klassischen Sinn, z. B. des OEEC-Codes oder der GATT-Bestimmungen dar, wohl aber eine autonome de facto-Liberalisierung sui generis, welche die Kontingente formell abschaff, die Einfuhren aber weiterhin genehmigungspflichtig beläßt. ' Bisher wurde weder die Ausschreibung noch ihre Zusammensetzung mit den östlichen Partnerländern ausgehandelt und auch nicht in den Handelsabkommen festgelegt. 2

Der Abbau der mengenmäßigen Beschränkungen für Einfuhren aus den kommunistischen Ländern ist in verschiedenen Etappen verlaufen. Die erste Liberalisierungsmaßnahme wurde bereits Anfang der fünfiger Jahre eingeleitet und erstreckte sich auf alle Ostblockstaaten. Sie betrag in erster Linie Rohstoffe und Halberzeugnisse (ca. 200 Warenpositionen), die in der Bundesrepublik überhaupt nicht oder nur unzureichend vorhanden waren und demzufolge sowieso eingeführt werden mußten. ${ }^{3}$

Der entscheidende Schritt zur Liberalisierung der Einfuhr aus den südosteuropäischen Staatshandelsländern (aber auch aus Polen und der Tschechoslowakei) erfolgte, wie bereits erwähnt, am 5.5.1966. Im "Bundesanzeiger" Nr. 86 vom 6.5.1966 wurden für die Einfuhren aus den Ostblockländern, mit denen Handelsverträge bestehen, entscheidende Erleichterungen verkündet. Damit konnten 61,5 v.H. der Einfuhren aus Bulgarien, Rumänien und Ungarn, insgesamt 3.642 Warenpositionen, das sind mehr als die Hälfte der Warennummern der gewerblichen Wirtschaft ( $53 \mathrm{v} . \mathrm{H}$. der Zolltarifpositionen) über die erweiterte Ausschreibung mit laufender Antragstellung eingeführt werden. ${ }^{4}$ Durch diese Regelung ist der Katalog der Waren, die bisher bereits der laufenden Antragstellung unterlagen, wesentlich erweitert und vor allem auch die liberalisierte Einfuhr von bestimmten Erzeugnissen aus den Bereichen der Chemie, der Maschinen-, Fahrzeug- und Stahlindustrie sowie der Elektrotechnik, der Feinmechanik und der Optik möglich geworden. ${ }^{5}$ Die seither letzte Etappe der Quasiliberalisierung wurde im Dezember 1967 erreicht und im "Bundesanzeiger" Nr. 234 vom 14.12.1967 verkündet. Damit hat die Liberalisierung gegenüber den genannten Ländern einen Stand von ca. 66 v. H. des betref-

\footnotetext{
' Vgl. Joachim BAUMANN, a.a.O., S. 79; Hans Andreas SIEMANN, a. a. O., ; Matthias SCHMITT, Osthandel auf neuen Wegen, a.a. O., S. 24.

${ }^{2} \mathrm{Vgl}$. Klaus-Heinrich STANDKE, a.a.O., S. 172.

3 Vgl. "Nachrichten für den Außenhandel", Köln v. 14. 5.1967.

$4 \mathrm{Vgl}$. Hans Andreas SIEMANN, a.a. O.

$5 \mathrm{Vgl}$. "Die Außenwirtschaft", Koln v. 12.5.1966.
} 
fenden Einfuhrvolumens aus diesen Ländern erreicht. '

Ursprünglich wollte die Bundesregierung schon im März 1967 über das Ausmaß der geplanten Erweiterung entscheiden. Grundsätzlich war diese vom Bundeskabinett schon im Januar beschlossen worden. Da sich jedoch 1. die Kontingente infolge der Liberalisierung im Jahre 1966 in erster Linie auf sogenannte neuralgische Waren erstreckten und somit dem Schutzbedürfnis der betroffenen Wirtschaftsbereiche Rechnung getragen werden mußte und da sich

2. die Bundesregierung bewußt war, daß zukünftige Fortschritte in der Ostpolitik entscheidend mit davon abhängen, inwieweit von deutscher Seite den Exportbemühungen der Staatshandelsländer entgegengekommen werden kann, verzögerte sich die endgültige Entscheidung beträchtlich. ${ }^{2}$

Vom kontingentierten Rest der Gesamteinfuhren ( 34 v. H.) dürften ca. 20 v.H. auf Mineralöle, Kohle, Eisen- und Stahlerzeugnisse entfallen. Ca. $15 \mathrm{v} . \mathrm{H}$. noch kontingentierter Erzeugnisse erstrecken sich auf Konsumund Ernährungsgüter. Die Mehrzahl von ihnen ist hoch-neuralgisch.

Im Zusammenhang mit den deutschen Neuregelungen des Handels mit den südosteuropäischen Staatshandelsländern vom Mai 1966 ist noch zu erwähnen, daß Einfuhrerklärungen nunmehr bereits vor dem Abschluß der Einfuhrverträge abgegeben werden können und nicht mehr wie zuvor binnen zwei Wochen nach Abschluß des Vertrages. Außerdem wurde die Kleineinfuhr bis zum Werte von 240, - DM je Sendung genehmigungsfrei. Diese Erleichterung gilt in erster Linie für den Import von Waren zum eigenen Ver- und Gebrauch (vorwiegend Nahrungs- und Genußmittel). ${ }^{3}$

\section{Frankreich}

Zu Beginn des Jahres 1966 entschloß sich die französische Regierung, die Einfuhr aus sämtlichen Ostblockländern, einschließlich Rotchinas, nicht jedoch der DDR, weitgehend von Mengenbeschränkungen zu befreien.

Für die liberalisierten Warengruppen finden folgende zwei Einfuhrverfahren Anwendung:

1. Die Einfuhr nichtne uralgischer Waren erfolgt gegen "Einfuhrzertifikate", die von den Importeuren selbst ausgestellt und bei einer Bank hinterlegt werden müssen.

' Vgl. Joachim BAUMANN, a.a.O., S. 80 .

Darüber hinaus sind die dem Bundeswirtschaftsministerium und dem Bundeslandwirtschaftsministerium nachgeordneten Behörden bemüht, den Ausfuhrwünschen Rumăniens in die Bundesrepublik so weit wie möglich entgegenzukommen. Vgl. auch "Süddeutsche Zeitung", München v. 10.11.1967.

¿Vgl. Hans Andreas SIEMANN, a. a. O.; "Süddeutsche Zeitung", München v. 28.2. 1967 .

$3 \mathrm{Vgl}$. "Bundesanzeiger" Nr. 86 v. 6.5. 1966. 
2. Die Einfuhr neuralgischer Waren erfolgt kraft eines "visa technique", das vom Industrieministerium auf Antrag ausgestellt wird.'

Dieser technische Sichtvermerk (2) erlaubt den Einfuhrbehörden eine genaue Beobachtung der Einfuhr aus kommunistischen Ländern sowie die laufende Kontrolle über Mengen und Konditionen der eingeführten Waren. Obgleich der Sichtvermerk grundsätzlich automatisch erteilt wird, kann die Einfuhr durch eine verzögerte Ausstellung beschränkt oder temporär ganz unterbrochen werden. ${ }^{2}$ Aus diesem Grunde hat die französische Regierung auch auf die Einführung einer ursprünglich erwogenen Schutzklausel verzichtet und darauf hingewiesen, daß sie die "autonome" Liberalisierung im Fall von Marktstörungen (bei anomalen Einfuhrpreisen) entweder unterbrechen oder durch eine Mitteilung im "Journal Officiel" widerrufen kann. ${ }^{3}$ Der Liberalisierung der Osteinfuhr vom 30.1.1966 war schon am 5.1.1961 eine weltweite Beseitigung von mengenmäßigen Einfuhrbeschränkungen vorausgegangen. Von insgesamt 919 Zolltarifpositionen waren damals bereits 123 Positionen - vorwiegend Rohstoffe - liberalisiert worden. 4 Diese Liberalisierungsliste, die auch gegenüber Ostblockländern Anwendung fand, wurde mehrfach ergänzt und umfaßte Ende 1965 bereits 250 Positionen. ${ }^{5}$

Der entscheidende Schritt zur Liberalisierung der Einfuhr aus den kommunistischen Ländern erfolgte jedoch 1966, als die Liberalisierungsliste auf die meisten der gewerblichen Positionen ausgedehnt und gegenüber den südosteuropăischen Staatshandelsländern sowie Albanien, Polen, Rotchina, der Sowjetunion und der Tschechoslowakei angewandt wurde. Entgegen den Bedenken des französischen Industrieverbandes führte man damit ca. 700 Zolltarifhauptpositionen vom kontingentierten in den nichtkontingentierten, also liberalisierten Bereich über. ${ }^{6}$ Bei den restlichen Waren erhöte man die Kontingente. ${ }^{7}$

Seit dem Jahre 1966 sind, einer Bekanntmachung im "Journal Officiel" vom 13.1.1967 zufolge, weitere 200 Waren der gewerblichen Wirtschaft in die Liberalisierungsliste einbezogen. Auch sind eine Reihe von Agrarprodukten - soweit sie nicht von der gemeinsamen EWG-Agrarpolitik er-

Vgl. "Nachrichten für den Außenhandel", Koln v. 2.2.1966.

$2 \mathrm{Vgl}$. ebd.

$3 \mathrm{Vgl}$. ebd.; "Vereinigte Wirtschaftsdienste", Frankfurt/Main v. 31.1.1966;

"Frankfurter Allgemeine Zeitung" v. 19.1.1966.

4 Vgl. Klaus-Heinrich STANDKE, a.a.O., S. 211.

$5 \mathrm{Vgl}$. "Nachrichten für den Außenhandel", Köln v. 2. 2.1966; Rundschreiben des Ostausschusses der Deutschen Wirtschaft vom 1.2.1967.

- Vgl. "Nachrichten für den Außenhandel", Köln v. 2.2.1966.

7 Der Bereich der sensiblen Waren enthält vorwiegend Werkzeugmaschinen, Traktoren, Sende- und Empfangsanlagen, Textilien. Vgl. "Vereinigte Wirtschaftsdienste", Frankfurt/M. v. 31.1.1966. 
faßt werden - von der Einfuhrkontingentierung ausgenommen worden. Damit hat Frankreich über 90 v. H. seiner Zollpositionen gegenüber den Ostblockländern liberalisiert und von Mengenbeschränkungen befreit. '

Italien

Im Vergleich $z u$ den anderen westeuropäischen Ländern verhielt sich Italien relativ zurückhaltend. 2 Erst Ende 1966 ließen Verlautbarungen des italienischen Außenhandelsministeriums darauf schließen, daß man eine Vereinheitlichung der bilateralen Liberalisierungslisten mit den Staatshandelsländern anstrebte und auch deren Angleichung an die GATT-Liberalisierung beabsichtigte. Das wurde Mitte 1967 verwirklicht. ${ }^{3}$

Das italienische Einfuhrverfahren basiert auf zwei Lănderlisten, nämlich der "Tabella A Import" und der "Tabella B Import". " "Tabella B" schlieBt alle kommunistischen Länder ein und unterscheidet zwischen kontingentierten und nichtkontingentierten (liberalisierten) Waren. Innerhalb des liberalisierten Bereichs wird wieder differenziert nach neuralgischen und nichtneuralgischen Waren. Wăhrend letztere Waren (ca. 820, d.h. 85 v. H. der Zolltarifpositionen) ohne Genehmigung importiert werden dürfen und nur den Vorschriften unterliegen, wie sie auch im Handel mit Ländern der "Tabella A" (Nicht-Ostblockländer) zu beachten sind, wird die Einfuhr der neuralgischen Waren von einem Einfuhrsichtvermerk des ICE abhängig gemacht. Darüber hinaus wird aber vom Landwirtschaftsministerium für ca. 50 liberalisierte Agrargüter eine qualitative Einfuhrkontrolle durchgeführt. Einfuhrlizenzen in Form des Einfuhrsichtvermerks werden nur jenen Unternehmen gewährt, die beim Außenhandelsministerium als Importunternehmen bekannt sind. 5

Dem Sichtvermerkverfahren unterliegen ungefăhr 120 Güterarten. Alle anderen Einfuhren aus Ostblockländern, die also unter den liberalisierten Bereich der "Tabella $B$ " fallen, sind von keinen besonderen Einfuhrkon-

'Vgl. "Neue Zürcher Zeitung" v. 17.1.1967; Economic Bulletin for Europe, Vol. 19, No. 1, United Nations, New York 1967, S. 54.

2 Vor der Liberalisierung im Jahre 1967 waren nur ca. 25 v. H. der Zollpositionen frei von Mengenbeschränkungen gegenüber Ostblockländern. Vgl. "Mitteilungen der Bundesstelle für Außenhandelsinformation", Köln v. 26.4.1967.

3 Vgl. Hans Andreas SIEMANN, a.a. O., S. 5.

4 "Tabella $A$ " ist gültig seit dem 3.12.1962, "Tabella B" seit dem 31.1.1964 ("Tabella $B$ " hat einen geringeren Liberalisierungsgrad als "Tabella $A$ ".) Vgl. A Background Study on East-West Trade, a.a.O., S. 76.

$5 \mathrm{Vgl}$. "Marktinformationsdienst der Bundesstelle für A ußenhandelsinformation", Frankfurt/M., Nr. c: 629, 1967 und Nr. c: 443, 1964; "Neue Zürcher Zeitung' v. 8.4.1967; Economic Bulletin Europe, Vol. 19, No. 1, a.a.O. 
trollen mehr abhängig. Um sich jedoch vor schädlichen Wirkungen der Osteinfuhren zu schützen, beabsichtigt Italien, mit den einzelnen Staatshandelsländern von Fall zu Fall Schutzklauseln auszuhandeln. Grundsätzlich bestehen solche nicht; wenn jedoch von italienischen Kaufleuten politische Preise gemeldet werden, kann die Einfuhr suspendiert werden. ${ }^{1}$ Bemerkenswert ist, daß Italien die Möglichkeit eröfnet, unter bestimmten Bedingungen auch Einfuhren über die vereinbarten Kontingente hinaus zuzulassen. 2

\section{Belgien - Niederlande - Luxemburg (Benelux)}

Sow ohl die Niederlande als auch Belgien und Luxemburg unterscheiden im Handel mit Ostblockländern - soweit mit ihnen handelsvertragliche Beziehungen bestehen - zwischen einem kontingentierten und einem liberalisierten Bereich der Einfuhr. Der Liberalisierungsgrad beträgt zwischen 70 und $80 \mathrm{v} . \mathrm{H}$. der Einfuhren aus diesen Lăndern. Für die in der Liberalisierungsliste verzeichneten Waren werden Einfuhrlizenzen ohne Mengenbeschränkungen erteilt. Alle drei Länder behalten sich jedoch vor, mengenmäßige Beschränkungen sofort und einzeln einzuführen, wenn Massenlieferungen vorgenommen werden, die wegen ihres marktstörenden Charakters die inländische Industrie in Gefahr bringen. Die verbliebenen Mengenkontingente beziehen sich zumeist auf neuralgische Waren. Gewöhnlich werden sie jedes Jahr neu festgesetzt. Mit allen südosteuropäischen Staatshandelsländern wurden bisher Handelsverträge bzw. - abkommen auf dieser Basis abgeschlossen. ${ }^{3}$

\section{c) Die Einfuhrpolitik Großbritanniens}

Grundsätzlich sind alle Einfuhren nach Großbritannien lizenzbedürftig. Die Einfuhrgenehmigungen, die das "Board of Trade" erteilt, lassen sich unterscheiden nach

1. "open general licences" (allgemeine Einfuhrlizenzen) und

2. "individual import licences" (Einzeleinfuhrlizenzen). "

Der allgemeinen Einfuhrlizenzierungspflicht unterliegen Waren, die nicht in der "first schedule" (Negativ-Liste) enthalten sind. Waren, die in dieser Negativ-Liste aufgeführt sind, benötigen eine Einzellizenz. Darunter

1 Vgl. "Handelsblatt", Düsseldorf v. 11.5.1967.

2 Vgl. Joachim BAUMANN, a.a.O., S. 80 .

$3 \mathrm{Vgl}$. "Mitteilungen der Bundesstelle für A ußenhandelsinformation", Frankfurt/ M. v. 28.11.1967; "Nachrichten für den Außenhandel", Köln v. 28.11.1967; A Background Study on East-West Trade, a.a.O., S. 76; Joachim BAUMANN, a.a.O., S. 80; Economic Bulletin for Europe, Vol. 19, No. 1, a.a.O., S. 54 f.

"Vgl. "Mitteilungen der Bundesstelle für A ußenhandelsinformation", Frankfurt/M. Nr. c: $625,1967$. 
fallen vor allem eine Reihe von Agrarerzeugnissen, aber auch gewerbliche Produkte und Textilien, die mit Rücksicht auf die Commonwealth- und EFTA '-Verpflichtungen Großbritanniens besonderer Behandlung bedürfen. ${ }^{2}$

Waren aus der "Eastern Area", die Mengenbeschränkungen nicht unterliegen, können nur dann ohne besondere Genehmigung (d.h. ohne Einzellizenz) eingeführt werden, wenn sie gleichzeitig in der "second schedule" (Positiv-Liste) enthalten sind. ${ }^{3}$ Ist dies nicht der Fall, dann ist ihre Einfuhr von einer Einzelgenehmigung abhängig. ${ }^{4}$ Vor dem Jahre 1964 wurden ca. 90 v. H. der britischen Importe aus der Sow jetunion und ca. 50 v. H. aus den ost- und südosteuropăischen Ländern mit allgemeinen Lizenzen eingeführt. ${ }^{5}$ Das restliche Importvolumen erforderte die Ausstelung von Einzellizenzen - jedoch wurden diese nur ausgestellt, wenn mit dem kommunistischen Handelspartner entsprechende Kontingente vereinbart worden waren. Solche Einfuhrkontingente wurden seitens Großbritanniens aber nicht für alle Güter eingeräumt, insbesondere nicht für Ölimporte aus der Sow jetunion und Rumänien. ${ }^{6}$

Das "Board of Trade" hat den Ostblockländern im Jahre 1964 vorgeschlagen, einen Großteil der mengenbeschränkenden Einfuhrregelungen für Fertigerzeugnisse zurückzunehmen. Damit bot Großbritannien als erstes der westlichen Industrieländer den Staatshandelsländern eine weitgehende Liberalisierung der Einfuhr an. Dieses Einfuhrverfahren ist jedoch an die Verpflichtung der Ostblockländer geknüpft, "... bei ihren Absatzbeziehungen jedes nach britischer Auffassung marktschädigende Verhalten zu vermeiden." Außerdem müssen diese Länder einer vertraglich vereinbarten Preisklausel zustimmen und Großbritannen die Zusicherung geben, selbst die Bezüge britischer Waren zu erhöhen. Im April desselben Jahres wurde das neue Einfuhrsystem zum ersten Mal gegenüber der Tschechoslowakei in Kraft gesetzt.

1 European Free Trade Association = Europäische Freihandelszone.

2 Vgl. East-West Trade, PEP, Vol. XXXI, No. 488, London 1965, S. 127 f.; Selling the Soviet Market, a.a.O., S. 41.

${ }^{3}$ First und Second Schedule werden von der Tariff Division des britischen Handelsministeriums ("Board of Trade") veroffentlicht.

Vgl. A Background Study on East-West Trade, a.a. O., S. 75.

$5 \mathrm{Vgl}$. ebd.

- Vgl. A Background Study on East-West Trade, a.a. O.

Die Einräumung von Einfuhrkontingenten für Öl aus den genannten Ländern wird von Großbritannien vor allem mit der Begründung zurückgewiesen, daß bisher keine Regelung der noch offenstehenden finanziellen Fragen im Zusammenhang mit der Enteignung britischen Kapitals nach dem Zweiten Weltkrieg zu erreichen war. Ganz sicherlich spielt hier aber auch eine gewisse Angst vor einer moglichen Abhăngigkeit vom Ostblock mit.

Vgl. East-West Trade, PEP, a.a.O., S. 128.

7 Klaus-Heinrich STANDKE, a.a.O., S. 190. 
Weiterhin bleibt eine im Umfang beschränkte Negativ-Liste mit Einzelgenehmigungspflicht gegenüber den Ostländern gültig. Gleichzeitig wurde indessen die Einfuhr von Waren, welche weder der bisherigen allgemeinen Genehmigungspflicht der Positiv-Liste noch dem Einzellizenzierungsverfahren der Negativ-Liste unterworfen waren, mit Hilfe sogenannter "open individual licences" (offene Einzelgenehmigung) möglich.

Einfuhren aus Ostblockländern unterliegen zukünftig also nur noch Mengenbeschränkungen, ' wenn es sich um Waren der Negativ-Liste handelt. Alle anderen können mit Hilfe von allgemeinen Lizenzen (d.h. praktisch frei) oder offenen Einzellizenzen (sie erfülen praktisch nur Kontrollfunktion) ${ }^{2}$ eingeführt werden. ${ }^{3}$ Mit anderen Worten: Importwaren aus Ostblockländern, die in der Negativ-Liste nicht, wohl aber in der Positiv-Liste verzeichnet sind, benotigten vor 1964 generell die Ausstellung von kontingentgebundenen Einzeleinfuhrlizenzen. 4 Mit Einführung des neuen Systems dagegen wurde der Handel eines Teiles dieser Warengruppen sogenannten offenen Einfuhrlizenzen unterworfen, so daß nur noch ein ganz geringer Anteil der Gesamteinfuhren vom Einzellizenzierungsverfahren abhängig bleibt.

Hervorzuheben ist, daß sich das "Board of Trade" das Recht vorbehält, die Einfuhr durch entsprechende Maßnahmen einseitig zu beschränken oder sogar aufzuheben, wenn der östliche Handelspartner gegen das Einfuhrsystem verstößt. 5 Damit kommt auch dem britischen Einfuhrverfahren der Charakter einer Quasiliberalisierung zu.

Das zufriedenstellende Funktionieren der weitreichenden britischen Liberalisierungsmaßnahmen gegenüber Osteuropa hat andere westeuropäische Länder zu ähnlichen Maßnahmen ermutigt. Großbritannien wendet dieses Verfahren heute gegenüber allen ost- und südosteuropäischen Staatshandelsländern an. ${ }^{\circ}$

1 Mengenbeschränkungen in Form von Kontingenten.

2 Die Ausstellung der offenen Einzellizenz ist davon abhängig, daß das Einfuhrunternehmen als solches bekannt ist (bona fide).

$3 \mathrm{Vgl}$. Selling the Soviet Market, a. a. O., S. 42.

4 Dies gilt auch nach 1964, sofern seitens der Ostblockländer die von den Briten gestellten Bedingungen nicht erfült werden.

5 Vgl. Hermann GROSS, Probleme der Handelspolitik und der wirtschaftlichen Zusammenarbeit $\mathrm{zwischen} \mathrm{dem} \mathrm{Westen} \mathrm{und} \mathrm{den} \mathrm{osteuropäischen} \mathrm{Staaten,} \mathrm{in:}$ Die Politik des Westens und Osteuropa, hrsg. von Alfred Domes, Köln 1966, S. 205.

- Zahlenmäßige Informationen über den gegenwärtigen Stand der britischen Importliberalisierung waren nicht zu erhalten. Nach übereinstimmender Meinung dürfte er aber wohl der höchste unter den betrachteten westeuropäischen I.ändern sein. 


\section{d) Die Einfuhrpolitik der USA}

Im Gegensatz zur Einfuhrpolitik der EWG-Mitgliedstaaten und Großbritanniens wenden die USA gegenuber Importen aus sozialistischen Ländern keine spezifische Mengenpolitik an. Quantitative Beschränkungen der Einfuhr spielen für die Vereinigten Staaten allgemein eine recht untergeordnete Rolle. Der Präsident kann jedoch die Einfuhr solcher Güter unterbinden oder einschränken, die die nationale Sicherheit gefährden oder die Gefahr von Marktstörungen hervorrufen. Dies wiederum gilt nicht nur für Einfuhren aus den kommunistischen Ländern, sondern ganz allgemein und damit auch für Einfuhren aus westlichen Ländern (z. B. Textileinfuhren aus Hongkong). Ausgenommen sind aber Einfuhren aus Rotchina, Nordkorea und Nordvietnam sowie Kuba, die immer Einfuhrgenehmigungen benötigen. Unabhängig vom Herkunftsland erfordern alle Einfuhren ein Ursprungszeugnis.

Weitere Einfuhrbeschränkungen, die gegenüber allen Ländern bestehen und die sozialistischen Länder Südosteuropas kaum betreffen, gelten für einige Agrarprodukte, verschiedene Metalle, Petroleum etc.'

Da die USA ihren Handel mit den sozialistischen Ländern (wie mit allen anderen Ländern auch) nicht bilateral abwickeln, kommt Preisbelasturgen (vor allem Zöllen) entscheidende einfuhrpolitische Bedeutung zu. ${ }^{2}$ Dies hat zur Folge, daß die Einfuhren aus den sozialistischen Ländern einer selektiven Preisbe- und -entlastungspolitik unterworfen sind: Die Einfuhren aus Polen und Jugoslawien unterliegen der Meistbegünstigungsbehandlung seitens der USA. Dagegen haben alle Einfuhren aus den anderen sozialistischen Ländern ausgesprochen hohe Einfuhrzölle zu überwinden. ${ }^{3}$

Die wichtigste gesetzliche Verankerung dieser Restriktionen und der Ausnahmeregelung für Polen und Jugoslawien findet sich in der "Trade Agreements Extension Act" vom Jahre 1951. Bis zu diesem Zeitpunkt wurden sämtliche Einfuhren aus den sozialistischen Ländern gemäß den Bestimmungen der "Reciprocal Trade Agreements Act" von 1934 meistbegünstigt behandelt. Damit kamen sie - gleichbe rechtigt allen anderen nichtkommunistischen Handelspartnern - in den Genuß der Zollkonzessionen der USA. Die Meistbegünstigung gegenüber den sozialistischen Ländern wurde jedoch unter dem Eindruck des Korea-Krieges im Jahre 1951 aufgehoben. Lediglich Jugoslawien war davon ausgenommen. Art. 5 der "Trade Agreements Extension Act" bestimmt, daß der Präsident der Vereinigten Staaten

I Vgl. Harold J. BERMAN, The Legal Framework of Trade between Planned and Market Economies: The Soviet American Example, "Law and Contemporary Problems", Vol. 24, No. 3, Durnham/N.C. 1959, S. 508 f.

2 Vgl. Robert B. WRIGHT, a.a.O., S. 817.

3 Vgl. das Beispiel auf S. 106. 
der Sowjetunion und allen anderen Ländern, welche von einer die kommunistische Weltbewegung steuernden Macht besetzt oder beherrscht werden, die Meistbegünstigungsbehandlung zu entziehen hat. ${ }^{1}$

Jugoslawien wurde von den Beschränkungen der "Trade Agreements Extension Act" nicht erfaßt und daher weiter meistbegünstigt behandelt. ${ }^{2}$ Da die Auslegung des Art. 5 dem Präsidenten eine gewisse Handlungsfreiheit gewährte, beschloß Präsident Eisenhower im Jahre 1960, Polen ebenfalls die Meistbegünstigung zuzugestehen. Seiner Meinung nach erfüllte Polen ebenfalls die positiven Bedingungen des Art. 5 .

Im Jahre 1962 wurde die "Trade Expansion Act" (Ermächtigungsgesetz zur Kennedy-Runde) verabschiedet. Dieses Gesetz verlangte nun auch die Einstellung der Meistbegünstigungsbehandlung gegenüber Jugoslawien und Polen. Art. 5 der "Trade Agreements Extension Act" wurde dahingehend abgeändert, daß nun nicht mehr die relative Abhängigkeit von der Sowjetunion als die die kommunistische Weltbewegung steuernde und beherrschende Macht als Kriterium des Entzugs der Meistbegünstigung gelten sollte, sondern grundsätzlich all den Ländern die Meistbegünstigung $z u$ versagen sei, die kommunistisch sind. Ein Jahr später, noch bevor der Präsident den beiden Ländern die Meistbegünstigung aberkannt hatte, ließ der Kongreß auf Grund intensiver Bemühungen der Regierung die Möglichkeit $z u$, solche Länder von den Bestimmungen der "Trade Expansion Act" auszunehmen, die vor dem 16.12.1963 eine meistbegünstigte Sonderstellung innehatten. Vorausgesetzt wird jedoch die Überzeugung des Prăsidenten, daß eine derartige Sonderbehandlung den amerikanischen Interessen diene und für die Unabhängigkeit dieser Länder vom internationalen Kommunismus notwendig ist. Während Art. 231 (b) der "Trade Expansion Act" diese Ausnahmeregelung von der allgemeinen Zollpolitik gegenüber Einfuhren aus sozialistischen Ländern fixiert, ergibt sich die eigentliche Ermächtigung des Präsidenten aus Art. 402 der "Foreign Assistance Act" vom Jahre 1963. Am 26.3.1964 wurde Jugoslawien und Polen die Meistbegünstigung offiziell wieder zuerkannt. ${ }^{3}$

Der eigentliche Grund für die Verschärfung der Einfuhrbestimmungen ist darin zu sehen, daß der Kongreß verhindern wollte, daß die Regierung, durch eine großzügige Auslegung des ursprünglichen Art. 5, auch anderen Ländern, vor allem Rumänien, Ungarn und der Tschechoslowakei, die Meistbegünstigung hätte zugestehen können, wie dies im Falle Polens 1960 geschehen war.

1 Vgl. BERMAN und GARSON, Possible Effects, a.a.O., S. 282.

2 Damit genießt Jugoslawien Meistbegünstigungsbehandlung seit 1881 .

$3 \mathrm{Vgl}$. BERMAN und GARSON, Possible Effects, a.a.O., S. 283; "The Battle Act Report of 1966", a.a.O., S. 7; East-West Trade Hearings, Part I, a.a. O., S. 54 . 
Zusammenfassend läßt sich feststellen, daß keines der südosteuropäischen Staatshandelsländer seitens der USA meistbegünstigt behandelt wird und daß sie seit dem Jahre 1952 dem sogenannten "Smoot-Hawley" - Zolltarif aus dem Jahre 1930 unterliegen. ' Die Uberwindung dieser hohen Zollmauer bedeutet eine entscheidende zollpolitische Benachteiligung dieser Länder gegenüber solchen mit Meistbegünstigungsbehandlung. ${ }^{2}$

Dies hat dazu geführt, daß die Erzeugnisse aus den südosteuropäischen Staatshandelsländern von vornherein allein wegen ihrer hierdurch weit überhöhten Preise auf dem amerikanischen Markt kaum wettbewerbsfähig sind. Diese Hürde wird sich noch vergrößern, wenn die Zollermäßigungen der Kennedy-Runde verwirklicht sein werden. ${ }^{3}$ Sofern sie jedoch diese Zollschranke überwunden haben, bestehen keine weiteren Hindernisse handelspolitischer Art durch die US-Bundesbehörden. Jedoch kann es geschehen, daß Waren aus kommunistischen Ländern von den lokalen Behörden durch besondere Kenntlichmachung der Herkunft aus kommunistischen Ländern diskriminiert werden. ${ }^{4}$

Über die zukünftige Entwicklung der amerikanischen Einfuhrpolitik gegenüber den Staatshandelsländern läßt sich schwer eine Prognose stellen. Sollte die "East-West Trade Relations Act" jedoch vom Kongreß angenommen werden, so ist anzunehmen, daß jenen kommunistischen Ländern die Meistbegünstigungsbehandlung zuerkannt wird, mit denen zweiseitige Handelsabkommen geschlossen werden und die $\mathrm{zu}$ entsprechenden kommerziellen Gegenleistungen bereit sind. Nach amerikanischer Auffassung dürfen sich diese Gegenleistungen jedoch nicht nur in Einfuhrzusagen der Staatshandelsländer erschöpfen, sondern müssen sich auch auf eine zufriedenstellende Lösung von Problemen, wie z.B. Schutz der industriellen Rechte, Arbitrage, Marktzugang, etc. erstrecken. ${ }^{5}$

Neben den geschilderten Beschränkungen der Einfuhr kann sich eine weitere auf Grund der Bestimmungen des "Buy American Law" vom Jahre

' Dieser Tarif gilt auch gegenüber allen anderen kommunistischen Ländern mit Ausnahme Polens und Jugoslawiens.

2 Da das allgemeine Zollniveau der USA seit 1930 von ca. 50 v. H. ad valorem auf ca. $15 \mathrm{v} . \mathrm{H}$. ad valorem im Jahre 1966 gefallen ist, stellt dieser Einfuhrzoll eine substantielle Handelsschranke dar. Im Fall der Sowjetunion bedeutet dies z. B., daß seit 1952 das Manganerz bei der Einfuhr in die USA je LB Reinmetallgehalt mit 1 Cent Zoll belastet wird gegenüber 0,25 Cents vor 1952 (also bei Meistbegünstigungsbehandlung).

Vgl. BERMAN und GARSON, Possible Effects, a.a.O., S. 280; A Background Study on East-West Trade, a. a.O., S. 40.

$3 \mathrm{Vgl}$. hierzu auch Theodore C. SORENSEN, Why we should trade with the Soviets, "Foreign Affairs", Vol. 46, No. 3, New York 1968, S. 576.

4 Vgl. Private Boycotts vs the National Interest, a.a.O.

$5 \mathrm{Vgl}$. BERMAN und GARSON, Possible Effects, a.a.O., S. $281 \mathrm{f}$. 
1963 ergeben. Obgleich sich dieses Gesetz nicht expressis verbis gegen die sozialistischen Länder richtet, kann es dennoch jederzeit dementsprechend ausgelegt werden. Dies würde bedeuten, daß eine amerikanische Behörde das Recht hat, ein Warenangebot eines kommunistischen Landes abzulehnen, wenn die Einfuhr aus diesem speziellen Land gegen das "öffentliche Interesse", das "nationale Interesse" oder auch gegen "wesentliche nationale Sicherheitsinteressen" verstößt. '

Im Gegensatz zu den meisten westeuropäischen Staaten schützen sich die Vereinigten Staaten gegen Niedrigpreiseinfuhren nicht durch Einfuhrquoten und sogenannte Preisklauseln, sondern lediglich durch eine entsprechende Anwendung ihrer Anti-Dumping-Gesetzgebung. ${ }^{2}$

$\mathrm{Zu}$ bedenken ist jedoch, daß die westeuropäischen Volkswirtschaften besonders ihre Binnenmärkte vor Störungen schützen, die häufig durch Niedrigpreiseinfuhren hervorgerufen werden, während die USA durch Anwendung ihrer Anti-Dumping-Bestimmungen vor allem ein Unterlaufen der Einfuhrzölle verhindern wollen. Da die US-Einfuhren aus den kommunistischen Ländern - Polen und Jugoslawien ausgenommen - sowieso eine große Tarifschranke zu überwinden haben, kommt der Gefahr von Marktstörungen praktisch keine große Bedeutung zu. Die Preisüberwachung von Einfuhren aus Staatshandelsländern erfolgt durch das "Treasury Department" (Schatzministerium). ${ }^{3}$

\section{e) Zusammenfassung}

Die Exporte der südosteuropäischen Staatshandelsländer in die Mitgliedstaaten der EWG haben, je nachdem ob es sich um gewerblich-industrielle oder agrarische Waren handelt, verschiedene handelspolitische Schranken zu überwinden.

Neben den vergemeinschafteten Einfuhrzöllen, die auf der Basis der zollpolitischen Meistbegünstigungsbehandl ung der südosteuropäischen Staatshandelsländer durch die EWG-Mitgliedsländer für gewerblich-industrielle Einfuhrgüter erhoben werden, sichert das gemeinsame Abschöpfungssystem für Agrareinfuhren eine gegenüber anderen Drittländern gleichberechtigte Behandlung der südosteuropäischen Staatshandelsländer in preisbelastender Hinsicht.

'Im einzelnen sei verwiesen auf: "The Battle Act Report of 1966", a.a.O., S. 18; N. LIVENTSEV, Soviet Commentary on U.S. Commercial Policy, Ubbers. aus "Vneshniaia", abgedruckt in "The American Review of Soviet and Eastern European Foreign Trade", Vol. I, No. 3, White Plains/N.Y., MayJune 1965, S. 75.

2 Gesetzliche Grundlage ist die "Anti-Dumping Act" von 1921. Am 1.7.1968 sind dazu neue Verwaltungsvorschriften erlassen worden. Vgl. "Neue Zürcher Zeitung'" vom 3.7.1968.

${ }^{3} \mathrm{Vgl}$. Selling the Soviet Market, a.a.O., S. 39. 
Im Hinblick auf die Mengenpolitik zeigt sich aber, daß sowohl für Einfuhren industriell-gewerblicher Art als auch für Agrareinfuhren über normale Drittländerbelastungen hinausgehende Beschränkungen existieren. Für nichtagrarische Einfuhren bestehen, wenn auch nur mehr in vermindertem Umfang, Kontingentsbeschränkungen; agrarische Einfuhren, die EWGMarktordnungen unterliegen, sind mengenmäßig an Schătzbetrăge gebunden. Im Fall der von Mengenbeschränkungen befreiten Einfuhrbereiche, also der liberalisierten Einfuhren gewerblich-industrieller sowie nichtmarktordnungsgebundener Art, ergibt sich ebenfalls eine Benachteiligung gegenüber aktiven GATT-Vollmitgliedsländern. Sie besteht darin, daß die kontingentsbefreite Einfuhr lediglich eine autonome de facto-Liberalisierung darstellt. Zu erwähnen ist aber, daß die Staatshandelsländer die damit verbundene Unsicherheit graduell beeinflussen konnen, indem sie sich eines liberalisierungskonformen wirtschaftlichen und politischen Verhaltens gegenüber den westlichen Handelspartnern befleißigen.

Die Einfuhrpolitik Großbritanniens gegenüber Bulgarien, Rumănien und Ungarn ist ăhnlich der der EWG-Mitgliedsländer, soweit es den industriellgewerblichen Bereich der Importe betrifft. Im Unterschied zur EWG erfahren die Agrareinfuhren keine Sonderbehandlung, sondern sind grundsătzlich den gleichen einfuhrpolitischen Maßnahmen - mengenbeschränkender Kontingentierung und de facto-Liberalisierung - unterworfen. Hervorzuheben ist, und zwar für alle betrachteten westeuropäischen Länder, daß sich die einfuhrliberalisierten Warengruppen nicht mit denjenigen Warengruppen zu decken brauchen, für die seitens der südosteuropäischen Staatshandelsländer die großße Ausfuhrpräferenz besteht. Dies bedeutet, daß formell durchaus ein Großteil der Warenkategorien einfuhrliberalisiert sein kann, damit aber nicht zwangsläufig eine Verbesserung der Ausfuh rfähigkeit der davon betroffenen Länder verbunden $z u$ sein braucht. ${ }^{\prime}$ Was die Vereinigten Staaten von Amerika betrifft, so wenden sie, von einigen wenigen und praktisch unbedeutenden Ausnahmen abgesehen, ausschließlich preisbelastende Maßnahmen in Form eines diskriminierend hohen Einfuhrzolls an.

' Die Frage, inwieweit der liberalisierte Einfuhrbereich der westeuropáischen Länder der Exportstruktur der südosteuropäischen Länder entspricht, bedürfte einer dringenden, quantitativ untermauerten Beantwortung. Im Rahmen dieser Untersuchung kann darauf jedoch nicht eingegangen werden. 


\section{Schlußbemerkung}

Die Untersuchung der ausgewählten osthandelspolitischen Aktivitäten der verschiedenen westlichen Länder zeigte, daß entscheidende handelspolitische Hemmnisse, die einer fruchtbaren Expansion des Ost-Westhandels entgegenstehen, von westeuropäischer Seite - sieht man von der Agrarpolitik der EWG ab - kaum mehr, von amerikanischer Seite jedoch noch in erheblichem Maße bestehen. Die Entwicklung der Osthandelspolitik der USA ist weit hinter den Normalisierungsbestrebungen Westeuropas zurückgeblieben, wenn auch seit Anfang der sechziger Jahre deutliche Anzeichen einer größeren handelspolitischen Aufgeschlossenheit gegenüber den ostund südosteuropäischen Ländern nicht $z u$ übersehen sind. Der Konflikt in Südostasien hat diese Entwicklung jedoch vorzeitig und vorläufig zum Stillstand gebracht.

Obgleich also zumindest von westeuropäischer Seite die Voraussetzungen für eine Normalisierung des Ost-Westhandels geschaffen wurden und die Länder Bulgarien, Rumänien und Ungarn seit einigen Jahren verstärkt und auch erfolgreich bemüht sind, ihre Außenhandelsbeziehungen zum Westen auszubauen, bestehen bislang keine wirklichen Anzeichen für eine dauerhafte Umorientierung nach Westen auf Kosten der Beziehungen zu anderen sozialistischen Ländern. Ganz abgesehen von den wirtschaftlichen, systemabhängigen und handelspolitischen Faktoren, die einer derartigen Entwicklung entgegenstehen, entspräche dies offensichtlich auch nicht der politischen Zielsetzung dieser Länder bzw. der Sowjetunion. Man muß sich demzufolge deutlich vor Augen halten, daß den Westkontakten, die aus rein wirtschaftlicher Notwendigkeit resultieren, auch weiterhin eine deutliche und zukünftig möglicherweise verstärkte Ostverankerung entgegensteht. Dies gilt auch für Rumänien; denn wenn dieses Land versucht, seine Wirtschaftsbeziehungen zum Westen zu forcieren, dann in der Absicht, sein Industrialisie rungsprogramm gegebenenfalls auch gegen den Widerstand Moskaus und des RGW ohne Abstriche auf 'technischem Weltniveau" voranzutreiben, nicht aber mit dem Ziel, sich dem Westen langfristig anzunähern.' $\mathrm{Es}$ liegt aber auf der Hand, daß diese Länder die Vorteile verstärkter Außenhandelsbeziehungen mit dem Westen erkannt haben und sich bemühen, diese soweit wie möglich zu nützen. Bulgarien, Rumänien und Ungarn sind sich darüber klar, daß "ein verstärkter Westhandel Schritt für Schritt den Anteil der substitutiven Produktionen gegenüber den komplementären verbessert" 2 und durch die damit verbundene Beschleunigung der wirtschaftlichen Entwicklung ein

I Vgl. "Wissenschaftlicher Dienst Südosteuropa", Jg. 14, H. 1/2, München 1965 , S. 13 und H. 5, S. 53 f.

2 Arbeitsdokument des Ausschusses für Außenwirtschaftsbeziehungen des Europäischen Parlaments, a.a.O. S. 17. 
höheres Ausgangsniveau im Rahmen der internationalen Arbeitsteilung erreicht werden kann. Eine größere internationale wirtschaftliche und politische Handlungsfreiheit sowie ein langfristig wirksamer Wachstumsund Einkommenseffekt ließe sich hiermit verbinden. Von nicht zu unterschätzender Bedeutung könnte auch der Rationalisierungseffekt des Westhandels sowie dessen positiver Einfluß auf das binnenwirtschaftliche Wirtschaftssystem im allgemeinen, auf das Außenhandelssystem im speziellen sein.' Der Erfolg der aus ökonomischen und sozialen Gründen dringend erforderlichen Reformen steht damit in engem Zusammenhang. ${ }^{2}$ Von den vom Westhandel ausgehenden Wachstums-, Einkommens - und Rationalisierungseffekten hängt es in hohem Maße ab, inwieweit die Handelsbeziehungen $z w i s c h e n$ den ost - und südosteuropäischen Staatshandelsländern und dem Westen intensiviert und ausgedehnt werden können. Denn eine engere wirtschaftliche Verbindung von Ländern setzt voraus, daß ihr Entwicklungsstand genügend hoch ist, ihre Produktionsstrukturen eher substitutiv als komplementär sind und die ökonomischen Lenkungssysteme den Austausch weder direkt noch indirekt behindern. ${ }^{3}$

Die gleichen Bedingungen müssen erfüllt sein, wenn eine "normale" Handelspolitik die Beziehungen zwischen den Handelspartnern regieren soll. $\mathrm{Zu}$ hoffen bleibt, daß mit zunehmendem Reifegrad, erhöhter Komplementarität der Produktionsstrukturen und erfolgreicher Reform des Außenhandelssystems der südosteuropäischen Staatshandelsländer jene ökonomischen Hindernisse beseitigt werden, denen auch die Osthandelspolitik bislang ihre wirtschaftliche Besonderheit verdankt.

Inwieweit jedoch die Entwicklung der außenpolitischen Be ziehungen der ost- und südosteuropäischen Länder sowohl untereinander als auch mit dem Westen eine wirtschaftlich gerechtfertigte Normalisierung der Osthandelspolitik zulassen wird, ist eine andere Frage.

1 Arbeitsdokument des Ausschusses für Außenwirtschaftsbeziehungen, a. a. O., S. 17; Rolf KRENGEL, Die Bedeutung des Ost-West-Handels für die OstWest-Beziehungen, Göttingen 1967, S. $100 \mathrm{f}$.

2 Vgl. M. GAMARNIKOW, Economic Reforms in Eastern Europe, Detroit/ Michigan 1968.

${ }^{3} \mathrm{Vgl}$. Arbeitsdokument des Ausschusses für Außenwirtschaftsbeziehungen, a.a.O., S. 17 . 


\section{Literaturverzeichnis}

1. Bücher, selbständige Schriften, Sammel-und Nachschlagewerke:

ADLER-KARLSSON, Gunnar, The Western Economic Warfare 1947 - 1967 , Stockholm 1968

ALBINOWSKI, Stanislaw, Die Handelspolitik der EWG, Warschau 1965 ALLEN, Robert L., Soviet Economic Warfare, Washington D. C. 1960 BEHRMAN, Jack N., SCHMIDT, Wilson E., International Economics, New York 1957

BERG VON, Michael, Die strategische Bedeutung des Ost-West-Handels, Leiden 1966

BERNHOLZ, Peter, Außenpolitik und internationale Wirtschaftsbeziehungen, Frankfurt am Main 1966

BROWN, James F., The New Eastern Europe, New York 1966

CAMPBELL, John C., American Policy Towards Eastern Europe: The Choices Ahead, Minneapolis and London 1965

Europe, East and West, in: The United States and Eastern Europe, ed. by Robert F. Byrnes, Englewood Cliffs/N. J. 1967, S. 125 ff.

Communism in Europe, Vol. II, ed. by William E. Griffith, Cambridge/ Mass. 1967

CURZON, Gerard, Multilateral Commercial Diplomacy, New York and Washington D.C. 1965

Developing the East European Market, hrsg. von Business International, Geneva 1966

Die Wirtschaftssysteme der Staaten Osteuropas und der Volksrepublik China, Schriften des Vereins für Socialpolitik, Neue Folge, Bd. 23/II, hrsg. von Georg Jahn, Berlin 1962

DRACHKOVITCH, Milorad, United States Aid to Yugoslavia and Poland, Analysis of a Cont roversy, Washington D.C. 1963

Eastern Europe in Transition, ed. by Kurt London, Baltimore 1966 European League for Economic Cooperation, East-West Commercial Relations, Publication No. 40, Brussels 
East-West Trade, PEP, Vol. XXXI, No. 488, London 1965

EMMANUEL, A., La division internationale du travail et le marché socialiste, Paris 1966

ERDMAN, Paul, ROGGE, Peter, Die Europäische Wirtschaftsgemeinschaft und die Drittländer, Basel und Tübingen 1960

ERNST, Heiner, Der Osthandel - eine politische Waffe?, Stuttgart 1964

EUCKEN, Walter, Die Grundlagen der Nationalökonomie, 7. Aufl., Berlin - Göttingen - Heidelberg 1959

EULENBURG, Franz, Grundriß der Sozialökonomik, VIII. Abt. Außenhandel und $A$ ußenhandelspolitik, Tübingen 1929

European League for Economic Cooperation; Economic, Industrial, Scientific and Technical Cooperation between the Countries of Eastern and Western Europe, Round Table Organized in Brussels, Feb. 24th and 25th 1967, Publication No. 41

FOX, Ursula, Das Bankwesen der europåischen Volksdemokratien, Wiesbaden 1967

GAMARNIKOW, M., Economic Reforms in Eastern Europe, Detroit/ Michigan 1968

GARA DE, John P., Trade Relations between the Common Market and the Eastern Bloc, Brugges 1964

GIERSCH, Herbert, Allgemeine Wirtschaftspolitik, Wiesbaden 1960

GRIFFITH, William E., Albania and the Sino-Soviet Rift, Cambridge/ Mass. 1962

GROSS, Hermann, Südosteuropa, Bau und Entwicklung der Wirtschaft, Beihefte zur Leipziger Vierteljahresschrift für Südosteuropa, H. 1, Leipzig 1937

HABERLER, Gottfried, The Theory of International Trade, London 1956

HABERLER, Gottfried, VEROSTA, Stephan, Liberale und planwirtschaftliche Handelspolitik, Berlin 1934

HALM, George N., Wirtschaftssysteme, Berlin 1960

Handworrterbuch der Sozialwissenschaften (HdSW), Göttingen 1956

HARVEY, Mose L., East-West Trade and United States Policy, New York 1966

HENSEL, Paul K., Einführung in die Theorie der Zentral-Verwaltungswirtschaft, Stuttgart 1959

HIRSCH, Hans, Mengenplanung und Preisplanung, Basel 1957 
HIRSCHMAN, Albert O. , National Power and the Structure of Foreign Trade, Berkeley and Los Angeles 1945

IMHOFF, L.P., Kommentar zum Allgemeinen Zoll- und Handelsabkommen (GATT), München - Berlin 1952

KASER, Michael, COMECON, Integration Problems of the Planned Economies, 2. Aufl., Oxford 1967

KENEN, Peter B., International Economics, Englewood Cliffs/N.J. 1967 KENNAN, George F., On Dealing with the Communist World, New York and Evanston 1964

KIESEWETTER, Bruno, Der Ostblock - Außenhandel des östlichen Wirtschaftsblocks einschließlich Chinas, Berlin 1960

KINDELBERGER, Charles P., Foreign Trade and the National Economy, New Haven - London 1962

International Economics, Homewood 1958

KLINKMÚlLLER, Erich, RUBAN, Maria, Die wirtschaftliche Zusammenarbeit zwischen den Ostblockstaaten, Berlin 1960

KREININ, Mordechai E., Alternative Commercial Policies - Their Effect on the American Economy, East Lansing/Michigan 1967

KRENGEL, Rolf, Die Bedeutung des Ost-West-Handels für die OstWest-Beziehungen, Göttingen 1967

KRUSE, Alfred, Außenwirtschaft, Die Internationalen Wirtschaftsbeziehungen, Berlin 1965

KUTT, Aleksander, East-West Trade and Industrial Trends in the Soviet Area, New York 1965

LIEBICH, Ferdinand, Grundriß des Allgemeinen Zoll- und Handelsabkommens (GATT), Baden-Baden 1967

LOHSE, Rolf, Kapital, Zoll und sozialistischer Außenhandel, Halle/ Saale 1964

McKITTERICK, Nathaniel, East-West Trade. The Background of U.S.Policy, New York 1966

MEADE, James E., The Theory of International Economic Policy, Vol. I, 1. Aufl., The Balance of Payments, London - New York - Toronto 1956

The Theory of International Economic Policy, Vol.II, 1. Aufl., Trade and Welfare, London - New York Toronto 1955

MEADE, J.E., LIESNER, H.H., WELLS, S.J., Case Studies in European Economic Unions, London - New York - Toronto 1962 
MEYER, F. V.,

The European Free Trade Association, New York 1960

MIKESELL, Raymond F., Foreign Exchange in the Postwar World, New York 1954

MIKESELL, Raymond F., BEHRMAN, Jack, Financing Free World Trade with the Sino-Soviet Bloc, Princetown/N.J. 1958

MILL, John Stuart, Principles of Political Economy, London - New York . Toronto 1929

MÖLLER, Hans, Außenwirtschaftspolitik, Wiesbaden 1961

$-$

Internationale Wirtschaftsorganisationen, Wiesbaden 1960

MYRDAL, Gunnar, An International Economy, New York 1956

OHLIN, Bertil, Interregional and International Trade, Cambridge/ Mass. 1967

NEUNREITHER, Karlheinz, Das Europa der Sechs ohne Außenpolitik, Köln und Opladen 1964

NÖLL v.d. NAHMER, Robert, Außenwirtschaft, Heidelberg 1959

NÖTZOLD, Jürgen, Möglichkeiten und Grenzen des Außenhandels mit den europäischen Ostblockstaaten, München und Wien 1966

NOVE, Alec, Die sowjetische Wirtschaft, Wiesbaden 1964

NOVE, Alec, DONELLY, D., Trade with Communist Countries, London 1960

Osteuropa-Handbuch Jugoslawien, hrsg. von Werner Markert, Köln und Graz 1954

Ost-Westhandel - Eine gemeinsame Politik für den Westen, hrsg. von der Europäischen Vereinigung für wirtschaftliche und soziale Entwicklung, Frankfurt am Main 1965

PEJOVIC, Svetozar, The Market-Planned Economy of Yugoslavia, Minneapolis 1966

POSSONY, Stefan, Wirtschaftshilfe oder Außenhandel mit dem Osten?, als Manuskript gedruckt, Stuttgart 1966

PREDÖHL, Andreas, Außenwirtschaft, Göttingen 1949

PRYOR, Frederic L., The Communist Foreign Trade System, London 1963

RONNEBERGER, Franz, Südosteuropa in den internationalen politischen Beziehungen der Gegenwart, Südosteuropa-Studien, hrsg. von Walter Althammer, H. 10, München 1968 
RONNEBERGER, Franz, Vorschläge zur Einordnung der SüdosteuropaForschung in die Aufbaupläne der deutschen Hochschulen, Südosteuropa-Studien, hrsg. von Rudolf Vogel, H. 1, München 1962

ROSE, Klaus,

Die Theorie der Internationalen Wirtschaftsbeziehungen, Köln und Berlin 1965

Theorie der Außenwirtschaft, Berlin und Frankfurt am Main 1964

Č. - SAIN, Ante,

Die Auswirkungen der wirtschaftlichen Integration auf ein Drittland, Diss. München 1965

SCHMIDT, J.L., DOMDEY, Karl-Heinz, Grundprobleme der Wirtschaftsbeziehungen zwischen den Staaten beider Weltsysteme, Berlin (Ost) 1966

SCHMITT, Matthias, Osthandel auf neuen Wegen, Aktuelle Fragen der Weltwirtschaft, Hamburg 1968

SEGRÉ, Claudio, Die mittelfristige Exportfinanzierung, hrsg. von der . Kreditanstalt für Wiederaufbau, Frankfurt am Main 1959

Selling the Soviet Market, hrsg. von Business International, Geneva 1965 SKENDI, Stavro, Albania. Mid European Studies Center of the Free Europe Committee, New York 1956

SMITH, Adam, Wealth of Nations, New York 1937

SPULBER, Nicolas, The Economics of Communist Eastern Europe, New York - London 1957

STANDKE, Klaus-Heinrich, Der Handel mit dem Osten, Baden-Baden 1968 STEINBERGER, Helmut, GATT und regionale Wirtschaftszusammenschlüsse, hrsg. vom Max-Planck-Institut für ausländisches offentliches Recht und Volkerrecht, Koln und Berlin 1963

THALHEIM, Karl C., Grundzüge des sowjetischen Wirtschaftssystems, Koln 1962

The Communist States at the Crossroad between Moscow and Peking, ed. by Adam Brombke, New York 1965

Trade and Planning, ed. by Alan A. Brown and Egon Neuberger, Berkeley 1967

UNGER, F.

VAJ DA, Imre,

VINER, Jacob,
A ußenhandelsfinanzierung, Frankfurt am Main 1963

The Role of Foreign Trade in a Socialist Economy, Budapest 1965

International Economics, Glencoe 1951 
VINER, Jacob,

Studies in the Theory of International Trade, New York - London 1937

The Customs Union Issue, New York 1950

Wirtschaftsfragen in und zwischen Ost und West, hrsg. von P. Pattis und H. U. Sonderegger, Düsseldorf und Wien 1966

Wirtschaftsplanung im Ostblock - Beginn einer Liberalisierung?, hrsg. von Erik Boettcher, Stuttgart - Berlin - Köln und Mainz 1967

Wirtschaftsreformen in Osteuropa, hrsg. von Karl C. Thalheim und HansHermann Höhmann, Köln 1968

ZENTNER, Peter, East-West Trade, London 1967

ZINSER, Robert, Das GATT und die Meistbegünstigung, Schriftenreihe zum Handbuch für Europäische Wirtschaft, Bd. 24, Baden-Baden und Bonn 1962

ZOTTMAN, Anton, Theorie und Politik der Außenwirtschaft, Stuttgart und Düsseldorf 1967

2. Aufsätze in Sammelwerken und Zeitschriften:

ADAMOVIĆ, Ljubisă, Yugoslav Foreign Trade, "Socialist Thought and Practice", No. 29, Belgrad, January - March 1968, S. $50 \mathrm{ff}$.

ADLER-KARLSSON, Gunnar, Der Circulus vitiosus der Autarkie im OstWest-Handel, in: Koexistenz zwischen Ost und West Konflikt, Kooperation, Konvergenz, hrsg. von Hans Mayrzedt und Helmut Romé, Wien - Frankfurt Zürich 1967, S. 243 ff.

Problems of East - West Trade. A General Survey, "Economics of Planning", Vol. 7, No. 2, Oslo 1967, S. $119 \mathrm{ff}$.

ALTHAMMER, Walter, Die EWG und der Handel mit den südosteuropåischen Ländern, "Mitteilungen der Südosteuropa-Gesellschaft", Jg. 6, H. 2/3, München 1966, S. $10 \mathrm{ff}$. Probleme des deutschen Osthandels, "Wissenschaftlicher Dienst Südosteuropa", Jg. 16, H. 9/10, S. $145 \mathrm{ff}$.

AMERONGEN von, Otto Wolf, Der bulgarische, rumänische und ungarische Markt in deutscher Sicht, "Mitteilungen der Südosteuropa-Gesellschaft", Jg. 5, H. 2/3, München 1965 , S. $103 \mathrm{ff}$. 
AMERONGEN von, Otto Wolf, Die EWG und ihre Möglichkeiten der Zusammenarbeit mit den Ostblockstaaten, in: Handelsund Währungspolitik im Gemeinsamen Markt, Schriftenreihe des Forschungsinstituts der Friedrich-EbertStiftung, Hannover 1965, S. $77 \mathrm{ff}$.

BAKER, Russel, BOHLIG, Robert, The Control of Exports. - A Comparison of the Laws of the United States, Canada, Japan and the Federal Republik of Germany, "International Lawyer", Vol. I, No. 2, Washington D.C., Jan. 1967 , S. $163 \mathrm{ff}$.

BAUMANN, Joachim, Außenwirtschafts-, zoll- und steuerrechtliche Fragen bei der Kooperation nach dem Recht der EWGStaaten, in: Rechtsfragen der Kooperation zwischen Unternehmen in Ost und West, Studien des Instituts für Ostrecht, München - Herrenalb 1967, S. $77 \mathrm{ff}$.

BENDHEIM, E., Amerika und die Frage des Osthandels, "Wirtschaftsdienst", Jg. 44, H. 12, Hamburg 1964, S. $538 \mathrm{ff}$.

BERG VON, Michael, Auswirkungen der EWG auf den Handelsverkehr zwischen EWG-Ländern und kommunistischen Staaten, "Osteuropa-Wirtschaft", Jg. 8, H. 3/4, Stuttgart 1963 , S. $161 \mathrm{ff}$.

BERG VON, Michael, KLINKMÜLLER, Erich, Die Einfuhrpolitik der Bundes republik Deutschland gegenüber den Ostblockländern und ihre Exportmöglichkeiten in die Bundesrepublik, "Konjunkturpolitik", Jg. 12, Berlin 1966 , S. $336 \mathrm{ff}$.

BERMAN, Harold J., A Reappraisal of U.S.-U.S.S.R. Trade Policy, Reprinted from "Harvard Business Review", JulyAugust 1964

The Legal Framework of Trade between Planned and Market Economies: The Soviet-American Example, "Law and Contemporary Problems", Vol. 24, No. 3, Durnham N C. 1959

BERMAN, Harold J., GARSON, John R., Possible Effects of the Proposed East-West Trade Relations Act upon U.S. Import, Export, and Credit Controls, "Vanderbild Law Review", Vol. 20, No. 2, Nashville/Te., March 1967, S. $279 \mathrm{ff}$.

United States Export Controls. Past, Present, and Future, "Columbia Law Review", Vol. 67, No. 5, New York, May 1967, S. $791 \mathrm{ff}$.

BILIMOVICH, Aleksander, The Common Market and Comecon, "Studies of the Soviet Union", München 1962, S. $40 \mathrm{ff}$. 
BOETTCHER, Erik, Die Integrationsbemühungen im Ostblock und deren Konsequenzen für die EWG und Weltwirtschaft, in: Möglichkeiten und Wege zu einer europäischen Wirtschaftsverfassung, hrsg. von Herbert Schmidt, Berlir 1964 , S. $119 \mathrm{ff}$.

BRADLEY, John, Die Haltung der UdSSR gegenüber dem Gemeinsamen Markt, in: Ost-West-Handel in Theorie und Praxis, hrsg. von Helmut Romé, Graz 1965, S. 2

Der Gemeinsame Markt in kommunistischer Sicht, "Osteuropa-Rundschau" $\mathrm{Jg}$. 13, H. 12, München 1967, S. $3 \mathrm{ff}$.

DEUTSCH, Emeric, Die Rolle des Devisen- und Bankensystems in der Wirtschaft der Rumänischen Volks republik mit besonderer Berücksichtigung des Außenhandels, in: Beiträge zum Bank- und Devisenrecht in Südosteuropa, Südosteuropa-Studien, Bd. 8, hrsg. von Rudolf Vogel, München 1965, S. $49 \mathrm{ff}$.

DOBIAS, Peter, Grundlagen des jugoslawischen Wirtschaftssystems, "Weltwirtschaftliches Archiv", Bd. 99, H. 2, Hamburg 1967, S. $316 \mathrm{ff}$.

DOMDEY, Karl Heinz, Ủber die ökonomischen Beziehungen zwischen sozialistischen und kapitalistischen Ländern Europas, "Probleme des Friedens und des Sozialismus", Jg. 8, H. 9, Berlin (Ost) 1965, S. $717 \mathrm{ff}$.

EHRHARDT, Carl A., EWG und die Koordinierung des Osthandels, "Außenpolitik", Jg. 16, H. 6, Stuttgart 1965, S. $389 \mathrm{ff}$

ELSHOLZ, Günter, Begrenzte Integration im COMECON, "Wirtschaftsdienst", Jg. 45, H. 6, Hamburg 1965, S. 297 ff.

FELDMAN, J., Trade between Eastern Countries and the US, in: East-West Trade - Analysis of Trade between Wester Nations and the Soviet Bloc, American Management Association, New York 1964

GROSS, Hermann,

Albanien zwischen den Mächten. Ein Beitrag zur Erschließung unterentwickelter Gebiete, Sonderdruck des "Wirtschaftsdienstes", H. 6, Hamburg 1949 , S. $3 \mathrm{ff}$.

Der wirtschaftspolitische Umbruch in Südosteuropa, "Wissenschaftlicher Dienst Südosteuropa", Jg. II, H. 10/11, München 1960, S. $113 \mathrm{ff}$.

Die Außenhandelsverflechtung der Südoststaaten, in: Südosteuropa-Jahrbuch, Bd. 4, hrsg. von Rudolf Vogel, München 1960, S. $3 \mathrm{ff}$. 
GROSS, Hermann,

GYORGY, Andrew,
Die Liberalisierungsprobleme im Ost-West-Handel, "Wissenschaftlicher Dienst Südosteuropa", Jg.XVII, H. 10, München 1968, S. $145 \mathrm{ff}$.

Economic Integration of Eastern Europe, in: Aspects of Modern Communism, ed. by Richard F. Staar, Columbia S. C. 1968, S. $143 \mathrm{ff}$.

Ergebnisse und Probleme des COMECON, "Wissenschaftlicher Dienst Südosteuropa", Jg. XVI, H. 4/5, München April-Mai 1967, S. 49 ff.

Kennedy-Runde und Ost-West-Handel, "Der Donauraum", Jg. 12, H. 3, Wien 1967, S. $121 \mathrm{ff}$.

Neuere Tendenzen in der Agrar- und Industrialisierungspolitik Ostmittel- und Südosteuropas, in: Südosteuropa-Jahrbuch, Bd. 3, hrsg. von Wilhelm Gülich, München 1959, S. $72 \mathrm{ff}$.

Probleme der Handelspolitik und der wirtschaftlichen Zusammenarbeit $z w i s c h e n$ dem Westen und den osteuropäischen Staaten, in: Die Politik des Westens und Osteuropa, hrsg. von Alfred Domes, Köln 1966, S. $160 \mathrm{ff}$.

Probleme in den Wirtschaftsbeziehungen der Donauländer zur EWG, "Der Donauraum", Jg. 10, H. 1/2, Wien 1965 , S. $30 \mathrm{ff}$.

Wirtschaftssysteme und Wirtschaftspolitik der Südosteuropäischen Staaten, in: Südosteuropa-Jahrbuch, Bd. 7, hrsg. von Walter Althammer, München 1966, S. $1 \mathrm{ff}$.

The Role of Nationalism in Eastern Europe: From Monolith to Policentrism, in: Eastern Europe in Transition, ed. by Kurt London, Baltimore 1966, S. $3 \mathrm{ff}$.

HAWLOWITSCH, Johann, Die Sozialistische Foderative Republik Jugoslawien, in: Osteuropa und die Hoffnung auf Freiheit, hrsg. von Alfred Domes, Köln 1967, S. 210 ff.

HEINEN, Edmund, Die Zielfunktion der Unternehmung, Sonderdruck aus: Zur Theorie der Unternehmung, Festschrift zum 65. Geburtstag von Erich Gutenberg, hrsg. von Helmut Koch, Wiesbaden 1962 , S. 9 ff.

HODGES, Luther H., United States Policy on East-West Trade, in: EastWest Trade, An Analysis of Trade between Western Nations and the Soviet Bloc, American Management Association, New York 1964 
HOFFMANN, E., Der Osthandel der Anderen, "Information über den innerdeutschen Handel und West-Ost-Handel", H. 1, Berlin Jan. 1960

KIESEWETTER, Bruno, Die Wandlung der Handelspolitik in Südosteuropa, in: Südosteuropa-Jahrbuch, Bd. 2, hrsg. von Wilhelm Gülich, München 1958, S. $63 \mathrm{ff}$.

KLINKMUULLER, Erich, Organisation und Planung der Außenwirtschaft, in: Osteuropa-Handbuch, Bd. Sow jetunion, Teil: Das Wirtschaftssystem, hrsg. von Werner Markert, Köln und Graz 1965, S. 484 ff.

Zur Strategie des Ost-West-Handels, "OsteuropaWirtschaft", Jg. 9, H. 3, Stuttgart 1964, S. 1 ff.

KNAPP, Viktor, The Function, Organization and Activities of Foreign Trade Corporations in the European Socialist Countries, in: The Sources of the Law of International Trade, ed. by Clive M.Schmitthoff, New York 1964, S. $52 \mathrm{ff}$.

KOHLER, Foy D., East-West Relations: Shapping a Stable World, "Department of State Bulletin", Washington D.C., Jan. 2, 1967

KRONSTEN, Joseph A., East-West Trade: Myth and Matter, "International Affairs", London, April 1967, S. $265 \mathrm{ff}$.

LEDERER, Ernst, Bilateralism in East-West Trade, "Intereconomics", H. 6/7, Hamburg June/July 1967, S. $189 \mathrm{ff}$.

Kreditprobleme im Verkehr mit dem Südosten, in: Südosteuropa-Jahrbuch, Bd. 4, hrsg. von Rudolf Vogel, München 1960 , S. $67 \mathrm{ff}$.

$-$

Ostkredite - neue Lösungen für alte Probleme?, Beiheft $z u$ "Der Volkswirt", Frankfurt am Main, Nr. 21 v. 26. 5.1967

LONDON, Kurt, Communism in Eastern Europe: Polycentrism, Splittism and After, in: Eastern Europe in Transition, ed. by Kurt London, Baltimore 1966, S. $19 \mathrm{ff}$.

LYUBIMOV, N.L., Soviet Foreign Trade Problems, "International Affairs", No. 8, Moscow 1965, S. 12 ff.

MEIER, Jens, ROHLEDER, Claus-D., Kooperation mit Ostblockstaaten der Vorteil liegt a uf beiden Seiten, "Südwestfälische Wirtschaft", Jg. 24, H. 3, Hagen, März 1968, S. 131 f

METZGER, Stanley D., Federal Regulations and Prohibition of Trade with Iron Curtain Countries, "Law and Contemporary Problems", Vol. 29, No. 4, Durham N.C. 1964 , S. $1000 \mathrm{ff}$. 
MÖLLER, Hans,

Handelspolitik zwischen Bilateralismus und Multilateralismus, "Weltwirtschaftliches Archiv", Bd.68, H. 2, Hamburg 1952, S. $203 \mathrm{ff}$.

MONTIAS, Michael, Planning with Material Balances in Soviet-Type Economies, "The American Economic Review", Vol.XLIX, No. 5, o. O., 1959

MURKO, Vladimir, Außenhandelspolitik und Zahlungsbilanzgestaltung in Jugoslawien, "Osteuropa-Wirtschaft", Jg. 10, H. 3, Stuttgart 1965, S. $175 \mathrm{ff}$.

NÖTEL, Rudolf, Die Rolle der Vereinten Nationen im Ost-West-Handel, in: Koexistenz zwischen Ost und West - Konflikt, Kooperation, Konvergenz, hrsg. von Hans Mayzedt und Helmut Romé, Wien - Frankfurt - Zürich 1967, S. $261 \mathrm{ff}$.

NOVE, Alec, East-West Trade in an Arms Control Context, in: Disarmament and World Economic Interdependence, ed. by Emile Benoit, Oslo 1967, S. $190 \mathrm{ff}$.

OAKESHOTT, R., The Strategis Embargo, An Obstacle to East-West Trade, "The World Today", Vol. 19, London Jan. Dec. 1963

OLSIENKIEWICZ, H., Problems of East-West Trade: Trade and Liberalisation, "Bulletin of the Institute for the Study of the USSR", Vol. 11, No. 6, München 1964, S. $3 \mathrm{ff}$.

PETROCICH, Michael B., United States Policy in East Europe, "Current History", Vol. 52, No. 308, Boulder/Colorado, S. $193 \mathrm{ff}$.

PRYOR, Frederic L., The Organisation of Trade in the European Communist Nations and the Implications for East-West Trade, in: East-West Trade. A Symposium, ed. by Philip E. Uren, Toronto 1966, S. $45 \mathrm{ff}$.

REDEI, Jenઠ,

Die Reform der Wirtschaftslenkung in Ungarn und der Außenhandel, "Osteuropa-Wirtschaft", Jg. 12, H. 1, Stuttgart 1967, S. 1 ff.

REY, Jean,

Die Zoll- und Handelspolitik der EWG gegenüber Drittländern, in: Handels- und Währungspolitik im Gemeinsamen Markt, Schriftenreihe des Forschungsinstituts der Friedrich-Ebert-Stiftung, Hannover 1965, S. 25 ff.

Les échanges extérieurs de la Communauté Economique Européenne, aspects particuliers des relations avec les pays de l'Est, in: Les Communautés européennes et les relations Est-Ouest, Bruxelles 1967 , S. $23 \mathrm{ff}$. 
ROHLEDER, Claus-D., Die rumănische Wirtschaftsentwicklung, Beginn einer neuen Phase, in: Wirtschaftsreformen in Osteuropa, hrsg. von Karl C. Thalheim und Hans-Hermann Höhmann, Köln 1968, S. 230 ff.

Deutsche Neuregelungen im Handel mit Ost- und Südosteuropa, "Mitteilungen der Südosteuropa-Gesellschaft", Jg. 6, Nr. 1, München Jan. - März 1966, S. $45 \mathrm{f}$.

Kooperation zwischen Marktwirtschaft und Staatshandelsländern, "Mitteilungen der Südosteuropa-Gesellschaft", Jg. 6, Nr. 1, München Jan. - März 1966, S. $12 \mathrm{ff}$.

Länderbericht Rumänien, Allgemeine Statistik des Auslandes, Statistisches Bundesamt Wiesbaden, Stuttgart und Mainz 1967

SANNWALD, Rolf, Die Europäische Wirtschaftsgemeinschaft und der Osthandel, "Europa Archiv", Folge 4, Bonn 1965, S. $115 \mathrm{ff}$.

Die Sowjetunion und die westeuropäische Integrationspolitik, in: Ostblock, EWG und Entwicklungsländer, hrsg. von Erik Boettcher, Stuttgart 1963, S. 80 ff.

SCHENK, Fritz, Die Enkel der Revolution, "junge Wirtschaft", Jg. 14, H. 9, Bad Godesberg 1966, S. $337 \mathrm{ff}$.

SCHENK, Karl Ernst, Integration und Westhandel Osteuropas, in: Wirtschaftsplanung im Ostblock, hrsg. von der Deutschen Gesellschaft für Osteuropakunde, Stuttgart 1966, S. $93 \mathrm{ff}$.

SCHMITTHOFF, Clive M., Commercial Treaties and International Trade Transactions in East-West Trade, "Vanderbilt Law Review", Vol. 20, No. 2, Nashville/Te., March 1967, S. 355 ff.

SCHÖFFLER, G., Die Revision des Allgemeinen Zoll- und Handelsabkommens, "Europa-A rchiv", Bd. 10, Bonn 1955

SCHRÖDER, Wolfgang, Osthandel politisch sehen, "junge Wirtschaft", Jg. 14, H. 9, Bad Godesberg 1966, S. 325 f.

SCHW ANKE, Robert, Entwicklungstendenzen in der albanischen Wirtschaft, "Osteuropa-Wirtschaft", Jg. 10, H. 2, Stuttgart 1965, S. $112 \mathrm{ff}$.

SCOTT, J.,

The London Viewpoint, in: East-West Trade - An Analysis of Trade between Western Nations and the Soviet Bloc, American Management Association, New York 1964 
SIEMANN, Hans Andreas, Liberalisierung der Osteinfuhr, Beiheft zu "Der Volkswirt", Frankfurt am Main, Nr. $21 \mathrm{v}$. 26. 5.1967

SORENSEN, Theodore C., Why we should trade with the Soviets, "Foreign Affairs", Vol. 46, No. 3, New York, April 1968, S. $575 \mathrm{ff}$.

SPULBER, Nicolas, Economic Modernization, in: The United States and Eastern Europe, ed. by Robert F. Byrnes, Englewood Cliffs/N. J. 1967 , S. $57 \mathrm{ff}$.

Effects of the Embargo on Soviet Trade, "Harvard Business Review", Cambridge/Mass., Nov.-Dec. 1962, S. 122

Staatliche Exportkreditfinanzierung in Großbritannien, USA und der Bundesrepublik, "Wirtschaftsdienst", o.Jg., H. 5, Hamburg Mai 1960

STITZ-ULRICI, Leonhard, Probleme im Investitionsgüterexport nach dem Südosten, in: Südosteuropa-Jahrbuch, Bd. 4, hrsg. von Rudolf Vogel, München 1960, S. $75 \mathrm{ff}$.

TROWBRIDGE, Alexander B., Harmonizing East-West Trade with U.S. National Interests, "Department of State Bulletin". Washington D.C., Jan. 10, 1966, S. $59 \mathrm{ff}$.

WALLENBERG-PACHALY von, H., Policy and Practice of the Federal Republik of Germany, in: East-West Trade, An Analysis of Trade between Western Nations and the Soviet Bloc, American Management Association, New York 1964

WESSELY, Kurt, Chinas Brückenkopf in Europa, "Der Volkswirt", Nr. 143, Frankfurt am Main

WILCZYNSKI, J., Dumping and Central Planning, "Journal of Political Economy", Chicago, June 1966

WILLMANN, Joachim, Grundsatzfragen des Ost-West-Handels, "Europa Archiv", Folge 1, Bonn 1965, S. $15 \mathrm{ff}$.

WRIGHT, Robert B., East-West Trade: The Iron Curtain Countries Eighteen Years Later, "Department of State Bulletin", Washington D.C., Dec. 7, 1964, S. $815 \mathrm{ff}$.

ZOTSCHEW, Theodor, Die Entwicklungsprobleme der polnischen Wirtschaft, in: Material über die wirtschaftliche Lage und Entwicklung der Volksrepublik Polen, Institut für Weltwirtschaft, Forschungsabteilung, Kiel 1957

Die wirtschaftlichen Probleme Albaniens, "OsteuropaWirtschaft", Jg. 7, H. 1, Stuttgart 1962, S.' $39 \mathrm{ff}$. 
3. Offizielle US-Publikationen und Untersuchungsberichte:

A Background Study on East-West Trade, Committee on Foreign Relations, U.S. Senate, Washington D.C., April 1965

A New Look at Trade Policy Toward the Communist Bloc, by Samuel Pisaz Subcommittee on Foreign Economic Policy, Joint Economic Committee, Washington, Nov. 10, 1961

Considerations Involved in Granting MFN Treatment to the Countries of Eastern Europe, United States Tariff Commission (prep. by Anton F. Malish, Jr.), Washington D.C. 1968

East-West Trade, A Common Policy for the West, A Statement on National Policy by the Research and Policy Committee of the Committee for Economic Development (CED), New York 1965

East-West Trade. A Compilation of Views of Businessmen, Bankers, and Academic Experts. Committee on Foreign Relations, U.S. Senate, Washington D.C. 1964

East-West Trade. Hearings before the Committee on Foreign Relations, U.S. Senate, Part I, Washington D.C., March-April 1964

East-West Trade. Hearings before the Committee on Foreign Relations, U.S. Senate, Part II, Washington D.C., February 24, $25,26,1965$

Export Controls, Hearings before the Subcommittee on International Trade, Committee on Banking and Currency, House of Representatives, Washington D.C., June 5, 1963

"Export Control", Quarterly Reports, Washington D. C.

Export of Strategic Materials to the U.S.S.R. and Other Soviet Bloc Countries. Hearings before the Internal Security Subcommittee, Committee on the Judiciary, U.S. Senate, Parts 1 - 4, Washington D. C., October 1961

International Security and International Trade, United States Council of the International Chamber of Commerce, Inc., New York 1956

Private Boykotts vs the National Interest, Department of State Publication No. 8117, Washington D.C. 1966

Report to the President of the Special Committee on U.S. Trade Relations with East European Countries and the Soviet Union, Department of State Publication No. 8061, Commercial Policy Series 201, Washington D.C., March 1966 
Statement on U.S. Policy Toward East-West Trade by Committee on

Commercial Policy. United States Council of the

International Chamber of Commerce Inc., Committee Report, April 21, 1967 o. O.

"The Battle Act Report", Reports to Congress, Department of State,

Washington D.C.

The Fiat-Soviet Auto Plant and Communist Economic Reforms. A Report pursuant to House Resolution 1043, 89th Congress, 2nd. Session for the Subcommittee on International Trade, Committee on Banking and Currence, House of Representatives, Washington D.C., March 1, 1967

4. Berichte und $M$ itteilungen der Europäischen Gemeinschaften:

Amtsblätter der Europäischen Gemeinschaften

Arbeitsdokument des Ausschusses für Außenwirtschaftsbeziehungen des

Europäischen Parlaments über die Probleme der Handelsbeziehungen zwischen der Gemeinschaft und den Staatshandelsländern Osteuropas, Berichterstatter: Karl Hahn, PE $18438,30.10 .1967$

Bericht des Außenhandelsausschusses des Europäischen Parlaments über die schrittweise Errichtung der gemeinsamen Handelspolitik, Berichterstatter: Karl Hahn, Dok. 3, 19651966 v. 22.3. 1965

Bericht im Namen des Landwirtschaftsausschusses des Europäischen Parlamentes über die allgemeinen Grundsătze für die Marktordnungen in der Endphase des Gemeinsamen Marktes, Berichterstatter: R. Blondelle, Dok. 43, 1967- 1968 v. 8.5. 1967

Bulletin der Europäischen Gemeinschaft für Kohle und Stahl, Luxemburg Europäisches Parlament, Sitzungsdokumente 1965 - 1966, Bericht im Namen des Außenhandel sausschusses über Fragen der gemeinsamen Handelspolitik der Gemeinschaft gegenüber Staatshandelsländern, Berichterstatter: Walter Löhr, Dok. 10 (Deutsche Ausgabe), 22. März 1965

Gesamtberichte über die Tätigkeit der Europäischen Gemeinschaft für Kohle und Stahl, Hohe Behorde, Luxemburg 
Gesamtberichte über die Tätigkeit der Europäischen Wirtschaftsgemeinschaft, Kommission, Brüssel

Erster Gesamtbericht über die Tätigkeit der Gemeinschaften 1967

(Europäische Gemeinschaft für Kohle und Stahl Europäische Wirtschaftsgemeinschaft - Europäische Atomgemeinschaft), Kommission, Brüssel-Luxemburg, Februar 1968

Report on Commercial Relations between Member States of the Council of Europe and the Countries of Central and Eastern Europe, Council of Europe-Consultative Assembly, Doc. 1676, Strasbourg, Sept. 30, 1963

5. Veroffentlichungen der Vereinten Nationen: (ohne periodische statistische Veröfentlichungen)

Economic Bulletin for Europe, Geneva

Economic Survey of Europe, Geneva

Trade Problems between Countries Having Different Economic and Social Systems, in: Proceedings of the United Nations Conference on Trade and Development, Geneva, 23 March 16 June 1964, Vol. VI, Trade Expansion and Regional Grouping, Part I, S. 113 ff.

6. Sonstige verwendete Zeitschriften, Zeitungen und Berichte:

"Budapester Rundschau"

"Bundesanzeiger", Köln, hrsg. vom Bundesminister der Justiz

"Business Abroad", New York

"Department of State Bulletin", Washington D.C.

"Der Gemeinsame Markt", Bonn

"Der Volkswirt", Frankfurt am Main

"Die Außenwirtschaft", Köln

"Die Welt", Hamburg

"Die Zeit", Hamburg 
"Dokumentation der Zeit", Berlin (Ost)

"Europäische Gemeinschaft", Bonn

"Frankfurter Allgemeine Zeitung"

"Handelsblatt", Düsseldorf

"Industriekurier", Düsseldorf

"Intereconomics", Hamburg

"International Affairs", Moscow

"International Lawyer", Washington D.C.

Jahresberichte des Bundesverbandes der Deutschen Industrie, (BDI)

"Le Courrier des Pays de l'Est", Paris

Marktinformationsdienst der Bundesstelle für Außenhandelsinformation, Köln

"Mitteilungen der Bundesstelle für Außenhandel" (BfA), Köln

"Neue Zürcher Zeitung"

"Nachrichten für den Außenhandel", Frankfurt am Main

"Österreichische Osthefte", Wien

"Ost-West-Kurier", Hannover

"Süddeutsche Zeitung", München

"Ostprobleme", Bonn

"Review of International Affairs", Belgrad

"The American Review of Soviet and Eastern European Foreign Trade", White Plains, N.Y.

"The Financial Times", London

"The New York Times"

"Vereinigte Wirtschaftsdienste", Frankfurt am Main

"Wall Street Journal", New York

"Washington Post"

"Wirtschaftsdienst", Hamburg

"Wirtschafts - und Sozialpolitik", Bonn

"Wissenschaftlicher Dienst Südosteuropa", München

"Yugoslavia Export", Belgrad 
BAKER, Russel,

Legal Aspects of East-West Trade - A Rational View. Address given before the "East-West Trade" Briefing Session of the American Management Association, New York, May 20, 1964, unveröffentlichtes Manuskript

Opportunities and Problems in East-West Trade, Speech given before the American Management Association Briefing Session on East-West Trade, New York, June 6, 1966, unveröfentlichtes Manuskript

CAMPBELL, Robert W., Yugoslavia and the World Market, Paper presen. ted to the VIth United States-Yugoslav Seminar on "Problems of Economic Policy", summer 1966, Décani, Yugoslavia, unveröffentlichtes Manuskript

FISCHER, Robert, Die gegenwärtige Situation der deutsch-jugoslawischen Wirtschaftsbeziehungen, Vortrag, gehalten am 5. 5. 1966 bei Drustvo Ekonomistov, Ljubljana, unveröfentlichtes Manuskript

GEORGE, Mishell J., Doing Business with Eastern European Countries, Address before the Export Expansion Conference, Savannah/Georgia, Nov. 15, 1966, unveröffentlichtes Manuskript

GUMPEL, Werner, VOGEL, Heinrich, Die Wirtschaft Ungarns, Bulgariens und Rumäniens, in: Gegenwartsfragen der Ost-Wirtschaft, Bd. 5, München - Wien 1968

HAWLOWITSCH, Johann, Länderbericht Jugoslawien, Grundlagenfragen mit Bezug auf die wirtschaftspolitischen Kooperationsmöglichkeiten mit dem Westen, Forschungsbericht für die Stiftung Wissenschaft und Politik, Eggenberg, Juli 1968

International Chamber of Commerce, Paris, Commission on the Expansion of International Trade (Meeting on 30th and 31 st January 1967), Trade between Collectivist Economies and the Rest of the World, Statement, adopted by the 81 st Session of the Executive Committee (15.2.1967), Doc. No. $102159 \mathrm{Rev}$. 16.12. 1967

PERUTZ, Tino, Opportunities for Trade with the East. Lost and Found. Paper presented to the East-West Trade Seminar, American Management Association, New York, March 4, 1968, unveröffentlichtes Manuskript 
Radio Free Europe Research Publications

RUSK, Dean,

Why we Treat different Communist Countries differently, Department of State Publication No. 7999, Washington D.C. 1964

SPULBER, Nicolas, East-West Trade and the Paradoxes of the Strategic Embargo, Paper presented before the Conference on International $\mathrm{T}$ rade and International Planning, University of South California, Dec. 1966, unveröffentlichtes Manuskript

TROWBRIDGE, Alexander B., Peaceful Engagement with the East, Address prepared for Delivery at the International Trade Session, National Foreign Trade Convention, New York, Nov. 2, 1966, U.S. Comm-Doc. 38341

VOGEL, Heinrich, ROHLEDER, Claus-D., Länderbericht Rumänien, Grundlagenfragen mit Bezug auf die wirtschaftspolitischen Kooperationsmöglichkeiten mit dem Westen, Forschungsbericht für die Stiftung Wissenschaft und Politik, Eggenberg, Juli 1968

ZOTSCHEW, Theodor, Bulgarien, in: Die Außenwirtschaft der südosteuropäischen Länder - Entwicklung, Probleme, Perspektiven, im Druck

Die Entwicklungsp robleme der polnischen Wirtschaft, in: Material über die wirtschaftliche Lage und Entwicklung der Volks republik Polen, Institut für Weltwirtschaft, Forschungsabteilung, Kiel 1957

8. Gesetze und Verordnungen:

Außenwirtschaftsgesetz vom 28. April 1961, in: Der Waren-, Dienstleistungs- und Kapitalverkehr mit dem Ausland (Stand Mai 1968), Wilhelm Köhler-Verlag, München - Frankfurt am Main u.a. O.

Runderlaß Außenwirtschaft, Nr. 17/66

Verordnung zur Durchführung des Außenwirtschaftsgesetzes (Außenwirtschaftsverordnung - AWV) vom 22. August 1961, in: Der Waren-, Dienstleistungs- und Kapitalverkehr mit dem Ausland (Stand Mai 1968), Wilhelm Köhler-Verlag, München - Frankfurt am Main u.a. $O$.

Vertrag zur Gründung der Europäischen Wirtschaftsgemeinschaft 
9. Statistische Veroffentlichungen:

Annuarul Statistic al Republicii Socialiste România 1967, Direç̧ia Centrală de Statistica

OECD Foreign Trade, Series A, Overall Trade by Countries

OECD Foreign Trade, Series B, Commodity Trade - Analysis by Main Regions

Statistical Yearbook 1965, 1967, Hungarian Statistical Office

Statistical Yearbook of the Peoples Republic of Bulgaria 1967, Central Statistical Office to the Council of Ministers

Statistical Yearbook 1964, United Nations, New York 1965

Statistical Yearbook 1966, United Nations, New York 1967

Statistiðki Godišnjak SFRJ 1967, Savezni Zavod za Statistiku

Statistisches Amt der Europäischen Gemeinschaften, Außenhandel, Analytische Übersichten, Export 1964, 1965

Statistisches Amt der Europäischen Gemeinschaften, Außenhandel, Analytische Ubersichten, Import 1964, 1965

Statistisches Amt der Europäischen Gemeinschaften, Ostblock 1968, Nr. 1, Außenhandel der Europäischen Ostblockländer

US- Exports - Country by Commodity Grouping, US-Department of Commerce, Bureau of the Census, FT 420, 1964 Annual, FT 4201966 Annual

US-Imports of Merchandise for Consumption, US-Department of Commerce, Bureau of the Census, FT 125, 1964, Annual, FT 125, 1966 Annual

Yearbook of National Accounts Statistics 1966, United Nations, New York 1967 
Tabelle 1: Der Anteil des Außenhandels der Staatshandelslander Südosteuropas ${ }^{a}$ am Gesamtaußenhandel ausgewählter westlicher Länder 1964 und 1966 in $\mathrm{v} . \mathrm{H}$.

\begin{tabular}{lcccc} 
& \multicolumn{2}{c}{ Einfuhr } & \multicolumn{2}{c}{ Ausfuhr } \\
& 1964 & 1966 & 1964 & 1966 \\
\hline \multirow{2}{*}{ EWG } & 0,8 & 1,0 & 1,2 & 1,4 \\
Großbritannien & 0,5 & 0,6 & 0,8 & 0,9 \\
USA & 0,1 & 0,1 & 0,2 & 0,1
\end{tabular}

Quellen: Statistisches Jahrbuch für die Bundesrepublik Deutschland 1967, Internationale Übersichten, Teil L, Außenhandel, Tabelle 4; Quellen der Tabellen 2 - 4 im Anhang; eigene Berechnungen.

\footnotetext{
${ }^{a}$ Bulgarien, Rumänien, Ungarn.
} 
Tabelle 2: Der Außenhandel Bulgariens mit ausgewăhten Landern bzw. Ländergruppen 1960, 1964 und 1966

\begin{tabular}{|c|c|c|c|c|c|c|c|c|c|c|c|c|c|}
\hline \multirow{2}{*}{$\begin{array}{l}\text { Lander bzw. } \\
\text { Landergruppen }\end{array}$} & \multicolumn{2}{|c|}{1960} & \multicolumn{2}{|c|}{1964} & \multicolumn{2}{|c|}{1966} & \multirow{2}{*}{$\begin{array}{l}\text { Lander bzw. } \\
\text { Landergruppen }\end{array}$} & \multicolumn{2}{|c|}{1960} & \multicolumn{2}{|c|}{1964} & \multicolumn{2}{|c|}{1966} \\
\hline & v. H. & $\begin{array}{l}\text { Mill. } \\
\text { Dollar }\end{array}$ & v.H. & $\begin{array}{l}\text { Mull. } \\
\text { Dollar }\end{array}$ & v. H. & $\begin{array}{l}\text { Mill. } \\
\text { Dollar }\end{array}$ & & v.H. & $\begin{array}{l}\text { Mul. } \\
\text { Dollar }\end{array}$ & v. H. & $\begin{array}{l}\text { Mill. } \\
\text { Dollar }\end{array}$ & v.H. & $\begin{array}{l}\text { Mill. } \\
\text { Dollar }\end{array}$ \\
\hline EINF UHREN & & & & & & & AUSF UHREN & & & & & & \\
\hline Insgesamt & 100,0 & 632,0 & 100,0 & 1062,4 & 100,0 & 1478,3 & Insgesamt & 100,0 & 571.5 & 100,0 & 995,0 & 100,0 & 1305,0 \\
\hline davon aus EWG & 9,1 & 57,3 & 10.4 & 110,5 & 16,3 & 240.9 & davon nach EWG & 6.5 & 37,2 & 8,1 & 80,7 & 9,8 & 127,4 \\
\hline Belg. - Lux. & 0,5 & 3,2 & 0,4 & 4,0 & 0,8 & 11,5 & Belg - - Lux. & 0,5 & 2,6 & 0,3 & 3,0 & 0,7 & 8,7 \\
\hline BRD & 5,9 & 37,6 & 4. 8 & 51,5 & 8,9 & 131,8 & BRD & 3,3 & 19,0 & 3,2 & 32,0 & 3,1 & 40,9 \\
\hline Frankreich & 1,2 & 7,8 & 2,4 & 25,9 & 3,2 & 47,6 & Frankreich & 0,9 & 4.9 & 1,0 & 9,7 & 1,1 & 13,8 \\
\hline Italien & 1,1 & 6,7 & 2,4 & 25,1 & 2,8 & 41,0 & Italien & 1,6 & 9,4 & 3,2 & 32,0 & 4,4 & 57,7 \\
\hline Niederlande & 0,4 & 2,4 & 0,4 & 4,0 & 0,6 & 9.0 & Niederlande & 0,2 & 1,3 & 0,4 & 4,0 & 0,5 & 6,2 \\
\hline Großbritannien & 1,7 & 11,0 & 1,3 & 14,2 & 2,1 & 31,7 & Großbritannien & 1,1 & 6,5 & 1,3 & 12,6 & 1,6 & 21,0 \\
\hline USA & 0 & 0,3 & 0,3 & 2,9 & 0,8 & 1,2 & USA & 0,3 & 1,7 & 0,2 & 1,5 & 0,2 & 3,1 \\
\hline COMECON & $80,4^{8)}$ & $508,3^{a)}$ & $72.8^{b)}$ & $773,7^{b)}$ & $65,9^{b)}$ & $974.5^{b)}$ & COMECON & $80,7^{a)}$ & $461,4^{a)}$ & $74,9^{b)}$ & $745,0^{b)}$ & $70,5^{b)}$ & $919,4^{b)}$ \\
\hline Sow jetuni on & 52,5 & 332,3 & 52,8 & 560.9 & 47,8 & 706,5 & Sow jet union & 53.8 & 307,3 & 52.3 & 521,3 & 50,9 & 663,6 \\
\hline
\end{tabular}

Quellen: Statistical Yearbook of the Peoples Republic of Bulgaria 1967, Central Statistical Office to the Council of Ministers; Statistisches Amt der Europuischen Gemeinschaften, Ostblock 1968, Nr. 1, Außenhandel der Europaischen Ostblocklander; eigene Berechnungen.

Anmerkungen: Zugrunde gelegter Umrechnungskurs: 1,17 Leva = 1 US- \$.

a) COMECON mit Albanien, ohne Mongolei

b) COMECON ohne Albanien und die Mongolei

0 = mehr als nichts, aber weniger als die in der Tabelle dargestellte kleinste Eínheit. 
Tabelle 3: Der Außenhandel Rumaniens mit ausgew ahlten Landern bzw. Landergruppen 1960, 1964 und 1966

\begin{tabular}{|c|c|c|c|c|c|c|c|c|c|c|c|c|c|}
\hline \multirow{2}{*}{$\begin{array}{l}\text { Lander bzw. } \\
\text { Landergruppen }\end{array}$} & \multicolumn{2}{|c|}{1960} & \multicolumn{2}{|c|}{1964} & \multicolumn{2}{|c|}{1966} & \multirow{2}{*}{$\begin{array}{l}\text { Lander bzw. } \\
\text { Landergruppen }\end{array}$} & \multicolumn{2}{|c|}{1960} & \multicolumn{2}{|c|}{1964} & \multicolumn{2}{|c|}{1966} \\
\hline & v. H. & $\begin{array}{l}\text { Mill. } \\
\text { Dollar }\end{array}$ & v. H. & $\begin{array}{l}\text { Mull. } \\
\text { Dollar }\end{array}$ & v.H. & $\begin{array}{l}\text { Mull. } \\
\text { Dollar }\end{array}$ & & v.H. & $\begin{array}{l}\text { Mull. } \\
\text { Dollar }\end{array}$ & v. H. & $\begin{array}{l}\text { Mull. } \\
\text { Dollar }\end{array}$ & v. H. & $\begin{array}{l}\text { Mill. } \\
\text { Dollar }\end{array}$ \\
\hline EINFUHREN & & & & & & & AUSF UHREN & & & & & & \\
\hline Insgesamt & 100,0 & 648,0 & 100.0 & 1168.1 & 100,0 & 1213,2 & Insgesamt & 100,0 & 717,2 & 100,0 & 1000,1 & 100,0 & 1186,2 \\
\hline davon aus EWG & 14,5 & 93,7 & 17,0 & 199,0 & 23,3 & 282.0 & davon nach EWG & 13,1 & 94,2 & 14,4 & 143,5 & 18,4 & 217,8 \\
\hline Belg. - Lux. & 0,4 & 2,5 & 0.8 & 9,1 & 0,8 & 9,7 & Belg. - Lux. & 0,3 & 2,1 & 0,9 & 8,6 & 0,7 & 7,9 \\
\hline BRD & 7,1 & 46,1 & 7,5 & 87,8 & 12,2 & 148,2 & BRD & 6,1 & 43,8 & 5,4 & 53,6 & 8,2 & 74,1 \\
\hline Frankreich & 3,8 & 24,8 & 3,8 & 45,4 & 4,7 & 56,8 & Frankreich & 2.7 & 19,5 & 2,6 & 26,3 & 4,3 & 51,3 \\
\hline Italien & 7,5 & 16,4 & 4,1 & 48,3 & 4,0 & 48.7 & Italien & 3,6 & 25,6 & 4,9 & 49,2 & 6,3 & 74,7 \\
\hline Niederlande & 0,6 & 3,9 & 0,7 & 8,4 & 1,5 & 18,6 & Niederlande & 0,4 & 3,2 & 0,6 & 5,8 & 0,8 & 9,8 \\
\hline Grobbritannien & 2.7 & 17,8 & 3,6 & 41,7 & 3,8 & 45,6 & Großbritannien & 2,1 & 14,9 & 3,2 & 31,7 & 9,8 & 45,9 \\
\hline USA & 1,0 & 6,3 & 0,4 & 5,2 & 2,2 & 26,7 & USA & 0 & 0,6 & 0,2 & 1,9 & 0.4 & 4,6 \\
\hline COMECON & $67,9^{2)}$ & $\left(39,8^{8)}\right.$ & $64,9^{b)}$ & $781,8^{b)}$ & $13,1^{b)}$ & $637,7^{b)}$ & COMECON & $65.8^{8)}$ & $472,1^{a)}$ & $64,5^{b)}$ & $645,0^{b)}$ & $56,0^{b)}$ & $660,4^{b)}$ \\
\hline Sow jetunion & 41,0 & 266,0 & 42,2 & 493,1 & 32,5 & 394,1 & Sow jetunion & 39,2 & 281,5 & 42,2 & 421,8 & 34,5 & 409,8 \\
\hline
\end{tabular}

Quellen: Annuarul Statistic al Republicii Socialiste România 1967, Directia Centrala de Statistica; Statistisches Amt der Europaischen Gemeinschaften, Ostblock 1968. Nr. 1, AuBenhandel der Europaischen Ostblocklander; eigene Berechnungen.

Anmerkungen: Zugrunde gelegter Umrechnungskurs: 6 Lei $: 1$ US- $\$$

a) COMECON mit Albanien, ohne Mongole1

b) COMECON ohne Albanien und die Mongolel

0 - mehr als nichts, aber weniger als die in der Tabelle dargestellte kleinste Einhoit. 
Tabelle 4: Der Außenhandel Ungarns mit ausgewăhlten Landern bzw. Lăndergruppen 1960, 1964 und 1966

\begin{tabular}{|c|c|c|c|c|c|c|c|c|c|c|c|c|c|}
\hline \multirow{2}{*}{$\begin{array}{l}\text { Lander bzw. } \\
\text { Landergruppen }\end{array}$} & \multicolumn{2}{|c|}{1960} & \multicolumn{2}{|c|}{1964} & \multicolumn{2}{|c|}{1966} & \multirow{2}{*}{$\begin{array}{l}\text { Lander bzw. } \\
\text { Landergruppen }\end{array}$} & \multicolumn{2}{|c|}{1960} & \multicolumn{2}{|c|}{1964} & \multicolumn{2}{|c|}{1966} \\
\hline & V.H. & $\begin{array}{l}\text { Mill. } \\
\text { Dollar }\end{array}$ & v.H. & $\begin{array}{l}\text { Mill. } \\
\text { Dollar }\end{array}$ & v. H. & $\begin{array}{l}\text { Mill. } \\
\text { Dollar }\end{array}$ & & v.H. & $\begin{array}{l}\text { Mull. } \\
\text { Dollar }\end{array}$ & v. H. & $\begin{array}{l}\text { Mill. } \\
\text { Dollar }\end{array}$ & v.H. & $\begin{array}{l}\text { Mill. } \\
\text { Dollar }\end{array}$ \\
\hline EINF UHREN & & & & & & & AUSFUHREN & & & & & & \\
\hline Insgesamt & 100,0 & 975,7 & 100,0 & 1494.5 & 100.0 & 1565,2 & Insgesamt & 100,0 & 873,9 & 100,0 & 1351,8 & 100,0 & 1593,3 \\
\hline davon aus EWG & 13,5 & 131,0 & 12,7 & 189,3 & 13,2 & 206,0 & davon nach EWG & 11,0 & 96,3 & 11,4 & 154,7 & 13,0 & 206,6 \\
\hline Belg. - Lux. & 1,3 & 12,2 & 1,3 & 20,1 & 1,2 & 19,4 & Belg. - Lux. & 0,7 & 5,8 & 0,6 & 7,5 & 0,6 & 8,9 \\
\hline BRD & 5,7 & 55,2 & 5,4 & 80,3 & 5,9 & 92,0 & BRD & 5,1 & 44,7 & 5,0 & 67,8 & 5,4 & 85,3 \\
\hline Frankreich & 2,6 & 25,3 & 2,0 & 30,2 & 2,1 & 32,9 & Frankreich & 1,5 & 13,5 & 0,9 & 12,4 & 1,7 & 27,2 \\
\hline IIalien & 2,7 & 26,7 & 2,3 & 34,9 & 3,0 & 47,6 & Italien & 2,4 & 20,8 & 3,8 & 50,9 & 4,2 & 67,6 \\
\hline Niederlande & 1,3 & 12.4 & 1,6 & 23,8 & 0,9 & 14,1 & Niederlande & 1,3 & 11,5 & 1,2 & 16,1 & 1,1 & 17,6 \\
\hline Großbritannien & 3,2 & 31,2 & 3,1 & 46,3 & 3,6 & 55,9 & Großbritannien & 2.0 & 17,7 & 2,5 & 33,2 & 2,0 & 32,0 \\
\hline USA & 0,2 & 1,9 & 2,5 & 37,2 & 1,0 & 15,3 & USA & 0,3 & 2,8 & 0,3 & 4,3 & 0,3 & 4.5 \\
\hline COMECON & $63,9^{a)}$ & $623,7^{a)}$ & $63,3^{b)}$ & $945,8^{b)}$ & $61,0^{b)}$ & $955,0^{b)}$ & COMECON & $61,4^{8)}$ & $536,8^{\text {a) }}$ & $66,9^{b)}$ & $904,2^{b)}$ & & $1020,1^{b)}$ \\
\hline Sow jetunion & 31,0 & 302,9 & 33,3 & 497,4 & 33,0 & 517,3 & Sow jetunion & 29,4 & 256,5 & 36,3 & 490,2 & 33,1 & 526,8 \\
\hline
\end{tabular}

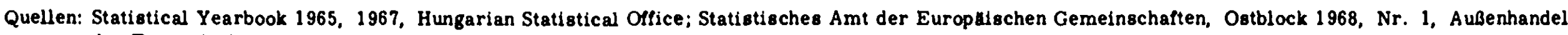
der Europaischen Ostblocklander; eigene Berechnungen.

Anmerkungen: Zugrunde gelegter Umrechnungskurs: 11,74 Forint $=1$ US- $\$$.

a) COMECON mit Albanien, ohne Mongolei

b) COMECON ohne Albanien und die Mongolei 
Tabelle 5: Der Außenhandel der EWG mit den sozialistischen Lăndern Südosteuropas nach anteiligen Warengruppen 1964 und 1965 in v. H.

\begin{tabular}{|c|c|c|c|c|c|c|c|c|c|c|c|c|}
\hline \multirow{4}{*}{\multicolumn{2}{|c|}{$\begin{array}{l}\text { Ein- bzw. } \\
\text { A usfuhrländer }\end{array}$}} & \multirow{4}{*}{ Insgesamt } & \multicolumn{8}{|c|}{ Warenbezeichnung } & \multirow{4}{*}{$\begin{array}{l}\text { Verschiedene } \\
\text { Fertig- } \\
\text { erzeugnisse } \\
\qquad 8\end{array}$} & \multirow{4}{*}{$\begin{array}{c}\text { Sonstiges } \\
\\
9\end{array}$} \\
\hline & & & $\begin{array}{l}\text { Nahrungs- } \\
\text { mittel und } \\
\text { leb. Tiere }\end{array}$ & $\begin{array}{l}\text { Getrănke } \\
\text { und } \\
\text { Tabak }\end{array}$ & $\begin{array}{l}\text { Rohmaterial } \\
\text { ohne } O_{1}\end{array}$ & $\begin{array}{l}\text { Mineralole, } \\
\text { Schmier- } \\
\text { stoffe }\end{array}$ & $\begin{array}{l}\text { Pllanzliche } \\
\text { und tierische } \\
\text { Ole und Fette }\end{array}$ & $\begin{array}{l}\text { Chemi- } \\
\text { kalien }\end{array}$ & $\begin{array}{l}\text { Fertig- } \\
\text { erzeug- } \\
\text { nisse }\end{array}$ & $\begin{array}{l}\text { Maschinen- } \\
\text { und Trans- } \\
\text { portaus- }\end{array}$ & & \\
\hline & & & \multicolumn{8}{|c|}{ sitc-Position } & & \\
\hline & & & 0 & 1 & 2 & 3 & 4 & 5 & 6 & 7 & & \\
\hline \multicolumn{13}{|l|}{ EINF UHR } \\
\hline Bulgarien & $\begin{array}{l}1964 \\
1965\end{array}$ & $\begin{array}{l}100,0 \\
100,0\end{array}$ & $\begin{array}{l}33,1 \\
41,8\end{array}$ & $\begin{array}{l}26,0 \\
20,0\end{array}$ & $\begin{array}{l}16,4 \\
15,8\end{array}$ & $\begin{array}{l}0,8 \\
0,4\end{array}$ & $\begin{array}{l}5,2 \\
2,1\end{array}$ & $\begin{array}{l}2,4 \\
2,3\end{array}$ & $\begin{array}{l}11,8 \\
14,6\end{array}$ & $\begin{array}{l}1,6 \\
1,4\end{array}$ & $\begin{array}{l}1,1 \\
1,3\end{array}$ & $\begin{array}{l}1,6 \\
0,6\end{array}$ \\
\hline Rumănien & $\begin{array}{l}1964 \\
1965\end{array}$ & $\begin{array}{l}100,0 \\
100,0\end{array}$ & $\begin{array}{l}30,6 \\
32,2\end{array}$ & $\begin{array}{l}0,6 \\
0,8\end{array}$ & $\begin{array}{l}38,7 \\
36,2\end{array}$ & $\begin{array}{l}21,7 \\
16,0\end{array}$ & $\begin{array}{l}1,0 \\
4,0\end{array}$ & $\begin{array}{l}2,2 \\
2,6\end{array}$ & $\begin{array}{l}4,2 \\
4,6\end{array}$ & $\begin{array}{l}0,3 \\
0,4\end{array}$ & $\begin{array}{l}1,0 \\
1,1\end{array}$ & $\begin{array}{l}0,1 \\
2,2\end{array}$ \\
\hline Ungarn & $\begin{array}{l}1964 \\
1965\end{array}$ & $\begin{array}{l}100,0 \\
100,0\end{array}$ & $\begin{array}{l}52,0 \\
57,3\end{array}$ & $\begin{array}{l}2,1 \\
1,8\end{array}$ & $\begin{array}{l}14,3 \\
12,1\end{array}$ & $\begin{array}{l}2,4 \\
1,9\end{array}$ & $\begin{array}{l}1,0 \\
0,8\end{array}$ & $\begin{array}{l}2,8 \\
2,7\end{array}$ & $\begin{array}{l}12,6 \\
11,7\end{array}$ & $\begin{array}{l}3,7 \\
3,9\end{array}$ & $\begin{array}{l}7,8 \\
7,4\end{array}$ & $\begin{array}{l}1,2 \\
1,3\end{array}$ \\
\hline \multicolumn{13}{|l|}{ AUSFUHR } \\
\hline Bulgarien & $\begin{array}{l}1964 \\
1965\end{array}$ & $\begin{array}{l}100,0 \\
100,0\end{array}$ & $\begin{array}{l}7,8 \\
4,2\end{array}$ & $\begin{array}{l}0 \\
0,2\end{array}$ & $\begin{array}{l}7,9 \\
6,6\end{array}$ & $\begin{array}{l}0,2 \\
0,2\end{array}$ & $\begin{array}{l}0,3 \\
0,5\end{array}$ & $\begin{array}{l}13,9 \\
12,6\end{array}$ & $\begin{array}{l}36,4 \\
39,7\end{array}$ & $\begin{array}{l}31,2 \\
32,4\end{array}$ & $\begin{array}{l}2,0 \\
3,4\end{array}$ & $\begin{array}{l}0,9 \\
0,2\end{array}$ \\
\hline Rumănien & $\begin{array}{l}1964 \\
1965\end{array}$ & $\begin{array}{l}100,0 \\
100,0\end{array}$ & $\begin{array}{l}2,2 \\
1,9\end{array}$ & $\begin{array}{l}0 \\
0\end{array}$ & $\begin{array}{l}6,5 \\
6,7\end{array}$ & $\begin{array}{l}1,4 \\
1,0\end{array}$ & $\begin{array}{l}0,2 \\
0,1\end{array}$ & $\begin{array}{l}12,0 \\
12,2\end{array}$ & $\begin{array}{l}28,4 \\
23,7\end{array}$ & $\begin{array}{l}46,5 \\
50,7\end{array}$ & $\begin{array}{l}2,5 \\
2,8\end{array}$ & $\begin{array}{l}0,3 \\
0,9\end{array}$ \\
\hline Ungarn & $\begin{array}{l}1964 \\
1965\end{array}$ & $\begin{array}{l}100,0 \\
100,0\end{array}$ & $\begin{array}{l}10,1 \\
10,7\end{array}$ & $\begin{array}{l}0 \\
0\end{array}$ & $\begin{array}{l}7,0 \\
8,0\end{array}$ & $\begin{array}{l}0,5 \\
0,2\end{array}$ & $\begin{array}{l}0,9 \\
0,8\end{array}$ & $\begin{array}{l}18,7 \\
17,0\end{array}$ & $\begin{array}{l}29,6 \\
31,2\end{array}$ & $\begin{array}{l}29,2 \\
28,0\end{array}$ & $\begin{array}{l}3,4 \\
3,4\end{array}$ & $\begin{array}{l}0,7 \\
0,6\end{array}$ \\
\hline
\end{tabular}

Quelle: Statistisches Amt der Europäischen Gemeinschaften, Außenhandel, Analytische Ubersichten, Export 1964,1965 - Import $1964,1965$. Eigene Berechnungen.

Anmerkungen: Summenabweichungen ergeben sich aus $\mathrm{Ab}$ - und $\mathrm{Aufrundungen.}$

- nichts vorhanden

$0=$ mehr als nichts, aber weniger als die in der Tabelle dargestellte kleinste Einheit

Zum Zeitpunkt der Erstellung der Tabelle lagen die Zahlen für 1966 noch nicht vor. 
Tabelle 6: Der Außenhandel Großbritanniens mit den sozialistischen Landern Sudosteuropas nach anteiligen Warengruppen 1964 und 1966 in v. H.

\begin{tabular}{|c|c|c|c|c|c|c|c|c|c|c|c|c|}
\hline \multirow{2}{*}{\multicolumn{2}{|c|}{$\begin{array}{l}\text { Ein- bzw. } \\
\text { Ausfuhrländer }\end{array}$}} & \multirow{4}{*}{ Insgesamt } & \multicolumn{10}{|c|}{ Warenbezeichnung } \\
\hline & & & \multirow{3}{*}{$\begin{array}{l}\text { Nahrungs- } \\
\text { mittel und } \\
\text { leb. Tiere } \\
0\end{array}$} & \multirow{3}{*}{$\begin{array}{l}\text { Getranke } \\
\text { und } \\
\text { Tabak } \\
\qquad 1\end{array}$} & \multirow{3}{*}{$\begin{array}{l}\text { Rohmaterial } \\
\text { ohne Ol } \\
\\
2\end{array}$} & \multirow{3}{*}{$\begin{array}{l}\text { Mineralole, } \\
\text { Schmier- } \\
\text { stoffe } \\
\quad 3\end{array}$} & \multirow{2}{*}{$\begin{array}{l}\text { Palanzliche } \\
\text { und tierische } \\
\text { Ole und Fette } \\
\text { ITC.Positio }\end{array}$} & \multirow{3}{*}{$\begin{array}{l}\text { Chemi- } \\
\text { kalien } \\
\text { n } \\
\\
\quad 5\end{array}$} & \multirow{3}{*}{$\begin{array}{l}\text { Fertig- } \\
\text { erzeug- } \\
\text { nisse } \\
\quad 6\end{array}$} & \multirow{3}{*}{$\begin{array}{l}\text { Maschinen- } \\
\text { und Trans- } \\
\text { portaus- } \\
\text { rilstungen } \\
\qquad 7\end{array}$} & \multirow{3}{*}{$\begin{array}{l}\text { Verschiedene } \\
\text { Fertig- } \\
\text { erzeugnisse } \\
\qquad 8\end{array}$} & \multirow{3}{*}{$\begin{array}{c}\text { Sonstiges } \\
9\end{array}$} \\
\hline & & & & & & & & & & & & \\
\hline & & & & & & & 4 & & & & & \\
\hline \multicolumn{13}{|l|}{ EINF UHR } \\
\hline Bulgarien & $\begin{array}{l}1964 \\
1966\end{array}$ & $\begin{array}{l}100,0 \\
100,0\end{array}$ & $\begin{array}{l}44,3 \\
37,5\end{array}$ & $\begin{array}{l}0,2 \\
0,1\end{array}$ & $\begin{array}{r}12,4 \\
6,6\end{array}$ & $\begin{array}{l}0 \\
0\end{array}$ & $\begin{array}{l}1,0 \\
=\end{array}$ & $\begin{array}{l}4,8 \\
1,8\end{array}$ & $\begin{array}{l}30,3 \\
48,7\end{array}$ & $\begin{array}{l}1,0 \\
0,6\end{array}$ & $\begin{array}{l}6,0 \\
4,7\end{array}$ & $\begin{array}{l}0 \\
0\end{array}$ \\
\hline Rumanien & $\begin{array}{l}1964 \\
1966\end{array}$ & $\begin{array}{l}100,0 \\
100,0\end{array}$ & $\begin{array}{l}51,1 \\
40,4\end{array}$ & $\begin{array}{l}0 \\
0\end{array}$ & $\begin{array}{l}23,2 \\
16,0\end{array}$ & $\begin{array}{l}0 \\
0\end{array}$ & $\begin{array}{l}2,4 \\
0,8\end{array}$ & $\begin{array}{l}0,8 \\
5,3\end{array}$ & $\begin{array}{l}14,0 \\
28,4\end{array}$ & $\begin{array}{l}0,4 \\
0,8\end{array}$ & $\begin{array}{l}8,1 \\
8,3\end{array}$ & $\begin{array}{l}0 \\
0\end{array}$ \\
\hline Ungarn & $\begin{array}{l}1964 \\
1966\end{array}$ & $\begin{array}{l}100,0 \\
100,0\end{array}$ & $\begin{array}{l}35,2 \\
40,7\end{array}$ & $\begin{array}{l}0,6 \\
0,6\end{array}$ & $\begin{array}{l}3,5 \\
4,7\end{array}$ & $\begin{array}{l}0 \\
0\end{array}$ & $\dot{-}$ & $\begin{array}{l}1.6 \\
4.7\end{array}$ & $\begin{array}{l}26,4 \\
20,5\end{array}$ & $\begin{array}{l}5,7 \\
5,9\end{array}$ & $\begin{array}{l}26.2 \\
22.2\end{array}$ & $\begin{array}{l}0,8 \\
0,8\end{array}$ \\
\hline \multicolumn{13}{|l|}{ AUSFUHR } \\
\hline Bulgarien & $\begin{array}{l}1964 \\
1966\end{array}$ & $\begin{array}{l}100,0 \\
100,0\end{array}$ & $\begin{array}{l}1,1 \\
3,0\end{array}$ & $\overline{0}, 5$ & $\begin{array}{l}1,3 \\
0,5\end{array}$ & 0.7 & $\begin{array}{l}0 \\
0\end{array}$ & $\begin{array}{l}18,7 \\
11,6\end{array}$ & $\begin{array}{l}23,5 \\
11,4\end{array}$ & $\begin{array}{l}47,4 \\
70,5\end{array}$ & $\begin{array}{l}6,1 \\
1,4\end{array}$ & $\begin{array}{l}0 \\
0,5\end{array}$ \\
\hline Rumănien & $\begin{array}{l}1964 \\
1966\end{array}$ & $\begin{array}{l}100,0 \\
100,0\end{array}$ & $\begin{array}{l}1,7 \\
2,6\end{array}$ & $\overline{0}, 5$ & $\begin{array}{l}5,4 \\
9,0\end{array}$ & $\begin{array}{l}3,1 \\
0,3\end{array}$ & $\begin{array}{l}0,1 \\
0,1\end{array}$ & $\begin{array}{r}13,3 \\
7,6\end{array}$ & $\begin{array}{l}22,3 \\
16,3\end{array}$ & $\begin{array}{l}50,9 \\
60,6\end{array}$ & $\begin{array}{l}2,4 \\
2,5\end{array}$ & $\begin{array}{l}0,7 \\
0,6\end{array}$ \\
\hline Ungarn & $\begin{array}{l}1964 \\
1966\end{array}$ & $\begin{array}{l}100,0 \\
100,0\end{array}$ & $\begin{array}{l}0,2 \\
0,3\end{array}$ & $\begin{array}{l}0,1 \\
0,2\end{array}$ & $\begin{array}{r}16.1 \\
8,4\end{array}$ & $\begin{array}{l}0,3 \\
0,1\end{array}$ & $\begin{array}{l}0,7 \\
0,1\end{array}$ & $\begin{array}{l}20,2 \\
17,6\end{array}$ & $\begin{array}{l}24,6 \\
14,4\end{array}$ & $\begin{array}{l}30,3 \\
49,5\end{array}$ & $\begin{array}{l}5,5 \\
7,1\end{array}$ & $\begin{array}{l}2,6 \\
2,2\end{array}$ \\
\hline
\end{tabular}

Quellen: Die absoluten Werte des AuBenhandels Großbritanniens mit Bulgarien, Rumanien und Ungarn wurden vom Bundesamt fur Gewerbliche Wirtschaft in Frankfurt/Main ermittelt und vom Bundesministerium fur Wirtschaft in Bonn zur Verfugung gestellt. Die absolute Summe der insgesamt von Grobbritannien in die sudosteuropaischen Staatshandelslander aus- bzw. von dort eingefuhrten Warenwerte in US- $\$$ weicht $z$. $T$. erheblich von den in den Tabellen 2 - 4 ermittelten Gesamtsummen ab. Die Ursache der Differenzen konnte nicht ermittelt werden. 
Tabelle 7: Der Außenhandel der USA mit den sozialistischen Ländern Südosteuropas nach anteiligen Warengruppen 1964 und 1966 in v. H.

Warenbezeichnung

\begin{tabular}{|c|c|c|c|c|c|c|c|c|c|c|c|}
\hline $\begin{array}{l}\text { Ein- bzw. } \\
\text { Ausfuhrlănder }\end{array}$ & Insgesamt & $\begin{array}{l}\text { Nahrungs- } \\
\text { mittel und } \\
\text { leb. Tiere }\end{array}$ & $\begin{array}{l}\text { Getrănke } \\
\text { und } \\
\text { Tabak }\end{array}$ & $\begin{array}{l}\text { Rohmaterial } \\
\text { ohne Ol }\end{array}$ & $\begin{array}{l}\text { Mineralole, } \\
\text { Schmier- } \\
\text { stoffe }\end{array}$ & $\begin{array}{l}\text { Pflanzliche } \\
\text { und tierische } \\
\text { Ole und Fette }\end{array}$ & $\begin{array}{l}\text { Chemi- } \\
\text { kalien }\end{array}$ & $\begin{array}{l}\text { Fertig- } \\
\text { erzeug- } \\
\text { nis8e }\end{array}$ & $\begin{array}{l}\text { Maschinen- } \\
\text { und Trans- } \\
\text { portaus- } \\
\text { rustungen }\end{array}$ & $\begin{array}{l}\text { Verschiedene } \\
\text { Fertig- } \\
\text { erzeugnisse }\end{array}$ & Sonstiges \\
\hline
\end{tabular}

SITC. Position

EINFUHR

\begin{tabular}{|c|c|c|c|c|c|c|c|c|c|c|c|c|}
\hline Bulgarien & $\begin{array}{l}1964 \\
1966\end{array}$ & $\begin{array}{l}100,0 \\
100,0\end{array}$ & $\begin{array}{l}50,0 \\
54,2\end{array}$ & 4,2 & $\begin{array}{r}8,3 \\
12,6\end{array}$ & - & - & $\begin{array}{l}25,0 \\
16,7\end{array}$ & $\begin{array}{l}8,3 \\
8,3\end{array}$ & $\begin{array}{l}0 \\
0\end{array}$ & $\begin{array}{l}8,3 \\
0\end{array}$ & $\begin{array}{l}0 \\
0\end{array}$ \\
\hline Rumănien & $\begin{array}{l}1964 \\
1966\end{array}$ & $\begin{array}{l}100,0 \\
100,0\end{array}$ & $\begin{array}{l}16,7 \\
11,1\end{array}$ & 0 & $\begin{array}{r}8,3 \\
11,1\end{array}$ & . & - & $\begin{array}{c}0 \\
11,1\end{array}$ & $\begin{array}{l}41,7 \\
33,3\end{array}$ & $\overline{0}$ & $\begin{array}{l}41,7 \\
31,1\end{array}$ & $\begin{array}{l}0 \\
0\end{array}$ \\
\hline Ungarn & $\begin{array}{l}1964 \\
1966\end{array}$ & $\begin{array}{l}100,0 \\
100,0\end{array}$ & $\begin{array}{r}11,8 \\
6,9\end{array}$ & $\begin{array}{l}5,9 \\
6,9\end{array}$ & $\begin{array}{l}0 \\
6,9\end{array}$ & - & - & $\begin{array}{l}0 \\
6,9\end{array}$ & $\begin{array}{l}17,6 \\
17,2\end{array}$ & $\begin{array}{l}11,8 \\
17,2\end{array}$ & $\begin{array}{l}41,2 \\
37,9\end{array}$ & $\begin{array}{l}5,9 \\
3,4\end{array}$ \\
\hline
\end{tabular}

AUSFUHR

Bulgarien $1964 \quad 100,0 \quad 33,3 \quad$ - $\quad 54$,

$\begin{array}{rrrrr}1966 & 100,0 & 44,4 & 0 & 2,\end{array}$

Rumanien $1964 \quad 100,0 \quad 3,9 \quad-\quad 45$,

$\begin{array}{rrrrrr} & 1966 & 100,0 & 0,7 & - & 30,9 \\ \text { Ungarn } & 1964 & 100,0 & 56,6 & 0 & 36,8\end{array}$

$\begin{array}{rccrrrrr}54,2 & - & 4,2 & 4,2 & 0 & 4,2 & 0 & - \\ 2,8 & 0 & - & 25,0 & 0 & 27,8 & 2,8 & - \\ 45,1 & 23,5 & 7,8 & 9,8 & 0 & 7,8 & 2,0 & - \\ 30,9 & 3,3 & 0 & 6,6 & 7,4 & 47,1 & 3,7 & 0 \\ 36,8 & - & 0,7 & 2,9 & 0,7 & 1,5 & 0,7 & 0 \\ 26,0 & - & 2,9 & 9,0 & 3,0 & 6,0 & 4,0 & 0\end{array}$

Quellen: US-Exports.Country by Commodity Grouping, US-Department of Commerce, Bureau of the Census. FT 420,1964 Annual. FT 420, 1966 Annual. US-Imports of Merchandise for Consumption. US-Department of Commerce, Bureau of the Census, FT 125, 1964 Annual, FT 125, 1966 Annual. Eigene Berechnungen.

Anmerkungen: Summenabweichungen ergeben sich aus $\mathrm{Ab}$ - und $\mathrm{A}$ ufrundungen.

- = nichts vorhanden

$0=$ mehr als nichts, aber weniger als die in der Tabelle dargestellte kleinste Einheit. 


\section{Veroffentlichungen der Südosteuropa-Gesellschaft}

Verlagsauslieferung: Dr. Dr. Rudolf Trofenik, Südostbuchhandel KG, München 13, Elisabethstraße 18

Reihe SUDOSTEUROPA - J AHRBUCH

1. Band: SÜDOSTEUROPA ZWISCHEN OST UND WEST - München 1957. 224 S., Ganzleinen DM 15, 80

2. Band: IDEOLOGISCHE, KULTURELLE UND WIRTSCHAFTLICHE WANDLUNGEN IN SÜDOSTEUROPA - München 1958. $199 \mathrm{~S}$., Ganzleinen DM 15,80

3. Band: WIRTSCHAFTLICHE ENTWICKLUNG UND VOLKLICHE EIGEN STÄNDIGKEIT IN SÜDOSTEUROPA - München 1959. 245 S., Ganzleinen DM 15,80

4. Band: DER GEGENW ÄRTIGE STAND DER WIRTSCHAFTLICHEN UND KULTURELLEN BEZIEHUNGEN ZU SUDOSTEUROPA - Mün chen 1960. 191 S., DM 15,80

5. Band: DIE DONAU IN IHRER GESCHICHTLICHEN, WIRTSCHAFTLICHEN UND KULTURELLEN BEDEUTUNG - München 1961. 187 S., Ganzleinen DM 15,80

6. Band: DIE VOLKSKULTUR DER SUDOSTEUROPÄISCHEN VOLKER München 1962. 216 S., Ganzleinen DM 18, -

7. Band: DEUTSCH -SÜDOSTEUROPÄISCHE WIRTSCHAFTSPROBLEME München 1966. 138 S., Ganzleinen DM 32,-

8. Band: DIE STADT IN SÜDOSTEUROPA - Struktur und Geschichte München 1968. 183 S. , Ganzleinen DM 38,-

Reihe SUDOSTEUROPA-SCHRIFTEN

1. Band: VÖLKER UND KULTUREN SÜDOSTEUROPAS - Kulturhistorische Beiträge - München 1959. 284 S., broschiert DM 22, -

2. Band: WIRTSCHAFT UND GESELLSCHAFT SUDOSTEUROPAS - Ge denkschrift für Wilhelm Gülich - München 1961. $600 \mathrm{~S}$., Ganz leinen DM 48,-

3. Band: AUFSÄTZE UND ABHANDLUNGEN ZUR GESCHICHTE SÜDOST EUROPAS UND DER LEVANTE I von Franz Babinger - München 1962. 474 S., Abb., Ganzleinen DM 56,- 
4. Band: WIRTSCHAFTSW ISSENSCHAFTLICHE SUDOSTEUROPAFOR SCHUNG - Grundlagen und Erkenntnisse - Ausgewăhlt und redi giert von Theodor Zotschew - Munchen 1963. 280 S., Ganzleinen DM 36, -

5. Band: PRIMUS TRUBER - Leben und Werk des slowenischen Reformators von Mirko Rupel. Deutsche Ubersetzung und Bearbeitung von Balduin Saria - München 1965. 332 S., Ganzleinen DM 56,-

6. Band: DIE KULTUR SUDOSTEUROPAS, IHRE GESCHICHTE UND IHRE AUSDRUCKSFORMEN - Balkanologentagung 1962 - Herausgegeben und redigiert von Günter Reichenkron und Alois Schmaus Verlag Harassowitz, Wiesbaden-München 1964. 337 S., 13 Bildtafeln, Ganzleinen DM 58,-

7. Band: VOLKSMUSIK SUDOSTEUROPAS - Beiträge zur Volkskunde und Musikwissenschaft anläBlich der ersten Balkanologen-Tagung in Graz 1964. Herausgegeben und redigiert von W. Wunsch - Mün chen 1966. 167 S., Ganzleinen DM 32,-

8. Band: AUFSÄTZE UND ABHANDLUNGEN ZUR GESCHICHTE SÜDOST EUROPAS UND DER LEVANTE II von Franz Babinger - München 1966. 310 S., Abb., Ganzleinen DM 56, -

9. Band: DIE OSTERREICH-UNGARISCHE MONARCHIE ALS WIRTSCHAFTS-GEMEINSCHAFT - Krisztina Fink - München 1968. 89 S. 3 Karten in Farbe, Ganzleinen DM 38.-

\section{Reihe SUDOSTEUROPA-STUDIEN}

1. Heft: Franz Ronneberger: VORSCHLAGE ZUR EINORDNUNG DER SUDOSTEUROPA -FORSCHUNG IN DIE AUFBAUPLANE DER DEUTSCHEN HOCHSCHULEN - Munchen 1962. $30 \mathrm{~S}$., broschiert DM 4, -

2. Heft: DIE DONAU - Ein Verzeichnis des in der Bibliothek des Instituts fur Weltwirtschaft an der Universität Kiel vorhandenen einschlägigen Schriftums - Zusammengestellt von Max Gamst und Gerhard Teich - Munchen 1960. 69 S., broschiert DM 8, -

3. Heft: Stefan Varga: WESEN UND FUNKTIONEN DES GELDES IM SOZLALISMUS - München 1962. 38 S., broschiert DM 6, -

4. Heft: Gert Ziegler: GRIECHENLAND IN DER EUROPAISCHEN WIRT SCHAFTSGEMEINSCHAFT - München 1962. $110 \mathrm{~S}$. , broschiert DM 10,-

5. Heft: Muhlis Ete: PROBLEME DER ASSOZIIERUNG DER TÚRKI MIT DER EUROPAISCHEN WIRTSCHAFTSGEMEINSCHAFT - MUn chen 1963. 106 S., broschiert DM 12,- 
6. Heft: Karl Förster: DIE BEDEUTUNG DER RHEINREGION FUR DEN DONAURAUM UND DES DONAURAUMES FUUR DIE RHEINREGION - München 1964. 28 S. , broschiert DM 6,-

7. Heft: Cornel Irimie: DAS HIRTENWESEN DER RUMÄNEN - Forschungen in der Marginimea Sibiului bei Hermannstadt/Sibiu - München 1965. 60 S. , 31 Abbildungen, broschiert DM 12,-

8. Heft: BEITRÄGE ZUM BAND- UND DEVISENRECHT IN SUDDOSTEUROPA - München 1965. 160 S. , broschiert DM 28, -

9. Heft: Constantin Daicoviciu: DIE HERKUNFT DES RUMANISCHEN VOLKES IM LICHTE DER NEUESTEN FORSCHUNGEN UND AUSGRABUNGEN - München 1967. $21 \mathrm{~S}$. , broschiert DM 6, -

10. Heft: Franz Ronneberger: SUDOSTEUROPA IN DEN INTERNATIONALEN POLITISCHEN BEZIEHUNGEN DER GEGENWART München 1968. 29 S. , broschiert DM 14,-

11. Heft: Dieter Meier: LEITUNG. BESTEUERUNG UND FINANZIERUNG DER JUGOSLAWISCHEN INDUSTRIEUNTERNEHMUNGEN IM VERGLEICH MIT DEUTSCHEN AKTIENGESELLSCHAFTEN München 1968. $116 \mathrm{~S}$. , broschiert DM 18,-

12. Heft: Rudolf Bicanić: JUGOSLAWIENS STELLUNG IN DER WELTWIRTSCHAFT UND DAS AUSLANDSKAPITAL IN JUGOSLAWIEN Müchen 1968. $30 \mathrm{~S}$. , broschiert DM 8, - 